\title{
A FRAMEWORK FOR PROFESSIONAL LEARNING AND DEVELOPMENT IN SCIENCE FOR NEW ZEALAND UPPER PRIMARY TEACHERS
}

\author{
BY \\ THEODORE JAMES CIZADLO
}

\begin{abstract}
A thesis
submitted to the Victoria University of Wellington

in fulfilment of the requirements for the degree of

Doctor of Philosophy
\end{abstract}

Victoria University of Wellington

2018 


\begin{abstract}
This doctoral thesis describes the development of a framework to guide the creation and delivery of bespoke professional learning and development programmes (PLD) in physical science for groups of Year 7 and 8 teachers. It identifies key principles and provides practical advice needed to produce PLD programmes specifically focused on the topics selected, in consultation with the teachers involved, that are tailored to the school environment and adhere to design principles informed by research, and tested in the New Zealand context. The framework was developed using a design-based research approach involving three iterations of use, analysis, and improvement. Audio recordings, structured interviews, classroom observations, concept maps, and field notes provided data for a qualitative analysis paradigm. The research employed a social-constructivist lens, with an emphasis on learner-centred science investigations, leading to the development of a new framework for physical science PLD design and delivery consisting of five major focus areas: Subject selection / curriculum, Subject matter understanding, Teaching practice, Support, and Logistical considerations. This research highlighted the challenges faced by generalist teachers with limited science backgrounds in working with New Zealand's non-prescriptive national curriculum, to develop specific physical science units that are relevant to their local school environment. Specifically, teachers with limited subject matter knowledge face challenges selecting topics from the New Zealand Curriculum, balancing breadth and depth of topic coverage, and selecting curriculum support materials. After participating in the PLD teachers were able to use their subject matter knowledge and teaching experience to select materials and confidently teach the physical science topics covered in the PLD.
\end{abstract}




\section{Acknowledgments}

I want to thank my supervisor Senior Lecturer Dayle Anderson for the relentless positive support she provided to me through her supervision of this research. Without her patient optimistic encouragement and wise advice this research would have lost its way in any number of snags and blind alleys. Thank you.

I also want to thank my second supervisor, Senior Lecturer Craig Rofe, whose wise advice and sensitivity helped me to understand several key aspects of the project.

This research would not have been possible without the contribution of the schools, and particularly the teacher volunteers who donated many afterschool hours to engage in an experimental professional learning and development programme. I just hope they learned half as much from me as I did from them.

Finally, I want to thank my wife Beth for her support through this project. Her selfless encouragement, patience, and confidence in me is the reason this document exists. I could not have done it without her. 


\section{Table of Contents}

Abstract ................................................................................................... ii

Acknowledgments ..................................................................................... ii

List of Figures ..................................................................................... viii

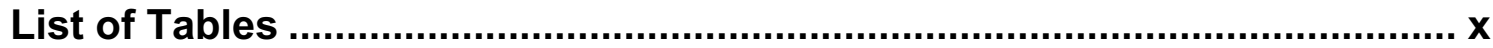

Chapter 1 Introduction and Rationale ................................................ 1

1.1 Nature of the problem ....................................................................... 1

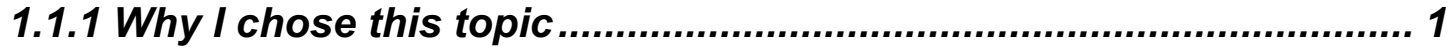

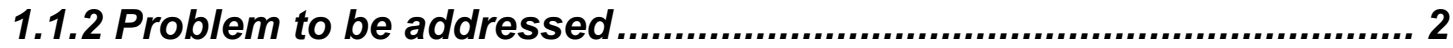

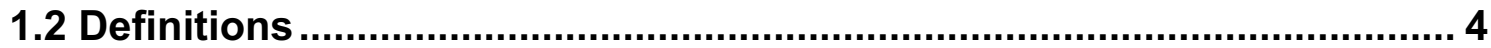

1.2.1 Definition of teaching ...................................................................... 4

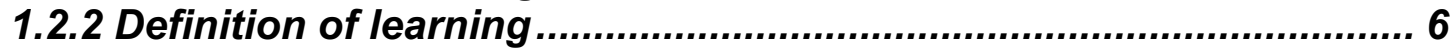

1.2.3 Definitions of science............................................................................ 7

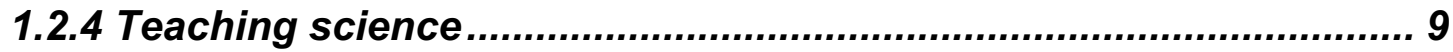

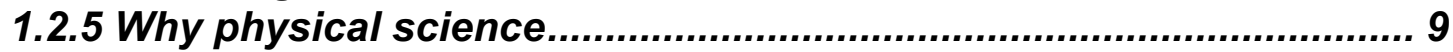

1.2.6 The role of PLD .................................................................................. 12

1.2.7 Science investigation as a learning tool ........................................ 13

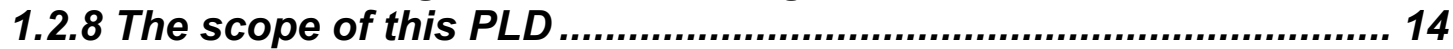

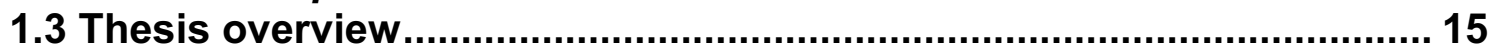

Chapter 2 Literature Review ................................................................ 16

2.1. Primary science in New Zealand....................................................... 16

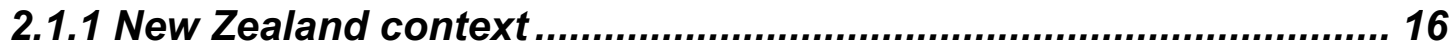

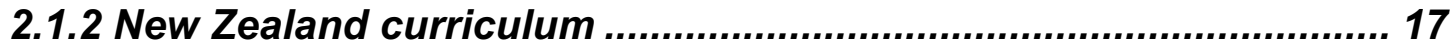

2.2 Science in New Zealand primary schools ............................................ 20

2.2.1 New Zealand primary students' science experience....................... 21

2.2.2 New Zealand primary science teaching.......................................... 25

2.2.3 Nature of knowledge needed for teaching physical science.......... 29

2.2.4 Development of teacher science knowledge .................................. 34

2.3 Professional learning and development programme design ............... 36

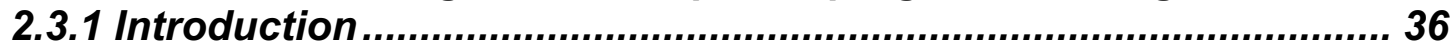

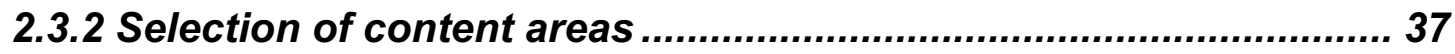

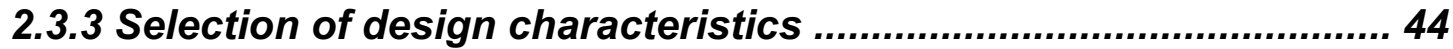

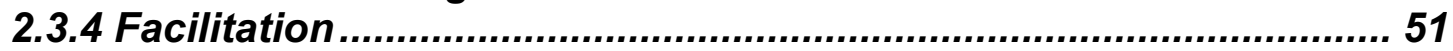

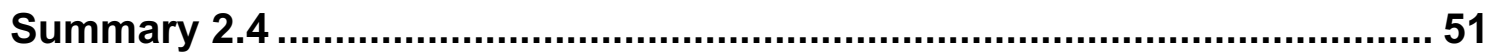

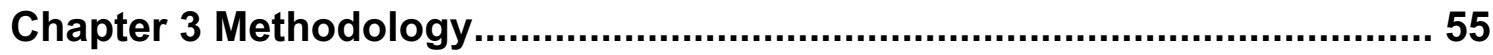

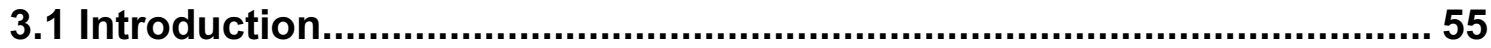

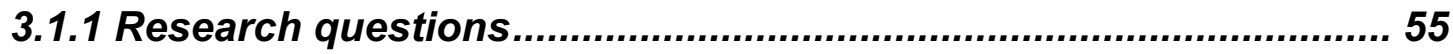

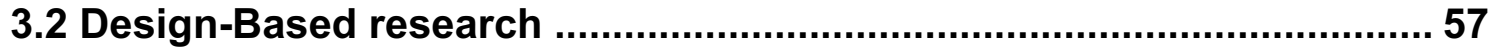

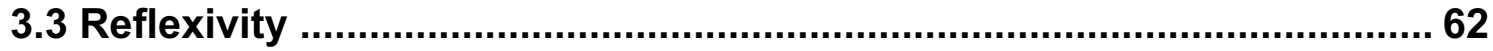

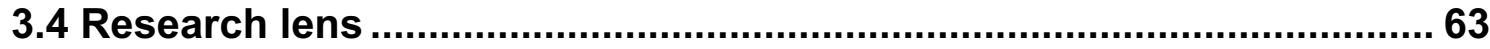

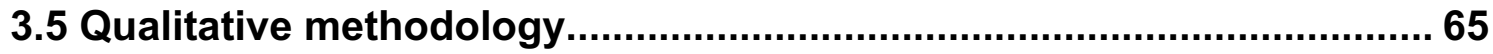




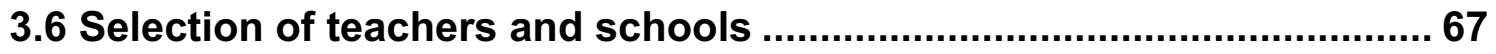

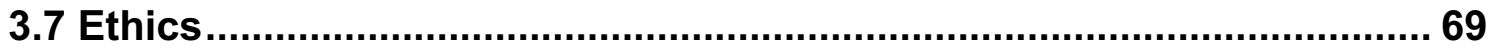

3.8 Overview of PLD and data collection ............................................... 71

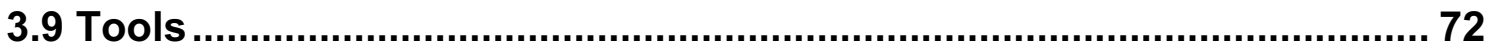

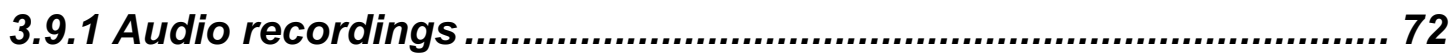

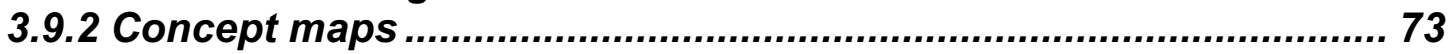

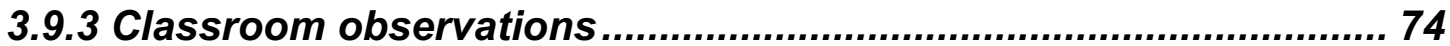

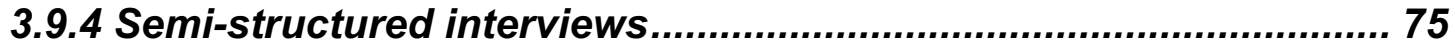

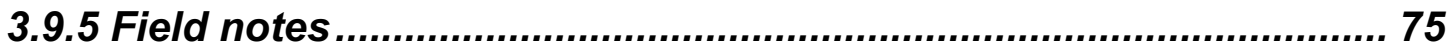

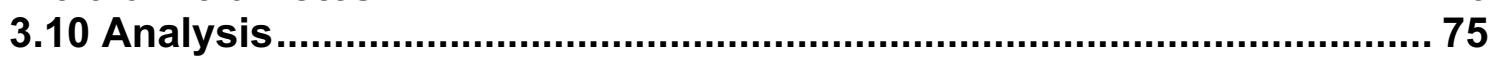

3.11 General Overview of PLD ................................................................ 78

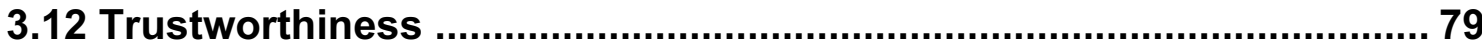

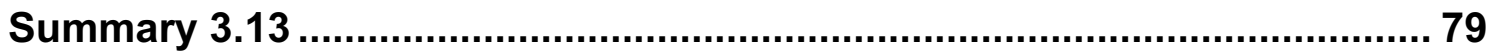

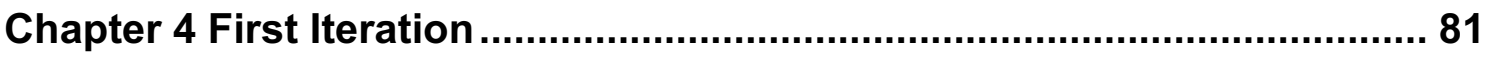

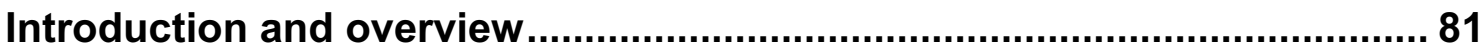

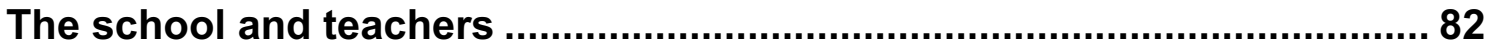

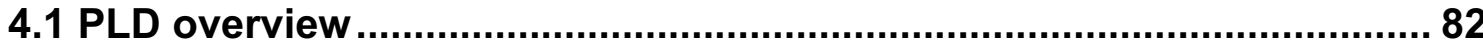

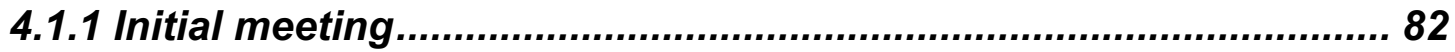

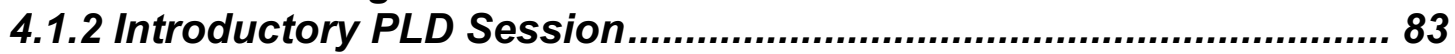

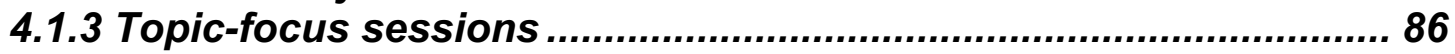

4.1.4 Unit planning, observation, and wrap-up .................................... 88

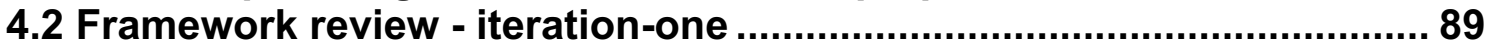

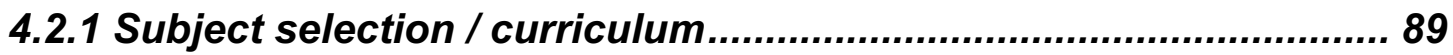

4.2.1.1. Consideration of student learning needs................................. 90

4.2.1.2 Alignment with local and national curriculum .............................. 91

4.2.2 Subject matter understanding …................................................... 94

4.2.2.1 Teacher subject matter and pedagogical knowledge ................... 97

4.2.2.2 Subject matter knowledge reinforcement .................................. 104

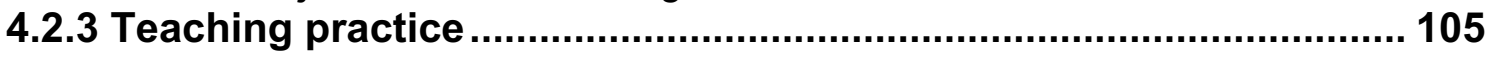

4.2.3.1 Practical lesson development, taking into account the local

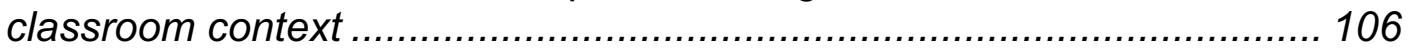

4.2.3.2. Modelling and practising activities and teaching methods .......... 107

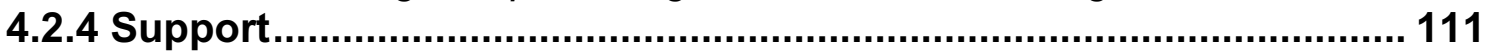

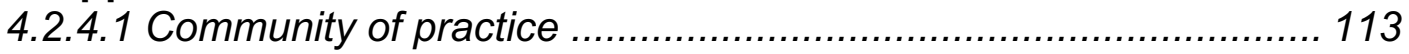

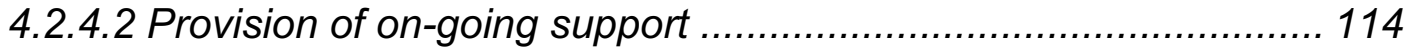

4.2.5 Logistical considerations ……...................................................... 115

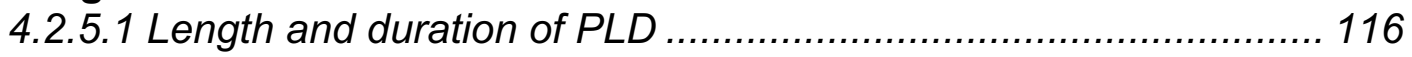

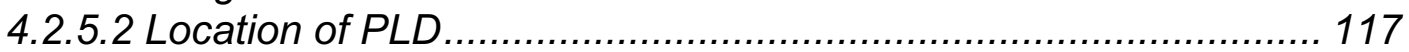

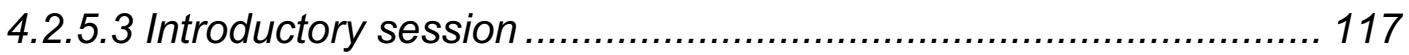

4.2.6 Classroom observation ................................................................... 118

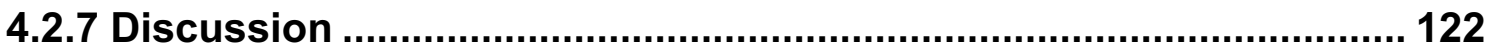

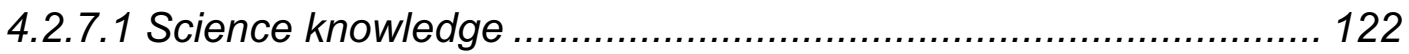

4.2.7.2 The New Zealand curriculum ................................................ 124

4.2.7.3 Breadth versus depth ............................................................ 124

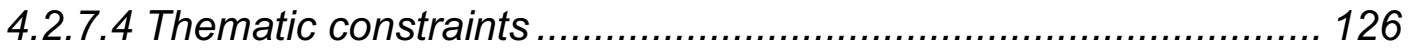

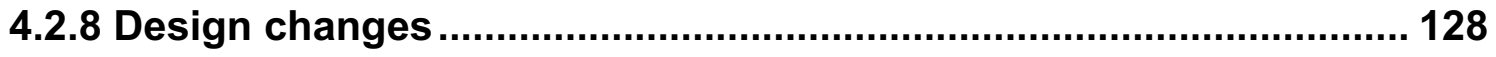




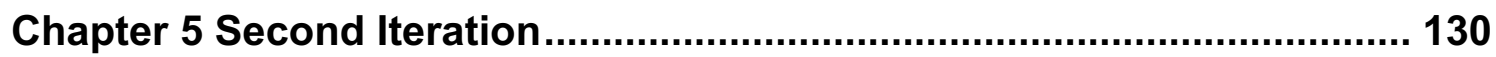

Introduction and overview......................................................................... 130

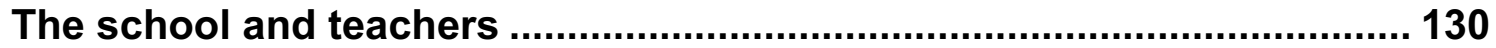

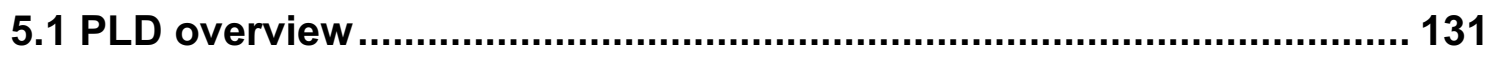

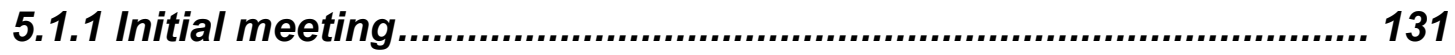

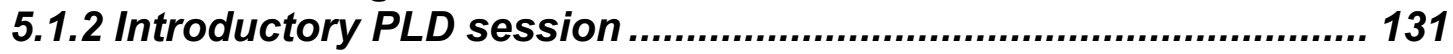

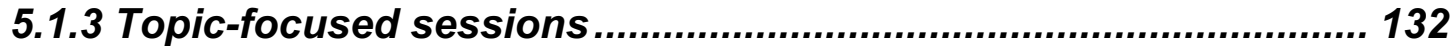

5.1.4 Unit planning, observation, and wrap-up ................................... 133

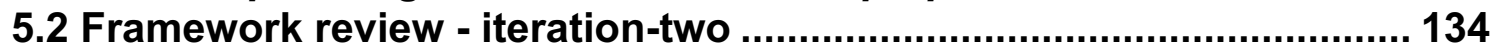

5.2.1 Subject selection / curriculum ....................................................... 134

5.2.1.1 Consideration of student learning goals and needs ................... 135

5.2.1.2 Alignment with local and national curriculum ............................ 136

5.2.2 Subject matter understanding .................................................... 137

5.2.2.1 Teacher subject matter and pedagogical knowledge .................. 139

5.2.2.2 Subject matter knowledge reinforcement ................................. 147

5.2.3 Teaching practice ......................................................................... 148

5.2.3.1 Practical lesson development, taking into account the local

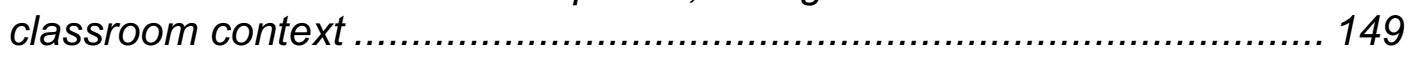

5.2.3.2 Modelling and practising activities and teaching methods .......... 150

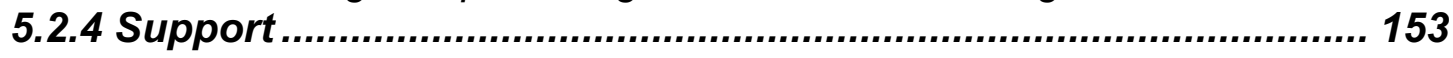

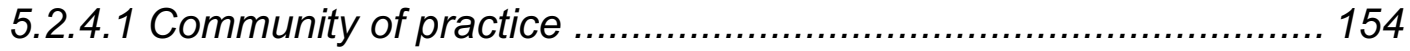

5.2.4.2 Provision of on-going support ................................................ 156

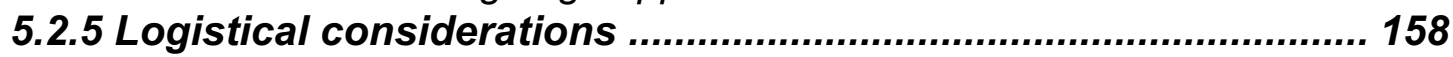

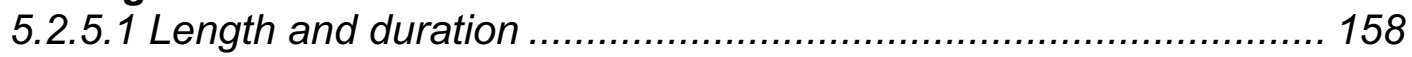

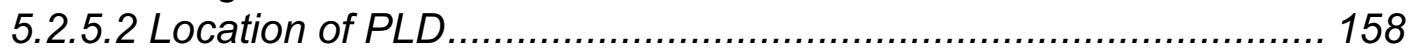

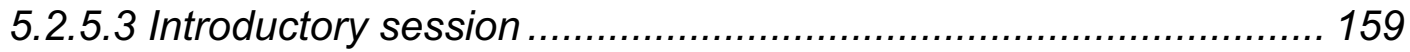

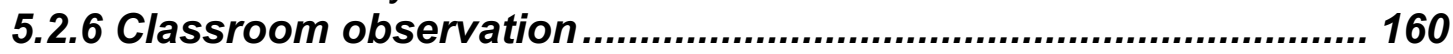

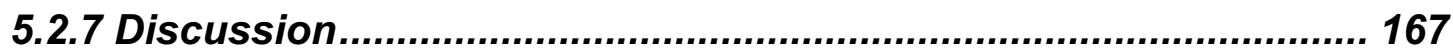

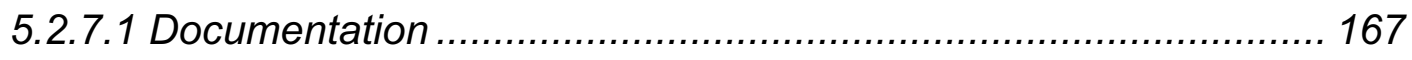

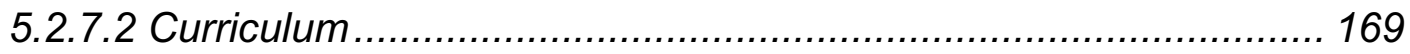

5.2.7.3 Physical science at primary level .......................................... 171

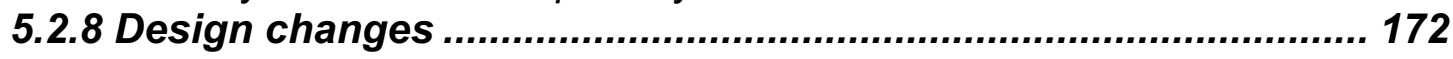

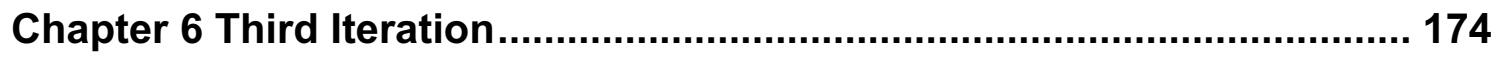

Introduction and overview....................................................................... 174

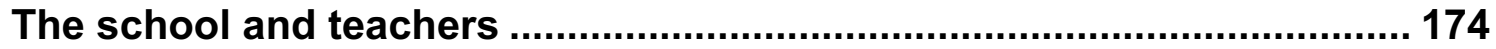

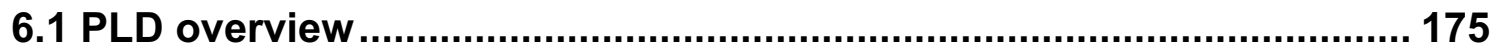

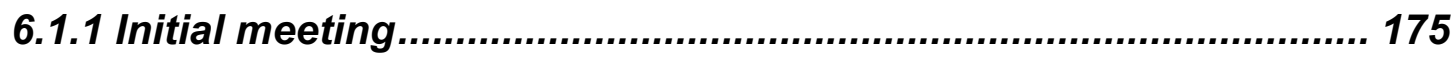

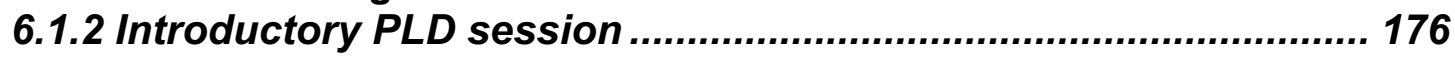

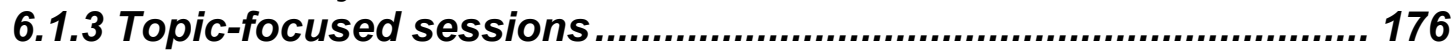

6.1.4 Unit planning, observation, and wrap-up ................................... 179

6.2 Framework review - iteration-three...................................................... 180

6.2.1 Subject selection / curriculum .................................................... 180

6.2.1.1 Consideration of student learning goals and needs ................... 181

6.2.1.2 Alignment with local and national curriculum ............................. 182

6.2.2 Subject matter understanding ................................................... 184 
6.2.2.1 Teacher subject matter and pedagogical knowledge................ 184

6.2.2.2 Subject matter knowledge reinforcement................................ 192

6.2.3 Teaching practice ......................................................................... 195

6.2.3.1 Practical lesson development, taking into account the local classroom context .................................................................... 196

6.2.3.2 Modelling and practising activities and teaching methods .......... 200

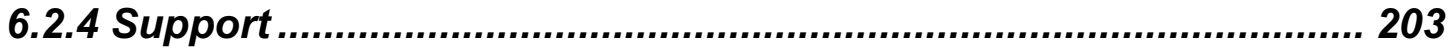

6.2.4.1. Community of practice .................................................... 204

6.2.4.2 Provision of on-going support .......................................... 206

6.2.5. Logistical considerations ...................................................... 208

6.2.5.1 Length and duration ....................................................... 209

6.2.5.2 Location of PLD............................................................. 209

6.2.5.3 Introductory session ......................................................... 210

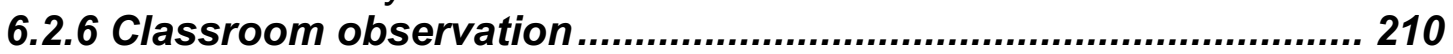

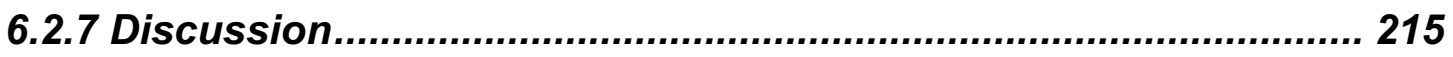

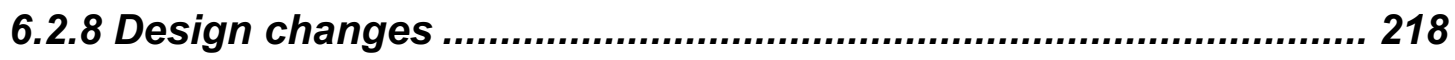

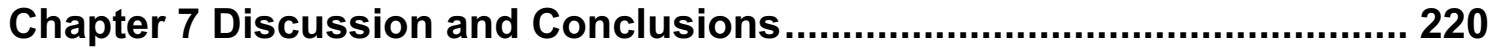

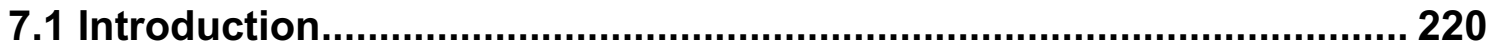

7.2 Summary of PLD framework development process ......................... 220

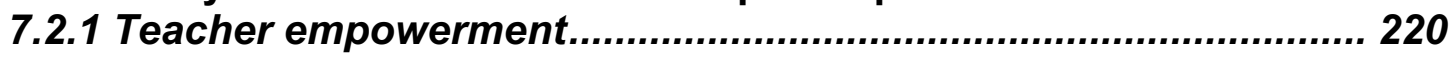

7.2.2 Subject selection / curriculum ..................................................... 221

7.2.3 Subject matter understanding ..................................................... 223

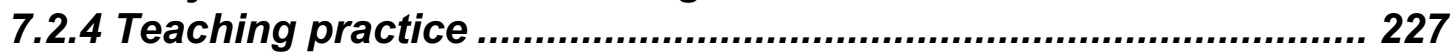

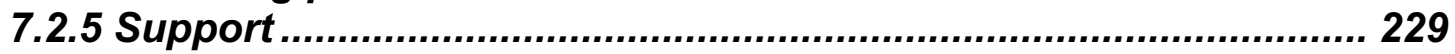

7.2.6 Logistical considerations ........................................................ 229

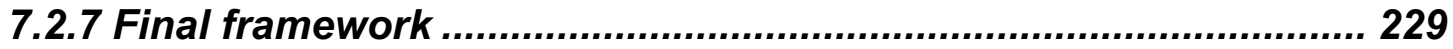

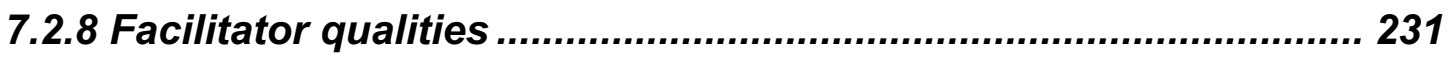

7.3 Related research questions .............................................................. 234

7.3.1 Barriers that inhibit physical science teaching ........................... 234

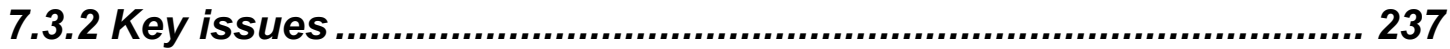

7.3.2.1 Selecting curriculum topics ............................................ 237

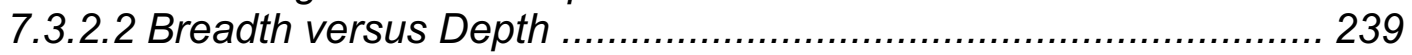

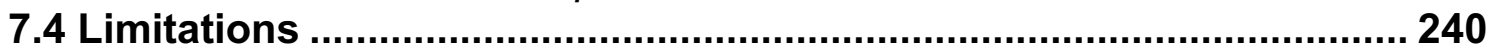

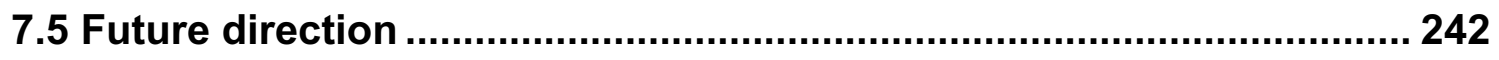

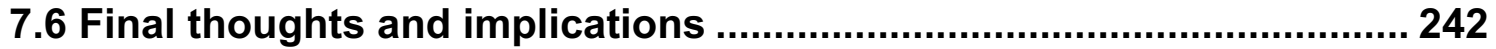

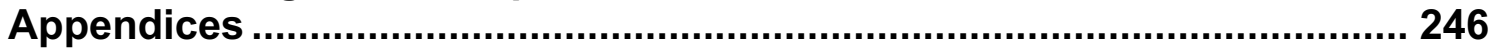

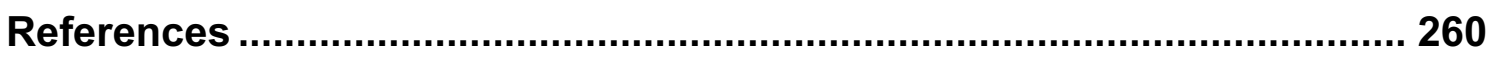




\section{List of Figures}

FIGURE 1: SCIENTIFIC REASONING ............................................................... 7

FIGURE 2: THE ROLE OF SCIENTIFIC INVESTIGATIONS IN TEACHING ...................... 14

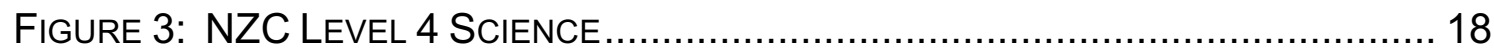

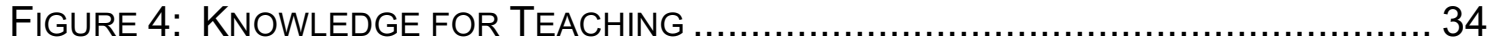

FIGURE 5: BELL AND GILBERT'S PLD MODEL ................................................ 38

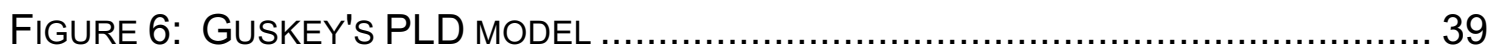

FIGURE 7: CLARKE AND HOLLINGSWORTH'S MODEL ........................................ 40

FIGURE 8: LOUCKS-HORSLEY ET AL.'S PLD FRAMEWORK................................ 41

FIGURE 9: MODEL OF TEACHER LEARNING ............................................... 42

FIGURE 10: PLD DESIGN FRAMEWORK DERIVED FROM REVIEW OF RESEARCH .........50 50

FIGURE 11: QUADRANT MODEL OF SCIENTIFIC RESEARCH.................................. 58

Figure 12: Comparison of PREdictive ANd Design-BASEd ReSEARCH ..............60

FIGURE 13: PRE-AND POST-PLD SOUND CONCEPT MAP .................................. 77

FIGURE 14: SUBJECT SELECTION / CURRICULUM .............................................. 90

FIGURE 15: SUBJECT SELECTION / CURRICULUM - ITERATION-ONE........................ 94

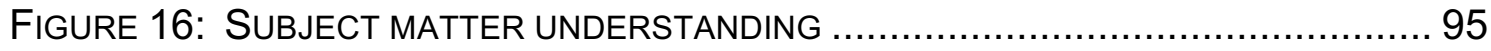

FIGURE 17: INITIAL SOUND CONCEPT MAP ................................................. 100

FIGURE 18: SUBJECT MATTER UNDERSTANDING - ITERATION-ONE ….................. 105

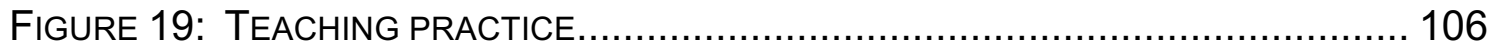

FIGURE 20: TEACHING PRACTICE - ITERATION-ONE ..................................... 111

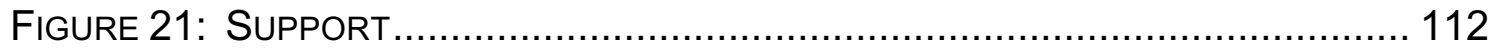

FIGURE 22: SUPPORT - ITERATION-ONE …................................................ 115

FIGURE 23: LOGISTICAL CONSIDERATIONS …............................................. 116

FIGURE 24: LOGISTICAL CONSIDERATIONS - ITERATION-ONE ............................ 118

FIGURE 25: DESIGN FRAMEWORK - ITERATION-ONE....................................... 129

Figure 26: SUbJeCt SELECTION / CURRICULUM AS ESTABLISHED IN ITERATION-ONE

FIGURE 27: SUBJECT SELECTION / CURRICULUM - ITERATION-TWO ..................... 137

FIGURE 28: SUBJECT MATTER UNDERSTANDING AS ESTABLISHED IN ITERATION-ONE

139

FIGURE 29: INITIAL CONCEPT MAP OF NEWTON'S LAWS ................................. 141

FIGURE 30: SUBJECT MATTER UNDERSTANDING - ITERATION-TWO..................... 148

FIGURE 31: TEACHING PRACTICE AS ESTABLISHED IN ITERATION-ONE ….............. 149

FIGURE 32: TEACHING PRACTICE - ITERATION-TWO …................................... 153

FIGURE 33: SUPPORT AS ESTABLISHED IN ITERATION-ONE.............................. 154

FIGURE 34: SUPPORT - ITERATION-TWO ……........................................... 157

FIGURE 35: LOGISTICAL CONSIDERATIONS AS ESTABLISHED IN ITERATION-ONE ...... 158

FIGURE 36: LOGISTICAL CONSIDERATIONS - ITERATION-TWO ............................. 160

FIGURE 37: DESIGN FRAMEWORK - ITERATION-TWO ....................................... 173

FiguRE 38: SUBJECT SELECTION / CURRICULUM AS ESTABLISHED IN ITERATION-TWO

FIGURE 39: SUBJECT SELECTION / CURRICULUM - ITERATION-THREE................... 183 
FIGURE 40: SUBJECT MATTER UNDERSTANDING AS ESTABLISHED IN ITERATION-TWO

FIGURE 41: SUBJECT MATTER UNDERSTANDING - ITERATION-THREE.................... 195

FIGURE 42: TEACHING PRACTICE AS ESTABLISHED IN ITERATION-TWO ................... 196

FIGURE 43: TEACHER QUESTIONS ABOUT LIGHT ............................................ 197

FIGURE 44: LIGHT PLD TOPICS AND INVESTIGATIONS ..................................... 199

FIGURE 45: TEACHING PRACTICE - ITERATION-THREE ..................................... 203

FIGURE 46: SUPPORT AS ESTABLISHED IN ITERATION-TWO ................................ 204

FIGURE 47: SUPPORT - ITERATION-THREE ............................................... 208

FIGURE 48: LOGISTICAL CONSIDERATIONS AS ESTABLISHED IN ITERATION-TWO ...... 209

FIGURE 49: DESIGN FRAMEWORK - ITERATION-THREE ................................... 219

FIGURE 50: FINAL DESIGN FRAMEWORK …............................................... 230 


\section{List of Tables}

TABLE 1: EVALUATION OF INVESTIGATIONS ............................................. 14

TABLE 2: Content AREAS AND GENERAL ChARACTERISTICS .......................... 48

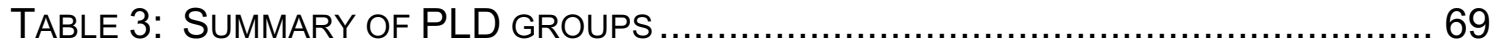

TABLE 4: GENERAL OVERVIEW OF PLD ................................................. 78

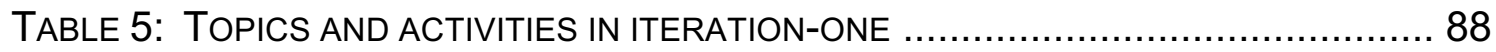

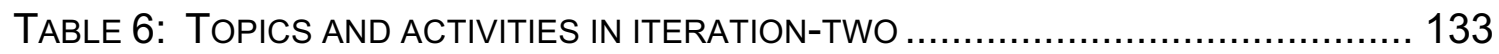

TABLE 7: BIG IDEAS ABOUT PARACHUTES ........................................... 144

TABLE 8: TOPICS AND INVESTIGATIONS IN ITERATION-THREE .......................... 178 


\section{Chapter 1 Introduction and Rationale}

\subsection{Nature of the problem}

\subsubsection{Why I chose this topic}

I am interested in science. I seem to have always been curious about how things work, and was more likely to take my toys apart to see how they worked than play with them in traditional ways. I enjoyed putting them back together to make them do things differently. I have found science to be a field that values curiosity and innovation. While in school I discovered I had a knack for helping my classmates figure things out, and I eventually found my way into teaching science. My student teaching was in physics and chemistry at a large urban school that used very progressive "hands-on" teaching with most of the time being spent on student-centred investigations. I was amazed how interesting and engaging it was.

When I began teaching in my own classroom I developed lessons that were similar to the ones I was involved with during my student teaching experience. I used a textbook for reference material, but the classroom was for doing things. I chose to teach through science investigations because investigations were an integral part of my training, it seemed to be a natural way to learn, and I had confidence in the science, and in my scientific knowledge. I now know the technique I was using is called guided inquiry or investigation, and research has shown it to be an effective and engaging teaching technique; it has formed most of my teaching. I taught chemistry and physics at the high school level for seven years prior to joining a research group at the University of lowa.

I wonder what my students' experience would have been like if I had been required to teach a subject in which I did not have knowledge and confidence, such as art? I took the art courses required in school, but did not take any of the advanced courses, nor did I take any courses in art at university. Imagine if I were required to give a set of students their introduction to art. Further, 
imagine that it was just one of seven or eight subjects I had the responsibility to cover as a generalist primary school teacher. I would need some help. I'm sure there are thousands of articles in teaching journals about effective art teaching, but where would I start? The busy schedule of a primary teacher leaves little time for doing research on teaching theory in scholarly journals. This brings me to the problem I would like to address in this research.

\subsubsection{Problem to be addressed}

My interest in primary school science stems from the experience of observing my son's decision not to take any optional science classes in high school. I realised that he did not have positive involvement with science from his primary school experiences to help guide his choices. Although my teaching experience was at the high school level, and I have never taught primary school science, my experience working with teachers in this research project gave me an appreciation for the challenges they face as teachers. Further, I found that my experience in teaching young adults was very helpful when facilitating the PLD sessions. I could relate to the teachers both as a teacher and a colleague.

The impressions students form about science while they are in school will likely form the foundation for their future understanding of scientific concepts as well as their attitudes to, and beliefs about science (Shulman, 1987). These views and beliefs influence decisions about the science taken in high school, which in turn influence choices at university, and career options (Hipkins et al., 2002). Early exposure to science are important (Ainley \& Ainley, 2011; Novak, 2005), and while school classrooms are not the only place where scientific ideas are presented, it is likely that they represent the first formal introduction to science.

In most primary schools in New Zealand, science is taught by generalist teachers whose only exposure to science was their primary and secondary 
courses, as well as a few ${ }^{1}$ hours of focused science education classes at university. Approximately one in twenty have a qualification in science beyond a first year university paper (McGee et al., 2003). In short, most primary teachers are being asked to provide an introduction to science, while not having been properly introduced to the subject themselves.

The most recent Trends in International Mathematics and Science Study (TIMSS) report covering the 2014/15 period shows that many teachers of Year 5 science were not confident in their ability to teach science, and had received less science professional development than their international colleagues (Caygill, Singh, \& Hanlar, 2016b). The lack of confidence in teaching science is also reported in the 2012 ERO report (Education Review Office [ERO], 2012). Teachers' limited background in science, combined with a lack of confidence and a paucity of professional support, has contributed to relatively little quality science being taught in New Zealand primary schools (Appleton, 2002; Bull, Gilbert, Barwick, \& Baker, 2010).

Additionally, research strongly indicates that the most effective way to teach science is through science investigation, a complex and challenging teaching technique that requires a teacher to handle equipment and questions that require comfort with the subject matter as well as strong pedagogical knowledge (Crawford, 1999).

Much research exists about what types of teaching lead to effective learning in science. However, classroom teachers are largely unaware of research in teaching and learning, or find it not directly applicable to their world of classroom practice (Cain \& Allan, 2017). Practising teachers often do not have easy access to educational research published in journals, and have difficulty finding

\footnotetext{
${ }^{1}$ Total contact hours in science (including labs and tutorials) varies between 10 and 25 hours depending on the university (Maclntyre, 2013).
} 
practical application of many research questions posed therein (Vanderlinde \& van Braak, 2010).

The goal of this research is to provide assistance to primary school teachers so they can build their science subject matter knowledge (SMK), and confidence to teach physical science. In the chapters that follow I will describe the decision to use professional learning and development (PLD) and work with experienced teachers to develop a design framework for a PLD programme for New Zealand Year 7 and 8 (middle school) teachers. The initial PLD design is underpinned by recent published research, drawing together common design characteristics from multiple PLD programmes. The design framework is refined using a three iteration design-based research methodology.

\subsection{Definitions}

I wish to be quite explicit in the definitions of teaching, learning and science used in this dissertation. These concepts can be defined in numerous ways, and it is important to establish a specific definition for clarity.

\subsubsection{Definition of teaching}

Teaching can be defined as: "the achievement of shared meaning in the context of educating ... the teacher acts intentionally to change the meaning of the student's experience, using curriculum materials" (Gowin, 1981, pp. 62-63). Gowin's definition of teaching implies an active process in which the teacher, in possession of the meaning to be shared, acts to create an environment which provide students with new experiences which stimulate the construction of new or enhanced meaning in a specific area.

As an example, if one is required to teach something simple such as the directions to your house, you have to know two things: where your house is, and where the traveller is starting from. It also helps to know the options for travel between the two locations, in order to choose one well suited to the traveller. They could simply look at a map, but a map does the traveller no good 
if they do not know where they are, and do not know the location of your house. Textbook and resource material in science serves the purpose of a map to a traveller, necessary, but not sufficient.

Consider the difficulty in teaching science from a position of not understanding the science concept being taught. Effective teaching means assessing what the students know and understand (prior naïve concepts) and then charting a course from that point to the desired level of understanding of the concept (Driver, Asoko, Leach, Mortimer, \& Scott, 1994). If the teacher has scant knowledge, or holds misconceptions, they will not be able to detect misunderstandings in the students and will have difficulty selecting a target level of understanding.

The challenge for the teacher is to choose the content to teach, to select activities and demonstrations that trigger curiosity, then provide the tools and techniques mixed with just the right amount of support (scaffolding to nudge the students away from some unproductive dead ends and ensure they are successful) for the students to understand science behind the phenomena.

Requirements for the teacher in this scenario involve awareness of appropriate science topics, adequate knowledge of the topics, sufficient out-of-class time to prepare the equipment, and enough classroom time to do the investigation and discuss the results while providing sufficient pedagogical support appropriate to the individual students, and managing it for a class of up to 30 students or more.

Knowledge of subject content, combined with knowledge of the teaching and learning process is known as pedagogical content knowledge and is described as "that special amalgam of content and pedagogy that is uniquely the province of teachers, their own special form of professional understanding" (Shulman, 1987, p. 8).

Teachers need help to identify appropriate topics, find cogent background material to fill knowledge gaps, and find supporting science investigations with 
modest equipment needs, that are the right length to fit into the time window available.

\subsubsection{Definition of learning}

The terms learning, knowing, meaning, and understanding likewise have numerous interpretations. The act of learning is described well by John Dewey (1933):

To grasp the meaning of a thing, an event, or a situation is to see it in its relations to other things: to note how it operates or functions, what consequences follow from it, what causes it, what uses it can be put to ... Since all knowing, including all scientific inquiry, aims at clothing things and events with meaning -- at understanding them, it always proceeds by taking the thing inquired into out of its isolation. Search is continued until the thing is discovered to be a related part in some larger whole. (pp. 137-138)

Learning by this definition implies understanding not only what a thing is, but also how it fits into one or more contexts.

In science, learning involves aligning our internal model of how things work, with the observations and established scientific theories. Solomon (1986) considers learning as: "The organic link between knowledge and experience, and the interaction between them, forms the growth point for new understanding" ( $p$. 152). 
Learning in science involves the application of scientific reasoning (see Figure 1 ), in which there is a comparison of the predictions generated from the theory or model with the data emerging from real world observations.

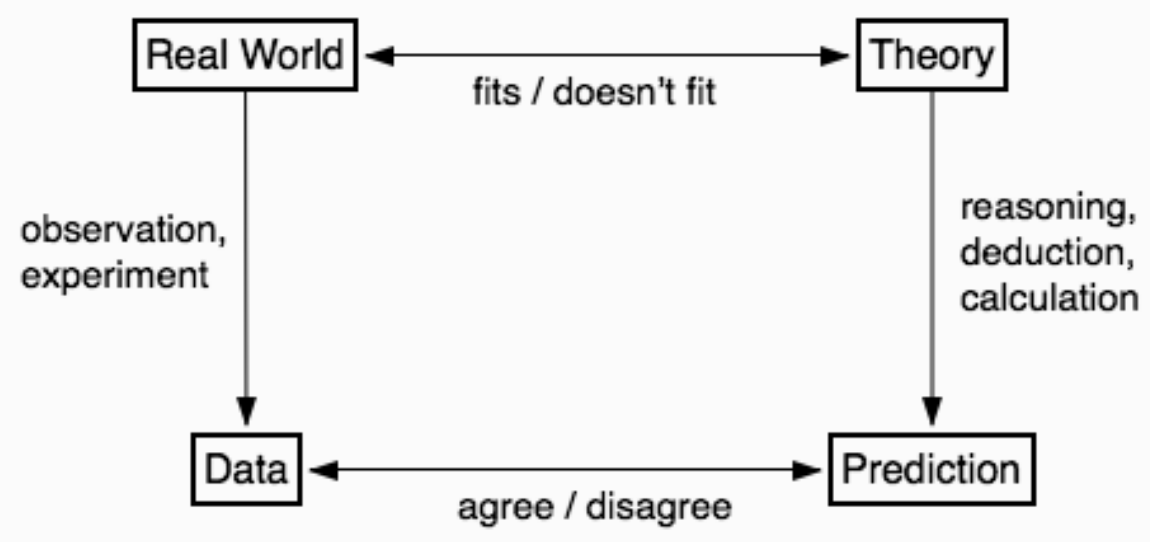

Figure 1: Scientific Reasoning (Driver, Leach, Millar, \& Scott 1996, p. 17)

The view of learning and teaching presented here is consistent with a theory of learning known as social constructivism, which is explored in section 3.4.

\subsubsection{Definitions of science}

There are many definitions of science. The Nobel Prize winning physicist Richard Feynman (1998) defined science as: "Science means, sometimes, a special method of finding things out. Sometimes it means the body of knowledge arising from the things found out" (p. 13). He likened science to trying to figure out the game of chess by silently observing the moves during the games. The understanding gathered in one lifetime is passed along to the next generation. A critical element in Feynman's definition involves the requirement of the generations receiving the collected knowledge to question the validity of inherited knowledge, and not hesitating to sceptically recheck it. To Feynman, the balance between trust and scepticism of inherited knowledge is essential to science (Feynman, 1969). 
Carl Sagan (2011) defined science as a way of thinking rather than a body of knowledge, and described understanding as ecstasy. The view that humans are hardwired to enjoy scientific discovery was also shared by Feynman (2005).

Joseph Schwab (1962) urges that teaching science should be an active process:

science be taught as science ... a product of fluid enquiry, understand that it is a mode of investigation which rests on conceptual innovation, proceeds through uncertainty and failure, and eventuates in knowledge which is contingent, dubitable, and hard to come by. (p. 5)

All of these definitions are inherent in the New Zealand Curriculum's (NZC's) definition of science:

Science is a way of investigating, understanding, and explaining our natural, physical world and the wider universe. It involves generating and testing ideas, gathering evidence - including by making observations, carrying out investigations and modelling, and communicating and debating with others - in order to develop scientific knowledge, understanding, and explanations. Scientific progress comes from logical, systematic work and from creative insight, built on a foundation of respect for evidence. (Ministry of Education [MOE], 2007a, p.30)

My personal definition of science is in line with the above. I think of science as a collection of principles that govern how things work, and have been figured out by those who have gone before, combined with methodologies invented to tease out why things happen the way they do, and a way of working that systematically collects and evaluates evidence to correct existing principles, and propose new ones. Science is, therefore, a combination of knowledge, curiosity, investigation, scepticism, and creativity. 


\subsubsection{Teaching science}

Teachers must choose how to balance teaching science as a way of finding out how things work with teaching science as a collection of accepted knowledge. At one extreme science can be taught by doing activities and observing, leaving the explanations and theory to be worked out by the students. At the other extreme science can be taught as simply collected knowledge to be learnt. Neither of these extremes does justice to science, which contains elements of both. It follows from the definitions that the science classroom should include elements of investigating, predicting, explaining, and understanding.

\subsubsection{Why physical science}

I have chosen to concentrate on physical science for the PLD framework development for two main reasons. Firstly, my background and teaching experience is deepest in the physical sciences, and secondly, that physical science is an area in which primary teachers typically lack confidence (ERO, 2012).

Physical science is the study of inanimate objects and their interactions.

Fundamental to understanding (ability to explain and predict) those interactions is a set of simple, mostly invisible, and often counter-intuitive 'laws' that can often be recited, but are seldom understood. People can recite Newton's third law that for every action there is an equal but opposite reaction, but may be unable to provide a real-world example (e.g., a rocket works by action/reaction, not by pushing against the ground).

The things we observe (natural phenomena) happen for reasons, and often the underlying physical law governing the phenomena is simple, but not directly visible by observation. What makes physical science difficult is that the fundamental reasons are often invisible, and generally run counter to our observations and experience (e.g., conservation of energy and Newton's first law). 
Physical science is similar to reading or maths in that there are some basic concepts which have to be understood, and once those are in place, connections can be formed to future material. If those concepts are mastered and understood deeply, future learning moves from recall to understanding. The bedrock concepts in physical science allow the learner to make connections and see the logic of how things work, and can serve as a foundation to support reasoning in more complex domains.

In a 12-year longitudinal study, Novak (2005) showed that primary school children are quite capable of attaining an understanding of highly abstract physical science concepts such as the particulate nature of matter, energy and energy transformations. Further, the study showed that students who developed these basic concepts in early grades were better able to master more complex concepts in later years. Similarly, Hardy, Jonen, Möller, \& Stern (2006), working with Year 3 students found significant differences between student groups receiving different levels of conceptual development support, concluding that "Directing young children's attention toward basic physics explanations may lay the foundation for their later understanding at a more formal level" (p. 324).

Many primary teachers in New Zealand lack confidence in science in general, and physical science in particular (ERO, 2012). Because this is an area of need and my background is strong in the physical sciences, I wish to encourage teachers to develop lessons in physical science.

The NZC is very broad in the specification of science content that is to be covered. If we limit ourselves to levels $3 \& 4$ of the "Physical World" strand it states that students will:

Explore, describe, and represent patterns and trends for everyday examples of physical phenomena, such as movement, forces, electricity and magnetism, light, sound, waves, and heat. For example, identify and describe the effect of forces (contact and non-contact) on the motion of objects; identify and describe everyday examples of sources of energy, forms of energy, and energy transformations. (MOE, 2007b, p. 24) 
The Nature of Science (NOS) is another stream reflected in the NZC. Understanding NOS involves understanding the process by which scientific knowledge is obtained. Research indicates that to effectively teach students about NOS, the teachers must have a knowledge of the subject matter, pedagogy, and NOS, and have the intention to explicitly teach NOS (Lederman, Schwartz, Abd-El-Khalick, \& Bell, 2001).

Understanding in the physical sciences frequently involves breaking down a complex observation into smaller and more fundamental parts. Understanding those parts allows one to begin to be able to explain how things work, and make accurate predictions about the results of experiments. Teaching a high-level concept without a degree of understanding of the fundamental underlying concepts becomes an exercise in remembering and believing rather than reasoning.

The use of scientific reasoning to explain an observation can be illustrated by an example. A demonstration I used in my physics classes when we were beginning a unit on phase of matter was to place a small beaker filled with water in a vacuum chamber, and as the pressure dropped, the water would begin to boil. When I removed the beaker from the chamber and passed it around, the students were surprised to find the water was very cold. I informed them that if I would continue to run the experiment, the water would eventually freeze solid. I asked the students to list the things that they observed, which typically included the boiling, low pressure, and lowering of the water temperature. Throughout the course of the unit we would return to these observations and explain, based on the science we were learning, why the various observations had occurred.

Teaching all of the background concepts necessary to fully understand all aspects of a concept would make teaching any physical science concepts difficult in primary school. Warren (1986) argues that many physical science topics should not be taught in primary school: 
To a beginner even the most elementary ideas are extremely difficult and we cause grave harm when we pretend that children (or adults) understand ideas about which they are actually totally ignorant or hopelessly confused. ... Energy is an abstraction from the physicists' quantity work. Thus one can only begin to learn about energy when one understands work. Work is an abstraction from the quantities displacement and force. So work can only be taught when these concepts have been mastered. Force is an extremely difficult abstraction which can only be taught on an axiomatic basis. It must be emphasised that forces cannot be felt or seen but can only be deduced mathematically from the results of experiments. (p. 155)

Such an all or nothing approach to physical science learning would remove the study of science from schools altogether. The approach taken in this research project is to attempt to provide teachers with an adequate background to the science concepts covered so that they feel confident to teach the material.

\subsubsection{The role of PLD}

Each level of the science section of the NZC specifies content across four areas: Living World; Planet Earth and Beyond; Physical World; and Material World. Each of these areas contains a general description of the material to be covered by the teachers. The curriculum encompasses a great deal of material. To illustrate the challenge, consider the Physical World section.

Level 4 students are to: "Explore, describe, and represent patterns and trends for everyday examples of physical phenomena, such as movement, forces, electricity and magnetism, light, sound, waves, and heat" (MOE, 2007c, p. 24). Leaving aside specifically what is meant by "Explore, describe, represent patterns and trends," consider what would be required to develop anything other than a surface level understanding of any one of the list of topics. Is it reasonable to expect a teacher, who has received very little specialist training in science teaching, and may not have taken science classes since Year 10, to have enough content knowledge in science to be able to select appropriate material to cover these complex topics? How could they select, adapt, or develop science inquiry lessons that bridge the gap between student knowledge and accepted scientific understanding of phenomena that they have never 
formally studied? These questions represent potential barriers which must be overcome.

A PLD experience for teachers of science must address the barriers that keep teachers from teaching science. The literature on science PLD (see section 2.3) identifies many potential barriers; however, much of the literature is based on North American teachers in specific situations which may not be applicable to New Zealand teachers. Teacher training also varies between locations, and these differences make generalisability difficult. It is therefore reasonable to tailor the PLD to the specific needs of the group at hand. A well-designed PLD must include flexibility to ensure a good fit with the needs of the teachers in their specific situation.

\subsubsection{Science investigation as a learning tool}

A number of terms are used to describe teaching that involves engagement with scientific phenomena. The terms activity, experiment, investigation, hands-on, and demonstration are all used to describe teaching in which the students are asked to probe and/or observe something in the physical world. For the purpose of this research project, I will use the term science investigation to describe activities in which students are involved in direct observation, whether through conducting a procedure of some type, or by making observations as someone else conducts a procedure.

The theory of learning employed in this study (described in section 3.4) is social constructivism, a theory which suggests that knowledge is actively constructed by the learner in collaboration with others. The act of learning, conceptualised as linking to or replacing one's current understanding, requires a degree of motivation, particularly when the scientific idea being presented requires changing existing understanding, or abandoning misconceptions. The use of science investigations can provide motivation, and aid in connecting what we observe in everyday life to a set of governing laws or theoretical frameworks, as depicted in Figure 2 (Millar, 2009). 


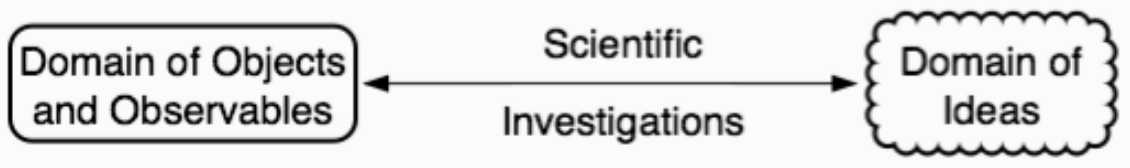

Figure 2: The role of scientific investigations in teaching (p. 4)

Millar (2009) suggests that a useful way to evaluate a science investigation is to consider student engagement with the objects and observables, as well as with the underlying ideas, in both in the present and future, as shown in Table 1.

Science investigations are used for a number of different purposes, ranging from simple observation and reporting through to serving as the foundation for establishment of important scientific theories.

Table 1: Evaluation of investigations (Millar, 2009, p. 5)

Domain of objects and observables

Domain of ideas

\begin{tabular}{|l|l|l|}
\cline { 2 - 3 } Present & $\begin{array}{l}\text { Students do what was intended with the } \\
\text { objects and materials provided, and } \\
\text { observe what they were meant to observe }\end{array}$ & $\begin{array}{l}\text { During the activity, students think about } \\
\text { what they are doing and observing, using } \\
\text { the ideas intended, or implicit in the } \\
\text { activity }\end{array}$ \\
\cline { 2 - 4 } Future & $\begin{array}{l}\text { Students can later recall and describe } \\
\text { what they did in the activity and what they } \\
\text { observed }\end{array}$ & $\begin{array}{l}\text { Students can later discuss the activity } \\
\text { using the ideas it was aiming to develop, } \\
\text { or which were implicit in it (and can } \\
\text { perhaps show understanding of these } \\
\text { ideas in other contexts) }\end{array}$ \\
\hline
\end{tabular}

\subsubsection{The scope of this PLD}

I have decided to limit the scope of this PLD to a very limited area of physical science and attempt to go into sufficient depth to give the teacher confidence to teach a unit on the content area. It is hoped that in participating in the process of approaching one narrow subject area, the teachers will be able to approach another area with a degree of confidence. 


\subsection{Thesis overview}

This chapter provided a context for the study and established some definitions for concepts that are used in the research project. The following chapter presents a review of the literature on science teaching in New Zealand primary schools, and PLD programme design. Chapter 3 lays out the research questions, methodology used, data collection methods, ethical considerations, and analysis techniques. The following three chapters describe each of the three iterations of using the design framework, evaluation of the PLD experience, and design changes. The final chapter summarises the final design, addresses the research questions and other issues encountered during the PLD iterations, considers the implications and limitations of the research, and suggests future research. 


\section{Chapter 2 Literature Review}

\subsection{Primary science in New Zealand}

In this chapter I present a review of literature which provides a background on science teaching in primary schools in New Zealand. I will review the science set out in the NZC, and the support provided by the MOE, and present literature that examines the performance of New Zealand primary school students in science from both a national and international perspective. Next I will review the challenge of teaching and learning science, particularly physical science internationally, and specifically in New Zealand primary schools. Finally, I will examine literature regarding teacher preparation and PLD, concluding with the construction of a PLD framework that will be used in this research project.

\subsubsection{New Zealand context}

New Zealand has compulsory education from age six to sixteen. Students typically begin primary school when they turn five in Year 1 and exit primary school at Year 8. Some primary schools offer all eight years at one school, while others only offer Years 1-6 with students in Years 7 and 8 attending an intermediate school (MOE, 2010).

New Zealand's founding document is the Treaty of Waitangi, a treaty between the original inhabitants, Māori, and the British Crown, establishing New Zealand as a British colony, and defining a partnership between Māori and the British immigrants. Publicly funded education is provided in both English and Māori. As English is the dominant language, the majority of schools are Englishmedium schools, with approximately $17 \%$ of Māori children attending Kura Kaupapa Māori schools which teach in Māori and emphasise Māori culture and values. The majority of Māori children attend English-medium schools. Schools that teach in the English language use the NZC. Schools that teach in the Mãori language use Te Marautanga o Aotearoa (a curriculum based on Māori philosophies) (May \& Hill, 2005). 
Resource funding, and some operational funding of New Zealand schools is currently based on the relative affluence of families in the school zone. Data from Statistics New Zealand are used as inputs into a formula involving household income, occupation, house crowding, education, and income assistance for each household in the zone. The resulting summed scores for each school are ranked and divided into ten groups or "deciles" with approximately equal numbers of schools in each group. Although this process is currently under review, as of this writing, each school is assigned a decile rating, with 1 being the least affluent and 10 being the most affluent (MOE, 2016). Much analysis of the New Zealand educational system makes reference to the decile of the school. The primary subject of this research is not related to issues of funding or affluence. A decile criterion was employed for candidate school selection, the intention being to avoid schools that could be characterised as highly affluent, or highly impoverished, potentially conflicting the findings (see section 3.2).

\subsubsection{New Zealand curriculum}

The NZC, published in 2007 and fully implemented in 2010 (MOE, 2007a), is a framework providing broad learning objectives to guide the development of school-specific detailed curricula (see Figure 3). The NZC does not differentiate between primary and secondary levels, but rather provides a continuous set of outcome-focused learning objectives to be used from Year 1-13 for each of eight learning areas: English, the arts, health and physical education, learning languages, mathematics and statistics, science, social sciences, and technology (Bull et al., 2010). Rather than specifying the topics by year, the curriculum divides the objectives into eight overlapping levels, with each level spanning approximately two years, at primary level. Each learning area contains a number of strands, each of which has a set of achievement objectives (MOE, 2007b).

As illustrated in Figure 3, the science learning area of the NZC is divided into five strands the: Living World; Planet Earth and Beyond; Physical World; 
Material World; and an over-arching NOS strand. The NOS strand is required learning for years $1-10$, and is designed to convey what science is, and how scientific knowledge is established, challenged, and refined. The other strands provide a context for learning, and students are expected to have learning opportunities in all four contextual strands over the course of Years 1-10 (MOE, 2007a).

\begin{tabular}{|c|c|c|c|}
\hline $\begin{array}{l}\text { Nature of Science } \\
\text { Students will: } \\
\text { Understanding about } \\
\text { science } \\
\text { - Appreciate that science is a } \\
\text { way of explaining the world } \\
\text { and that science knowledge } \\
\text { changes over time. } \\
\text { - Identify ways in which } \\
\text { scientists work together and } \\
\text { provide evidence to support } \\
\text { their ideas. }\end{array}$ & $\begin{array}{l}\text { Investigating in science } \\
\text { - Build on prior experiences, } \\
\text { working together to share } \\
\text { and examine their own and } \\
\text { others' knowledge. } \\
\text { - Ask questions, find evidence, } \\
\text { explore simple models, } \\
\text { and carry out appropriate } \\
\text { investigations to develop } \\
\text { simple explanations. }\end{array}$ & $\begin{array}{l}\text { Communicating in science } \\
\text { - Begin to use a range } \\
\text { of scientific symbols, } \\
\text { conventions, and vocabulary. } \\
\text { - Engage with a range of science } \\
\text { texts and begin } \\
\text { to question the purposes } \\
\text { for which these texts are } \\
\text { constructed. }\end{array}$ & $\begin{array}{l}\text { Participating and } \\
\text { contributing } \\
\text { - Use their growing science } \\
\text { knowledge when considering } \\
\text { issues of concern to them. } \\
\text { - Explore various aspects of } \\
\text { an issue and make decisions } \\
\text { about possible actions. }\end{array}$ \\
\hline $\begin{array}{l}\text { Ecology } \\
\text { - Explain how living things } \\
\text { are suited to their particular } \\
\text { habitat and how they } \\
\text { respond to environmental } \\
\text { changes, both natural and } \\
\text { human-induced. } \\
\text { Evolution } \\
\text { - Begin to group plants, } \\
\text { animals, and other living } \\
\text { things into science-based } \\
\text { classifications. } \\
\text { - Explore how the groups of } \\
\text { living things we have in the } \\
\text { world have changed over } \\
\text { long periods of time and } \\
\text { appreciate that some living } \\
\text { things in New Zealand are } \\
\text { quite different from living } \\
\text { things in other areas of } \\
\text { the world. }\end{array}$ & $\begin{array}{l}\text { Planet Earth and Beyond } \\
\text { Students will: } \\
\text { Earth systems } \\
\text { - Develop an understanding } \\
\text { that water, air, rocks and } \\
\text { soil, and life forms make up } \\
\text { our planet and recognise } \\
\text { that these are also Earth's } \\
\text { resources. }\end{array}$ & $\begin{array}{l}\text { Physical World } \\
\text { Students will: } \\
\text { Physical inquiry and } \\
\text { physics } \\
\text { concepts } \\
\text { - Explore, describe, and } \\
\text { represent patterns and } \\
\text { trends for everyday } \\
\text { examples of physical } \\
\text { phenomena, such as } \\
\text { movement, forces, electricity } \\
\text { and magnetism, light, } \\
\text { sound, waves, and heat. } \\
\text { For example, identify and } \\
\text { describe the effect of forces } \\
\text { (contact and non-contact) } \\
\text { on the motion of objects; } \\
\text { identify and describe } \\
\text { everyday examples of } \\
\text { sources of energy, forms } \\
\text { of energy, and energy } \\
\text { transformations. }\end{array}$ & $\begin{array}{l}\text { Material World } \\
\text { Students will: } \\
\text { Properties and changes } \\
\text { of matter } \\
\text { - Group materials in } \\
\text { different ways, based } \\
\text { on the observations and } \\
\text { measurements of the } \\
\text { characteristic chemical and } \\
\text { physical properties of a range } \\
\text { of different materials. } \\
\text { - Compare chemical and } \\
\text { physical changes. } \\
\text { The structure of matter } \\
\text { - Begin to develop an } \\
\text { understanding of the particle } \\
\text { nature of matter and use this } \\
\text { to explain observed changes. }\end{array}$ \\
\hline
\end{tabular}

Figure 3: NZC Level 4 Science

The science area that is the focus of this study is physical science, which is covered by the Physical World curriculum strand. The Physical World strand 
covers many of the basic topics of physics, such as light, sound, forces, motion and energy, and is designed to give students a basic knowledge of how things work from a physics perspective. As an example, achievement objectives for levels three and four of this strand, which cover Years 5-8, are identical, and state that students will:

Explore, describe, and represent patterns and trends for everyday examples of physical phenomena, such as movement, forces, electricity and magnetism, light, sound, waves, and heat. For example, identify and describe the effect of forces (contact and non-contact) on the motion of objects; identify and describe everyday examples of sources of energy, forms of energy, and energy transformations. (MOE, 2007c, p. 18)

This study will also address aspects of the NOS strand of the NZC. The NOS strand consists of four general areas: understanding about science, investigating in science, communicating in science, and participating and contributing. Students are to gain an appreciation of what science is, the nature of scientific knowledge, how to conduct scientific investigations, and how science can help in understanding the everyday world around them (MOE, 2007a, c).

The NZC is not a prescriptive detailed curriculum. Schools are expected to construct their local curriculum in alignment with the values and expectations of their community, while addressing the broad expectations of the NZC, and developing detailed teaching and learning sequences around selected topics and contexts to reinforce that alignment (MOE, 2007a). Science advisors, provided by School Support Service arms of universities and funded by the MOE, were available to assist schools with local curriculum development and advice until the programme was discontinued in 2009. Beginning in 2012, support was re-initiated in the form of PLD providers contracted to the MOE with requirements to provide evidence of improvements in student learning and the school's ability to carry out self-review. The result of this change is that less help is available to schools for detailed curriculum planning in science (Bull, 2014). 
Some guidance is available for teachers in planning and implementing the science area of the NZC through the "ScienceOnLine" area of Te Kete Ipurangi, funded and administered by the MOE (http://scienceonline.tki.org.nz). The website is designed for both primary and secondary teachers, and contains links to the NZC, teaching ideas for the NOS strand, assessment tools, and summaries of available hard-copy resources. Two additional sets of support material developed for the previous 1993 curriculum (MOE, 1993) are also available to teachers in the form of a set of 64 Building Science Concepts (BSC) booklets, and a four-volume Making Better Sense series. Each BSC booklet (e.g., MOE, 2003) covers a single science concept, and contains review material for teachers, and science investigation ideas for the classroom. The Making Better Sense books are designed to provide science background and ideas for science investigations for primary school teachers. The second book in the series, Making Better Sense of the Physical World (MOE, 1999) focuses on physics, and is designed to help Year 1 to 8 teachers understand physics principles, and to plan programmes of instruction.

The Science Learning Hub website (http://www.sciencelearn.org.nz), established in 2007 and funded by the New Zealand Ministry of Business, Innovation and Employment, also provides curriculum support materials and information on science topics related to New Zealand science and scientists, primarily designed to support secondary level science teachers but has a section that includes some support for primary school teachers.

\subsection{Science in New Zealand primary schools}

Primary school teachers in New Zealand are usually generalists in that they are required to teach all subject areas of the NZC. Although subject matter specialists exist in some situations, science is taught by the regular classroom teacher in the majority of primary schools. The majority of primary school teachers do not have a background in science, only $5 \%$ to $7 \%$ having university level science qualifications, and $13 \%$ having done some specialist study in science (Bull et al., 2010; Martin, Mullis, Foy, \& Stanco, 2012; McGee et al., 
2003). For the majority of teachers, their only exposure to science was their secondary school science class(es), and a few hours of focused science education classes at university during teacher education, ranging from 10 to 25 hours of instruction, depending on the university (Maclntyre, 2013).

As stated earlier, rather than following a fixed national curriculum, New Zealand provides a curriculum framework which is used to guide the development of a specific curriculum, unique to each school environment and produced by each school (MOE, 2007a). Since each school develops its own detailed curriculum, it is not surprising that only $5 \%$ of New Zealand schools use textbooks as a primary resource in science, and less than half of the schools use science textbooks at all (Martin et al., 2012).

\subsubsection{New Zealand primary students' science experience}

The quality of science teaching in New Zealand can be gauged by several national and international assessments. Student achievement against the NZC is monitored by government funded annual studies based on representative samples of randomly selected students in Year 4 and Year 8. All areas of the curriculum are covered by selecting two or three academic areas per year in a multi-year cycle. From 1995 to 2010 the programme was called the National Education Monitoring Programme (NEMP) conducted by the Educational Assessment Research Unit (EARU) of the University of Otago, under contract to the MOE. The NEMP ran in a four-year cycle, examining science in years 1995, 1999, 2003, and 2007. Beginning in 2012, a new programme, the National Monitoring Study of Student Achievement (NMSSA), conducted by EARU and the New Zealand Council for Educational Research (NZCER), extends the NEMP design but retains fundamental elements in order to provide continuity. The science curriculum area was the subject in 2012 and is scheduled again in 2017 (EARU \& NZCER, 2013).

Schools in New Zealand are also evaluated by the ERO (Educational Review Office), a governmental department charged with examining and reporting on 
education and student care. The ERO evaluates individual schools approximately once every three years, producing reports on the quality of education provided by the individual school. These reports are made available to the school boards of trustees, and the government, and are posted on the ERO website (http://www.ero.govt.nz/review-reports/). In addition to individual school reports, the ERO publishes national reports on specific topics using data from its reviews. The two most recent reports that focused on science were produced in 2010 and 2012 (ERO, 2010, 2012).

International comparisons can be found in the TIMSS, an international research study, conducted by the International Association for the Evaluation of Educational Achievement that measures student achievement in mathematics and science at middle primary (Year 5) and lower secondary (Year 9) levels. Approximately 60 countries participate in the TIMSS, including 28 countries in the Organisation for Economic Co-operation and Development (OECD) (Caygill, Hanlar, \& Singh, 2016; Chamberlain \& Caygill, 2013). Another international assessment which measures the performance of 15-year-old (New Zealand Year 10/11) students in reading, mathematics, and scientific literacy is the Program for International Student Assessment (PISA), which was begun in 1997 and is administered in a three-year cycle. The focus of the science area of the PISA is scientific literacy, defined as the application of scientific knowledge in real world situations (Bybee \& McCrae, 2009; Kirkham \& May, 2016).

In order to get a comprehensive picture of the condition of science instruction in New Zealand primary schools one needs to consider both international and national assessment data. Science is the major focus of PISA every third assessment cycle, and science test scores for New Zealand stayed roughly even between 2006 and 2009, but decreased significantly in 2012, with a slight drop in 2015. The percentage of New Zealand students failing to meet the minimum proficiency level also increased between 2009 and 2012, and remained unchanged in 2015, with an over representation of Māori and Pasifika students in this group (May, Cowles, \& Lamy, 2013; May, Flockton, \& Kirkham, 
2016). An overview of the performance of New Zealand students can be found in Bull et al.'s (2010) analysis of national and international data. Based on data from the TIMSS and PISA from 2006, the authors point out that while New Zealand students scored well in the identification of scientific issues and using scientific evidence, they were weaker in their ability to explain scientific phenomena, with higher scores in biology and earth science, and lower scores in the physical science areas. They also emphasised the wide range of performance, highlighting that although the mean New Zealand science score is above the OECD average, and the top performing New Zealand Year 10/11 students score very well when compared to other countries, there are a large group of low performers which are among the lowest performers in the study. These distribution trends are also found in the latest TIMSS data (Caygill, Singh, \& Hanlar, 2016).

In the 2011 and 2015 TIMSS assessments, New Zealand Year 9 students scored slightly above the international mean, and Year 5 students showed a slight improvement, scoring below the mean in 2011 , and slightly above the mean in 2015 (Martin et al., 2012; Martin, Mullis, Foy, \& Hooper, 2016). The MOE analysis of the TIMSS data across time shows that while the science scores for New Zealand Year 5 students showed steady gains in TIMSS exams taken over 1994/95 and 2002/03; since 2002/03, the average science achievement of Year 5 students has decreased steadily back to 1994/95 levels, with physical science being a particular area of weakness (R. Baker \& Jones, 2005; Chamberlain \& Caygill, 2013). The 2011 and 2015 cycles of TIMSS also showed a high proportion of very low achievers (students who did not reach the low benchmark) compared with countries with similar or higher mean science achievement with $13 \%$ of Year 5 students not reaching the lowest benchmark. The range of achievement within New Zealand was wider than nearly all of the high-performing countries and nearly all of the countries that tested in English, with substantially fewer Māori and Pasifika students reaching the higher benchmarks (Martin et al., 2012; Martin et all, 2016). 
The NEMP data between 1995 and 2007 show little change in students' performance overall, although concern is raised regarding a small but consistent decline in Year 4 students' physical science mastery (Crooks, Smith, \& Flockton, 2008). There is also a sharp decline in students' engagement in science between Year 4 and Year 8 as gauged by answers to the question: "Do you think you would make a good scientist when you grow up?" Just over one in four Year 4 students answered "yes", and this already low number dropped to one in twenty for Year 8 students (Bolstad \& Hipkins, 2008). This drop-off is also reflected in the latest available NMSSA results which show a significant drop-off of students' attitudes to science between Year 4 and Year 8, a trend which was also found in the TIMSS data (Martin et al., 2012). These results are concerning, particularly in light of research showing that decisions about pursuing ongoing study in science are largely formed for a majority of students at an early age, prior to Year 9, and the decision as to whether or not to pursue science in high school is strongly influenced by previous experiences in school science (Hipkins \& Bolstad, 2005), and are a significant predictor of career choice, particularly in the physical sciences (Tytler \& Osborne, 2012).

Another perspective is found in the latest available NMSSA results, which show that approximately $85 \%$ of Year 4 students are able to communicate the science ideas at the appropriate levels described in the NZC (Curriculum Levels 1 and 2 for Year 4 students, and Levels 3 and 4 for Year 8 students). However, this proportion drops to only $19 \%$ for the Year 8 students (EARU \& NZCER, 2013). Performance of Māori and Pasifika students attending English-medium schools was lower than the average of all students, particularly in lower decile schools.

In summary, a cursory glance at the performance of New Zealand students in science might not seem problematic, with mean performance being on a par with the OECD mean, and high performing New Zealand students ranking highly internationally. These data, however, reveal several areas of concern. The distribution of our learners is wider than typical, indicating that while the high performers are doing well, the lower performers are among the lowest tested, 
and the higher representation of Māori and Pasifika students in the lower performing group is troubling. The studies presented indicate student attitudes toward science decline as they progress through primary school, and also decline within each group across time. Additionally, student achievement in physical science is significantly lower than the overall science scores (Martin et al., 2012; Martin et al., 2016).

\subsubsection{New Zealand primary science teaching}

A picture of teaching in New Zealand primary schools can also be drawn from the TIMSS data. Instructional hours in science in New Zealand middle primary classrooms were lower than nearly all other countries in the study, estimating approximately 43 hours per year compared to the international average of 76 hours (Martin et al., 2016). In their analysis of the 2010/11 TIMSS data, Caygill, Kirkham, and Marshall (2013) note that a number of teachers reported that they did not teach science at all during 2011, and suggest that 52 hours reported in the 2011 TIMSS may have been an over-estimation because more than a quarter of the respondents did not answer this question. The time spent teaching science is sharply down from the 66 hours reported in 2002 (Bull et al., 2010). By comparison, primary school students are taught 168 hours of mathematics, and 72 hours of physical education during the school year (Cowley, Hamlin, \& Grimley, 2011).

Turning to the national data, the ERO (2004) report "The Quality of Teaching in Years 4 and 8: Science" examined science teaching in 233 schools. The 2004 report found that $87 \%$ of the schools examined were adequate or effective in their implementation of the curriculum in science. The report also found a significant correlation between recent involvement in PLD and effective science teaching, specifically that $89 \%$ of the teachers who were not effective in their science teaching did not receive science PLD within the previous 12 months. Approximately $27 \%$ of teachers received externally provided science PLD during the 12-month period from beginning Term 2, 2002, primarily through the science 
advisors contracted through the MOE, and an additional $15 \%$ of teachers received PLD provided by staff within their school.

In 2010 the ERO published a report on an analysis of 13 schools selected based on their performance in previous ERO reviews as examples of good practice in their science teaching. Schools were selected to include a range of rural and urban schools, as well as a mixture of high and low decile schools. The report found a number of common characteristics of science teaching, including:

- high quality planning, including strategies for identifying and responding to students' prior knowledge, and for teaching students the significant scientific concepts (or big ideas);

- flexible approaches that took advantage of students' curiosity and were able to meet the diverse needs of students;

- an emphasis on the quality of thinking, or conceptual development, undertaken by students;

- high quality investigations, reflection and discussions that helped students develop their understanding of scientific knowledge and scientific processes;

- engaging practical activities that allowed students to investigate their own ideas as well as those of others - these activities were collaborative, relevant, and drew on local context as well the interests of students. (ERO, 2010, p. 2)

The report also found that effective science teaching required the support of the school principal, and an effective science leader. The effective teachers did not all have science qualifications, but drew on solid science SMK, and were confident in their ability to teach science well.

Effective science lessons were structured in a way that emphasised both science content and science investigation:

While many educators emphasise the process of scientific investigation, effective science teaching is also concerned with developing scientific knowledge. However, scientific knowledge is not just about learning facts. Knowledge in this case refers to the development of scientific ideas and concepts and a deep understanding of how things work. Perhaps ironically, in order to develop such knowledge students need to use investigative processes 
along the way. Both of these components make the learning engaging. (ERO, 2010, p. 14)

The ERO again focused on science in their report published in 2012, which examined the quality of the science programmes of 100 schools during the first two terms of 2011 (ERO, 2012). Of the 100 schools examined, three were highly effective, 24 were deemed generally effective, leaving the remaining 73 schools rated partially or not effective in their science programmes. The report also highlighted the lack of availability of professional development in science due to the disbanding of science advisors. The teachers in the effective and highly effective schools taught using science investigations and subsequent discussions; however, these practices did not occur in the majority of schools. The authors concluded:

A key factor in the quality of science teaching and learning is the lack of confidence demonstrated by many teachers in teaching this curriculum area. This reflects a lack of knowledge and understanding of the science curriculum, and of what constitutes effective science teaching and learning. It is manifest in the fact that some teachers avoid teaching science as part of their classroom programme. When science is taught this lack of confidence leads to a more easily managed, teacher directed approach. Teachers find the certainty of teaching content knowledge is easier than facilitating students' participation in an investigative process where the outcome may be uncertain. (ERO, 2012, p. 17)

In the same report the authors found that $73 \%$ of the schools examined considered science a low priority subject, and concluded that many schools have not been able to balance the priority imposed by the literacy and numeracy standards with the requirement to deliver high quality science education. The low prioritisation of science was reinforced by new reporting requirements introduced in 2010 which required teachers to submit progress reports on student achievement relative to literacy and numeracy standards twice yearly to parents (Thrupp, 2013). In 2012 the data on student achievement against the literacy and numeracy national standards began to be collected by the MOE, with individual school data made available in a summarised form on the 
"Education Counts" website

(http://www.educationcounts.govt.nz/statistics/schooling/national-standards), increasing the focus on literacy and numeracy and away from other subjects.

In a report commissioned by the New Zealand Education Institute, Thrupp and White (2013) found that while there were some positive impacts of the literacy and numeracy standards such as increased understanding of the curriculum levels, these were overshadowed by narrowing of the curriculum, and reinforcement of a two-tier curriculum with high and low priority subjects. The tension between a non-prescriptive curriculum and national standards was examined further by Fisher and Ussher (2015) in their study of 16 high performing schools, which found a strong emphasis on literacy and numeracy over other areas of the NZC suggesting that "the National Standards have become the new curriculum" (p. 227). They caution educational leaders to be mindful of the unintended consequences of targets and standards.

The 2012 ERO report also found that two-thirds of schools in the study lacked a coherent science framework for planning. In lower performing schools the science planning was done on a term-by-term basis focusing at a topic level without attempting to establish a foundation or context. The focus of the science taught related to the "Living World" or "Planet Earth and Beyond" strands of the NZC with less attention on other strands, and little or no attention given to the NOS strand. This focus aligns with research on teacher confidence. For example, Murphy, Neil, and Beggs (2007) found that teachers are more confident to teach about living things than physical science topics.

In summary, relatively little time is spent teaching science in the primary years, and many primary school teachers are not confident in their ability to teach science, particularly the physical sciences. The problem is exacerbated by an emphasis on literacy and numeracy in recent years resulting in lower priority being given to science. A PLD programme designed to build teachers' 
competence and confidence in teaching physical science topics could make a difference in the amount of science taught.

As Bull (2014) suggests, the view of the role of science as stated in the NZC has significant implications for teaching and assessment. Given the nonprescriptive design of the NZC, the local school and teachers must translate the broad range of topics of the NZC into classroom praxis to meet local learning objectives. Bull argues that the traditional assumptions about the lack of teacher knowledge and confidence may not signal a lack of ability or potential, but rather an unclear direction regarding the purpose and importance of science, and that teacher knowledge deficits could be addressed if and when science is seen as a priority.

\subsubsection{Nature of knowledge needed for teaching physical science}

This section examines the international literature to identify the complex knowledge primary school teachers need in order to use the NZC framework to select science topics that are appropriate for their students and in line with their communities' needs, and then to develop or choose the classroom materials to be used in the teaching of the selected topics.

The NZC states that students learn science so that they can be "critical, informed, and responsible citizens in a society in which science plays a significant role" (MOE, 2007a, p. 17). The extent of scientific knowledge necessary to function as responsible citizens is defined explicitly by Sir Peter Gluckman, the Prime Minister's Chief Science Advisor:

First, all children need to have a practical knowledge at some level of how things work - not in detail but with enough understanding to appreciate the technological environment in which they live and work, the environmental complexities of the world they live in, and the way the biological world, including their own body, works. Secondly, all children need to have some knowledge of how the scientific process operates and have some level of scientific literacy so that they can take an informed participatory role in the science-related decisions that society must take - ranging from climate change to the use of new assisted reproductive technologies. Thirdly, all children need to have enough knowledge 
of scientific thinking as part of their development of general intellectual skills so that they are able to distinguish reliable information from less reliable information. (Gluckman, 2011, pp. 3-4)

The three types of science knowledge described by Gluckman can be summarised as: how things work, how science functions to determine how things work, and how to think scientifically. I would argue that a thorough understanding of how science functions includes the ability to think scientifically, and therefore the purpose of science education is twofold: to instil a basic understanding of how the natural world works, and an understanding of how science functions to establish how things work. These two kinds of knowledge were described by Schwab (1964) as substantive knowledge, the knowledge established by a discipline, and syntactic knowledge, the process and procedures a discipline employs to establish knowledge. As described earlier, the NZC divides science into four disciplinary strands (Living World, Planet Earth and Beyond, Physical World, and Material World) which are concerned with substantive knowledge, and one over-arching syntactic strand, (NOS) (MOE, 2007a).

In her comprehensive review of teacher knowledge, Abell (2007) reviewed research on the relationship between content knowledge, or SMK and science teaching dating back to the 1930s. Abell found that researchers have used a wide variety of measures of SMK, including formal science courses taken, testing, responses to hypothetical teaching situations, and direct classroom observation. The studies also involved a wide range of experience and grade levels taught. However, despite the mixture of methods and settings she found the evidence supports a positive relationship between SMK and teaching, concluding that "Perhaps SMK is necessary, but not sufficient, for effective teaching" (p. 1120).

The simple solution of requiring additional science courses during teacher training has not been found to be a successful mechanism to increase teacher SMK. Several studies, including Stepans and McCormack (1985), Skamp 
(1989), and Appleton (1995) found that more formal science training was not associated with increased levels of conceptual science knowledge. In more recent work, Schwartz, Shapiro, and Gregory (2013) found that nearly all of the students in their graduate level teacher certification course did not understand the basic structures of science, despite all of them being science majors. The study confronted teacher candidates with a situation in which they had to apply a theoretical model (Archimedes' principle) to explain their observations and make predictions. For the majority of the students, this task required a level of understanding that was well beyond the recall and algebraic problem solving which was sufficient for success in their university class. The abstract and counter-intuitive nature of physics requires a level of understanding sufficient to allow the teacher to not only be aware of the various analogies and activities that can be employed to explain a concept, but also to choose ones that are appropriate for the students' background, pre-conceived ideas and cognitive level (Ornek, Robinson, \& Haugan, 2008; Redish, 1994). Effective teaching therefore requires a level of understanding beyond the simple application of concepts, and the teacher's SMK must be broad enough to enable the translation of the complex and abstract ideas of physics into language, images, and experiences that have meaning to young students.

Arzi and White (2008) conducted a 17-year longitudinal study of Australian science teachers' knowledge. Their study found that SMK of teachers grew, and understanding increased in areas involved in teaching, but unused knowledge was largely forgotten. They also found that the most powerful influence on teacher SMK was the required curriculum, which served as a source and organiser of teacher knowledge. The clear implication for primary school teachers in New Zealand who teach specific topics infrequently and do not have a detailed curriculum is that they would have difficulty keeping their SMK refreshed and developed.

The previous paragraphs indicate that knowledge needed for teaching science is different to knowledge needed for non-science areas. Additionally, research 
shows that because of the misconceptions teachers hold regarding physics concepts, the knowledge necessary to teach physics is different to other areas of science (Kind, 2009). In a study comparing Finnish and English beginning teachers, Johnston and Ahtee (2006) found a strong difference in teachers' confidence and attitudes about teaching a unit on force, which the researchers proposed was the result of differences in training in the two countries. English beginning teachers had covered both subject and pedagogical knowledge of forces within the last year, whereas their Finish counterparts' training focused on attitudes and methods rather than subject matter. The authors proposed that the conceptual understanding of the abstract physics concepts involved took time to consolidate, which made the English teachers more confident. They noted, however, that their confidence was not necessarily well founded, and did not always result in more effective teaching.

The influence of middle school teachers' physics knowledge on student performance was probed by Sadler, Sonnert, Coyle, Cook-Smith, \& Miller (2013) looking at teachers' SMK, and also their knowledge of student misconceptions (KOSM) across a number of physics concepts and found that knowledge of the subject without understanding the students' misconceptions did not result in effective teaching, and that highly effective teachers had both SMK and also KOSM. They also noted that recognising a misconception requires significant SMK.

Shulman (1986b) proposed that, at a minimum, a teacher must have an understanding which includes both substantive and syntactic knowledge of the topic taught, as well as a specific kind of knowledge unique to teaching called Pedagogical Content Knowledge (PCK). He defined PCK as specific knowledge necessary for teaching. He includes such things as frequently taught topics in the subject area, useful analogies, examples and demonstrations, and frequently held misconceptions. In a later work Shulman proposes seven specific types of knowledge required to effectively teach: content knowledge, both substantive and syntactic; general pedagogical knowledge such as 
organisation and classroom management; curriculum knowledge and awareness of appropriate available resources; PCK; knowledge of learners and their characteristics; knowledge of educational contexts, school characteristics and community culture; and knowledge of educational ends including values and purposes, philosophy and history (Shulman, 1987).

Shulman's work has been a useful focus for research since it was introduced with over 15,000 citations of the original 1986 paper. Some 20 years after the introduction of PCK, Abell (2008) looked back on the research and asked whether PCK remains a useful idea. She notes that aspects of PCK are difficult to define or measure, and most of the research to date has been descriptive; however, she concludes it is a useful construct for understanding the knowledge used in teaching, and that:

Learning to teach science is not about acquiring a bag of tricks based on a set of general pedagogical strategies, it is about developing a complex and contextualised set of knowledge to apply to specific problems of practice. PCK helps us recognise that the knowledge needed for teaching science is different from the knowledge needed to teach literature. (p. 1414)

Many researchers have further explored and refined Shulman's original model of PCK, (e.g., Cochran, DeRuiter, \& King, 1993; Gess-Newsome \& Lederman, 1999). The refinement proposed by Ball, Thames, and Phelps (2008) is illustrated in Figure 4. They divide the knowledge domain into the two major divisions of SMK and PCK. (Although this research focused on mathematics, I have translated the illustrations into physics examples.) The SMK domain contains common knowledge, defined as the knowledge employed in areas other than teaching. An example of this type of knowledge is understanding why a car crash at $100 \mathrm{kph}$ causes more than twice as much damage as a crash at $50 \mathrm{kph}$. Horizon content knowledge is knowledge about how a specific curriculum topic relates to other topics in the curriculum (Ball, et al., 2008). An example of this type of knowledge is the relationship between the electro-static attraction, magnetic attraction, and gravitational attraction. The third division of SMK is specialised content knowledge, which is knowledge of the topic that has 
value only in the context of teaching. An example of specialised content knowledge would be various ways to explain the concept of energy conservation. Once a concept is understood the only value in creating additional explanations is for use in teaching. The PCK domain contains combinations of content knowledge and knowledge of students, teaching, and curriculum. An example of the combination of content and student knowledge is the awareness of commonly held misconceptions. The content and teaching area is knowledge of which specific teaching strategies work well with specific content such as making the choice between the use of a demonstration, video, or science investigation. Finally, the content and curriculum area involves knowledge of the materials and resources available to teach specific topics. In addition, this area involves vertical knowledge of where the topic being taught fits into a sequence of material learned previously and material which will come next, and also horizontal knowledge involving the potential connections between the material and topics being taught in other subject areas such as mathematics or literature.

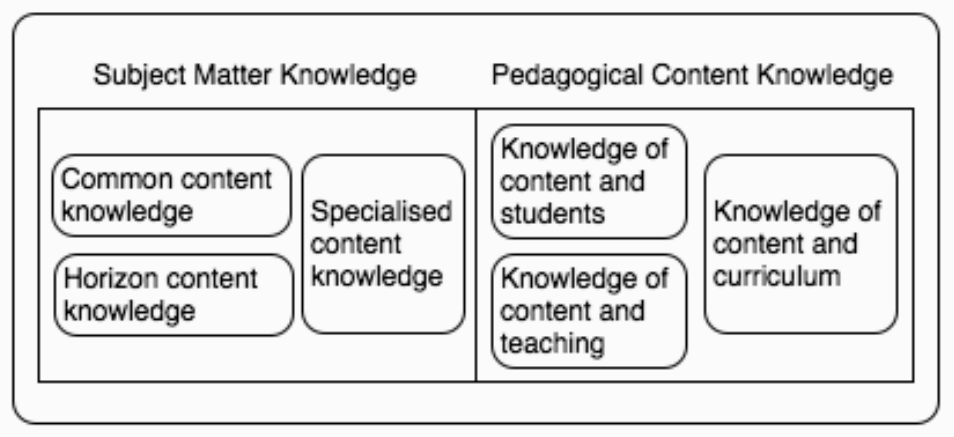

Figure 4: Knowledge for Teaching (p. 403)

\subsubsection{Development of teacher science knowledge}

The research described thus far establishes that knowledge for teaching involves substantive and syntactic science content knowledge as well as various types of pedagogical knowledge. The question of how primary school teachers can develop such knowledge for science has been addressed by several groups (e.g., Appleton, 2003; Cochran et al., 1993; Sanders, Borko, \& Lockard, 1993). 
The complex nature of teacher knowledge development is illustrated clearly by Mulholland and Wallace (2005) in their description of the growth of a primary school teacher over a 10 -year period. The subject of their study, Katie, had studied science in high school and taken science classes at university and began her teaching career with deeper science knowledge than most of her classmates. Her strong science background, however, did not equate to successful science teaching in her early years while she developed general pedagogical knowledge. As Katie's classroom skills became stronger, her science knowledge began to grow again, and investigative lessons which were disastrous during her first years became manageable and effective after several years of teaching. "We believe that the flowering of Katie's general teaching and interactive knowledge bases served to bolster her science subject knowledge bases and enrich and strengthen her overall science PCK" (p. 786). In the New Zealand context, Anderson \& Clark (2012), in their case study of a primary school teacher, found that SMK was a limiting agent in the development of Pedagogical Content Knowledge (PCK).

The effectiveness of science content instruction delivered to teachers with differing levels of experience was explored by Luft (2001). She worked with a mixed group of induction and experienced teachers, encouraging them to teach science using hands-on science investigations. She found that the beliefs of the induction teachers were influenced by the PLD more than their practice, whereas the practice of the experienced teachers was influenced more than their beliefs, suggesting that the PLD needs of beginning teachers are different to those of experienced teachers. The suggestion that science training for experienced teachers should be structured differently to that for inexperienced teachers was also suggested by Tseng, Tuan, and Chin (2012). Their research found that beginning teachers required more examples of teaching techniques and classroom management, whereas the experienced teachers, in possession of classroom skills, recognised the importance of science knowledge beyond what was directly involved in the lesson being taught. 
In summary, students in New Zealand primary schools are not performing well in science when compared internationally, and New Zealand primary teachers, much like their international colleagues, do not feel competent or confident to teach science. Therefore, relatively little science is taught in New Zealand primary schools. The NZC is designed as a framework, allowing schools to design a local curriculum well suited to their communities; however, research suggests a major source of science SMK for primary school teachers with limited science backgrounds is the school curriculum. The NZC is structured to leave the specific development of curriculum to the schools, and gives a great deal of freedom of choice to New Zealand teachers, but may not provide them with the support they need to increase their science knowledge and confidence to teach. Research also indicates that an academic background in science does not correlate with effective teaching, which requires specific PCK, involving a mixture of general classroom management skills, and specific knowledge that is unique to the science disciplines involved. Teachers need opportunities to develop their teaching of specific science topics, and confidence in their SMK is needed to choose appropriate curriculum topics and classroom activities. One way to fill this need is a PLD programme designed to give teachers experience in physical science investigations, and provide them with an opportunity to build their understanding.

\subsection{Professional learning and development programme design}

\subsubsection{Introduction}

The literature reviewed in the previous sections highlights the general condition of primary school science in New Zealand. Most classrooms spend little time on science topics, and the science knowledge of many students is relatively low internationally, with the lowest scores in physical science. The research reviewed also indicates that the number of university science classes taken by teachers is not correlated with high quality science teaching. PLD has been shown to be effective in increasing the quality of science teaching; therefore, I have chosen to approach the problem of increasing the science taught to 
primary school students in New Zealand by considering the design of a PLD programme specifically for New Zealand primary school science teachers.

The terms "Professional Learning and Development" and "Professional Development" are used somewhat interchangeably in the literature. I have chosen to use PLD, primarily because professional learning denotes a process wherein teachers are actively involved in their own learning, whereas PD tends to be associated with more passive, top-down programmes (O'Brien \& Jones, 2014, Timperley, 2011).

In this section I will review relevant literature on PLD design with the aim of discerning common characteristics of high quality PLD, and to incorporate them into the design of a science PLD programme for use with New Zealand primary school teachers. I have chosen to incorporate the theoretical and practical components of the PLD programme design into a "design framework" (DF) which will be used to guide the development of specific implementations of PLD. The DF will need to depict design considerations such as: content selection, presentation style, length and duration, teacher knowledge, teaching techniques, and curriculum, and perhaps others.

A useful framework for the PLD programme will need to be practical and implementable, yet flexible and tailored to the New Zealand context. The initial DF will be used to guide the organisation, planning, and delivery of a PLD programme for the first group of teachers in this study. The DF will be examined and refined with experience gained during and after the PLD, then used and refined with a second and third group of teachers. This iterative design improvement process aligns well with Design-Based Research (DBR) methodology, which will be described in chapter 3 .

\subsubsection{Selection of content areas}

Much of the research in the field of PLD is oriented around models or frameworks. In the section that follows I will examine a series of models 
frequently cited in the literature, and pull together common characteristics to form the structure for the DF to be used in this study. These models can be described in words, but are usually depicted diagrammatically. One such model was proposed by Bell and Gilbert (2004) shown in Figure 5. Their model includes factors in the social and personal domains that motivate teachers toward sustained and ongoing professional development. In the social domain, teachers progress through recognising isolation as a problem, understanding the value of collaborative ways of planning, and finally establishing collaborative ways of working. Likewise, in the personal domain teachers first recognise aspects of their teaching are problematic, learn to deal with constraints, and emerge feeling empowered, and motivated. As a result of the motivators in the social and personal domains, the teachers seek and experiment with new activities, which result in development of a more sophisticated classroom practice, and finally they seek out additional PLD opportunities.

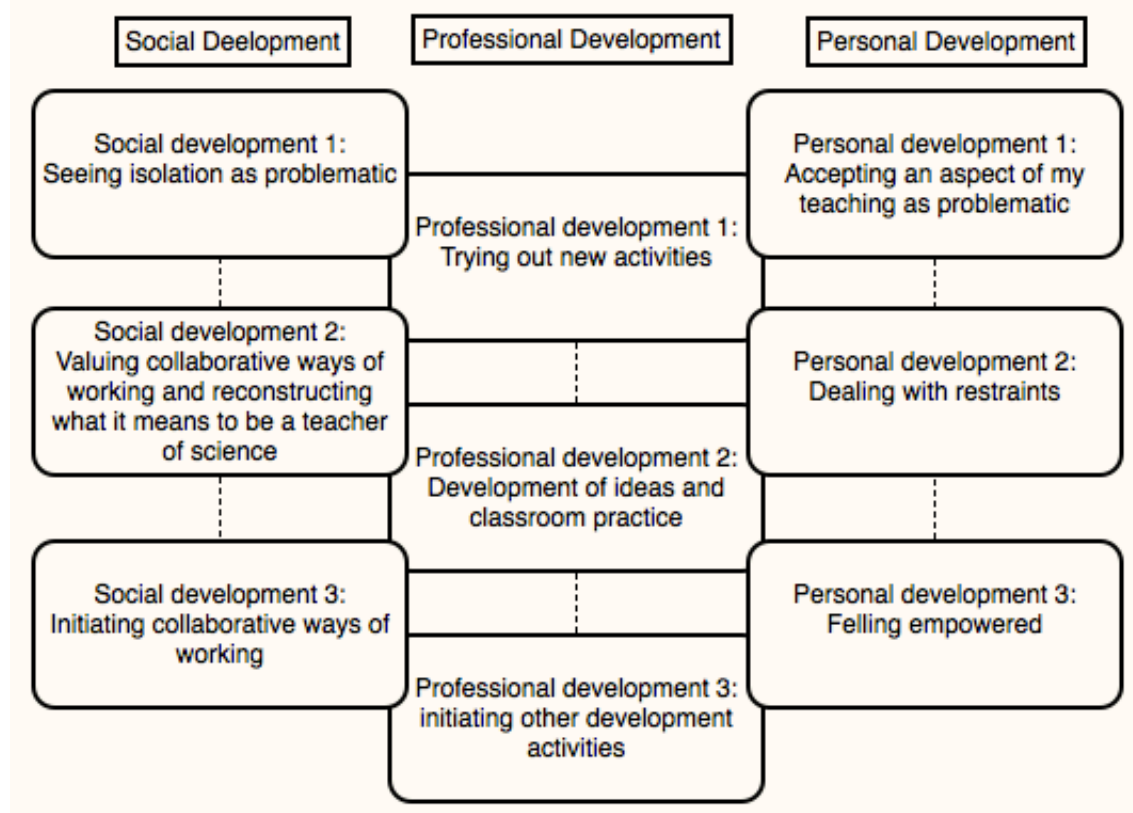

Figure 5: Bell and Gilbert's PLD model (p. 259)

The simple linear model developed by Guskey (2002), shown in Figure 6, involves a PLD stimulus which leads to changes in classroom practice, resulting in changes in student outcomes, which in turn lead to changes in teachers' 
beliefs and attitudes. Guskey found that changes in teachers' attitudes and beliefs occur primarily in the period directly after a PLD intervention, rather than during the PLD. In order for change to occur, teachers must feel they successfully taught the unit, and their students learned from the experience. Guskey also found that for teachers to put the training into practice, they must feel a certain degree of pressure, and be confident in the availability of support.

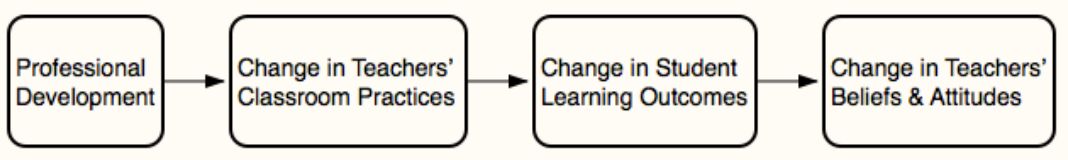

Figure 6: Guskey's PLD model (p. 383)

The environment needed to foster changes in teaching practice is the focus of Clarke and Hollingsworth's (2002) research. Their model, shown in Figure 7, depicts the "change environment" of teacher PLD as consisting of four "domains" that play a role in teacher learning and PLD. The external domain contains the factors driving change and the associated constraints, the personal domain contains factors that involve personal growth and change, the domain of practice is the translation of the personal change into teaching activity, and the domain of consequence contains factors relating to the results of the practice. 


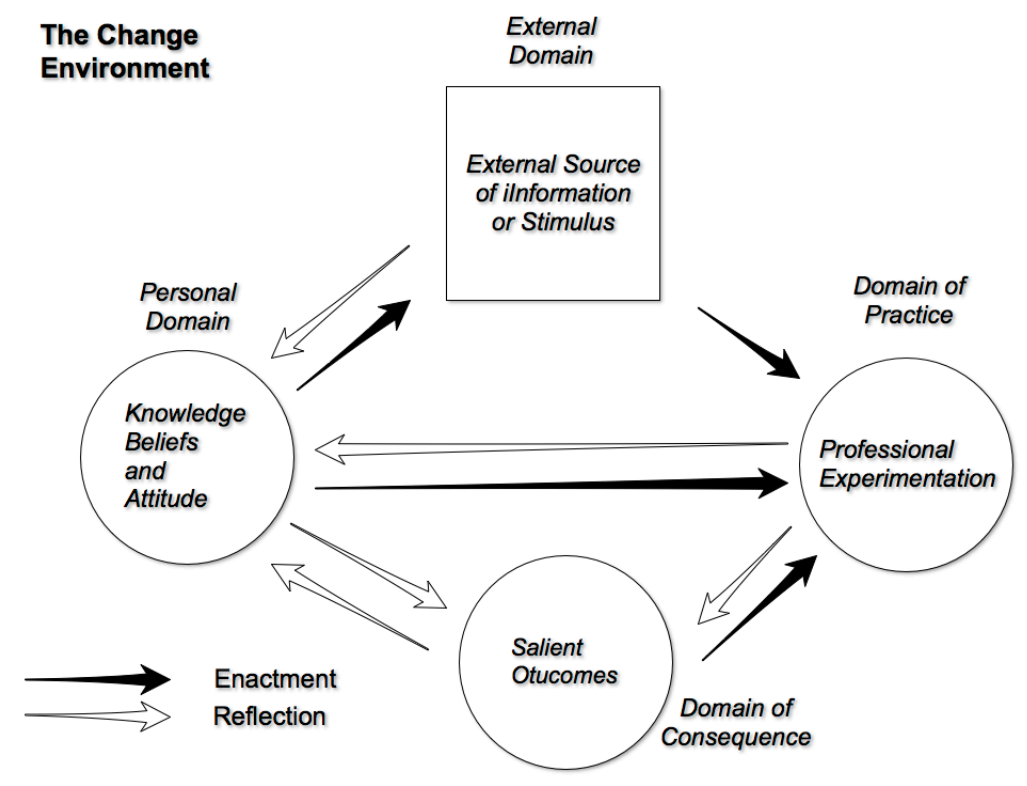

Figure 7: Clarke and Hollingsworth's model (p. 951)

A framework developed by Loucks-Horsley, Stiles, Mundry, Love, and Hewson (2010) is illustrated in Figure 8. Their framework contains four "inputs" (circles) which PLD designers should consider at specific stages of the design process, namely: knowledge and beliefs, context, critical issues, and strategies.

Knowledge and beliefs addresses the questions of what theories of learning and teaching are to be considered, and what research-based knowledge should inform the design. Context includes the site-specific factors that should be considered, such as available resources, and local conditions. Critical Issues reflects factors such as making time for PLD, building a professional learning culture, gaining public support, and equity considerations. Strategies involve the implementation phase of the PLD and include four strategic directions: immersion in content, standards and research; analysis of teaching and learning; implementation of a specific curriculum; and organisational structure of the PLD (i.e. study groups, workshops, institutes, seminars, professional networks, or online PLD).

Loucks-Horsley et al. (2010) identify seven critical issues that should be considered when designing teacher professional development. These are: (1) 
building capacity for sustainability, (2) making time for professional development, (3) developing leadership, (4) ensuring equity, (5) building a professional learning culture, (6) garnering public support, and (7) scaling up.

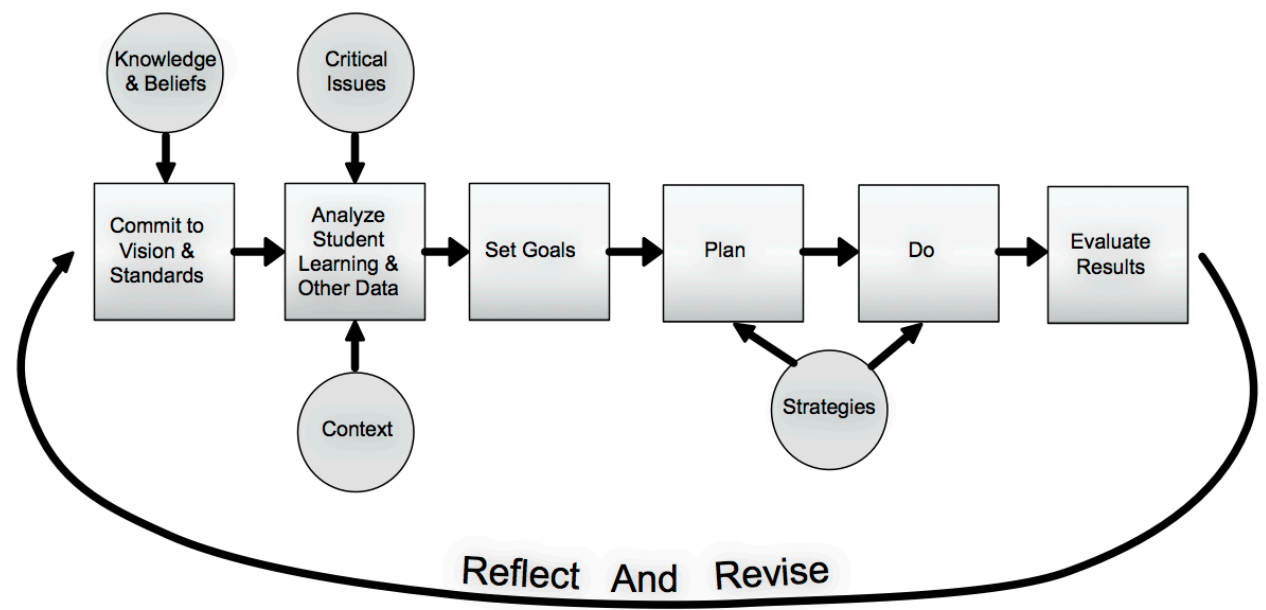

Figure 8: Loucks-Horsley et al.'s PLD framework (p. 18)

The central role of teacher knowledge and beliefs is found in the model of teacher learning proposed by Fishman, Marx, Best, and Tal (2003) shown in Figure 9. The model suggests that PLD programmes can only have a direct influence on the knowledge, beliefs, and attitudes of the teachers, which in turn can result in changes in classroom practice, that eventuate in improvement of student performance which in turn reinforce the knowledge, beliefs and attitudes of the teacher. They propose the four primary design elements that should be considered when planning a PLD programme are: content of the programme, the strategies employed, the site chosen, and the media used. 


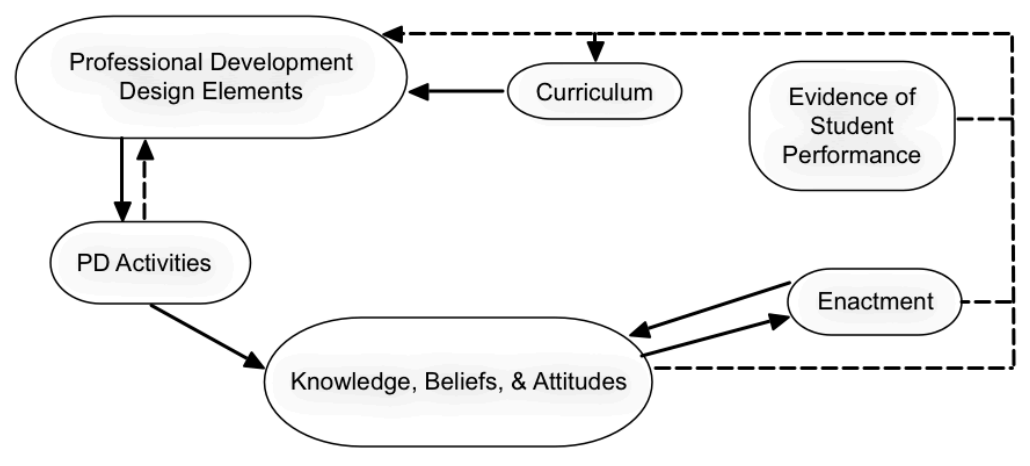

Figure 9: Model of teacher learning (Fishman et al., p. 645)

While there are many other models of PLD found in the literature (e.g., Borko, 2004; Coenders \& Terlouw, 2015; Desimone, 2009; Lipowsky \& Rzejak, 2015;

Owen \& Dunmill, 2014; Stolk, Bulte, de Jong, \& Pilot, 2009; van Veen, Zwart, \& Meirink, 2012); the models described above illustrate the range of thinking in this area.

All of the models of PLD described above break down the process of PLD into components or content areas and articulate the interactions between the content areas to conceptualise the complex process of PLD. Although it is useful to have mental models with which to test ideas, it is difficult to design a programme from these theoretical models alone. In the paragraphs that follow I will group characteristics of the models into similar "content areas", and then in the remainder of this chapter, use relevant literature to populate the areas with general PLD design characteristics, and finally to operationalise the design characteristics by proposing specific implementation advice for each design characteristic.

A common consideration in several models is the importance of selecting the specific material to be covered in the PLD. The external domain described by Clarke and Hollingsworth (2002) is similar to the context and critical issues described by Loucks-Horsley et al. (2010), as well as the "Curriculum" input of Fishman et al (2003). These all relate to the material content of the PLD, and 
can be thought of as the set of requirements that must be addressed by the PLD. For the purposes of this study, this area will comprise issues and content related to selection of appropriate topics within the constraints of the NZC, and the school environment, and will be collected in the Subject selection / curriculum content area.

Several authors describe a set of characteristics that relate to personal growth and teacher knowledge. The Personal Development domain of Bell and Gilbert (2004) as well as the Changes in Beliefs \& Attitudes of Guskey's (2002) model align with the personal domain of Clarke and Hollingsworth's (2002) model, all describing aspects of teacher knowledge and classroom practice to be addressed by the PLD programme. The set of design characteristics relating to these areas of personal knowledge growth will be collected in a content area I will refer to as Subject matter understanding.

Most models of PLD contain considerations relating to putting the PLD content into practice in the classroom. Clarke and Hollingsworth's (2002) Domain of Practice aligns with the Changes in Classroom Practice in Guskey's (2002) model as well as the "Do" area in the Loucks-Horsley et al. (2010) model. Considerations that relate to putting the PLD into action will be collected in the Teaching practice content area.

An area that is unique to Bell and Gilbert's (2004) model is social development, referring to factors associated with working within a supportive collaborative environment. Support and stimulation are also implicit in the "External Domain" in the Clarke and Hollingsworth (2002) model, and are recognised in the 2012 lan Axford Fellowship report on public policy, which identified common characteristics of New Zealand schools that were successful in science teaching (Vannier, 2012). These schools had supportive principals who encouraged team planning, collegial support, and collaborative working environments. An effective PLD programme should include a focus on support by fostering a 
collaborative working environment, and providing stimulus and external support. These factors will be collected in the Support content area.

There is another content area implicit to all of the models, which relates to logistical considerations of the PLD. These are things such as location and duration of the PLD. These considerations are collected in an area I will call Logistical considerations.

The entire framework to guide this study consists of five content areas: Subject selection / curriculum, Subject matter understanding, Teaching practice, Support, and Logistical considerations. In the next section I will examine the literature to populate the content areas.

\subsubsection{Selection of design characteristics}

In this section I will review the recent literature on science PLD concentrating on characteristics of effective science PLD programmes with the goal of selecting a set of characteristics to be included in the various content areas of the design framework described in the previous section. As the studies are described, the characteristics of effective programmes will be gathered and summarised in Table 2 below.

Characteristics of effective PLD programmes were the subject of the analysis of Van Veen et al. (2012), who reviewed 11 review articles and 34 empirical studies, covering the previous 25 years of research on PLD interventions, covering a variety of subject matter. The focus of the study was to identify the general features of PLD programmes that made them effective. They analysed the studies using a framework based on Desimone's (2009) set of five critical features of PLD programmes: content focus, active learning, coherence, duration, and collective participation. The analysis framework links the critical features of the PLD intervention with changes in teachers' knowledge, skills and attitudes, which in turn produce a change in teacher behaviour, resulting in improved student outcomes, all within the constraints imposed by the local 
school environment. They conclude that the nature of the studies, which are primarily qualitative examine one PLD programme in one specific setting, and do not include conducting the same intervention in several settings and with different coaches, have limited generalisability. However, despite the limitations, some features of effective programmes are indicated. These include an emphasis on subject content knowledge, particularly as it relates to teaching and the learning processes of students, an emphasis on active inquiry learning, collegial learning, sufficient time, and consideration of local school organisational factors. They conclude by stressing the need for an emphasis on translation of the general features of effective programmes into specific advice in situations and contexts (see Table 2).

The importance of subject content was also highlighted in the Kennedy (1998) review of the maths and science PLD literature, which focused on programmes that demonstrated positive student outcomes. Kennedy concluded that successful PLD programmes focused on the subject matter content, including how students learn that content, noting that the form or structure of the programmes did not significantly influence success.

Looking specifically at science PLD, Capps, Crawford, and Constas's (2012b) literature review of research into PLD supporting teaching and learning through science inquiry is particularly relevant to this study. Their review of science PLD found that while the programmes reviewed were in general alignment with best practice and addressed some of the desired outcomes of effective PLD as described in the literature, the programmes generally lacked support for teachers in developing science investigation lesson plans. Effective programmes provided the teachers with experience in teaching through science investigation, and provided science content for teachers. None of the studies they examined included all of the outputs necessary for gauging the efficacy of teacher PLD, specifically: enhanced teacher knowledge, change in beliefs and practice, and enhanced student achievement. 
In the New Zealand context, Timperley, Wilson, Barrar and Fung (2007) produced a Best Evidence Synthesis of research on teacher PLD for the New Zealand MOE. The report includes a chapter devoted to science teacher PLD and included eight studies in their core analysis. Timperley et al. restricted their review to published reports of PLD programmes that met strict methodological criteria and included evidence of substantive student learning as a result of the PLD. The report supports the importance of content knowledge, context, pedagogical knowledge, consideration of student learning needs, and of ongoing support. Although it was not part of the inclusion criteria, all of the science PLD programmes involved teaching through science investigation.

The importance of subject matter content was also found by Ingvarson, Meiers, and Beavis (2005) in their study of 3250 Australian teachers involved in 80 PLD programmes. The study examined characteristics of PLD programmes that were significantly correlated with the impact of the PLD, as measured by a survey of participants at least three months after completing the PLD. Survey questions measured the impact of the programmes on knowledge, practice, student learning outcomes, and teacher efficacy. Content focus, active learning and reflection on their current practice, availability of follow-up on knowledge, and strengthening professional community were found to be aspects of PLD programmes significantly correlated to impact.

Content knowledge was also highlighted in the study by Garet, Porter, Desimone, Birman, and Yoon (2001) who surveyed 1027 teachers from 358 school districts across the United States. They found that effective PLD is focused on content and engages teachers in active learning. Focusing on the local context, and the use of teachers' own classrooms was also important, as were the use of peer support, and allowing adequate amount of time.

A concentration on the local environment was also found to be a critical feature of the PLD programmes examined by Penuel, Fishman, Yamaguchi, and Gallagher (2007). Their study consisted of 454 teachers from various nations 
engaged in PLD designed to prepare them to implement an international earthscience education programme. In addition to highlighting the need to align the PLD to relevant local standards and curriculum was an emphasis on the importance of on-going support.

A set of six design characteristics found in effective PLD programmes was proposed by van Driel, Meirink, van Veen, and Zwart (2012), consisting of: focus on classroom teaching and learning of subject matter; active and inquirybased learning; collaborative learning; duration and sustainability; coherence; and school organisational conditions. These design characteristics were derived from recent reviews of research on PLD and form "a consensus on what constitutes effective PLD" (p. 131). They developed an analysis framework based on the characteristics to analyse 44 studies of science PLD programmes. They found that almost all of the studies analysed included some aspects of the six key design features, and all studies analysed reported a positive change in the teachers involved. They also noted an important topic missing in almost all studies was an analysis of the experience and expertise of the providers or facilitators of the PLD programme in relation to the success of the programmes. They also noted that the role played by the local school context was often only minimally addressed.

The importance of the facilitator was also emphasised in the research synthesis of Lipowsky and Rzejak (2015). The authors examined several meta-analyses of PLD programmes, finding components mentioned previously, such as participant characteristics and the school environment, but also highlighting necessary characteristics of the facilitator, which in turn influenced the quality of the learning materials and experiences chosen.

The previous two studies highlight the requirement of the facilitator of the PLD to have experience and expertise in the subject matter content involved in the PLD. This emphasis reinforces the decision to concentrate on physics for this research due to my interest in this area and my experience of teaching physics. 
From the literature summarised above a set of characteristics of effective science PLD can be selected. I have placed the design characteristics into the appropriate content areas (as described in the previous section) which are shown in Table 2 below.

Table 2: Content Areas and General Characteristics

\begin{tabular}{|l|l|}
\hline Content area & Design Characteristic \\
\hline Subject matter understanding & teacher subject matter and pedagogical knowledge \\
\hline Subject selection / curriculum & $\begin{array}{l}\text { consideration of student learning goals and needs } \\
\text { alignment with local and national curriculum }\end{array}$ \\
\hline Teaching practice & $\begin{array}{l}\text { practical lesson development taking into account the local } \\
\text { classroom context } \\
\text { modelling and practising activities and teaching methods }\end{array}$ \\
\hline Support & $\begin{array}{l}\text { development of community of practice support } \\
\text { provision of on-going support }\end{array}$ \\
\hline Logistical considerations & $\begin{array}{l}\text { length and duration of the PLD } \\
\text { location of the PLD }\end{array}$ \\
\hline
\end{tabular}

Design characteristics are potentially quite broad and somewhat ambiguous, and specific operational or implementation advice is rare (see van Veen et al., 2012); therefore, in order to make the design as clear as possible, a translation of the characteristic into specific implementation advice is provided for each of the design characteristics, as illustrated in Figure 10. The implementation advice should be regarded as merely the starting point for the operationalisation of the design characteristics, and will be examined, refined, and added to as the DF is used to design and facilitate the PLD in each iteration of the research.

The specific implementation advice provided for each design characteristic is not unique; for example, the advice to have teachers work through the science investigations with teachers in the role of students serves both as the principal mode of engagement with the teachers in the Subject matter understanding area, as well as to model and practise activities and teaching methods in the Teaching practice area. In this case, the advice is consistent with the constructivist model of learning, and based on the idea that teachers learn in the same way as their students (Shymansky, 1992). Another example of advice 
serving a dual role is the advice to conduct the PLD in teachers' classrooms, found in the Teaching practice area as well as the Logistical Consideration area. 

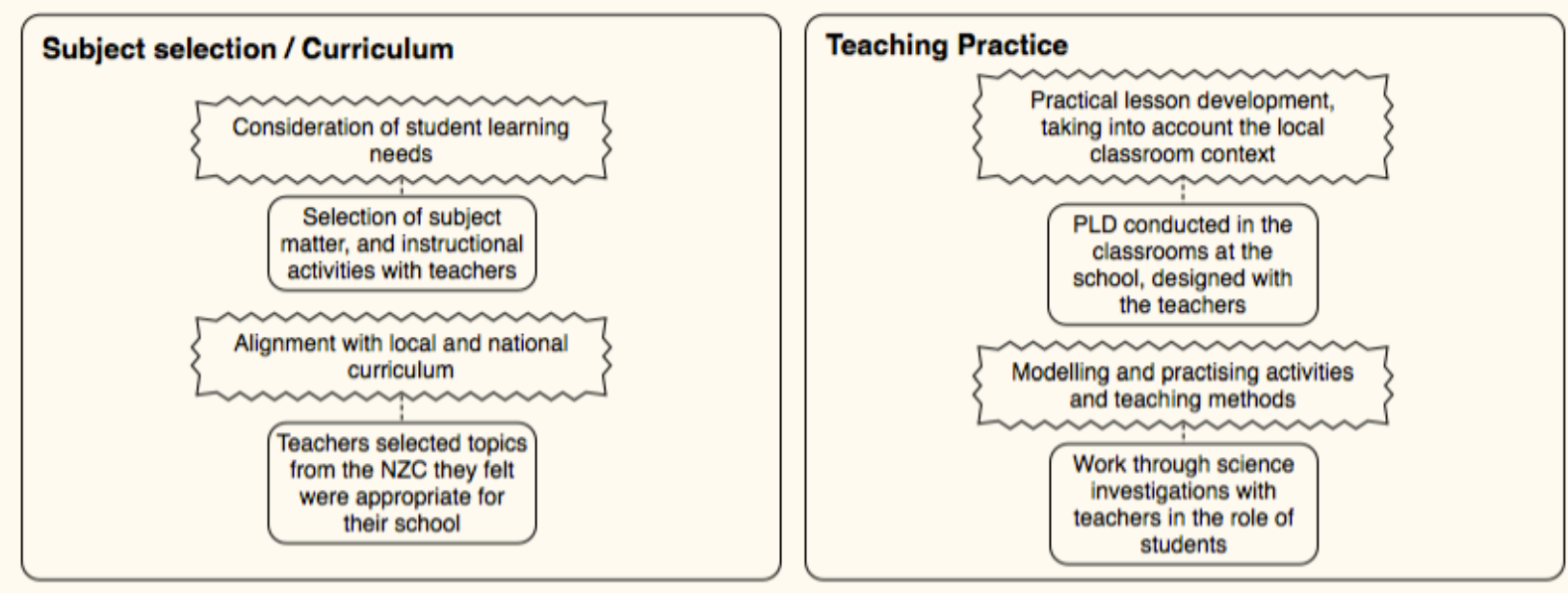

\section{Subject Matter Understanding}

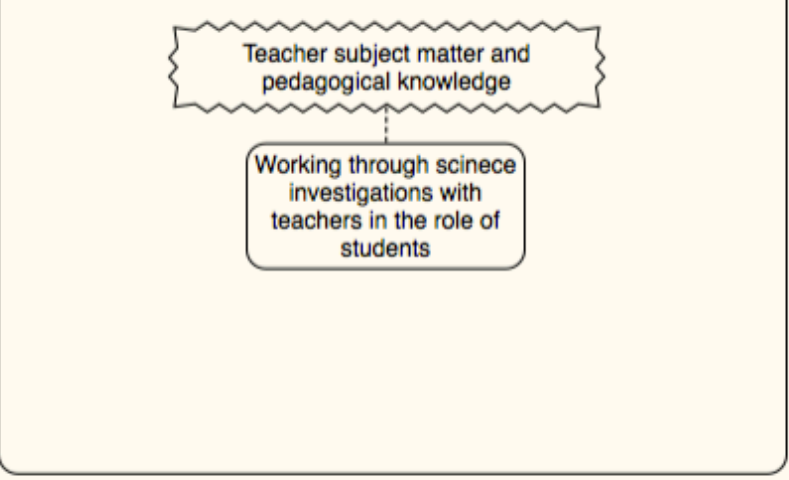

\section{Support}
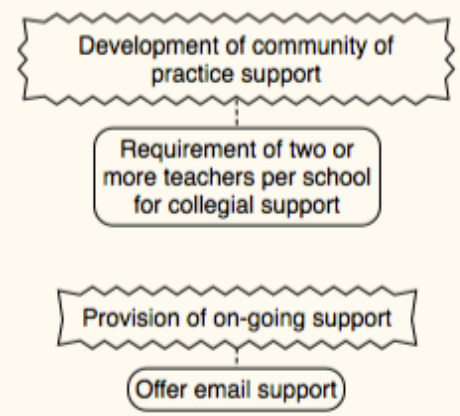

Rounded frame - Implementation Advice

Logistical Considerations
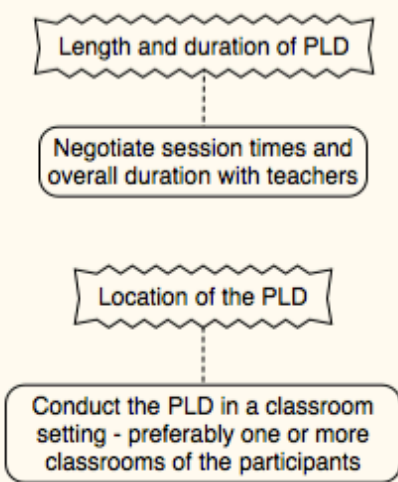

Figure 10: PLD Design framework derived from review of research

In summary, a PLD framework allows the design of the PLD programme to address the specific needs of the teachers involved, to be tailored to the school 
environment, and to focus on topics selected in conjunction with the teachers, while adhering to a set of design principles informed by research.

I will conclude this chapter with a quote from Hewson's (2007) review of a number of studies of professional development in science, which focused on how teachers develop as professionals, and how PLD programmes are developed. He concludes that a PLD programme is sufficiently complex to make a comparison of various programmes and approaches difficult, and that:

...the practice of professional development is a process of design. On the one hand, professional developers have a set of purposes that they want to achieve. On the other hand, they are working in a particular context, with a particular group of teachers, in a set of circumstances that are unique to this particular project. The process of design requires that purposes be matched with context. (p. 1185)

\subsubsection{Facilitation}

The purpose of this research is to iteratively develop a framework to guide the construction of bespoke PLD programmes. The framework is the focus of the research study; however, as suggested above, successful delivery of a PLD programme requires a facilitator with a specific set of knowledge and skills (Perry \& Boylan, 2017). Specifically it requires someone who is able to interpret the framework, negotiate with the teachers to select curriculum topics and logistical factors, and effectively facilitate the PLD sessions. The methodology of this research project used a single participant observer to design and deliver the PLD; therefore, the role of the PLD implementer or facilitator was not within the scope of the research. However, it became clear during the data analysis that if this framework is to be something other than a theoretical exercise, application of the framework in real world situations requires a person or team of people with specific skills and knowledge. I will therefore present here a review of relevant research literature on PLD facilitation. The reader should be cautioned, however, that because the decision to include facilitator skill and knowledge requirements was not made until after the data were gathered, the 
following literature did not inform the development or refinement of the PLD framework. I will return to the topic of facilitator knowledge and skills in relation to this research in the final discussion.

The research literature on teacher PLD is quite extensive, as described in the previous sections; however research on facilitators of PLD is comparatively sparse, and aside from a few examples (see Borko, 2004; Seago, 2004), which mention the importance of quality facilitation, research examining PLD facilitation is quite recent.

The importance of quality facilitation was a guiding principle in Seago's (2004) analysis of mathematics PLD. She concluded that the PLD facilitator had to understand the materials, and take charge of the learning experience for the teachers in the PLD, creating a community of learners in the process. Seago noted that the facilitator was required to have a high level of understanding of the material in order: "to prompt deep and considered discussion, while at the same time trying to pull back to get the group to interact" (p. 273).

The importance of creating a supportive environment was also observed by Lotter, Smiley, Thompson, and Dickenson (2016) in their analysis of PLD programmes designed to improve middle school teachers' use of science investigations or inquiry methods in their classes. They found that the facilitation that led to the development of a supportive environment within the PLD programme was critical to the success of the programme. "Creating this supportive environment both within a PLD programme but more importantly within teachers' schools might be essential to long-term changes in teachers' instruction and student learning" (p. 2736).

Borko, Koellner, and Jacobs (2014) highlighted three areas in which the facilitator of PLD programmes must be skilled: the ability to develop a workshop culture, the knowledge of specialised content used in the PLD, as well as knowledge of teacher PCK. Workshop culture refers to developing a relationship with and between workshop participants, fostering a collegial 
working environment, and encouraging participation. Specialised content knowledge refers to knowledge of the specific subject matter on which the PLD focuses. In Borko et al.'s study, PCK was required so that the facilitator was able to select appropriate and relevant material for analysis by teachers.

The recent study of PLD facilitation by Perry and Boylan (2017) focused on the types of knowledge and skills necessary in the facilitator in order to deliver effective PLD. The results of their study were similar to Borko et al.'s (2014), finding that expertise in teaching was a prerequisite, along with subject knowledge, and facilitation skills.

The importance of expert scaffolding (the adaptive support given by a teacher to enable learners to solve problems that would otherwise be beyond their current ability level (Wood, Bruner, \& Ross, 1976) was the subject of a study by Kleickmann, Tröbst, Jonen, Vehmeyer, and Möller (2015). Kleickmann et al.'s study examined several matched groups of German primary school teachers receiving physical science PLD, with varying degrees of expert scaffolding. Their study found that the provision of expert scaffolding was an essential factor in the success of the PLD as measured by teacher satisfaction, teacher learning, and student outcomes.

\subsection{Summary}

In this chapter I have attempted to present the situation as it exists for primary school science education in New Zealand, the challenges faced by generalist primary school teachers in working with a non-prescriptive curriculum, and the performance of the system as measured by national and international examinations. New Zealand primary school teachers generally are not confident in their science teaching, and spend relatively little time teaching science. The performance of New Zealand students is above the OECD mean, but there is a very wide distribution of scores, with a high percentage of low achievers. I then presented literature showing that primary school teachers frequently avoid teaching science, particularly physical science, because they 
lack confidence in their SMK. I examined the literature for methods to increase SMK, finding that the most effective method is through high quality PLD. Finally, I examined a number of well-respected models of PLD, and attempted to extract the characteristics of those programmes, and create a framework for designing bespoke PLD programmes. In the next chapter I will show how the framework will be used in this design-based research project to test and customise it for use in New Zealand. 


\section{Chapter 3 Methodology}

\subsection{Introduction}

In this chapter I will introduce the research questions and the methodological aspects of this research. Specifically, I will describe the decision to employ design-based research (DBR) as the framing methodology and outline the basics of DBR. The remainder of the chapter will describe the choice of a qualitative methodology, subject selection criteria, data collection, ethical considerations, tools, data analysis, and issues of trustworthiness, reliability and validity.

\subsubsection{Research questions}

As described in the previous chapter, the students in New Zealand primary schools have substantial room for improvement in their science achievement in general, and in physical science in particular, as measured by international and national assessments. The literature also shows that primary teachers spend relatively little time teaching science, and do not feel confident or competent in their teaching or knowledge of science. In Section 2.2.3 I reviewed the literature which indicates that the specific type of knowledge necessary to teach science is not readily gained by increasing the number of university science courses required in teacher training. The literature also demonstrated that PLD designed for beginning teachers should be structured differently to one designed for teachers with a few years of experience (section 2.2.4). Therefore, in an effort to make the PLD design applicable to the widest audience, I chose to focus on experienced teachers. While it is important to engage with students as early as possible, the physical science concepts in levels three and four of the Physical World strand of the NZC are particularly challenging to teachers with limited science backgrounds (ERO, 2012). Finally, a student's decision to pursue a career in science occurs early, with the majority of students making up their minds prior to age 14 (Bolstad \& Hipkins, 2008; Tytler, Osborne, Williams, Tytler, \& Clark, 2008). 
The decision to focus on late primary or middle school (Years $7 \& 8$ ) is an attempt to investigate a means to improve the science experience of students immediately prior to the choices they will make in high school. I have chosen therefore to focus this research on designing a PLD programme to support middle school teachers in teaching physical science.

There are areas of general agreement within the literature with regard to critical design characteristics for science PLD with an emphasis on science investigation. These common characteristics led to the development of the PLD framework presented at the end of the previous chapter. The framework, which embodies the design principles suggested by international research literature, was used to guide the planning and design of the initial iteration of the PLD programme. Such a framework, however, may or may not be ideally suited to the New Zealand context. This argument is the focus of the primary research question for this study:

What are the components of a PLD programme which will empower New Zealand middle school (Year $7 \& 8$ ) primary school teachers to teach the Physical World contextual strand of the NZC?

The term 'components' refers to both the high-level design characteristics and the associated implementation advice which operationalise the characteristics which make up the PLD framework. The term 'empower' is used to encompass the internal changes in confidence and competence experienced by teachers.

In addition to the primary research question, the following related questions also guided this study.

1. What, if any, barriers inhibit the teaching of physical science by New Zealand middle school teachers?

2. What key issues need to be considered in the design of a physical science PLD programme for middle school teachers in the New Zealand context? 


\subsection{Design-Based research}

In this section I argue that DBR is appropriate for investigating the design of a PLD programme for New Zealand primary school science teachers, because it is a methodology that recognises the complexities of real-life educational settings, and rather than attempting to control the complexities, it is rooted in them. DBR investigates the performance of an evolving design in real-world complex environments, recognising the difficulty of controlling variables in situations as complex as a classroom (Collins, 1992; Collins, Joseph, \& Bielaczyc, 2004). DBR is specifically designed to provide educators with practical advice on the implementation of educational research (Anderson \& Shattuck, 2012).

Research is frequently described along a continuum between basic or predictive and applied (McKenney \& Reeves, 2012). The emphasis on practicality and implementation clearly positions DBR as applied research. Basic research and applied research differ in their objectives, context and area of interest. The objective of applied research is to increase our understanding of a problem, with the clear intent of contributing to a solution, whereas basic research seeks to understand, with the intent of increasing knowledge. In short, applied research seeks to solve real-world problems and basic research seeks to increase knowledge. Because of this difference in purpose, theories in applied research are seen as tools and guides, while in basic research the theory is seen as the central focus (Bickman \& Rog, 2009).

Applied research is typically conducted in the environment of interest, and is concerned about the similarity between the environment of the research and the environment of the application of the research. Basic research is typically conducted in an environment in which the variables can be isolated and controlled in order to reduce complexity. DBR is designed to be conducted in the environment of interest, in this case the teachers' schools, and individual classrooms (Collins et al., 2004). Applied research is primarily interested in effects (independent variable), whereas basic research is primarily interested in 
causes (dependent variable). It is therefore critically important that variables be well controlled in a basic research project so that the cause can be attributable to the variable of interest. DBR does not require the isolation of variables, and is designed to work within the complexities of real-world situations (Collins et al., 2004).

Stokes (1997) proposed a two dimensional model for research that is useful when considering DBR. He described a graph with "Consideration of use" on the $x$ axis and "Quest for fundamental understanding" (p. 11) on the $y$ axis (see Figure 11).

\section{Quadrant Model of Scientific Research}

Research is inspired by:

\begin{tabular}{|c|c|c|}
\hline & & use? \\
\hline & No & Yes \\
\hline Yes & $\begin{array}{l}\text { Pure basic research } \\
\text { Example: Bohr }\end{array}$ & $\begin{array}{l}\text { Use-inspired basic research } \\
\text { Example: Pasteur }\end{array}$ \\
\hline Quest for & & \\
\hline understanding? & & \\
\hline No & & $\begin{array}{l}\text { Pure applied research } \\
\text { Example: Edison }\end{array}$ \\
\hline
\end{tabular}

Figure 11: Quadrant Model of Scientific Research (Stokes, 1997, p. 73) An exemplar of pure basic research, Niels Bohr studied and published theoretical atomic structure theories and was not concerned with practical applications, whereas Thomas Edison was an American inventor who was 
interested in creating technologies rather than pursuing and sharing theoretical research. These two scientists typify the basic science and applied science approaches. Now consider the research of Louis Pasteur, who was concerned with understanding microbiology with the goal of direct application. Stokes (1997) termed this approach "Use-inspired basic research" (Stokes, 1997, p. 57). The quadrant representing research that seeks neither fundamental understanding nor practical use is left blank in Stokes' diagram. Some critics of educational research suggest that some educational research falls into the blank corner (lower left), as it contributes little to understanding or to practical use (Reeves, 2000). DBR lies in the use-inspired basic research quadrant (Pasteur's quadrant).

The history of DBR in education begins in 1992 with the concept of "design experiments" introduced by Ann Brown and Allan Collins as a way to develop, test and refine educational designs based on the results of educational research (Brown, 1992; Collins, 1992; Collins et al., 2004). The methodology has also been called "design experimentation" and "design research"; however, DesignBased Research has emerged as the preferred term (Sandoval \& Bell, 2004). It has become increasingly popular with approximately 2000 articles published between 2000 and 2010 employing DBR (Anderson \& Shattuck, 2012). DBR is applied research rather than basic research, and therefore not primarily predictive in nature; rather, data are generated, collected and analysed, and theories are developed (Baumgartner et al., 2003). An educational DBR study typically: is situated in a real educational context; is focused on the design and testing of a significant intervention; uses qualitative or mixed methods; involves multiple iterations; involves a collaborative partnership between researchers and practitioners; and is focused on improving design principles (Anderson \& Shattuck, 2012).

DBR is in several respects similar to Action Research. Both are examples of applied research in education; however, the two methodologies differ in important respects. In Action Research the teacher is usually in the role of 
researcher, and the goal is to address local needs. The researcher directs the research in DBR, acting in partnership with teachers, drawing on their expertise regarding the local practical complexities. While both have a goal of improvement over iterations, the goal of DBR is to develop a set of researchbased design principles which give practical advice in light of theoretical relationships in specific educational contexts (Anderson \& Shattuck, 2012).

The steps of applied research generally follow what has been characterised as a regulative cycle, described by van Strien (1997), consisting of problem identification, diagnosis of the problem in context, development of an intervention plan, intervention, and evaluation, steps which map to the DBR portion of Figure 12.

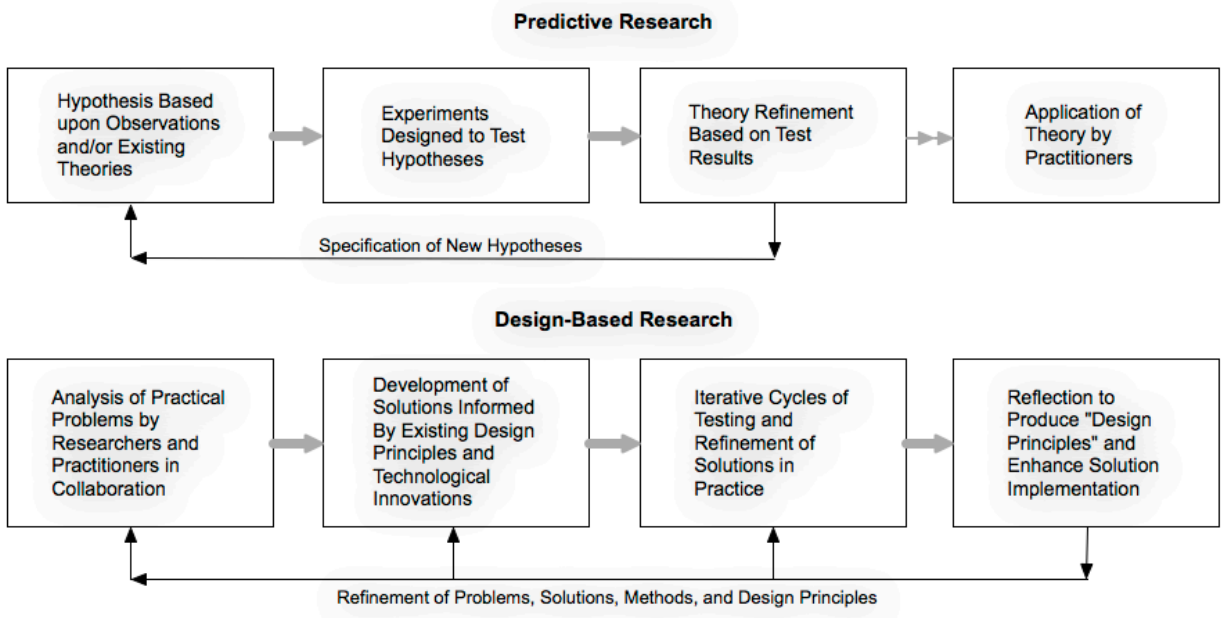

Figure 12: Comparison of Predictive and Design-Based Research (Herrington, McKenney, Reeves, \& Oliver, 2007, p. 2)

Both predictive research and DBR can be cyclical as illustrated in Figure 12 (Herrington et al., 2007). In predictive research the hypothesis is tested via an experiment; the hypothesis is then refined based on the results of the experiment, and the process repeated until the experiment confirms (fails to falsify) the hypothesis at which point the theory can be applied by practitioners. 
The general process for a DBR project begins with the identification of a problem to be solved and the development and application of an initial design to address the problem. A range of data is collected during the implementation, which is used to gauge the performance of the design. Refinements are made to the design during and after the implementation, and the process is repeated in a series of iterations. An analogy that may help explain how DBR works is the design of an airplane wing. An initial design is produced based on what is known from theoretical considerations and previous experimental research (Brown, 1992; Collins, 1992). The initial design is constructed and subjected to testing in a wind tunnel, data are collected, performance is evaluated, and the design of the wing is adjusted. The testing and adjusting cycle repeats until the design is deemed adequate. The result is a design that is optimised for the testing conditions. The initial design for the PLD programme in this study was produced by examining the research available on PLD programmes. The majority of the research was not, for the most part, conducted in the New Zealand context, and the scope was seldom constrained to middle-school physical science. The initial design will therefore be subjected to a series of test applications, adjustments will be made, and the final result will be better suited for use with New Zealand middle-school teachers teaching physical science.

The subject of this DBR project is a PLD programme for Year 7 and 8 primary school teachers, designed to help them to teach the Physical World strand of the science learning area as intended in the NZC. The principles for the initial design were gathered from the literature on PLD as described in section 2.3.3. Much of the available research is produced in North America, and is not typically restricted to physical science topics, or teachers of late primary school students. Further, factors such as differences in teacher training, national testing, and New Zealand's orientation toward local development of curriculum may limit the applicability of international research data in the New Zealand context. Refining the general principles found in the literature for a specific use case is a task well suited to DBR (Anderson \& Shattuck, 2012; Collins et al., 2004). 


\subsection{Reflexivity}

My role in the research was as the designer, facilitator, presenter of the PLD content, as well as being an observer of the process. By playing this compound role I was in the position of a participant observer (P. A. Adler \& Adler, 1987; Creswell, 2013a). In order to critique the influence that my background had on the interpretation of the data, it is important that I provide the reader with an understanding of my experience in, and orientation to teaching science, and that I attempt to reflect on decisions made during the presentation of the PLD, as well as the decision-making process for refinements of the PLD framework.

The participant observation approach allowed me to work with the teachers in a casual, comfortable situation (Fraenkel, Wallen, \& Hyun, 2012). Data were gathered via audio recordings of conversations (with full knowledge and consent of the participants) in a conversational rather than question-and-answer format. Given this orientation, I have elected to follow the advice of Rubin and Rubin (2005) and use the active voice (first person) rather than the more traditional third person passive style for the portions of this dissertation that involve my interaction with the participants, and have used my own name (Ted) when quoting samples of dialogue.

As a former secondary science teacher, I have the advantage of having shared many of the experiences of my research subjects and have an understanding of the teaching process. This allows me to be viewed as a colleague, but may also lead to assumptions based on my experience rather than pure observation (Berger, 2015). In my teaching experience, effective teaching involves developing a relationship and camaraderie with my students, as well as maintaining a position of respect and authority. I believe that learning science is the active process of figuring out how, and frequently why things happen the way they do, and that teaching is the process of putting students in situations that lead to learning. Teaching frequently involves providing experiences which make learners uncomfortable with their current level of understanding, and stimulating their curiosity. During my teaching career it was not uncommon for 
me, while presenting a lesson, to deviate from my planned approach when it became clear that the plan was not going to work in the dynamic of the classroom. This happened at times during the delivery of the PLD. I regard these "course corrections" as the teacher's way of being responsive to the students and a natural part of the teaching process. I will attempt to describe significant deviations in the delivery of the PLD and my motivations as clearly as possible in the chapters that follow. I will employ the two-part concept of reflexivity, by clearly describing my experience and pedagogical orientation, as well as describing in this study how my experience and orientation influenced decisions made based on the various forms of research evidence collected (Creswell, 2013a). I have never taught primary school aged children, and my teaching experience is primarily in the physical sciences, predominantly physics and chemistry. This experience has influenced my decision to structure this research in a way that relies on the pedagogical knowledge of the teachers, and restricts the science content to the Physical World strand of the NZC.

\subsection{Research lens}

The decision to select the social constructivist paradigm for this study was made primarily because it reflects the way I believe knowledge is acquired. From an ontological perspective, the positivist and postpositivist view that an absolute reality exists aligns with my views of the world; however, I also hold that people's perception of that reality is constructed based on our interpretations, which in turn are influenced by others (Denzin \& Lincoln, 2005; Mertens, 2010). From an epistemological perspective, my views are aligned with Mertens: "The inquirer and the inquired into are interlocked in an interactive process; each influences the other. The constructivist therefore opts for a more personal, interactive mode of data collection" (2010, p. 19). I therefore chose to approach this research from a social constructivist perspective.

Social constructivism falls within the broad category of constructivism, which can be summarised as a learning theory in which: 1) all learning is an active process of constructing meaning performed by the learner, and 2) teaching 
involves supporting that process rather than communicating knowledge (Cunningham \& Duffy, 1996).

Constructivism, in its purist form, posits that learning is the process of constructing and refining mental structures or schemata (Piaget, 1952). New knowledge is acquired either by adding to the existing schemata (assimilation), or by reorganising or rebuilding the schemata if existing structures are inadequate (accommodation) (Posner, Strike, Hewson, \& Gertzog, 1982).

Observing what happens in real classrooms reveals that students do not construct the knowledge in isolation, but rather they talk with each other and negotiate their way to meaning (Salomon \& Perkins, 1998). The development of scientific concepts and even observations are influenced heavily by the community of the classroom. Social constructivism originates in the work and thinking of Lev Vygotsky, a Soviet contemporary of Jean Piaget (Van Der Veer \& Valsiner, 1994). Like Piaget, Vygotsky recognised that knowledge is built through active processes of construction of meaning, and places an emphasis on the role that dialogue with others plays in learning (Moshman, 1982). The theory of social constructivism recognises that all learning involves activity and conversation about shared problems and tasks (Driver et al., 1994). Aikenhead (1996) argues that the border of influence extends well beyond the walls of the classroom and extends to the wider community, including the cultural background of the students. The cultural background in New Zealand includes the unique bicultural relationship between Māori and Pākehā ${ }^{2}$ established in the Treaty of Waitangi (Lourie, 2016). These considerations are particularly relevant given the intent in the NZC to develop a specific curriculum in the context of the local community (MOE, 2007a). The importance of social context in science learning is summarised by Solomon (1987):

Our pupils are strongly social beings for whom the teaching of a rigidly insulated science which makes no contact with the everyday context is simply not an

\footnotetext{
${ }^{2}$ People of non-Maōri heritage.
} 
option. Social influences of every kind permeate both the learning of science and its application. (p. 79)

Given a social constructivist orientation, the teacher's task is to provide classroom situations that allow students to: build on their existing knowledge; generate motivation via hands-on investigations, counter-intuitive demonstrations and community relevance; and take advantage of the social nature of knowledge acquisition. These considerations have led to the choice of science investigation as a teaching strategy (Minner, Levy, \& Century, 2010).

The teaching strategies for implementing a constructivist orientation in the classroom are described in great detail and variety in the literature (see, for example, Appleton, 1993; Baviskar et al., 2009; Schulte, 1996; Yager, 1991). In the New Zealand context, these constructivist approaches were adopted by the Learning in Science project (Bell, 2005), an extensive research project running from 1979-1996. For the purpose of this research I selected three characteristics that are present in virtually all implementations: examination of the pre-existing student knowledge (Naylor \& Keogh, 1999; Sewell, 2002), explicitly addressing motivation to learn (Sewell, 2002), and reinforcing the new knowledge by putting it to use (Vermette et al., 2001). These characteristics are consistent with a constructivist view of learning, shape the way I designed the PLD activities for teachers, and are reflected in aspects of the PLD framework developed in the following chapter. Retrospective reflections on the fit of social constructivism for this research project are further explored in section 7.6.

\subsection{Qualitative methodology}

The decision to use DBR as the methodology for this research does not necessarily imply a qualitative or quantitative methodology, with the specific choice predicated by the research questions (McKenney et al., 2012). Qualitative analysis is appropriate for situations in which there are relatively small numbers of subjects, where the type of data collected require interpretation, and where the data collection environment is complex (Creswell, 
2013b). Creswell (2013b) describes the qualitative research process for a participant observer with a constructivist world view in this way:

In this scenario, the researcher seeks to establish the meaning of a phenomenon from the views of participants. This means identifying a culturesharing group and studying how it develops shared patterns of behavior over time (i.e., ethnography). One of the key elements of collecting data in this way is to observe participants' behaviors by engaging in their activities. (p. 16)

A quantitative approach is best suited for situations in which variables can be isolated and objectively measured, and the number of subjects is sufficient for statistical analysis (Creswell, 2013b).

My original intent was to use a combination of qualitative data, consisting of audio recordings and field notes, and quantitative data obtained from pre- and post-PLD written examinations of teacher subject matter knowledge in a fixed mixed methods design (Creswell \& Clark, 2011). The recordings and observations would be required in order to understand the teachers' requirements for a PLD programme, as well as providing a nuanced evaluation of the effectiveness of the PLD on their confidence and teaching methods. The quantitative data from the pre-tests and post-tests would provide unambiguous evidence of teacher learning. My thought was that a mixed methods design would allow for the richness of subjective qualitative data while also providing objective numerical metrics of performance (Creswell, 2013b). During the first iteration of the PLD however, after the initial discussions with the teachers and observations during the first PLD session, I decided against formally testing their science content knowledge, a decision that eliminated the collection of quantitative data. The teachers in iteration-one stated clearly that they felt their major barrier to teaching more science was their lack of science content knowledge, and they were hopeful that the PLD would help them in this area. I felt that subjecting them to a formal testing would be quite stressful for them, and would add little usable data that could not be assessed by other means. I also felt that the relationship they were developing with me would not be helped by putting them through a formal testing process. A test would also need to 
measure not merely science subject matter knowledge, but also the specific type of subject matter knowledge required in teaching (Anderson \& Clark, 2012; Ball, Thames, \& Phelps, 2008), and finding or developing an objective validated examination suited to the specific subject matter we would be covering in the PLD would be difficult and time consuming. Finally, testing SMK could easily convey the inaccurate message that knowledge of science facts is the goal of the PLD, and of science education itself. For all of these reasons I elected to forgo formal testing and to probe their science content knowledge through informal questioning, observation of their approaches to the investigations, audio recorded conversations, construction of concept maps, and observation and analysis of their teaching that was part of the PLD. Content knowledge has been shown to be an area of weakness in primary science teachers (see Section 2.2.2), so little new knowledge was to be gained by diagnostic formal testing, and much could be lost in terms of relationship by putting teachers under the stress of formal testing.

The study therefore sits fully within the qualitative interpretivist paradigm. The social constructivist lens described previously is also the appropriate lens through which to make research judgements in this study. The nature of an DBR iterative process, through which information is gradually built up based on the interpretation of complex multifaceted data, is in alignment with the definition of the social constructivist world view (Creswell, 2013b). Judgements regarding specific content of the PLD framework will be made on the basis of interpretation of observations, frequently in consultation and negotiation with the PLD participants.

\subsection{Selection of teachers and schools}

Candidate schools were chosen based on three criteria: decile, proximity to Wellington, and school size. The decile (see Section 2.1.1) is an indication of the relative affluence of the school community. Data from the TIMSS showed that schools in very high and very low deciles differed sharply in science achievement (Caygill et al., 2013). In an effort to make the research applicable 
to the widest range of schools as well as minimise the variability between schools, a decision to avoid very high or low decile schools was made. Using data obtained from the MOE for the 2013 school year, the average decile of primary schools, weighted by number of students, is 6.3; therefore, candidate schools were limited to decile five through seven (MOE, 2013). Transportation practicalities dictated limiting the participants to schools in the Wellington region, and finally, in order to provide local support, a decision was made to select schools large enough to have at least two teachers teaching Years 7 and 8. Application of the above criteria produced a pool of 35 potential schools.

Finally, the goal of the research was to identify the characteristics of a PLD programme that helps teachers to teach more science in their classroom, and not general classroom management. Research of Luft (2001) and Tseng, Tuan, and Chin (2012), mentioned in Section 3.2, indicated that beginning teachers have different concerns to those of experienced teachers, such as student discipline and classroom management issues, so a decision was made to focus on teachers with at least three years' teaching experience (Richter, Kunter, Klusmann, Lüdtke, \& Baumert, 2012).

When ethics approval for the study was obtained, a letter was sent to the principals of the 35 candidate schools introducing the research and seeking permission to invite teachers to participate (see Appendix A).

The initial plan was to contact the principals of schools in the target pool, and form teachers into three groups. It was anticipated that each group would be formed of teachers from two or three different schools, and the PLD would be conducted for part of the time at each participating school. With advice from my research supervisors, I decided to begin with a group of three teachers, and increase the group size gradually with each iteration, with a target of 6 teachers in iteration-three. The response to the initial round of contact produced only one school with three teachers. A decision was made to begin the research project, and fill out the remaining iterations while conducting the first iteration. Follow-up 
phone calls to principals resulted in a second positive response from a school with a group of four teachers. When an unsuccessful second round of follow-up phone calls failed to identify additional participants, a decision was made to expand the decile range to decile four through eight in order to find an additional teacher group. This produced an additional 18 candidate schools. The same procedure was followed with this expanded group, and during the second round of follow-up calls a group of five teachers from a single school was identified for the final iteration.

\section{Table 3: Summary of PLD groups}

\begin{tabular}{|l|c|c|l|}
\hline School pseudonym & Decile & Number of Teachers & Dates of PLD \\
\hline School-one & 6 & 3 & $30 / 6 / 14-19 / 10 / 14$ \\
\hline School-two & 7 & 4 & $22 / 9 / 14-14 / 11 / 14$ \\
\hline School-three & 8 & 5 & $7 / 9 / 15-3 / 12 / 15$ \\
\hline
\end{tabular}

The actual composition of the three iteration groups is summarised in Table 3. The overlap in dates between iteration-one and iteration-two is due to an illness of one teacher in the iteration-one group, and the subsequent postponement of an observation in his classroom which overlapped the start of the second iteration. The longer gap between schools two and three reflects the difficulty in attracting participants for the final iteration and finding a time suitable to them, as described above. A detailed description of the schools and teachers will be given in the individual iteration chapters that follow. A PLD programme was crafted for each group based on the physical science topic agreed between the researcher and the teachers in the iteration group. At the conclusion of the PLD, the topic was then taught by each teacher at a time shortly after the PLD.

\subsection{Ethics}

This study was approved by the Victoria University of Wellington Human Ethics Committee, approval reference: 0000020480 . The nature of educational research requires that consideration be given to: external issues, such as institutional rules, codes of practice and risk; consequential issues, such as benefits to individuals, organisations, and society; deontological issues, such as 
honesty, fairness, and being worthwhile; and relational issues, such as establishing a genuine collaboration, respecting autonomy, and respecting persons equally (Stutchbury \& Fox, 2009). The design of the project, selection of methodology, and decisions made during the project were made with these ethical considerations in mind. Information sheets for the principals and teachers were developed and approved by the Human Ethics Committee.

The decision to choose DBR was made in part to ensure the results of the research are as practical and as useful as possible in addressing the problem of the amount of classroom time spent in science. I was also conscious ethically of the importance of making the time teachers gave to participate in the research project as worthwhile for them as possible, and the delivery of a science PLD gave them something practical to use in their classrooms.

Upon receiving a positive response from the principal, we discussed the research, completed the signed consent form, and I was granted permission to contact teachers. I sent teacher information sheets and consent forms to each prospective teacher. All teachers who were part of the study returned signed consent forms. Sample information sheets and consent forms are provided in Appendix B. During the first meeting with teachers we discussed the research, and confirmed that they understood the research and were comfortable with the audio recording of the discussions and the PLD. I made it clear when the recording was started and stopped. Teachers were given assurance that their names and the names of their schools would be kept confidential in the research; therefore, the names of teachers and schools have been anonymised in this document.

The focus of this research project is the teachers rather than students. During the classroom observations, the teachers introduced me to their classes, and informed them that I would be observing them teaching the class and taking notes. During the classroom observations, no video or audio recordings were made and no individual students were identified. 


\subsection{Overview of PLD and data collection}

In this section I will give a brief overview of the structure of each PLD iteration. Full descriptions of each iteration will be found in the chapters that follow. The choice of science topic and duration of the PLD was made in consultation with each teacher group; however, all three iterations followed the same general structure.

During the introductory meeting with teachers we discussed the information sheets and consent forms (see Appendix B), selected a science topic as the focus for the PLD, and agreed times and durations of the PLD sessions. Given the schedules and after-school commitments of the teachers, a series of six weekly meetings of approximately 1.5 hours directly after school was selected by all three groups.

An introductory investigation was used at the beginning of the first topic-focused PLD meeting. I decided to begin the PLD with a science investigation to set the tone of the PLD as an active and hands-on exploration of science, rather than an instructor-centred didactic exercise. I wanted to create a first impression that this PLD would be interesting and fun, as well as intellectually challenging and useful for their teaching praxis.

Each PLD session was a mixture of science investigations and discussions with data gathered in the form of audio recordings and field notes. Once a topic was identified a concept map was generated by the teachers as a group to determine their initial level of understanding, and to aid in planning the PLD. During the final PLD session another concept map was generated to gauge changes in understanding as a result of the PLD.

At the conclusion of the PLD all teachers agreed to allow me to observe them teaching a science lesson and taking notes. Following the observations, one final follow-up meeting was held with each iteration group to reflect on the experience and make recommendations. During the follow-up meetings I 
occasionally used the observation notes to prompt the teachers to discuss their teaching.

\subsection{Tools}

As mentioned previously in this chapter, this research employs a qualitative methodology. There are typically four tools used in qualitative research: questionnaires, interviews, observations, and documents (Denscombe, 2014). The data for this research consist of audio recordings of structured discussions with teachers, audio recorded observation of the PLD sessions, and concept maps developed during the PLD.

\subsubsection{Audio recordings}

A recording of the discussions and PLD sessions provides a permanent and auditable data record (Denscombe, 2014). Although video recordings provide a richer data source, they are more intrusive, and given the amount of movement involved in a science PLD involving hands-on activities, moving and setting up a video recorder would be intrusive, complex, and time consuming. The relative simplicity of audio recording provides an advantage.

Discussions were recorded via a digital audio recorder and an iPad using recording software. Where recording was not possible field notes were taken. In one session during the first iteration the audio recording was lost and a reconstruction was made from notes and memory immediately after the session. In addition to a record of discussions, recordings of the investigations provided a rich source of participant-to-participant discussions providing an insight into SMK progress and PCK development.

All audio recordings were transcribed using the current version of Elan software (Elan - Linguistic Annotator ( 4.8 .0 - v5.0.0), freely available from https://tla.mpi.nl/tools/tla-tools/elan/) (Wittenburg, Brugman, Russel, Klassmann, \& Sloetjes, 2006). 


\subsubsection{Concept maps}

It is difficult to assess, or for that matter define understanding; however, given a constructivist orientation, concept mapping is an appropriate tool with which to gauge understanding. Nickerson's (1985) description of understanding clearly makes this connection:

Understanding is an active process. It requires the connecting of facts, the relating of newly acquired information to what is already known, the weaving of bits of knowledge into an integrated and cohesive whole. In short, it requires not only having knowledge but also doing something with it. (p. 235)

As mentioned earlier, concept maps were co-constructed by each group of teachers during the first PLD session, and at the conclusion of the PLD. An audio recording was also made during most of the concept map construction, and, where present, was analysed as part of the data. A concept map is a graphical representation of understanding, usually consisting of a network of related events or objects (concepts), with connections showing how the concepts are related (Novak, Gowin, \& Johansen, 1983). Concept maps are useful for assessing knowledge of a topic, including areas of understanding and misconceptions (Novak \& Cañas, 2008). They have been used for both qualitative and quantitative evaluation; however, as noted by Novak and Gowin (1984), the qualitative aspects of the maps are more valuable than a quantitative score. The use of concept mapping is also well aligned with the social constructivist theory of learning, the research lens of this project (Beyerbach \& Smith, 1990; Roth \& Roychoudhury, 1993). The concept map produced at the beginning of each iteration was used to provide a qualitative evaluation of the teachers' understanding of their chosen topic by showing the breadth of understanding, gaps in background knowledge, and misconceptions. I acted as a scribe for the process, asking questions of clarification, and asking if connections should be drawn, but did not contribute new items or connections to the map. The initial map assessment was used to aid the selection of subject matter content of the PLD. Development of the maps as the PLD progresses 
provides an indication of teacher learning. An example concept map is provided in Section 3.10.

Concept maps were constructed through the use of a Scapple (Literature and Latte, 2014), a computer whiteboard programme.

\subsubsection{Classroom observations}

Putting the PLD into action serves two purposes in this research. As discussed in the literature review, Guskey (2002) found that the effectiveness of PLD programmes was enhanced by incorporating a teaching element into the PLD design. Observing the teaching also provided an opportunity to collect additional data in the form of notes taken during a science class taught by each teacher at the conclusion of the PLD. I was introduced to the class and took notes, but otherwise did not participate in the classroom activity. While audio recordings would have produced a more detailed record, this would have added complexity and I did not have ethical approval so I chose instead to carry out focused observations. Given the complexity of classroom environments, I chose to narrow the focus of my observations to the teachers' presentation of material, and the engagement of the students (Good \& Brophy, 2008). An example of an observation form is provided in Appendix C.

Initial plans for this study included the additional component of student focus group discussions to provide student voice. This component was abandoned because the amount of data generated by the number of multiple-participant focus groups that would be required to establish the effectiveness of the teaching would significantly increase the scope of the project. The focus was on empowering teachers to teach physical science.

The notes taken during the classroom observation were reviewed, and formed the basis for discussion topics during the audio recorded final meeting. Using the notes, I prompted the teachers about parts of the lesson that I gauged went well, or not so well. 


\subsubsection{Semi-structured interviews}

The initial conversations with each teacher group were conducted as semistructured interviews consisting of a series of open-ended questions. The audio recordings of these conversations were transcribed, and used to establish the teachers' own perceptions of their students' ideas about science, their own ideas about science, their science backgrounds, and their views on teaching science. The following topics were used to structure the discussion following introductory PLD session for all iterations:

- the students' definition of science,

- the teachers' definition of science,

- how scientific theories are established and evolve,

- the teachers' background in science,

- how much science is taught in the teachers' classes, and

- the role of science investigation in teaching.

\subsubsection{Field notes}

Although the PLD sessions were recorded and transcribed, notes and audio recorded reflections were made following sessions. When an audio recording was not available, notes were made as soon after the session as possible. For example, the recording was inadvertently switched off during one discussion in iteration-one, and on another occasion the discussion occurred while we were outside conducting the speed-of-sound investigation.

\subsection{Analysis}

The audio recordings were transcribed by dividing the recording into statements by each participant. A further division was made of longer statements (where appropriate) into single-themed statements for ease of analysis. An example of a transcription is provided in Appendix D (column D).

A coding procedure was devised based on the PLD framework developed the conclusion of the literature review. The framework consists of five content 
areas: Subject selection / curriculum, Subject matter understanding, Teaching practice, Support, and Logistical considerations, each of which contain design characteristics with specific implementation advice. The transcripts were first coded by ascribing each single-themed participant statement to one or more of the five content areas. If statements did not fit into a content area category it was coded Not Applicable (NA). The NA statements were scrutinised to determine if another major content-area should be considered; however, the NA statements did not coalesce into a sixth area. A second pass was made through the data to determine if a statement supported or contradicted an existing characteristic in the framework, or if a statement suggested a new characteristic. An example section of coded transcription can be found in Appendix D. If multiple participants' statements converged on a similar theme, a new design characteristic was introduced into the framework. Likewise, if multiple participants' statements contradicted an existing characteristic, the characteristic was removed from the framework. A paucity of statements either supporting or contradicting a characteristic was not considered as evidence to support a change.

This analysis is consistent with the constant comparative methodology introduced by Glaser and Strauss (2006). Although associated with grounded theory, the methodology is frequently used in analysis of qualitative data requiring comparison to existing categories, and particularly where the induction of new categories may be required (Merriam, 2009).

As mentioned in the previous section, each group of teachers produced a concept map of their selected topic at the beginning and the end of the PLD. An example of pre- and post-PLD maps is shown in Figure 13 below. 

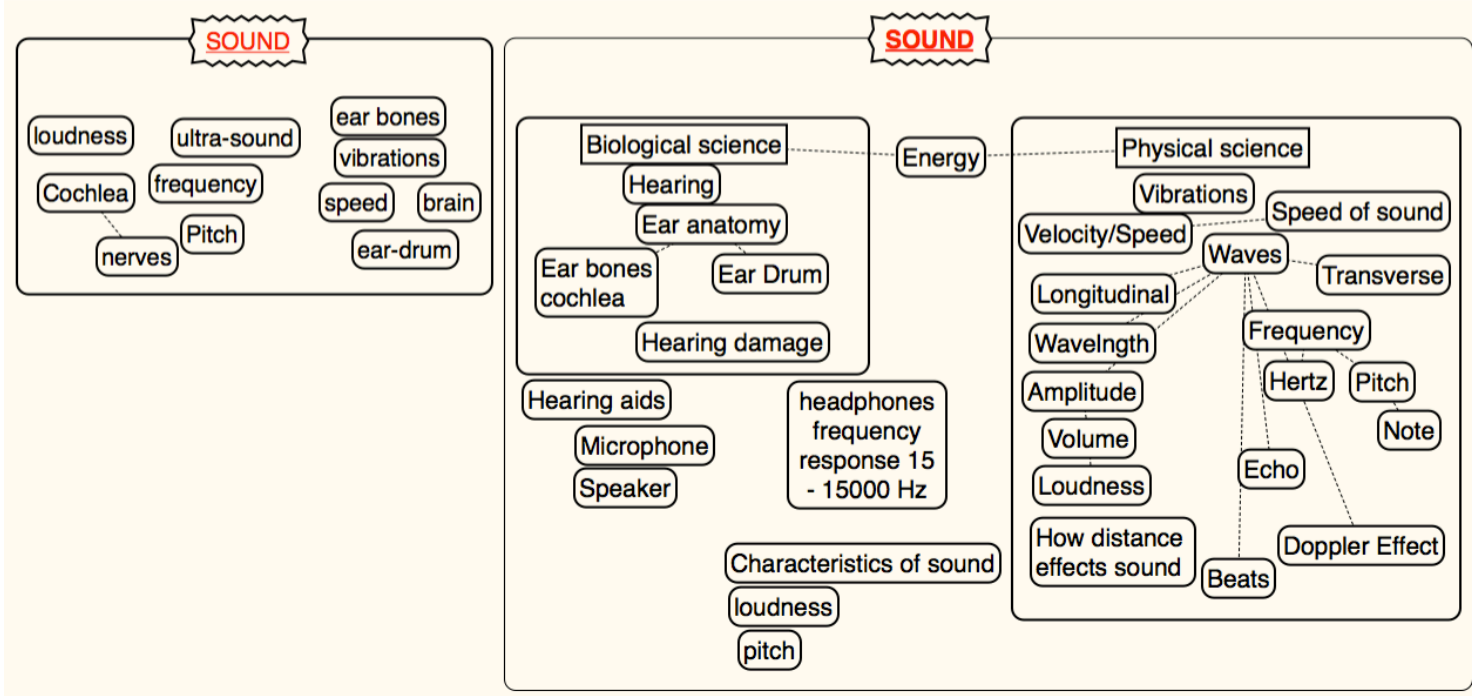

Figure 13: Pre-and Post-PLD Sound Concept Map

Generally, the quality of a concept map can be judged by the number of appropriate concepts shown, the links between the concepts, and existence of cross-linking between the concepts (Kinchin, 2000). A concept map consisting of a list of words relating to the concept but with few accurate connections generally indicates a low level of understanding. A map which contains a hierarchal arrangement of items with multiple connections indicates a more sophisticated level of understanding.

The evaluation of a concept map can be quantified using various scoring schemes based on the number of items, levels of hierarchy, and links (Novak \& Gowin, 1984). The validity and reliability of the schemes are relatively low, and important characteristics such as the presence or absence of meaningful cross linkages is difficult to formulaically score (Cañas, Coffey, Carnot, \& Feltovich, 2003). In this project, concept maps were evaluated qualitatively by describing the number and type of items, the number and quality of connections, information gaps, misconceptions, and degree of background knowledge.

The initial level of SMK of the teachers was gauged by evaluating the concept map developed during the first PLD session for each group. It is important to note that producing a group concept map does not show the strengths and 
weaknesses of individual teachers, and care must be taken to avoid a situation of a single individual teacher supplying all of the information. If an individual teacher with extensive knowledge provided most of the items on the map, I would have had each individual teacher produce a map; however, this situation did not occur in any group in this study. The concept map produced at the conclusion of the PLD was used to evaluate the learning that occurred through the PLD process.

The formal science background of the teachers in each group was established in the semi-structured interview during the first meeting. The interview also probed their definition of science, their views on teaching science, and quantified the approximate amount of classroom time spent on teaching science. These data were used, to characterise the sample, and along with the concept maps and transcriptions, to inform the design.

\subsection{General Overview of PLD}

Table 4 presents a general overview of the PLD, indicating the timeline, activities, and data collected at each stage. The groups generally met once a week after school, although iteration group three chose to meet during the break between school terms. The time between completing the PLD and the classroom observation varied between groups, and is a topic that will be mentioned in the chapters that follow.

Table 4: General Overview of PLD

\begin{tabular}{|l|l|l|l|l|}
\hline Time & $\begin{array}{l}\text { Initial meeting } \\
\text { Week 1 }\end{array}$ & $\begin{array}{l}\text { PLD sessions 1-5 } \\
\text { Weeks 2-6 }\end{array}$ & $\begin{array}{l}\text { Classroom } \\
\text { observations } \\
\text { After week 6 }\end{array}$ & $\begin{array}{l}\text { Final meeting } \\
\text { After observation }\end{array}$ \\
\hline \multirow{2}{*}{ Investigation } & $\begin{array}{l}\text {-Ice breaker } \\
\text { investigation } \\
\text {-Semi-structured } \\
\text { interview } \\
\text {-Science topic } \\
\text { choice }\end{array}$ & $\begin{array}{l}\text { Group specific } \\
\text { science content } \\
\text { presented through } \\
\text { hands-on science } \\
\text { investigations, } \\
\text { demonstrations, } \\
\text { and presentations }\end{array}$ & $\begin{array}{l}\text { Teachers teach } \\
\text { science topic }\end{array}$ & $\begin{array}{l}\text {-Review of PLD } \\
\text {-Review of } \\
\text { classroom } \\
\text { teaching } \\
\text {-Reflections on } \\
\text { PLD }\end{array}$ \\
\hline Data type & Audio recordings & $\begin{array}{l}\text { Concept maps } \\
\text { Audio recordings }\end{array}$ & Field notes & Audio recordings \\
\hline
\end{tabular}




\subsection{Trustworthiness}

The decisions to add or remove characteristics of the PLD framework are not black and white. Qualitative research demands an attention to factors which make the research trustworthy, such as reliability, and validity. These factors ensure decisions made and conclusions drawn arise from the data rather than pre-conceived notions of the researcher (Guba, 1981; Creswell, 2013b).

Reliability implies steps are taken that provide assurance that other researchers in other situations have sufficient information to attempt to replicate the research (Flick, 2008). This involves clearly describing data collection modes and methods, using analysis methods that are grounded in the literature, and stating the disposition and perspectives of the researcher. The decision to use audio recordings, and employ the analysis methodologies described in the previous section ensure the reliability of this study.

Validity in qualitative research involves the strategies used to provide assurance that the findings flow from an accurate interpretation of the data (Creswell, 2013b). Several strategies are used in this research to ensure validity, including: the use of audio recordings, enabling the teachers' voices to be used rather than the researcher's interpretation of the voices; classroom observation of teachers interacting with their students rather than in the artificial environment of the PLD; the rule that changes to the PLD framework, other than simple logistics, must be the result of data that are reinforced through multiple occurrences; and finally that the iterative nature of DBR allows for the findings from previous iterations to be evaluated in light of subsequent iterations.

\section{Summary 3.13}

This chapter introduced the research questions, established DBR as an appropriate framing methodology for designing a science PLD framework in the New Zealand context, and described the specific design to employed. Once 
these were established, the remainder of the chapter described the ethical considerations, and outlined the qualitative tools used to collect data, and the methods employed to analyse the data, concluding with the steps taken to ensure the research would be reliable and valid.

In the chapters that follow I will describe the three iterations of the PLD and the changes in the PLD framework prompted by the data collected in each iteration. In keeping with the principles of reflexivity, I will attempt to illustrate my thinking process and make the decisions as transparent as possible.

The following three chapters describe the three iterations of the PLD. In each of these chapters I will describe the schools and teachers involved in the PLD, the content area selected, and give an overview of the PLD sessions. I will describe the findings from the analysis of the data obtained, and discuss how those findings impacted the design framework used in the next iteration. A summary discussion chapter will follow the final iteration, proffering the design principles found as the result of the three iterations, and drawing together other observations from the research project that have a bearing on primary school science PLD programme design in New Zealand. 


\section{Chapter 4 First Iteration}

\section{Introduction and overview}

This chapter is the first of three chapters describing the use and refinement of the PLD framework developed in section 2.3 and summarised in Figure 10. The iterative cycle of design, application, analysis and refinement is central to the process of DBR. In this chapter I will describe the school and teachers involved in iteration-one, provide an overview of the meetings with teachers, development and presentation of the PLD, and observations of the teachers during the PLD and while teaching a unit based on material covered by the PLD. The second part of the chapter will be a review of the PLD framework, evaluating the various design elements and associated implementation advice in light of the PLD experience, with each element being either supported or contradicted. Additional elements will also be proposed when data from the iteration highlight a gap in the framework.

It is important to note that the researcher (myself) is also the designer of the PLD, the presenter, and evaluator, and that a group of participating teachers was actively giving feedback during the presentation of the PLD over several weeks. Analysis was therefore conducted not only at the conclusion of each full iteration of PLD, but also after, and occasionally during each PLD session. In order to provide the highest quality PLD possible within the constraints of the research project, design changes were made both during the iteration, and, at the conclusion of each iteration. Observations, in the form of audio recordings of semi-structured discussions, open discussions, PLD sessions, field notes, and concept maps, were collected during the PLD sessions, and field notes were collected during classroom observations of each teacher at the conclusion of each PLD iteration. One final discussion meeting was held for each iteration group following the classroom observations. 


\section{The school and teachers}

The principal at School-one responded to my initial letter, and sent an email to the staff describing the project; three teachers expressed interest in participating. School-one is a decile six intermediate school (Years $7 \& 8$ ) with between 350 and 400 students. All classrooms contain a mixture of Year 7 and 8 students. All subjects are taught in the classroom by the single classroom teacher with the exception of physical education and technology classes, which have a dedicated specialty teacher, and there is no dedicated science laboratory available.

The three teachers in iteration group one, whom I will call Jack, Tom, and Bree have taught this age group (Year $7 \& 8$ ) for between seven and eleven years. Bree had some science background, completing one biology and one chemistry paper at university, the others did not take any science beyond the compulsory Year 11 science level. Their class sizes range from 28 to 32 students. The teachers all indicated the reason they elected to participate in the study was because they wanted to teach more science and saw the PLD as an opportunity to increase their science knowledge.

\subsection{PLD overview}

This section presents an overview of the PLD consisting of an initial brief scheduling meeting, the introductory PLD, selection of the topic area, the topicfocused PLD sessions, planning, classroom observation, and the final wrap-up session.

\subsubsection{Initial meeting}

I initially met with the participating teachers to give them an introduction to the research project and work out a schedule of meetings. I had previously provided them with a written description of the research project, which we reviewed verbally to answer questions, and confirm their understanding of what 
their participation involved. I also collected signed consent forms (See Appendix B). The PLD was planned following this initial meeting with the teachers which established a schedule of meetings and the overall duration of the PLD.

We agreed to a schedule of five weekly 1.5 hour meetings immediately after school, after which they would teach a unit on the material covered in the PLD. We also agreed that I would observe one class with each teacher following the PLD. We would conclude the PLD with a final meeting at which we would discuss my observations of the teaching, and we would discuss their impressions of the PLD.

The duration of the PLD, length of PLD sessions and scheduling of the observation was an attempt to balance the competing demands of the literature, which documents a high correlation between the benefit of a PLD and its duration (contact hours) (Garet et al., 2001), the schedule pressure on the teachers, and the practicalities of a PhD research timeframe.

\subsubsection{Introductory PLD Session}

As mentioned in Section 3.8, I began the first PLD with an introductory investigation to set the tone of the PLD. I chose an investigation of a pendulum, which was an investigation I had done many times with physics students, and I felt it would be mildly challenging but accessible and interesting for the teachers. The period of a pendulum has a strong dependence on only one variable, length, and is only slightly dependent on the amount of arc, or mass of the pendulum fob, which is quite counter-intuitive. The activity required little specialised equipment, and could easily be completed in 45 minutes. We began by watching a 4-minute video of the Big Ben clock (WHTR Television, 2012), after which I asked them a question based on a rather counter-intuitive statement in the video that the timing of Big Ben was adjusted at regular intervals by adding or removing pennies from the weight on the pendulum. If the clock was running fast, a penny was removed, and if slow a penny added. I 
asked the teachers what they knew about pendulums and what variables determined the period of a pendulum. They indicated they did not know, so I provided some simple materials and asked them to do some investigation, and to find out what matters in the period of a pendulum.

I had designed this activity as a level three guided inquiry (in which a topic area is chosen and a question is stated, but the procedure is left to the investigator) as described by Bell, Smetana, and Binns (2005). The decision to start with an activity was an attempt to set an engaging and enjoyable tone for the PLD, and provide an example of an investigation where teachers engaged with the students' point of view, working with something they did not necessarily understand. It also gave me an opportunity to observe the teachers conducting an investigation, revealing their understanding of both science content, and their investigative procedural knowledge. They thought their way through what the variables were in the system, and devised a procedure to isolate the variables. I left them to their investigation, only offering suggestions when they got stuck. The purpose of the activity was to set the tone of the PLD as active hands-on, intellectually challenging and fun, not an in-depth study of the physics of pendulums. I asked the teachers to ponder their questions about why the only factor that seemed to influence the period of the pendulum was the length, and we agreed to discuss the investigation at the next meeting.

This initial PLD session was divided into two parts, the investigation, described above, and a discussion session, each lasting approximately 45 minutes with audio recordings made during the discussion session. I felt, during my initial planning, that this format would concentrate the discussion into one short session and streamline the data gathering for the research aspect of the PLD. I realised after this first session that capturing the discussions during the entire PLD session would provide richer data, as spontaneous discussions during the investigation portion would be lost if not recorded. The full sessions were recorded in all subsequent meetings. 
When the teachers finished the pendulum activity, we gathered for the discussion portion of the PLD. In this discussion I briefly reviewed the goals of the research, and structured the discussion using discussion topics mentioned in Section 3.9.4. I then asked the teachers to select a particular area within the broad category of physical science on which to focus. They were not comfortable making the choice however, and did not state a preference, saying they knew very little about physical science, and that they would prefer me to choose a topic area. I will return to this point in sections 4.2.1.1 and 4.2.1.2. The teachers informed me that their school had a stated theme for each term, and the theme this term was "iBod"; which relates to the human body. The teachers explained that literacy and numeracy are considered "core" subjects with a set curriculum, and that each teacher is expected to select content in the "non-core" subjects such as science, art, and social studies to fit into the theme. School-one utilises a curriculum integration approach discussed in the NZC by structuring the entire curriculum around a theme, with content of subjects selected to relate to that theme (MOE, 2007a) (see section 4.2.1.2 for details).

The Physical World section of the NZC (2007c) is quite non-prescriptive, and schools are encouraged to use it as a guiding document and to develop their own specific curriculum within the school to suit their unique environment (described previously in section 2.1.2). The teachers were unsure how any physical science topic would relate to the "iBod" theme, and after a brief discussion I suggested a focus on two topics, sound and forces, as I could see various connections to the human body that would provide useful learning opportunities for these topics, and we agreed to start with sound. Now that the subject focus was agreed I went away and planned the PLD. 


\subsubsection{Topic-focus sessions}

Each topic-focused session was structured as a mixture of investigations and discussion. At the beginning of each session I would briefly review the previous session and discuss any outstanding questions or concerns. During the first session on sound, I probed the teachers' knowledge of sound by working with them to construct a concept map (Novak, 2002), introduced in Section 3.92, and described in Section 3.10.

I then designed a series of PLD sessions on sound based on my teaching experience and findings from the concept mapping. My own teacher training had a heavy emphasis on inquiry approaches advocated by Yager, Engen, and Snider (1969), and Shymansky (1983), influencing my teaching toward handson guided inquiry approaches. My teaching developed to be in line with the inquiry-based approach resulting from the research synthesis of Pedaste et al. (2015), which consists of: stimulating curiosity, generating questions and predictions, investigating, making sense of the data, and discussion or reflection.

I elected to take them through a number of investigations and demonstrations to help them build their basic understanding of sound using investigations that they could use in their own classrooms. This approach to learning science is consistent with the social constructivist model of learning used in this study (Driver et al., 1994). My plan was to help the teachers understand the phenomenon, and then to work with them to develop and plan a unit for their students.

The fundamental concepts I selected were vibration, waves, transport media and energy, which are the principal or "big idea" concepts contained in teaching materials provided by the MOE, Making Better Sense of the Physical World (MOE, 1999), and the Building Science Concepts booklets (MOE, 2002). The basic science of sound relies on some key concepts such as vibration, waves, and basic knowledge of particle theory and states of matter. Other concepts 
such as the speed of sound, transmission of sound, and echoes require an understanding of those basic concepts. I prepared a number of investigations and demonstrations to help establish these foundation concepts.

The teachers assumed the role of students as we worked through the investigations. We discussed the subject matter, and potential ways to present it to their classes while they were doing the investigation and in discussion sessions afterwards. As we progressed through the material I encouraged the teachers to ask questions as they arose, and where possible, allowed the teachers' curiosity to influence the order of the remaining topics. An example of such an opportunity occurred during the first sound PLD when Jack asked how fast sound waves travelled. We went out to a field and measured the time it took an echo to travel to a distant building and back, and calculated the speed of sound. The subject matter content of iteration-one is summarised in Table 5. 
Table 5: Topics and activities in iteration-one

\begin{tabular}{|l|l|l|}
\hline Session & Subject matter content & Investigations \\
\hline PLD 1 & $\begin{array}{l}\text { Introductory investigation and semi- } \\
\text { structured interview }\end{array}$ & Pendulum \\
\hline PLD 2 & $\begin{array}{l}\text { Sound as compression wave, } \\
\text { longitudinal and transverse waves, } \\
\text { waves and energy, speed of sound }\end{array}$ & Waves on springs, measuring an echo \\
\hline PLD 3 & $\begin{array}{l}\text { Sound through a string, waves and } \\
\text { sound, amplitude/volume, } \\
\text { frequency/pitch, parts of the ear, } \\
\text { detecting sound direction using our } \\
\text { ears }\end{array}$ & $\begin{array}{l}\text { Paper-cup telephones, listening to } \\
\text { different pitches and volumes, listening } \\
\text { through tubes }\end{array}$ \\
\hline PLD 4 & $\begin{array}{l}\text { Sounds through substances (air, } \\
\text { solids/strings), frequency-wavelength- } \\
\text { energy connection, ear anatomy and } \\
\text { hearing loss }\end{array}$ & $\begin{array}{l}\text { Listening to sound through a metal fence, } \\
\text { waves on a spring part 2, parts of the ear }\end{array}$ \\
\hline PLD 5 & $\begin{array}{l}\text { Waves and echoes, waves and } \\
\text { interference, how energy diminishes } \\
\text { with distance, lesson planning }\end{array}$ & Wave simulation software \\
\hline
\end{tabular}

\subsubsection{Unit planning, observation, and wrap-up}

At the final topic-focused session, we took some time to plan a unit on sound. I began by asking the teachers what topics they felt were the most important to include in the unit, and to consider a logical order for the topics.

We agreed that the concepts of vibration, waves and energy transfer would be included as key concepts. The teachers suggested the order we went through things in the PLD was a good order to use for their teaching of the sound unit (see Section 4.1.3).

The teachers informed me that they had recently started working with student teachers, and they would postpone teaching the unit on sound until the student teachers finished. This introduced a six-week gap between finishing the PLD and teaching the material. The gap proved to be a significant issue (see Section 4.2.2.2).

I arranged to observe a lesson from all three teachers on the same day; however, Jack was ill on the observation day, and he arranged for an 
observation two weeks later. The classroom observations are discussed in Section 4.2.6.

We met one final time after school the day I observed Jack's class for a wrap-up session. During this time I asked the teachers to reflect on the PLD, and their teaching of the unit. I asked them to consider what changes they would suggest to improve the PLD. The teachers made several suggestions and recommendations, which I have included at relevant points in Section 4.2.

\subsection{Framework review - iteration-one}

The review of iteration-one will be organised using the five broad areas of the design framework developed in Section 2.3.3 and summarised in Figure 14. The changes to the design framework are, in effect, preliminary findings, which will be tested and further refined in subsequent iterations. Existing design characteristics and the supporting implementation advice will be discussed in light of data from the PLD, and additional design characteristics and/or implementation advice will be proposed when data from the PLD suggest additions to the framework.

\subsubsection{Subject selection / curriculum}

The literature review indicated effective PLD programmes have characteristics that emphasise the importance of consideration of students' learning needs, and align the PLD content with local and national curricula (see Section 2.3.3). Data from iteration-one supports these characteristics and initial implementation advice; however, additional implementation advice regarding the school theme is suggested. 


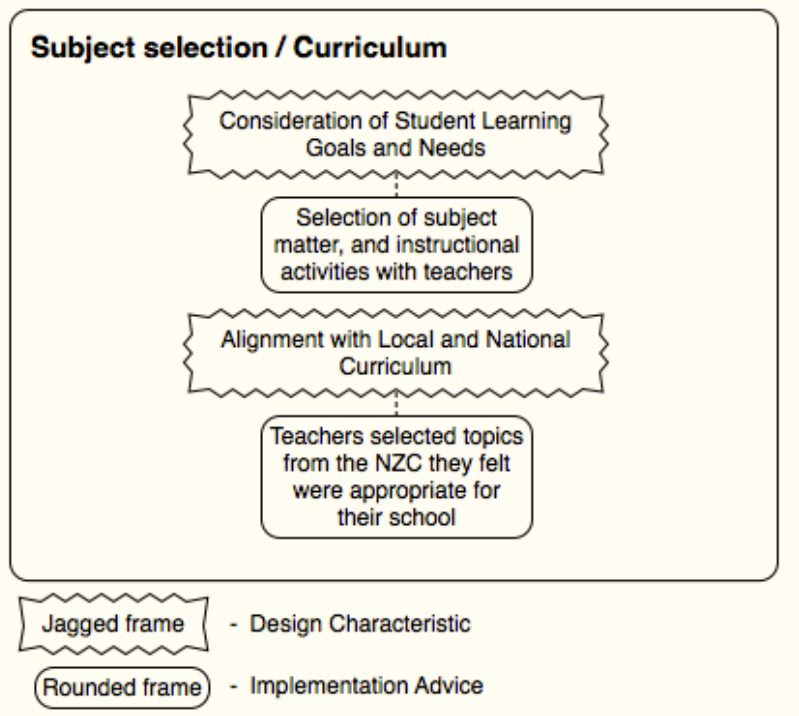

\section{Figure 14: Subject selection / curriculum}

\subsubsection{Consideration of student learning needs}

Factors that should be considered when determining student learning needs require the teachers to consider what the students need to know, what the students already know, and how to make the material interesting and relevant. During the first meeting with the teachers I asked them to choose an area within the physical sciences on which to focus our PLD. They were not comfortable choosing an area, and at the time I did not consider this was significant. Subsequent discussions with the teachers revealed two related factors that appear to have contributed to their discomfort: the breadth of topics in the NZC, and their knowledge of those topics.

The NZC spells out high-level topics, leaving it to the teacher to select topics and develop specific course content (MOE, 2007a). This gives teachers the autonomy to select appropriate topics that address students' needs and interests; however, the teachers at School-one did not have sufficient understanding of the topics in the NZC to see the connections between the science and the everyday lives of their students or themselves to select fruitful topics (Hulleman \& Harackiewicz, 2009). 
During the final topic-focused session, the teachers and I were discussing how they chose which topics from the NZC they would teach. They said it was up to the teachers to decide what to teach, but they would not have chosen sound as a topic:

Tom: I would never have chosen sound as a topic ... it would never have been something that appealed to me. It does now, and I reckon I'm going to use it as soon as possible.

Bree: I wouldn't have known where to start ... How do you make it fun? I would have been like - sound, really?

These comments highlight the difficulty teachers face when choosing science topics from the Physical World strand of the NZC. If the teachers lack SMK of a topic, they could not consider whether it would be an appropriate choice or not. Additionally, the NZC does not prescribe specific topics to be taught in specific years, which makes it difficult for the teachers to know what science topics, or specific aspects of broad topics such as 'forces', may have been taught previously, making a coherent presentation difficult as noted by Priestly and Sinnema (2014).

The experience with the teachers in iteration-one supports the need to select the subject matter of the PLD in consultation with the teachers, as the expertise of the PLD facilitator may be helpful in identifying the connections between the science and the everyday lives of the students.

\subsubsection{Alignment with local and national curriculum}

The teachers explained that School-one employed a thematic approach, designed to connect different subject areas, as described by Boyd and Hipkins (2012). School-one selects a theme for each term, and teachers are expected to select the content of subjects other than numeracy and literacy to fit into the theme. The theme for the current term was "iBod", which constrained the teachers to curriculum topics that could be related to the human body.

The Physical World strand of the NZC for level 3 states that students will: 
Explore, describe, and represent patterns and trends for everyday examples of physical phenomena, such as movement, forces, electricity and magnetism, light, sound, waves, and heat. For example, identify and describe the effect of forces (contact and non-contact) on the motion of objects; identify and describe everyday examples of sources of energy, forms of energy, and energy transformations. (MOE, 2007c, p. 18)

The broad scope of the NZC allows teachers a wide latitude in choosing specific curriculum topics that are relevant to the school and community (MOE, 2007a). As mentioned previously, the teachers in iteration-one did not indicate a preference regarding the science topic area, and the decision to choose the topic of sound, while made by the teachers, was my suggestion. I suggested sound because I could see an easy link to the "iBod" theme, and I was aware of a number of simple demonstrations and investigations that used easily available materials. At the time, the topic selection process did not seem significant; however, in hindsight, it was my knowledge of the topics in physical science, and the related PCK that enabled me to consider various topics in the NZC and select one that fitted the situation. The teachers at School-one, who did not have strong physical science knowledge did not see connections between the NZC topics and the "iBod" theme. Jack commented that he had initially agreed to participate in the PLD because he thought the term "physical science" was a biological science that was related to physical activity, such as sports. Without an understanding of the science topics, and the associated PCK, the teachers were unable to make relevant topic choices.

Likewise, when I asked the teachers what they would like to cover within the topic of sound they replied that they had no idea. They said they had never studied sound, and, aside from knowing some terms related to sound (see the concept map (Figure 17) constructed during the first sound PLD session) had limited knowledge of the topic. The situation was summed up in a statement from Tom:

You may have gone through the whole of secondary school doing virtually no science, then gone on to university and done no science, and then you end up being the teacher, and having to teach science, you know what I mean? We've 
all done maths, because you have to do maths. We've all done literacy, and reading and writing, but science is one of those subjects that you could have actually, not only avoided on purpose, but just it hasn't cropped up for you.

As Jack said, "You don't know what you don't know", a message reiterated by all three teachers. The lack of content knowledge about a topic such as sound, and how it could relate to the school theme "iBod" makes it very unlikely they would have considered it as an appropriate topic for their students. The existence of good quality curriculum support materials such as the Building Science Content (BSC) series (e.g., MOE, 2002) which provide information about relevant foundational concepts and related activities, could help the teachers understand and teach a unit on sound; however, these are not helpful if the teachers lack the content knowledge to even consider teaching the topic. The teachers indicated they had not used, and in fact were not aware of the BSC materials.

Given the difficulties the teachers in iteration-one had in linking potential physical science topics to the school theme, an additional piece of implementation advice was added to the Alignment with local and national curriculum focus area. The PLD should include a discussion of the school theme (if applicable), designed to help the teachers to recognise the linkages between the school theme and potential science topics (see Figure 15). 


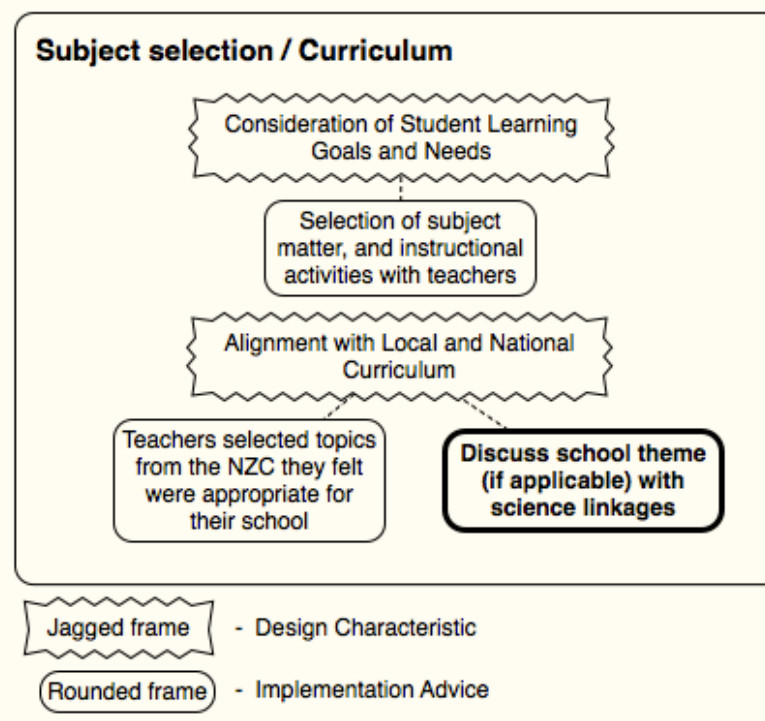

Figure 15: Subject selection / curriculum - iteration-one

\subsubsection{Subject matter understanding}

The review of the literature led to the inclusion of the single design characteristic

"Teacher subject matter and pedagogical knowledge" and the implementation advice "Working through science investigations with teachers in the role of students" in the initial Subject Matter area of the PLD framework. 


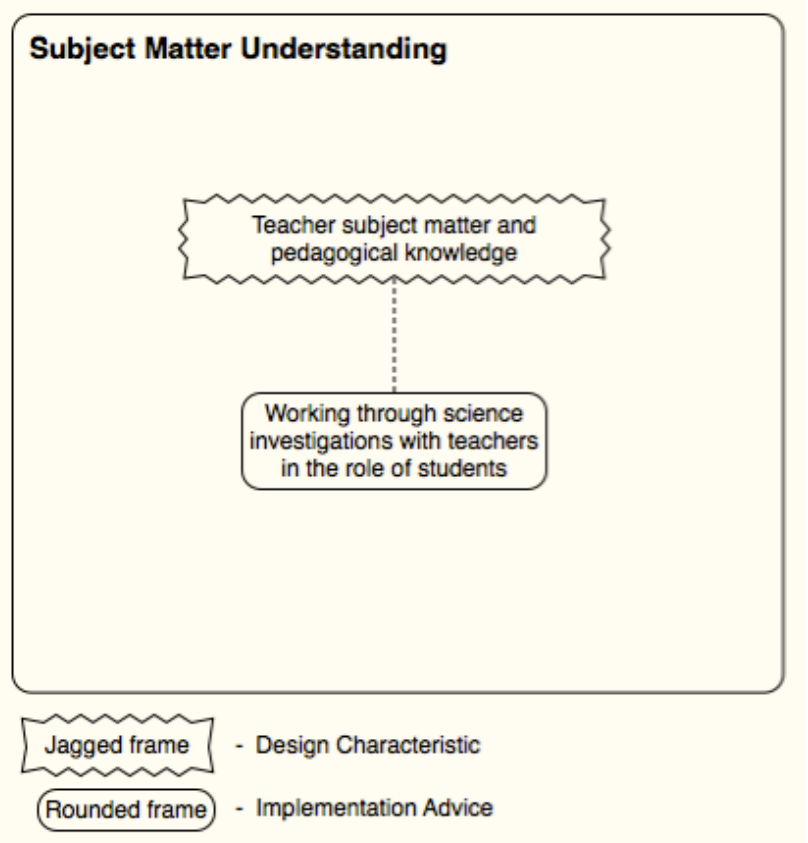

Figure 16: Subject matter understanding

The literature indicates a number of potential reasons New Zealand teachers avoid teaching science. Teachers have limited knowledge of science, particularly physical science, and frequently lack the confidence to teach something they do not understand (Appleton, 2002; Bull et al., 2010; Chamberlain \& Caygill, 2013; McGee et al., 2003). The teachers in iterationone are much like other primary school teachers in New Zealand in that they are generalists, lack specialised training in science, and expressed doubts about their ability to teach science well. They stated clearly that lack of SMK in science was the reason little science is taught in their classrooms, and speculated that other teachers in the school were similar. During the first PLD session Jack said: "I just think the barrier [to teaching science] to teachers is probably the knowledge" and Bree agreed: "the knowledge - I think there is a great lack of [science] knowledge in teachers." As already reported, Tom summed up the situation faced by many primary teachers in New Zealand:

My degree is a history degree. We all did different stuff. ... So you may have gone through the whole of secondary school doing virtually no science, then gone on to university and done no science, and then you end up being the 
teacher, and having to teach science, you know what I mean? We've all done maths, because you have to do maths. We've all done literacy, and reading and writing, but science is one of those subjects that you could have actually, not avoided on purpose, but just it hasn't cropped up for you.

They saw SMK as a vital missing ingredient in their ability to teach science. The teachers in iteration-one suggested that, when faced with teaching a topic they do not understand, teachers respond in two ways. As Bree said:

The hardest part may be breaking down the teacher barrier of they can't be bothered. I don't have the knowledge, so I'll either bluff my way through it, or I'll do it really - just skim the surface of stuff, then you'll get another group of teachers that say, I don't know anything about sound, so I'm going to go investigate and find things.

Bree and Tom estimated a majority of $70 \%-80 \%$ would "put it in the too hard basket." In conversations with the teachers in iteration-one, their limited science SMK, and the difficulties this creates in choosing topics were mentioned frequently. They expressed frustration with teachers who conducted science demonstrations and activities but did not engage the students in the underlying science that was being observed. Jack summed up the feelings of teachers in iteration-one: "... the follow-up discussion after the experiment, like 'what's actually happened?' It's all well and good doing the frills and whistles, but what's actually happened?" For the three teachers in iteration-one, teaching involved developing understanding in their students, not merely doing activities with them. It was important for them to be in the position of being able to facilitate a productive discussion to explore, in Bree's words: "the science behind the activity." However, this did not mean that they felt they had to be experts in an area in order to teach it. Tom explained:

... but I'm one of those people who don't mind saying to the kids, actually, I don't know. I'll try and find out for you, or let's find out together, but there are some teachers that would never admit that they don't know. .... lot of teachers don't like to admit that they don't know, because for some reason you're meant to know, and that's ridiculous. 
These comments from the teachers caused me to question how much SMK a teacher needs in order to teach a topic. It is hardly a new question, as evidenced by Dewey's (1902) discussion of the unique subject matter challenges faced by science teachers:

As a teacher he is not concerned with adding new facts to the science he teaches; in propounding new hypotheses or in verifying them. He is concerned with the subject-matter of the science as representing a given stage and phase of the development of experience. His problem is that of inducing a vital and personal experiencing. Hence, what concerns him, as teacher, is the ways in which that subject may become a part of experience; what there is in the child's present that is usable with reference to it; how such elements are to be used; how his own knowledge of the subject-matter may assist in interpreting the child's needs and doings, and determine the medium in which the child should be placed in order that his growth may be properly directed. (p. 30)

I chose to cover the background content that addressed the basic questions the teachers asked during investigations and discussions. My intention was to provide sufficient understanding for them to feel confident enough to teach the topic, trusting that the experience of teaching would deepen and fill out their knowledge. The concept of deep learning occurring through teaching is illustrated by the opening quote in Wilson, Shulman, and Richert's (1987) paper on teacher knowledge:

...When you learn it to teach, you have to be able to handle ... 150 different approaches to it because you have to be able to handle every different student's approach ... They're going to ask you questions from different areas and you're going to have to be able to approach it from their mind-set. (p. 104)

In our investigations, I urged the teachers to ask questions, and in our discussions I probed their understanding by asking them the kinds of questions I thought students might ask with the intention of broadening their understanding, increasing their confidence, and deepening their PCK.

\subsubsection{Teacher subject matter and pedagogical knowledge}

The Teacher subject matter and pedagogical knowledge design characteristic in the PLD framework is linked to a single piece of implementation advice: 
working through science investigations with teachers in the role of students. The experience at School-one suggested additional implementation advice was required, specifically: include basic data gathering and manipulation, provide practical everyday examples of science and relate science to the school theme, and discuss foundational concepts with examples.

\section{Teachers in the role of students}

I chose to present the material with teachers actively engaging in investigations because it aligns with the constructivist theory of learning. Constructivist learning assumes that students have existing ideas about how things work which are based on previous experience, and changing, or extending those ideas occurs in response to some type of stimulus such as an experimental observation or discussion (Hodson \& Hodson, 1998; Tytler, 2012). Science investigations offer an opportunity to challenge conceptions or misconceptions held by students, and help to create cognitive conflict, creating opportunities for conceptual change and improved understanding (Driver \& Oldham, 1986). For example, in the pendulum experiment, a common misconception is that, for a given length, the further a pendulum swings, the longer it takes to make one full swing. ${ }^{3}$ Working through an investigation, the student is confronted with an experimental result that is in conflict with their mental model. Teachers, without having received expert training in physics, are likely to hold similar naive ideas and misconceptions to their students (Baviskar et al., 2009). A twofold benefit is achieved by teachers working through the investigations in the role of students: their own misconceptions are challenged; and they have the opportunity to practise the investigation and experience the practical aspects of the equipment. Given the dual role, the implementation advice "Working

${ }^{3}$ As in many physics topics, the actual situation is complex, and the period has a slight dependence on the amplitude of the swing (For a full analysis see Baker \& Blackburn, 2005). 
through science investigations with teachers in the role of students" is therefore found in the Practise area as well as the Teaching practice area.

Teachers set up the investigations, collected data, and participated in discussions about the investigations. They were also able to ask questions as they arose naturally. During the initial PLD, which began with the pendulum investigation described earlier (see section 4.1.2), I was able to observe the teachers' knowledge and skill in conducting an investigation. Working through the investigations gave teachers experience in conducting investigations, and also revealed gaps in their understanding which could be subsequently addressed in the PLD.

One such gap occurred during the pendulum investigation. The teachers correctly determined that the only variable that significantly affected the pendulum period was the length, and that other variables such as mass and arc length of swing had almost no effect. The question of why Big Ben is adjusted by adding or removing pennies proved quite difficult. The teachers had ruled out mass as a significant contributor to the period of a pendulum; therefore, adding or subtracting pennies did not make sense to them. The fact that adding a penny to the top of the pendulum effectively shortens the pendulum by moving the centre of mass of the fob did not occur to the teachers because they had not previously encountered the concept of "centre of mass".

The knowledge gap identified in the pendulum investigation highlighted a gap in the PLD framework. The importance of addressing subject matter was clear from the literature; however, the importance of some form of diagnostic assessment as a starting place for designing the subject matter content was not emphasised. The constructivist teaching model dictates the need to examine pre-existing student knowledge; therefore, a constructivist approach to teaching the teachers requires a diagnostic component. I elected to not conduct a formal SMK assessment for the reasons discussed in section 3.5. I therefore added 
"Informal subject matter knowledge assessment" as additional implementation advice.

Once the topic of sound was selected I used a concept map (McConnell, Parker, \& Eberhardt, 2013; Novak \& Cañas, 2008) to establish what the teachers already understood about sound, and to help identify gaps in their understanding. With some leading, the teachers produced a concept map (Figure 17) depicting their knowledge of sound. The map included the terms pitch, loudness, ear-drum, ear bones, nerves and brain, and they knew sound had something to do with waves and vibration. Although they were able to make a list of terms that related to the concept of sound, they were unable to describe how the terms related to one another, and the only connection they identified was a link between the cochlea and nerves. This demonstrated the teachers had limited understanding of what sound was, and how it works, because the recognition of the connections between concepts is at the heart of understanding. John Dewey (1933) wrote about the importance of connections:

...all knowing, including all scientific inquiry, aims at clothing things and events with meaning-at understanding them-it always proceeds by taking the thing inquired into out of its isolation." (p. 136)

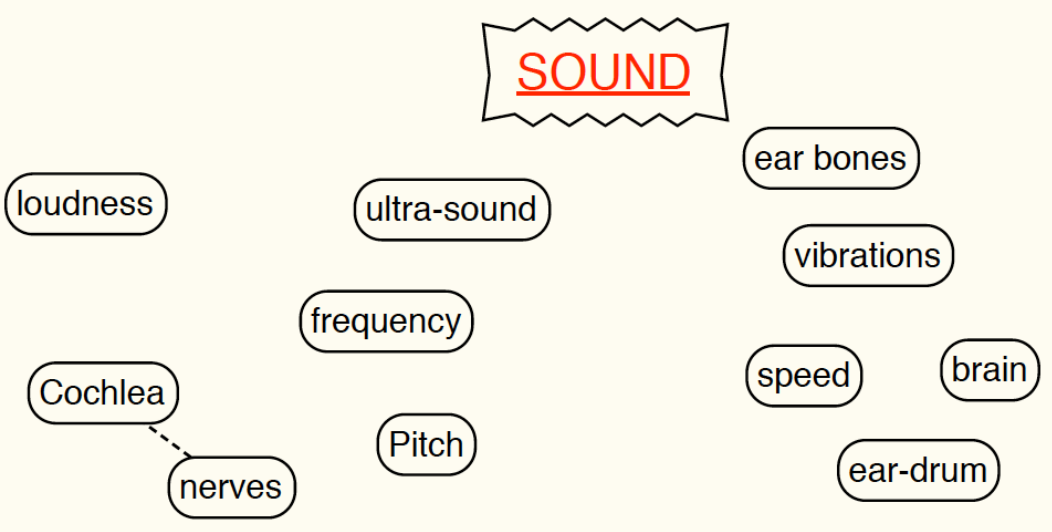

Figure 17: Initial sound concept map 
The teachers expressed appreciation for investigations that were simple, and worked. Their views echoed the findings of Appleton (2002) which examined the characteristics of successful science activities identified by a sample of Australian primary school teachers. When Jack asked about the speed of sound during an early PLD session and we immediately went outside and did a crude measurement, the teachers were very impressed that we could step off a distance, and use the stopwatch on a phone to measure the time it took for a clap to travel to a distant building and back and calculate an answer that was within a few percent of the speed of sound they could find on the internet.

They also appreciated having the experience of doing the investigations themselves:

Tom: I would have never have chosen to teach sound, it would never have been something that would have appealed to me. It does now. And I reckon I'm going to use it, as soon as possible. Just a stand-alone thing regardless of whatever else we were doing. It would be cool, but it was never something that would have jumped out as interesting.

Jack: ... Yes, I would have been exactly the same as you. It would be like, how the hell would I do it?

The teachers' comments reinforce the importance of structuring the PLD so the teachers actually assume the role of students and work through a variety of investigations and demonstrations with the easy-to-obtain equipment. Working through science investigations with teachers in the student role gave them the opportunity to observe the teaching of the lesson, while simultaneously learning or reinforcing SMK. When they understood the phenomena, they were able to suggest alternative equipment and additional activities.

\section{Include basic data gathering and manipulation}

While observing the pendulum investigation I noticed that the teachers did not think of methods to increase the accuracy of the timing of the swing such as timing multiple swings or averaging data across multiple single swings. They also did not collect their data in an organised way, and were not sure if they 
could reject obvious outlying data points. As noted by Osborne (2014), "Data do not wear their meaning on their sleeves" (2014, p. 186), and data collection, manipulation and interpretation are important skills in science. The observation of teachers in iteration-one indicated that if the topic of the PLD includes activities involving data collection and use, practice in those skills would need to be included in the PLD.

\section{Provide practical everyday examples of science and relate science to the school theme}

As discussed previously, the teachers at School-one are expected to structure the curriculum around a school-wide theme. The theme for the term was "iBod", which is an emphasis on the human body, and discretionary class time was to be used to further the theme. This presented a challenge to teachers who do not have a background in science, and therefore do not readily see connections between science concepts and every day life. It is important for the PLD to emphasise how the abstract science concepts relate to, and help us to understand things encountered in everyday life. Once we began to relate the loudness of sound to energy, and discussed the structure and function of the ear, the connections became clear to the teachers. Relating physical science concepts such as light or force to a year-long school theme such as sustainability requires significant content knowledge and a bit of creativity.

\section{Discuss foundational concepts with examples}

The teachers in iteration-one understood that sound was a vibration, but they did not know how that vibration could get from one point to another. They needed to understand the fundamental concept of how waves transfer energy from one point to another via a medium. We used a large spring to visualise how a vibration could travel along a medium from one point to another as compression waves, as well as transverse waves. Waves are a fundamental concept that are useful in understanding not only sound, but also other physical phenomena such as light and heat. Some areas of science can be taught as 
discrete independent units; however, an understanding of many concepts in the physical sciences rely on a foundation of general science knowledge. For example, it is difficult to describe how sound can travel in solids, liquids and gasses, but not in a vacuum, without some understanding of the structure of matter, as well as some basic wave theory. A lack of this general science knowledge makes identifying both key concepts and linkages difficult or impossible without guidance. This highlights a flow-on effect of the lack of science knowledge, namely, if a teacher has not been introduced to a topic, and does not have an understanding of the underlying concepts, it is difficult to judge what constitutes appropriate introductory material, and it is challenging to evaluate the quality of curriculum resources.

The material presented to teachers during the PLD was an overview of many aspects of sound such as frequency, pitch, speed, effect of different sound conducting media, and an overview of the physical structures involved in hearing. The unit did not lay a solid foundation of waves, and only briefly touched on how sound could be viewed from an energy standpoint. At the wrap-up session Bree described teaching the sound unit:

Bree: And there were questions asked too that I didn't know the answers to [supporting Yeahs from others] and I know that it has kind of changed, in that as a teacher you aren't expected to know everything, but, I still didn't feel that I knew enough to be able to answer many of the questions.

Tom: ... so I know when I was doing my little session I started talking about frequency and pitch and I was very aware that actually I don't know what I'm talking about here. I have a little bit of knowledge, but not a lot of knowledge, but that was all right, because the kids didn't know, and that's fine, but if you are trying to teach them something you still want to teach them correctly.

The discussion following their teaching of the sound unit indicated the teachers wished they had a greater depth of knowledge, and were not comfortable teaching with their current level of understanding. The PLD should therefore aim to provide enough depth and background of topics to lay a foundation. 


\subsubsection{Subject matter knowledge reinforcement}

The experience in iteration-one suggested an additional design characteristic: subject matter knowledge reinforcement should be added to the framework.

\section{Ensure prompt teaching of material to provide reinforcement and prevent information fade}

The teachers at School-one did not teach the science unit immediately upon finishing the PLD. For scheduling reasons, several weeks separated the conclusion of the PLD and teaching the unit. The teachers all mentioned that information "fade" had occurred, and the material that was very clear to them during the PLD, was not as clear when they finally taught the unit, and they found themselves on uncertain ground. It is important therefore to minimise the gap between the conclusion of the PLD and the first teaching of the unit. At the follow-up meeting Tom said:

I was saying to Jack, and I think we've talked about it as well with Bree, when we did our little sessions after school that was quite a long time ago. There was a big gap between then and when we did the lesson. And that it like a lot of PLD, and science PLD is quite a specialist area and you may do - go on a PLD course and you learn the different concepts in context, and that sort of stuff, but it might be 6 months or a year before you actually do that, and of course that kind of fades.

And then later during the same meeting:

Bree: I find the more you do it the better you explain it, and the better understanding you have of it.

Jack: [comparing primary to high school science teaching] ... if you do it 5 times in a day, we'd have it, but we do it once, and then shelve it for two years, or a year.

Bree: I think too the way they ... you know, their classes change so often, we get a new class every year but it's the same as you get one kid that doesn't get it and you try to explain it in a different way a couple of times and then you think, actually that way is a better way to explain it, so that's the way you will start it the next time you do it. It can change the way... 
These comments illustrate the importance of teaching the material learnt in the PLD in a timely way as a form of knowledge reinforcement.

The degree of subject matter emphasis requested by the teachers in iterationone called for several additional elements to be added to the subject matter understanding area (changes shown in bold). The Teacher subject matter and pedagogical knowledge focus is expanded to include the four additional implementation elements: informal SMK assessment, discussion of foundational concepts, provision of everyday examples of science, and opportunities for data gathering and manipulation. An additional content design characteristic: Subject matter knowledge reinforcement, was added, along with the associated implementation advice to "Ensure prompt teaching of material to provide reinforcement and prevent information fade", as depicted in Figure 18.

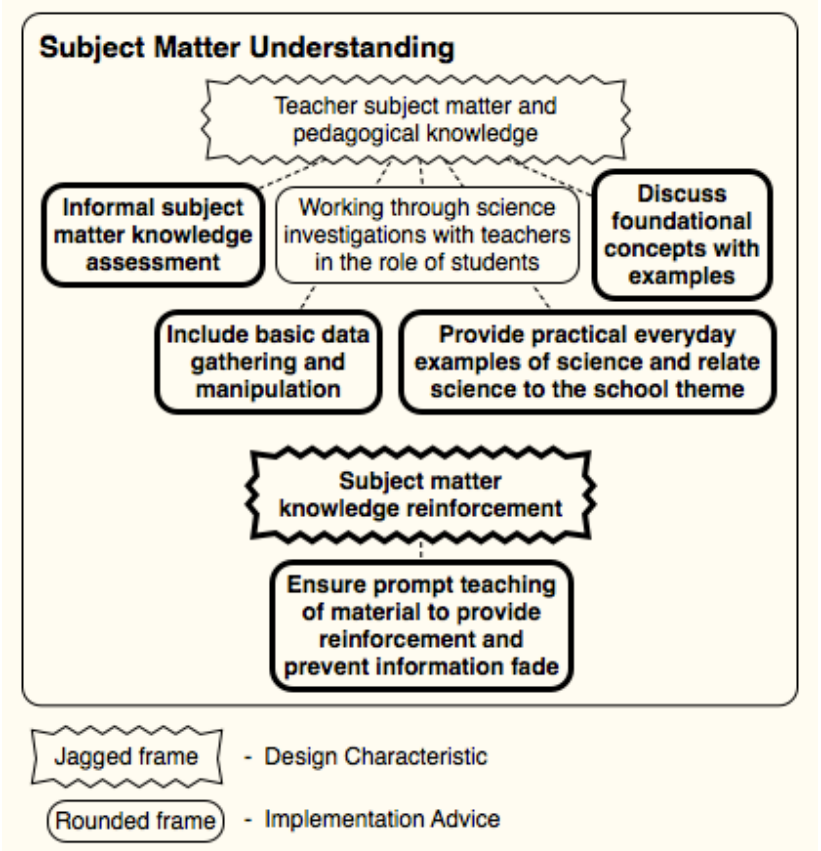

Figure 18: Subject Matter Understanding - iteration-one

\subsubsection{Teaching practice}

A review of the literature suggested two design characteristics which I have placed in the Teaching practice area of the PLD framework: Practical lesson 
development, taking into account the local classroom context; and Modelling and practising activities and teaching methods shown in Figure 19.

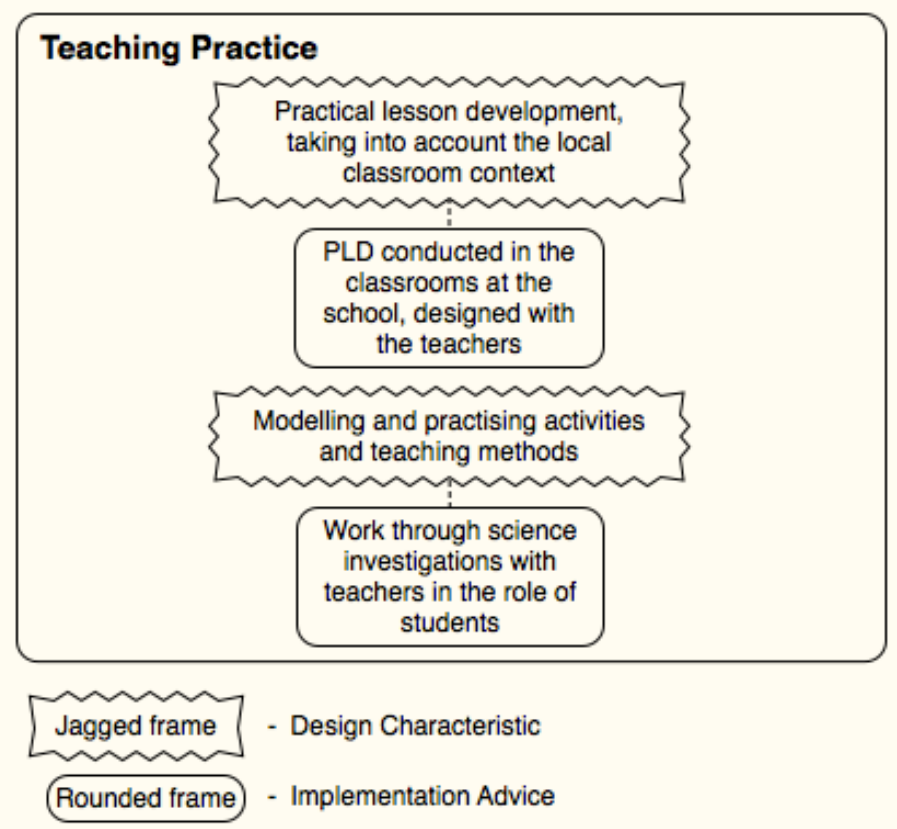

Figure 19: Teaching practice

4.2.3.1 Practical lesson development, taking into account the local classroom context

\section{PLD conducted in the classrooms at the school, designed with the teachers}

The decision to conduct the PLD in the classrooms of the teachers involved was made in an effort to provide teachers with a familiar environment, utilise local resources when modelling science investigations, and minimise inconvenience for the teachers. Utilising the environment of the school and locally available resources was affirmed by the teachers, as evidenced by Bree's comment:

What we need are activities that require very little equipment, like the one we did today, all of that stuff, I mean a couple of pegs is probably all we would have had to worry about, the rest we could have got within the classroom. That's a big part of it too, I mean equipment. 
Other investigations utilised the school desks as sound boards for amplifying tuning forks and stretched strings, and a distant building became the target for echoes when measuring the speed of sound. The teachers commented that they had begun to recognise the science in everyday objects, as reflected by a comment by Jack: "...the kids need to realise that, and we talked about this in the class today, that science is everywhere. You turn on a light, and that's science." There appears to be strong benefit in locating the PLD in the teachers' classrooms.

\subsubsection{Modelling and practising activities and teaching methods}

\section{Work through science investigations with teachers in the role of students}

Research on science PLD, a large portion of which is conducted in North America, indicates a substantial portion of the PLD would need to be devoted to convincing teachers of the benefits of hands-on science investigation (see, for example Capps et al., 2012a; Diaconu, Radigan, Suskavcevic, \& Nichol, 2012; Lotter, Yow, \& Peters, 2014; Shymansky, Hedges, \& Woodworth, 1990). During the initial design of the PLD therefore, I made an assumption that teachers would need to be informed of the value of teaching through science investigations. I assumed the teachers' introduction to science was likely to have been in classrooms that did not employ science investigations, but rather taught with traditional teacher-centred methods and that their orientation would be to teach science using a teacher-centred approach. This proved not to be the case.

The teachers in iteration-one needed no encouragement to use science investigations in their teaching, and equated hands-on student-centred approaches with good teaching. When we were discussing the pendulum experiment, Jack suggested why it would be a good experiment for his classroom: "I think that, experiments like that, they would love, absolutely love, because it is hands-on and it would be teaching them so much". The orientation of the teachers in iteration-one toward teaching science through science 
investigations is at odds with much of the PLD research conducted in North America, and may indicate a point of difference between teachers in New Zealand and North America. The iteration-one teachers were keen to teach via science investigations; they were simply not comfortable teaching something they did not understand.

They also identified other barriers to teaching science: school scheduling, time pressure, and pressure from other higher priority curriculum topics. These factors are supported in the literature (Appleton, 2002; Bull et al., 2010) however they are generally issues beyond the teachers' direct control, and therefore which will not be directly addressed by this PLD.

The iteration-one teachers expressed some hesitation about investigations in which the students were not given complete instructions, e.g., "Find out what factors influence the period of a pendulum." Jack and Bree, reflecting on the pendulum experiment:

Jack: Yeah, I mean you could do the Big Ben one, you just would have to tell them what they were looking for ... I think you gave us enough clues for us to take the bait if you know what I mean, and to start to put things together for ourselves. There was enough scaffolding there for us to start to think about what you were trying to do and what we were supposed to be looking for.

Bree: And when we got stuck you gave us some hints as well, when we weren't on the right track.

Ted: How did that feel?

Jack: It was good. A) it moved things along rather than dragging it out, and B) it gave us another bit of information for us to carry on looking.

Bree: I think if you did that with the kids you would definitely need a lot more. I know you were doing that with us, but if you were to do that with kids, they would be... there would have to be a whole lot more. Because half of them would be [unsure] if you gave them the stuff and said, right this is what you are doing some of them would be like, what's a pendulum? They would need more [instructions].

These comments reinforce the need to provide opportunities for the teachers to experience the investigations themselves, and also perhaps show the value of modelling scaffolding in science investigations. The hesitancy the teachers 
were expressing regarding the non-prescriptive investigations may indicate an insecurity about their understanding of the underlying science, given that such investigations frequently generate questions which can be uncomfortable for teachers with limited SMK (Abell, 2007; Anderson, 1980). The experience of teachers in iteration-one affirms the implementation advice to "Work through science investigations with teachers in the role of students".

\section{Teachers understood advantages of teaching through investigation}

Jack frequently talked about himself as not very scientifically literate:

Jack: I wanted to mention it to you. I think the three of us could sit down and bang out a few good lessons now, that would be hands on and practical and the kids would be able to pick it up because... If I can..., well the kids sure could. ... And I think the kids would be very interested in how fast sound travels.

Bree - And measuring it themselves - So often now they'll just go, oh let's just go find out, and they'll sit in front of their computer to find it. I was quite surprised that we were able to measure the speed of sound. It was cool.

The teachers at School-one spoke in very positive terms of a science lesson they had developed on the heart. A high school biology teacher friend came in and helped them develop a set of lessons on the heart and lungs. Using sheep hearts and lungs provided by a local butcher the teachers first observed lessons taught by the high school teacher, and then taught their own lessons. They have continued to teach this unit every year, and have passed on their knowledge to other teachers in the school.

The teachers description of this one topic is very similar to the experience described by Appleton (2008) in which he worked with early primary teachers to develop science lessons through mentoring. Teachers in Appleton's study lacked science content knowledge, and therefore confidence. Appleton found that one-to-one in-class mentoring of primary teachers led to lasting improvement in science teaching practice. It may not be surprising that such intensive mentoring would be effective; however, that type of intervention is 
unlikely to be practical on a system-wide, or even school wide scale. It is therefore useful to investigate if the elements that made the mentoring so effective, so they can be used in more traditional PLD experiences.

Jack, who arranged for the teacher to come in to coach the heart unit, felt strongly that teaching new material with someone who is experienced would be very helpful:

I think team teaching, you know, if you had someone who really knew it, who could come in and did it with you it would be beneficial too. You know?

I was struck by how difficult it would be to conduct an activity like dissecting a heart without having any training or experience. I was impressed with Jack's initiative in getting this organised, particularly since he had never done it before either.

The description of this initiative caused me to consider the level of self-reliance that exists in the teachers in iteration-one. I was amazed by the idea that someone was going to come around with a big bag containing 17 bloody hearts, and that, on that day the teachers were going to conduct their first dissection, with the only preparation being the knowledge that they were expected to use the hearts to conduct a classroom activity. The teachers were expected to prepare themselves as best they could, via whatever material they could find. Yet the activity was deemed a success, and the school was going to do it again in a few weeks.

The Modelling and practising activities and teaching methods design characteristic does not need to include material to emphasise the advantages of teaching science through science investigations. The Teaching practice area was therefore modified to reflect this finding, adding the advice to simply "affirm the efficacy of teaching with science investigations" (see Figure 20). 


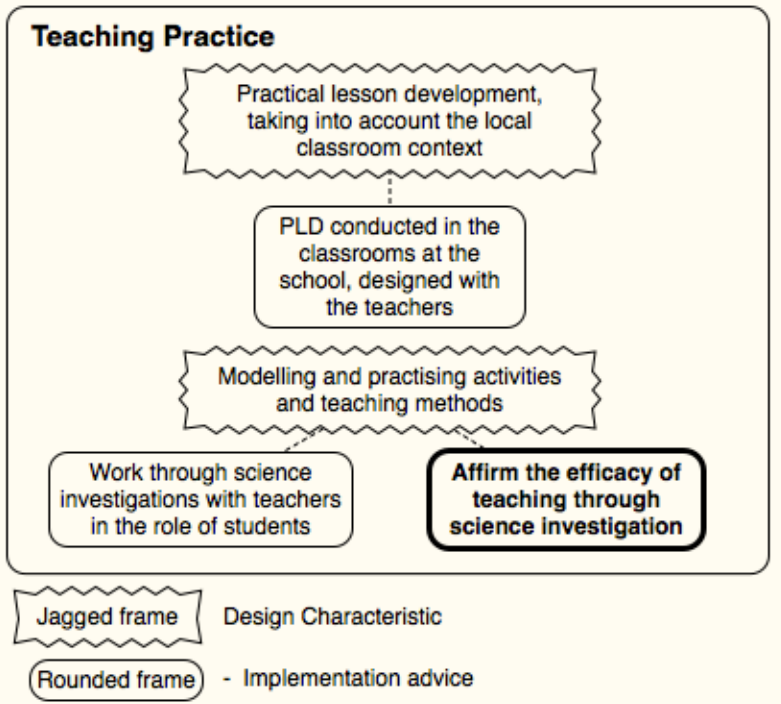

Figure 20: Teaching practice - iteration-one

\subsubsection{Support}

The literature review indicated that many effective science PLD programmes contained a mechanism for developing a supportive community of practice, as well as providing for on-going support for the participants. The initial support framework area is shown in Figure 21. 


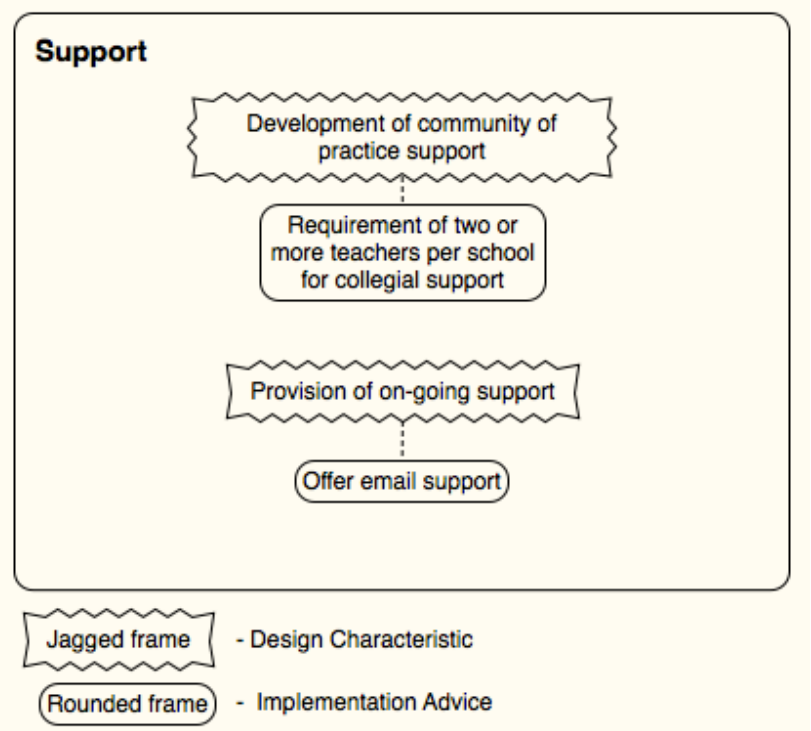

Figure 21: Support

\section{Requirement of two or more teachers per school for collegial support}

The teachers in iteration-one have worked together as a team for several years, and during that time they took the initiative to invite people with expertise and experience into their school to build up their SMK, and expand their science teaching. In addition to the heart investigation described in the previous section, the teachers described a similar investigation of chicken legs. Jack read up on an investigation of muscles and tendons in a chicken leg, and shared the idea with the other teachers on the team. Jack asked a local high school biology teacher to come in and help them practice the investigation as a group. Tom visited a neighbourhood butcher, and delivered classroom sets of chicken legs to the other teachers. The investigations of the heart and chicken leg were so successful they shared them with the other teachers in the school, and they have become school-wide activities.

Additionally, during the fourth PLD session Jack commented that:

I wanted to mention it to you. I think the three of us could sit down and bang out a few good lessons now, that would be hands on and practical and the kids would be able to pick it up because... If I can..., well the kids sure could. 
Jack is describing planning a science unit together as a group, based on the experience gained in the PLD.

It is possible that an individual teacher, without the support of colleagues would benefit from a PLD, however, the advantages demonstrated by the teachers of iteration-one of working together as a team, supports the implementation advice requiring multiple participants.

\subsubsection{Community of practice}

\section{Requirement of two or more teachers per school for collegial support}

The teachers in iteration-one worked together to plan the sound unit, and shared equipment such as paper-cup telephones and long springs, timing the unit so they could share one set of equipment. Given the relatively low priority of science in the school curriculum, the teachers simply did not have the time to spend on assembling and setting up complex equipment, and greatly valued shared and easy to source equipment.

When Bree was discussing the unit on dissection of the heart, she reinforced the importance of sharing equipment and supplies:

We do dissections later on in the term, and everyone and their kids love it, absolutely love it, but it takes [preparation] Tom will go and get all of the hearts and chicken legs and stuff and hand deliver them to the classes, and that's OK, and they [teachers] will do it if it's like "here you go". If they had to get it themselves, they will put it in the too hard basket and say "oh- can't be bothered".

The experience with collaboration and equipment sharing at School-one reinforced the importance of a community of practice, supporting the requirement for two or more participants from each school. 


\subsubsection{Provision of on-going support}

\section{Offer email support}

I extended an offer to the teachers in iteration-one that should they have any questions or desire any assistance with planning or teaching that I would be happy to help via email. The offer was accepted with voiced appreciation; however, the teachers did not contact me for assistance during or following iteration-one. I made the decision to not remove the offer of an email help line based solely on the basis of nil use during an iteration, and the advice will remain, to be evaluated later in the iterations.

\section{Provide sources of review material and Internet resource list}

An area identified by the iteration-one teachers that was not prominent in the literature was their desire for cogent science review material. This came as a surprise, given the amount of support material provided by the MOE and the rich resources freely available on the web. However, for whatever reason, the teachers in iteration-one were not aware of the MOE resources mentioned previously (e.g., MOE, 2002), and talked about starting with Google and YouTube searches to get information if asked to teach a new area. The teachers felt it was important to be able to quickly find quality resources that provided the basics of a topic presented in a simple way. I asked the teachers how they would approach a new topic such as light:

Tom: l'd go to google.

Jack: Yeah, l'd find out exactly what light is, and start from there, you know, the definition of light.

Bree: It would have to be about how to make it interesting for the kids, because if you said, right, we're going to study light, l'll bet half of them would...

Jack: We're not scientists, and we haven't focused on those things ... Like, if I have to teach light, sweet, there it is boom boom boom, I know what I'm doing and it's all here and I can get up there and do it because an expert has given me a list of things to teach them what light is, this is what I need to do. 
A Google query for "middle-school science sound" returns over 52 million hits, and YouTube returns just under 1.3 million videos on the topic. If one is not acquainted with the science of sound, sorting through material and making decisions about which demonstrations and investigations are likely to work, and would clearly support the development of a concept, would be difficult and time consuming. Therefore, providing a list of sources of review material and internet resources was added to the framework.

The support area of the design framework was modified to include the review material in the implementation advice, as indicated in Figure 22 below.

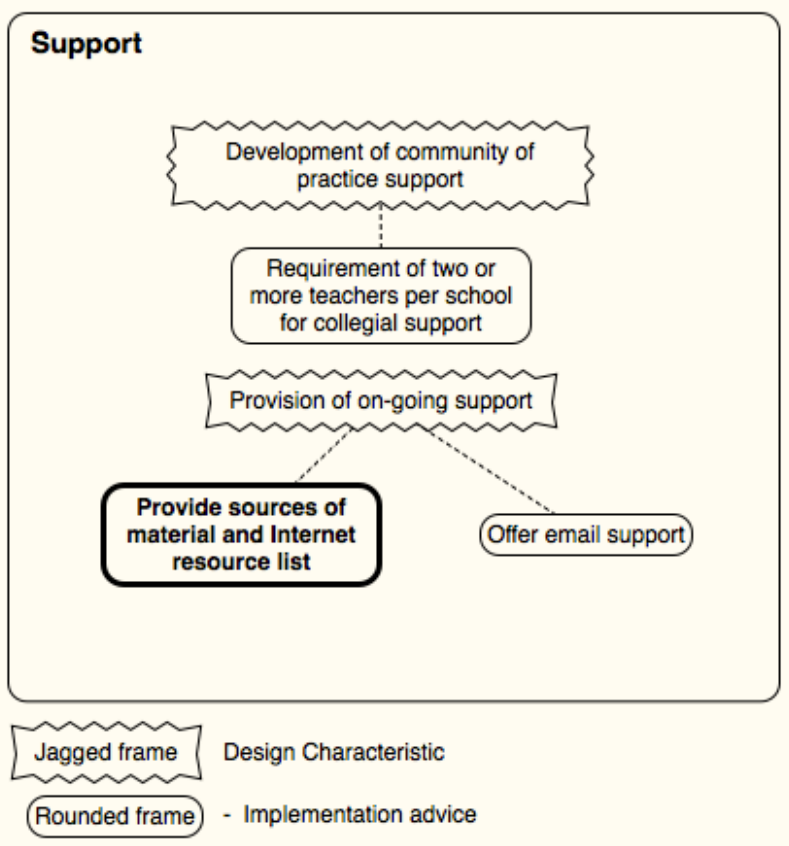

Figure 22: Support - iteration-one

\subsubsection{Logistical considerations}

The review of the literature on effective PLD programmes emphasised the importance of working with the teachers to agree the length, duration, and location of the PLD. These structural aspects are collected in the Logistical considerations content area of the framework, shown in Figure 23. As a result of the experience in iteration-one, an additional piece of implementation advice 
involving prompt teaching of the PLD material, as well as an additional design characteristic detailing the nature of the introductory session were indicated, as discussed below.

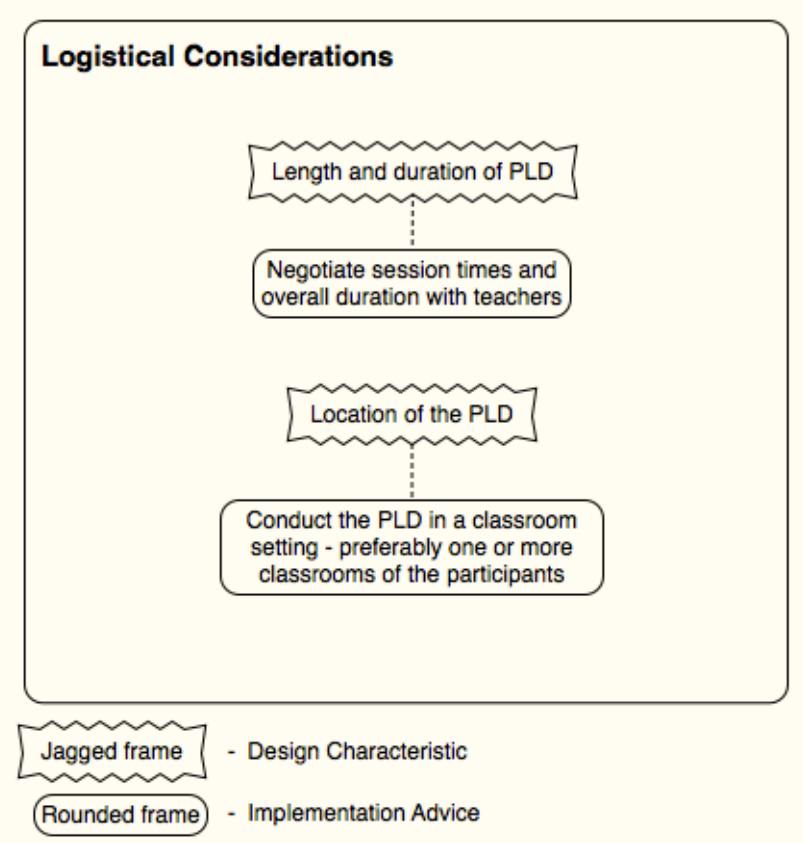

Figure 23: Logistical considerations

4.2.5.1 Length and duration of PLD

Negotiate session times and overall duration with teachers

A PLD that addresses science SMK must balance the amount of material that is covered with the time invested in the PLD. The teachers and I agreed that we would meet for five sessions of approximately 1.5 hours plus one wrap-up session after teaching the unit. This time included the PLD, and some extra time for discussion pursuant to the research. The teachers decided that 1.5 hours was as long as was reasonable for an after-school meeting, and the teachers and I agreed that five sessions provided enough time to cover the topics in the science of sound to give them a basic grounding. More time would have allowed us to cover other aspects of sound, but it would have been difficult to establish the basics in much less time while giving the teachers experience with the science investigations. Agreeing the basic timing of the PLD 
accommodated their schedule, and they attended all sessions, except in the case of illness.

\section{Ensure prompt teaching of material}

The implementation advice discussed in Section 4.2.2.2, is also a matter of scheduling, which is a logistical consideration. The advice to "ensure prompt teaching of PLD material" is therefore added to the length and duration of PLD design characteristic.

\subsubsection{Location of PLD}

The decision to locate the PLD in the school and conduct the investigations in the classrooms was supported during iteration-one. School-one did not have any dedicated laboratory space for science, and during the initial meeting with the teachers they told me the school had very little science equipment. Therefore, the science investigations in the PLD were designed to use very simple easy-to-obtain equipment and be carried out in the classroom. This was an important consideration for the teachers in iteration-one. Jack, when speaking of the pendulum investigation, said:

...whereas really it is what you just showed us, you don't. You need a ruler from the classroom, a bit of string and a couple of washers and a peg. It wouldn't even have to be washers, you could probably find something to use for a weight in the classroom

\subsubsection{Introductory session}

Beginning the PLD with an investigation was an attempt to create a positive first impression by creating a learner centred environment, and an active tone. Feedback from the teachers was positive, and the experience provided a focus for subsequent discussions of science teaching. However, an investigation of a pendulum did not contribute to their understanding of the content area (sound) ultimately chosen for the PLD. The investigation provided a point of reference for pedagogy, but not for content, and therefore, given the time limitations of the 
PLD, was not an ideal choice. Choosing a science area prior to the first topicfocused PLD and designing an initial activity related to the agreed topic area would be a pragmatic way of using time to the best advantage, and maintaining the focus on the agreed content.

The resulting Logistical considerations area with the additional design characteristic, and added implementation advice described above are shown in Figure 24.

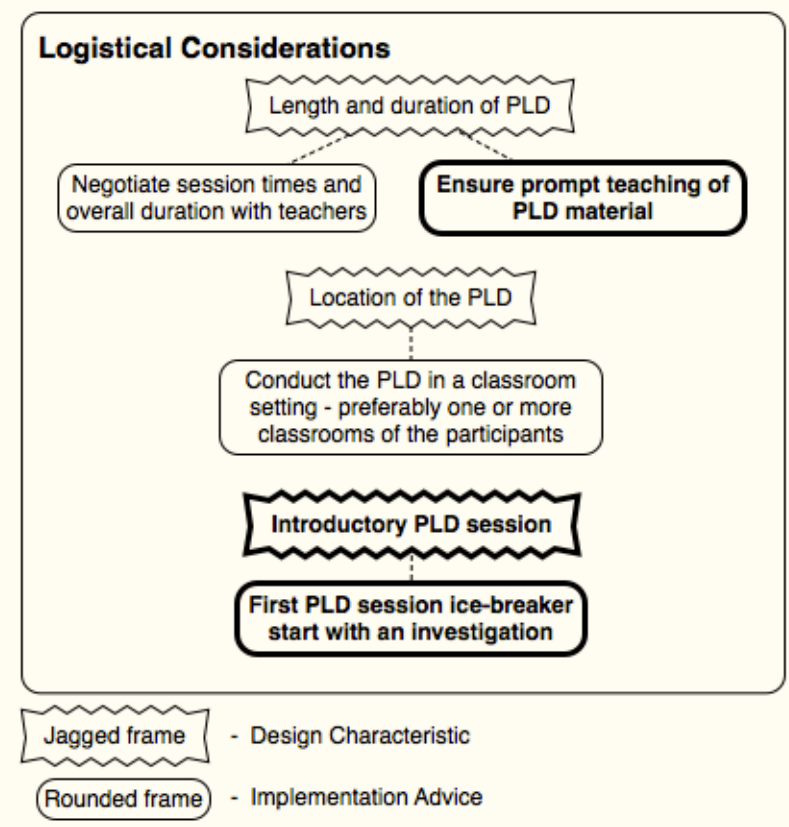

Figure 24: Logistical considerations - iteration-one

\subsubsection{Classroom observation}

The reason to include classroom observation in this research was two-fold: as discussed in Section 2.3.2, effective PLD programmes ensure teachers put new knowledge to use by transforming the subject matter learned in the PLD into teaching; the second reason was to provide a basis for subsequent evaluation and reflection in a wrap-up discussion.

I arranged a time during their teaching of the sound unit to observe one lesson (lasting approximately one hour) with each teacher, and made field notes during 
the class. The plan was to make the observations all on the same day; however, Jack was ill during the scheduled day, so I arranged to observe his classroom at a later date.

Bree was into her third class period on the sound unit and started with a review of what the students knew about sound so far. She asked the class about the concepts of pitch and volume, and they equated pitch with frequency, and volume with amplitude of sound waves. She then asked for volunteers to draw sound waves on the board and students produced three different representations (transverse, compression, and a drawing of an oscilloscope screen). She moved on to the investigation of paper cup telephones. She had the cups and strings already made, and introduced the unit by asking if the students knew what the paper cups and strings were used for. She asked them to get into small groups and go outside, and see if they really worked, and to investigate what factors influenced how well they worked. The students then went out, and worked with the cups and strings. Some students chose to vary the tension in the string to see how that affected the sound, another group took two sets and tied them together in the middle to investigate if multiple phones could hear the one voice. Other groups investigated whether the sound would be stopped by touching the string in the middle, or closing it in a door. After about 30 minutes she brought the students back into the classroom for a discussion of what they tried and what they found. The students were enthusiastic about sharing what their group found. After the discussion, she talked about the similarity between the cup and string and the human ear.

Tom began his unit on sound with a short video about the human ear. During my observation, he conducted a classroom activity with the students working in small groups to list everything they knew about sound for a few minutes. The groups then contributed their results to construct a concept map of what they knew about sound on the whiteboard. He then worked with the class to group the terms thematically. The groupings that emerged were biological, sound sources, and physical science. After grouping the terms Tom clapped his hands 
once, and asked the class what was happening - what made the sound they heard and how did it get from his hands to their brains? That question started a discussion of the various things involved in producing and transferring sound. He then moved to the question of how sound moves through the air, and if sound could move through solids or liquids. He demonstrated sound moving through solids by using a rubber cord and sending a pulse down the cord, and demonstrated sound in a gas by using a set of petanque balls, each separated by a distance, rolling one in from one end and watching disturbance propagate through the line of balls.

Jack was on his third class period in the sound unit. The class had watched a short seven-minute video on the physiology of the ear just prior to the observation. Jack did a brief review of what they had learned so far, which included how sound travelled through air, solids and liquids, the frequency of hearing, and echoes. Jack moved on to a demonstration of sound travelling through a string by suspending a metal oven rack by a piece of string, and holding the string to his ear while a student struck the rack with her hand. The class could not hear the sound, but Jack said he could. Jack then passed out several oven racks with string to the class, and asked them to form groups and give it a try. The students took a few minutes to get started with the activity, but gradually the entire class became enthusiastically involved. During the investigation, Jack moved around the room asking questions and suggesting that students try various things such as touching the string, and holding the oven rack. Under Jack's guidance, the students concluded that the sound travelled more efficiently through the solid string than through the air. The second investigation was a cup and string investigation, which used the same equipment Bree's class had used previously. When the students came back into the classroom, Jack conducted a brief discussion of the cup and string investigation. He then brought out a large spring (slinky) and demonstrated how compression waves travel down the spring, making the analogy to how sound waves travel in string. 
During my observations, the teachers in iteration-one conducted several of the investigations that were used during the PLD. I did not see evidence that the teachers looked for additional investigations to augment the sound topics beyond those introduced during the PLD. However, Jack and Bree extended the investigations involving sound travelling through a string to include aspects that we had not covered in the PLD, investigating how string tension, branching, and pinching the string would affect sound transfer.

In the discussion subsequent to my observations, all of the teachers described not feeling confident in their level of knowledge of the concepts they were teaching in the sound unit. As discussed in Section 4.2.2.1, they felt they did not have sufficient SMK to respond creatively to student questions generated by the investigations.

During the PLD, we discussed the concept of sound travelling in solids, liquids and gasses. The concept of sound waves travelling in solids was particularly interesting for the teachers, and we covered the propagation of longitudinal waves in solids in some detail. I had not noticed the possible linkage between the extension Jack and Bree introduced to the investigation of sound travelling in string, and the depth of coverage given to the topic during the PLD, until analysing the data; and was not able to question the teachers on whether or not they identified a connection. However, a connection appears likely given the well-established role of SMK (and related PCK) in the recognition of connections between science concepts and real-world examples (e.g., Davis, 2003; GessNewsome, 1999; Shulman, 1987). The teachers appeared to be the most confident teaching the areas covered in the greatest depth in the PLD. 


\subsubsection{Discussion}

This section is a brief discussion of the major findings for this first iteration. Major findings from all of the iterations will be discussed in a final summary discussion chapter.

In discussions with teachers at School-one it became clear that there are a number of factors that constrain them from teaching more science, such as the schedule of the school day which affords only two 50-minute periods per week shared between science and social studies, which cannot be addressed through PLD. In the discussion that follows I will address four constraints: SMK in general, the question of breadth versus depth, NZC, and a thematic approach to curriculum integration.

\subsubsection{Science knowledge}

During our first conversation, the teachers at School-one said that limited science content knowledge was the major barrier that hinders them from teaching more science. A PLD for the teachers at School-one must therefore address science content knowledge. This could be addressed in two ways, either by convincing the teachers that they can teach science without content knowledge and provide them with materials that they can use, or teach them the science that gives them sufficient understanding to select curricular resources themselves and that instils confidence to teach the material. Having been a teacher myself I have been in the position of teaching material I understood well, and I have also had experience teaching material I did not really understand. I made the decision to help the teachers understand the science. The challenge was how to design PLD that would give the teachers sufficient understanding in the science topic area.

It is reasonable to question how deeply a teacher must understand a science topic in order to teach it. The teachers at School-one were quite adamant on that point, as Jack said: 
For us it is OK, because we have had all of this [PLD]. But when you talk about barriers, teachers would be afraid of some of the questions they would get, because they wouldn't be able to answer them. You know.

Later Bree discussed how teachers approach a subject in which they lack knowledge. The teachers at School-one estimated that between $20 \%$ and $30 \%$ of teachers they had worked with would research and attempt to learn about an unfamiliar topic if they were required to teach it. It is clear from Bree's comment that she does not condone teaching a topic with insufficient knowledge: "... you will get those that are prepared to do the work to be able to teach it properly, and the others who will do a half ass job really."

As noted by Garet et al. (2001), it is difficult to provide science content meaningfully in a short time. The approach I chose was to take the teachers through a series of science investigations and demonstrations that would help them understand the science, and serve as potential classroom activities for their students. The teachers at School-one expressed appreciation for the experience of going through the science investigations themselves, As Tom said:

I don't know why, but now since we've been doing these activities, and I've thought about it I find it really interesting ... because l've really enjoyed doing these (Bree: Same) activities, and I think the kids would as well.

A weakness of this approach is that it takes at least as much time to conduct the investigations and subsequent discussions with teachers as it does a class of students; however, learning takes time. The teachers expressed appreciation for the opportunity they had to learn about the narrow area of sound, and planned to incorporate a sound unit in their teaching going forward, as they had incorporated the unit on the heart mentioned previously. The impetus for teaching about the heart was an opportunity to learn about the heart from an experienced teacher in an educational context, i.e., their classroom. A key element in both the heart unit and the sound unit was the teachers' exposure to specific SMK for teaching, as described by Shulman (1986a) and later by 
Hashweh (2005) and others. During the follow-up PLD I asked the teachers how they would approach a new topic, such as light. They indicated they would probably begin by googling light. We discussed the value of having a resource of classroom tested investigations and a suggested order of light related topics.

\subsubsection{The New Zealand curriculum}

The NZC is very broad in the specification of content to be covered. As previously stated, the Physical World strand states that students will:

Explore, describe, and represent patterns and trends for everyday examples of physical phenomena, such as movement, forces, electricity and magnetism, light, sound, waves, and heat. For example, identify and describe the effect of forces (contact and non-contact) on the motion of objects; identify and describe everyday examples of sources of energy, forms of energy, and energy transformations. (MOE, 2007c, p. 18)

It is not expected that all of the topics in any of the strands would be covered for a given level of students, and the breadth in the NZC allows a great deal of teacher choice; however, for the teachers in iteration-one this freedom was not helpful. The teachers said that they would have never chosen sound as a topic, because they would not have known where to start.

Bree: I think for us as primary teachers it's hard, because we need to know a lot about a lot of things. You can't be an expert at everything. (it would be nice...) but when they ask you questions like that you can't know it all.

There seems to be a level of understanding that is necessary for the teachers to feel comfortable teaching a science topic, however there is also the knowledge that they cannot be expected to be experts, and are willing to expose the limits of their knowledge to their students. The challenge is to find the balance between depth and breadth of science knowledge necessary for teaching.

\subsubsection{Breadth versus depth}

In my initial planning of the PLD, I intended to cover sound and forces, as both were good fits for the iBod theme. When I realised the teachers did not have 
any science background, I quickly narrowed the focus to just sound. When we began to plan the unit on sound, I asked the teachers what they felt were the "big ideas" in sound that they wanted their students to know. Jack replied:

"...that's a good overriding inquiry question, what is sound and what do we need to do to find out what sound is?" They did not respond directly, which perhaps indicated they did not know enough about the topic to think in terms of foundational concepts.

At the conclusion of the PLD I asked the teachers in what order they thought they should introduce the various sound concepts to their students. Tom said "We talked about that this morning ... It made sense to me to do it in the order that we've been doing it in." Bree suggested the starting place would be to determine what the students knew about sound, and then begin with the cups and strings (which was the first activity in the PLD). Overall, the teachers seemed to be principally concerned with the activities and equipment rather than the establishment of a logical basis of the topic. They had developed a limited knowledge of sound, but were not able to evaluate the relative importance of the foundation concepts such as waves and energy, which would provide a foundation for other physical science topics such as light and heat.

Teachers who are not knowledgeable in an area of science are dependent on an outside authority, either a textbook or an expert advisor, to establish a logical order. This lack of overview and knowledge of the relationships between science topics also makes it challenging to approach a non-prescriptive curriculum such as the NZC as discussed above, and make decisions about the topics to teach, and in what order to teach them.

During my observation of Tom's class, the topic of pitch and frequency came up during the classroom discussion, and in the final PLD session the Tom described feeling uncertain about the topics.

I started talking about frequency and pitch and I was very aware that actually I don't know what I'm talking about here. I have a little bit of knowledge, but not a 
lot of knowledge, but that was all right, because the kids didn't know, and that's fine, but if you are trying to teach them something you still want to teach them correctly.

Tom's uncertainty indicated he did not feel he had sufficient knowledge about those concepts to confidently teach his students. The PLD covered a number of interesting topics in sound, but did not examine the foundational elements in depth. Consideration must be given to the balance between lightly covering a broad range of topics and concentration on one discrete area of science content and striving for conceptual understanding, with particular attention paid to the underlying foundational concepts. Subsequent science topics can build on those foundations, providing the teachers have sufficient SMK to recognise the connections.

\subsubsection{Thematic constraints}

Many primary schools in New Zealand employ a thematic approach (Boyd \& Hipkins, 2012), which seeks to integrate different areas of study such as social studies, health and science, around a particular concept. Teachers are expected to select science topics that relate to the theme. The theme for the current term in School-one was the body and how it works ("iBod"), the following term the theme changed to sustainability. The teachers at School-one were expected to select science topics which directly related to the theme. Bree described teaching science in a theme-based context:

I did lots of science in my classroom, but it was not exactly what we were meant to be doing at the time. ... here it is very prescribed for us, so this term we are doing iBod, so we do a bit of science about the body and how it works, your muscles and things, but I don't see a place at the moment for any of the experiments we have just talked about. And depending on what we do next term there may not be a place either. Next term is sustainability.

Schools that endorse a thematic approach and require science topics to align with the school theme put a significant constraint on teachers. The teacher must have knowledge of the theme, as well as knowledge of a broad range of potentially related science topics. It may be particularly challenging to find 
linkages between physical science topics such as forces, light, sound, electricity and magnetism, and themes such as sustainability or community. The teachers at School-one indicated they did not see many relationships between the potential topics in the Physical World strand of the NZC and the school themes "iBod" or sustainability.

The challenges described in this section all stem from SMK, the principal issue identified by the teachers during our first meeting. Someone with sufficient knowledge of physical science can see the relationships between the basic physical science concepts and virtually any theme, and can select an appropriate topic from the broad range offered in the Physical World section of the NZC. Without a fairly comprehensive SMK base, the linkages between the potential topics in the NZC and a school theme would not be visible.

The methods and strategies a teacher would select to teach the basics of the topic can only be selected if the teacher knows what the basics of the topic are. Teaching materials are available that help teachers understand the basics, once the decision of a topic is made; however, the work involved in surveying all of the teaching materials available for a range of topics, before a topic is chosen is not reasonable for a teacher, particularly given the relatively small amount of class time which is allocated to science.

If a teacher is given the assignment to teach about a specific topic such as heat, they would be able to look for teaching materials and be able to educate themselves on the topic. Starting from a specific topic at least gives them a starting place, but asking them to select a topic from a list of unknown topics, and then begin the process of learning about it, in the hope that quality teaching materials exist and linkages to a school theme can be found, makes the teachers' job very difficult. 


\subsubsection{Design changes}

This chapter described the use and modification of a PLD framework developed in chapter 2, using the methodology described in chapter 3 . Figure 25 depicts the PLD design framework, with changes resulting from the first iteration shown in bold. This augmented framework will be used to plan and implement the second PLD, thus beginning the second iteration cycle. 


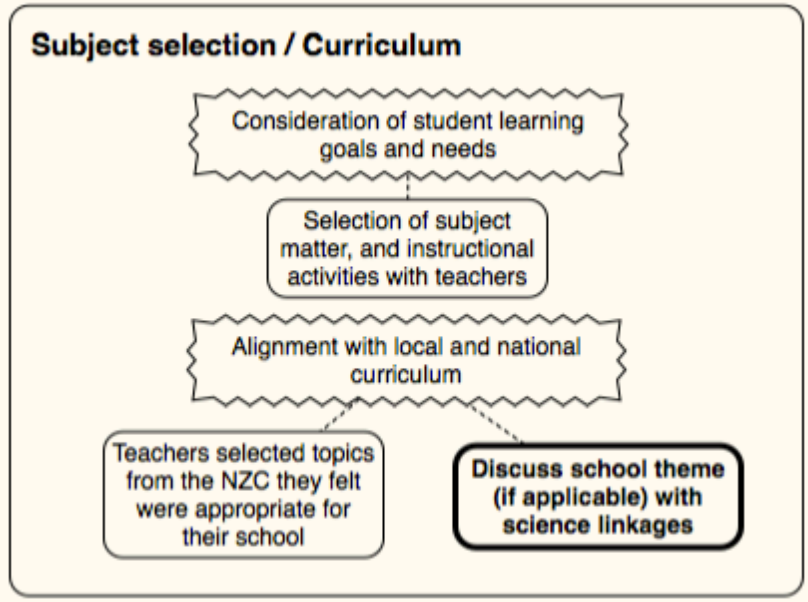

\section{Subject Matter Understanding}

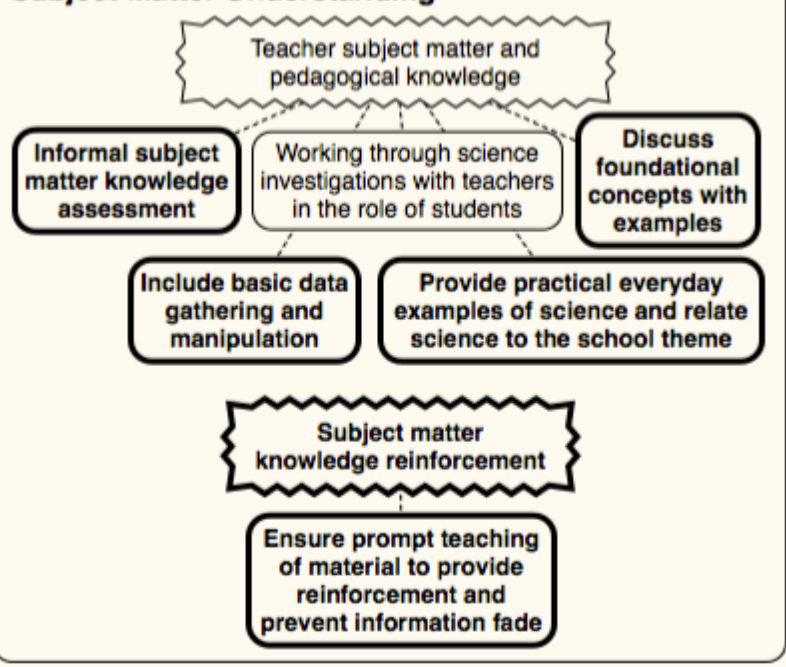

\section{Logistical Considerations}

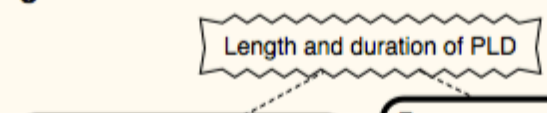

Negotiate session times and
overall duration with teachers $\quad \begin{gathered}\text { Ensure prompt teaching of } \\ \text { PLD material }\end{gathered}$

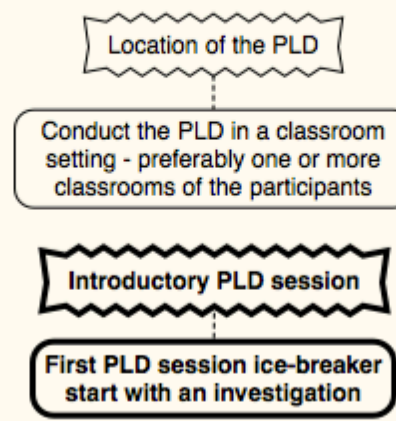

\section{Teaching Practice}

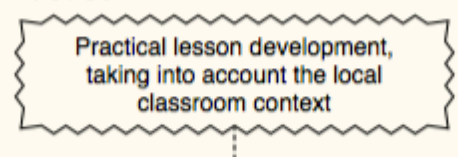
lassroom context

$$
\begin{aligned}
& \text { PLD conducted in the } \\
& \text { classrooms at the } \\
& \text { school, designed with } \\
& \text { the teachers }
\end{aligned}
$$

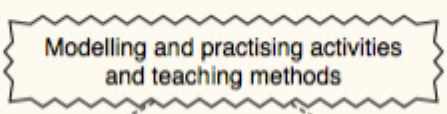

Work through science investigations with teachers in the role of students

Affirm the efficacy of teaching through science investigation

\section{Support}

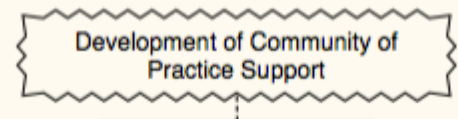

$$
\begin{gathered}
\text { Requirement of two or } \\
\text { more teachers per school }
\end{gathered}
$$
for collegial support

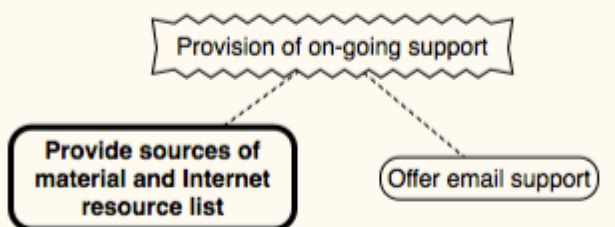

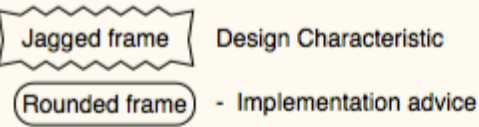

Figure 25: Design framework - iteration-one 


\section{Chapter 5 Second Iteration}

\section{Introduction and overview}

This chapter provides a description of the second iteration of science professional learning and development for a small group of Year 7 and 8 teachers. The PLD framework developed from an analysis of PLD literature in Section 2.3 and refined in the previous chapter was used to design the PLD developed in iteration-two (see Figure 25).

In this chapter I will briefly describe the school and the teachers, give an overview of the PLD, and present a review of the PLD framework. The framework review will examine each area of the PLD framework based on analysis of data and reflection on the experience gained in working with the teachers in iteration-two.

\section{The school and teachers}

School-two is a decile 8 full primary school with an enrolment of approximately 400 students. The principal at School-two responded to my invitation, and identified a group of four teachers who agreed to participate in the project. Year 7 and 8 students are divided into four classrooms of between 20 and 25 students, each class consisting of a mixture of students from Years 7 and 8. The classrooms are self-contained, and there is no dedicated science laboratory available. All subjects in each class are taught by the single generalist teacher.

All four Year 7 and 8 teachers at School-two wanted to participate in iteration group two. The original design of this research limited participation to teachers with at least three years' teaching experience, and three of the teachers, Claire, Karen, and Ann, met this criterion; however, the fourth teacher, Jane, was in her first year of teaching. Because three teachers met the teacher experience criterion, and they were insistent that they wanted to work together as a group, I made a decision to include Jane as a participant. 
None of the teachers had taken science papers at university. The teachers indicated they chose to participate because they wanted to teach a unit on Newton's laws. They had previously done isolated experiments in their classes with electricity, sound, and the chemistry of bread making, but they felt these were disconnected, and they wanted to teach a more integrated topic, and saw the PLD as an opportunity to increase their knowledge.

\subsection{PLD overview}

This section is an overview of the PLD consisting of an initial brief scheduling meeting, the introductory PLD, the topic-focused PLD sessions, planning, classroom observation, and the final wrap-up session.

\subsubsection{Initial meeting}

I had an initial meeting with the teachers in iteration-two to give them the introduction to the research project, develop a schedule for the PLD meetings, and agree on a science topic for the PLD. We discussed the written description of the research provided previously, and answered questions. We agreed to meet approximately once a week after school for five meetings, lasting between 60 and 90 minutes. At the conclusion of these meetings they would teach a unit on the topics covered, and I would schedule a classroom observation with each teacher, and following that, we would gather for one final group meeting at which we would discuss my observations of the teaching and their impressions of the PLD.

My intention to select a science topic area for the PLD during this first meeting so that the introductory PLD session would be on topic was not necessary, because the teachers in iteration-two already had chosen the topic of Newton's laws of motion.

\subsubsection{Introductory PLD session}

The introductory investigation with the teachers in iteration-one had set the tone of the PLD as hands-on and practical, and gave me the opportunity to observe 
the teachers while they attempted to solve a problem. I decided to conduct a similar introductory investigation with the teachers in iteration-two; however, the teachers had a meeting which limited the time for this session to 45 minutes, so I chose a simple investigation involving gravity. I produced several different sized steel balls, and asked them to predict which would fall faster. They predicted the larger and heavier ball would fall faster than the smaller and lighter balls. I then asked them to conduct an investigation that would test their prediction. They initially tried to time the fall of the various balls, but found it difficult to get consistent times, and finally conducted side-by-side simultaneous drops and simply observed which ball hit the floor first. They were quite surprised that the balls all took the same amount of time to fall to the ground. I asked them to consider comparing a falling ball and piece of paper, and they accurately predicted that the paper would take longer to reach the ground, and they confirmed that with an experiment. I asked them how they could make the paper go faster, and Karen suggested making the paper into a small ball might work, and again they confirmed that with an experiment. When asked to explain why it worked that way, Karen correctly answered the air was responsible for making the flat sheet of paper fall slower. I then asked them to consider what would happen if we were to remove all of the air in the room and repeat the experiment. Karen replied that if we could do that, both the paper and the balls would float, like in space, and the other teachers agreed with her. I made note of the misconception, but did not address it during this first meeting.

At that point we agreed to discuss the investigation further at the next meeting and I conducted a semi-structured interview, as described in Section 3.9.

\subsubsection{Topic-focused sessions}

Each of the topic-focused sessions was a mixture of investigations and discussions, as noted earlier (see Section 4.1.3). My initial outline for teaching Newton's laws over the course of five sessions was to begin with an investigation of gravity, assess what they already understood about Newton's laws, and then devote one lesson to each law, concluding with a review session. 
What transpired was not so well structured, but rather began with what the teachers already understood, and focused on their understanding of the fundamental concepts which make up Newton's laws, then exploring how the concepts can be recognised in real world situations. From my own teaching experience, and research I have a number of investigations and demonstrations that illustrate concepts such as acceleration, mass, inertia, momentum, and force that provide a sound foundation for exploration of relationships between concepts. I brought a wide variety of equipment with me each day, and rather than follow a rigid structure for the lessons, I attempted to be guided by the teachers' questions, interests, and apparent misconceptions. What transpired is summarised in Table 6.

\section{Table 6: Topics and activities in iteration-two}

\begin{tabular}{|l|l|l|}
\hline Session & Subject matter content & Investigations \\
\hline PLD 1 & $\begin{array}{l}\text { Introductory investigation and semi- } \\
\text { structured interview }\end{array}$ & Falling objects of different mass \\
\hline PLD 2 & $\begin{array}{l}\text { Concept map of Newton's Laws, } \\
\text { concepts of mass, weight, speed, and } \\
\text { acceleration }\end{array}$ & $\begin{array}{l}\text { Mystery boxes of different mass, terminal } \\
\text { velocity of styrofoam bead, measuring } \\
\text { speed and acceleration, speed trap }\end{array}$ \\
\hline PLD 3 & Inertia, momentum & $\begin{array}{l}\text { Ball on moving cart, table cloth with } \\
\text { styrofoam and heavy plates, coin drop, } \\
\text { shepherd's sling, Newton's cradle }\end{array}$ \\
\hline PLD 4 & Forces and friction & $\begin{array}{l}\text { Constructing force measurers, measuring } \\
\text { friction }\end{array}$ \\
\hline PLD 5 & Inertia revisited, review, planning & $\begin{array}{l}\text { Thread breaking - mass on string } \\
\text { investigation }\end{array}$ \\
\hline
\end{tabular}

\subsubsection{Unit planning, observation, and wrap-up}

The teachers in iteration-two began using material from the PLD in their classrooms prior to completing the entire PLD, even though we had discussed planning and teaching a unit at the conclusion of the topic sessions. During session four they described conducting the falling objects, and inertia and momentum investigations with their classes. The teachers also decided to have their classes put on a science "road show" for the junior classes. The teachers divided their classes into small groups, and each group was asked to produce a 
science demonstration to show to the younger students. The students practised by giving the demonstration to their classmates and answering questions.

Beginning to teach the material during the PLD was a deviation from the plan of the research project; however, it fell generally in line with the "Subject matter knowledge reinforcement" change to the PLD framework added after iterationone (see Section 4.2.2.2). I will include our discussion following the "road show" along with the formal classroom observations section later in this chapter.

I was able to arrange all of the observations on the same day, and we met one final time after school, again on the same day. We discussed my observations of their classes, and their reflections on the PLD and their teaching.

\subsection{Framework review - iteration-two}

As with iteration-one, the review of iteration-two will be organised using the five broad areas of the design framework (see section 4.2.8, Figure 25): Subject selection / curriculum, Teaching practice, Subject matter understanding, Support and Logistical considerations. Changes to the design framework suggested below are, in effect, preliminary findings, which will be examined and further refined in the final iteration. Existing design characteristics and the supporting implementation advice will be discussed in light of data from the PLD, and additional design characteristics and/or implementation advice will be proposed when data from the PLD suggest additions to the framework.

\subsubsection{Subject selection / curriculum}

The Subject selection area developed in Section 4.2.1 was modified as a result of experience gained in iteration-one, by the addition of additional implementation advice shown in bold in Figure 26. The experience in iterationtwo was quite different than that in iteration-one in this content area because the teachers at iteration-two came to the PLD with the specific topic of Newton's laws in mind, and School-two did not employ a thematic curriculum integration approach. The teachers had previously decided that a unit on Newton's laws was a good fit for their students and school. Because of these factors, the 
validation of the Student needs and Alignment with local and national curriculum design characteristics was limited in iteration-two. However, the experience gave rise to one piece of implementation advice in the Alignment with local and national curriculum characteristic, discussed in section 5.2.1.2.

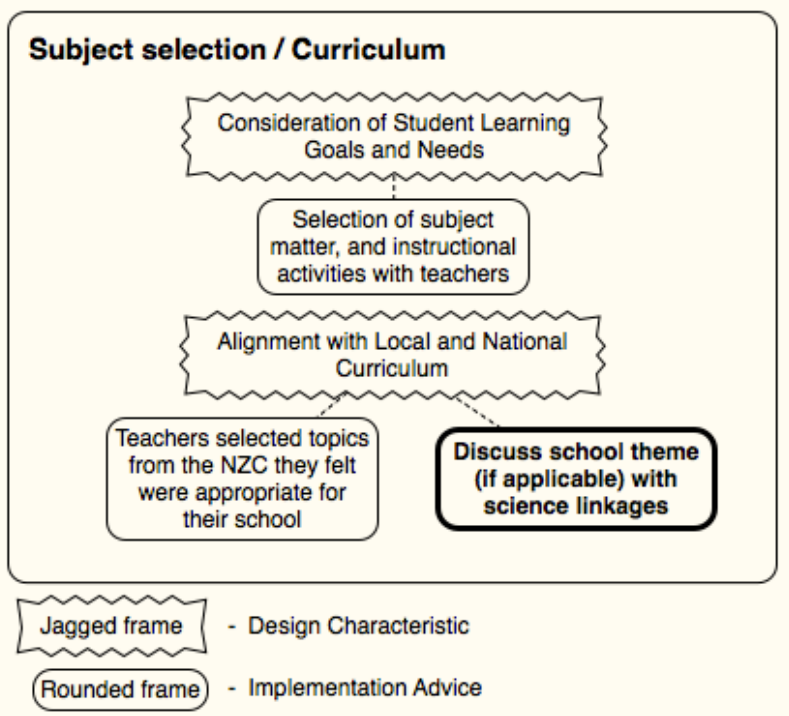

Figure 26: Subject Selection / Curriculum as established in iteration-one

\subsubsection{Consideration of student learning goals and needs}

\section{Selection of subject matter and instructional activities with teachers}

The teachers at School-two had made a decision to include additional topics from the Physical World strand of the NZC prior to my arrival. They felt that a study of Newton's laws would cover several topics in the curriculum, and also be engaging for their students. Therefore, the process of selecting subject matter in this iteration was limited to the selection of instructional activities and investigations.

During the final PLD session, Ann described the responsibility teachers have to give students a variety of experiences with science during their time at school, and that teachers must sometimes stretch themselves to teach areas not yet familiar to them (see dialog in Section 5.2.7.2). 


\subsubsection{Alignment with local and national curriculum}

\section{NZC topic selection and theme}

As discussed in the previous section, the teachers had decided to teach Newton's laws and asked for the PLD to be structured around the topic; also, School-two did not structure their curriculum using a thematic approach. Therefore, these areas of the framework were not able to be evaluated in iteration-two. One aspect of the experience in iteration-two does impact on this area, however. During the fourth topic-focused PLD session, Claire suggested that there might be an advantage to narrowing our focus down from a study of all of Newton's laws of motion to just one law:

For me, I think that doing a range of experiments, but focussing on one law, just to get a real grounding of what inertia is, for me, I'm wondering if the kids would... Like explaining one law at a time.

[And in the following session] Ann and I were talking a couple of days ago, we were talking about keeping this alive so that we are, like our professional knowledge is building, so a lot of it is personal, but it is relating it back into the classroom, and that was why last week I said I think what I need to do is to look at one law.

These comments lend support to the discussion of breadth versus depth in Section 4.2.7. It was important to these teachers, as well as the teachers in iteration-one, to feel they had a "real grounding" in a topic in order to teach it well. The comments apply to both the selection of topics for students, and for the PLD. As the teachers built up their SMK on the topic they became better able make curriculum decisions in light of student needs. The teachers recognised that covering all of Newton's laws would be too much material in one unit for their students.

Given that the teachers in both iterations indicated a need for well-grounded understanding, and given the time it takes to work through investigations that lead to that understanding, there is a need to select a suitably narrow area of focus for the PLD. Because the Physical world area of the NZC is very broad, 
and teacher knowledge of the background science necessary to understand a topic may need support, specific advice on selecting a suitably narrow topic should be included in the framework. Therefore, I have added the additional implementation advice to "negotiate with teachers a narrow focus to be studied in depth", as shown in Figure 27.

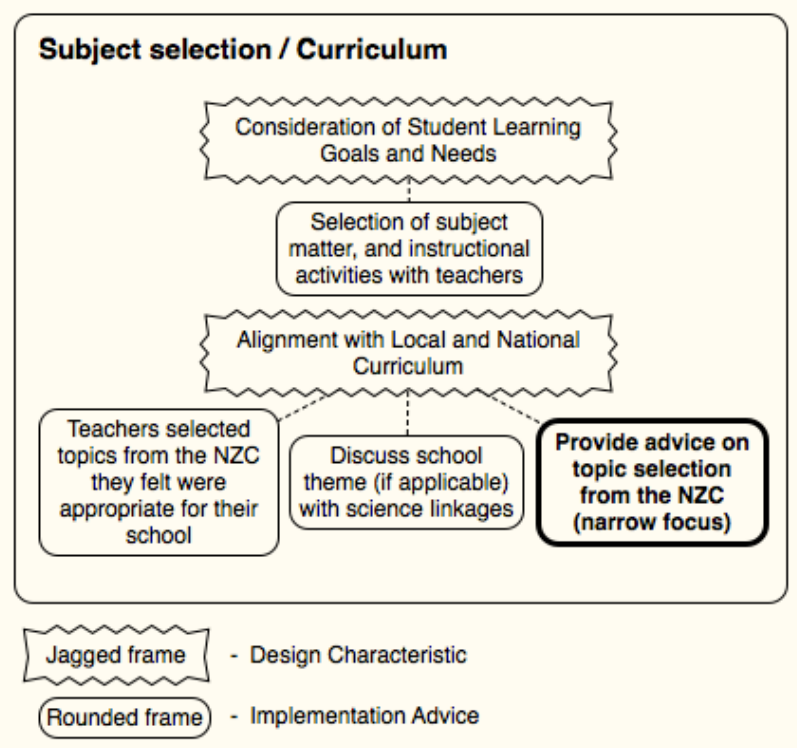

Figure 27: Subject selection / curriculum - iteration-two

\subsubsection{Subject matter understanding}


Experience gained in iteration-one led to the inclusion of new implementation advice and an additional content design characteristic discussed in section 4.2.2,

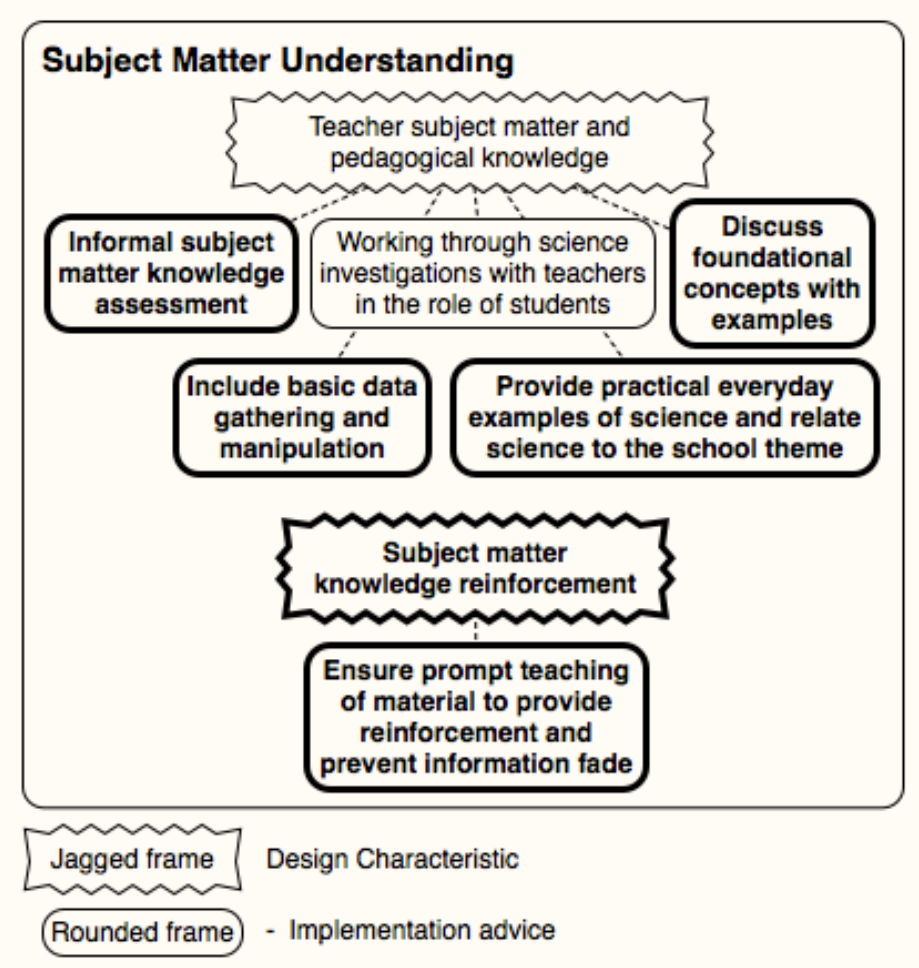

and shown in bold in

Figure 28. In this section I will examine the implementation advice for the two content design characteristics: Teacher subject matter and pedagogical knowledge, and subject matter knowledge reinforcement. The experience of applying the framework in iteration-two led to one new piece of implementation advice in each design characteristic and confirmed the inclusion of others identified in iteration-one. 


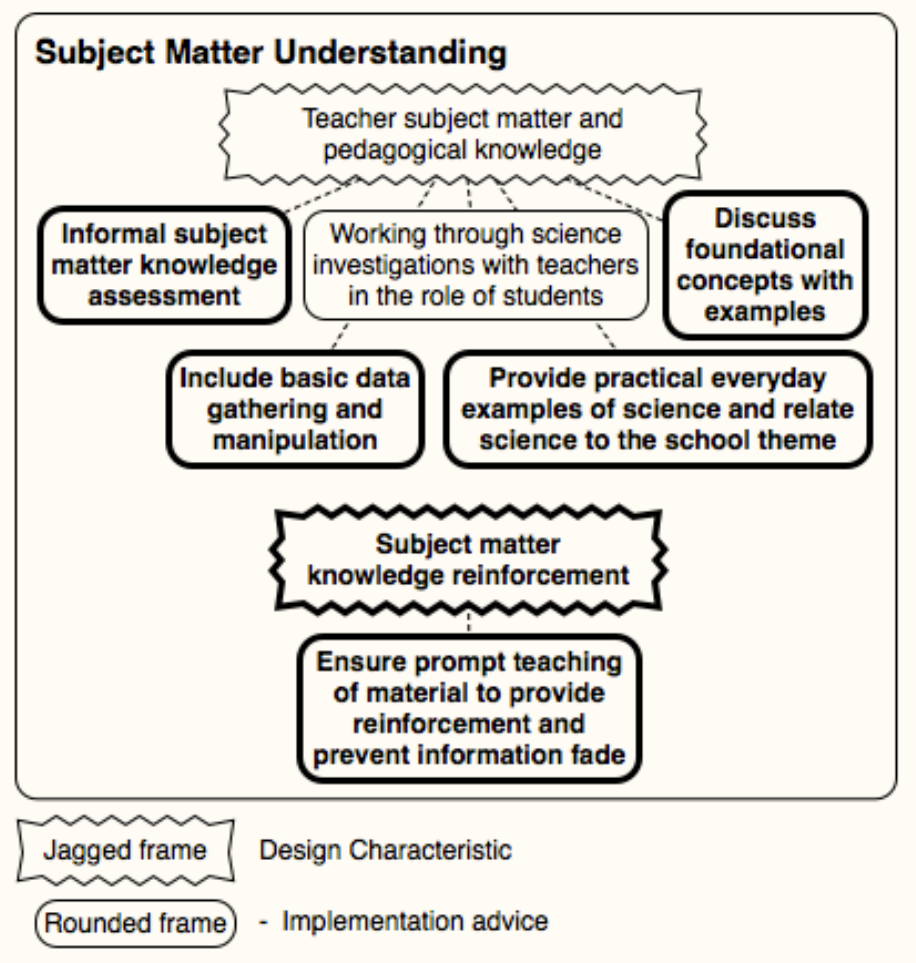

Figure 28: Subject Matter Understanding as established in iteration-one

\subsubsection{Teacher subject matter and pedagogical knowledge}

\section{Teachers as students}

The teachers in iteration-two conducted the investigations in the role of students as we worked through a number of different investigations involving Newton's laws. The following is a section of dialogue during an investigation of falling objects:

Karen: So what you are saying is if you drop a shoe and pen they would drop at the same speed, regardless of their shape? ...Because gravity is the only force... So when you drop the balloon will it fall at the same speed?

Ann: It is going to land at the same time. A balloon?

Claire: And that has nothing to do with density?

Karen: No gravity - the only thing acting on the empty balloon is the force of gravity, but if you fill the balloon with air then you change something...

Ted: If you think of the air exerting just a tiny amount of force up, so if you have something like this [small ball] the air is exerting a puny amount of force, but if you take something the same mass with a big surface area, like a parachute, 
that weighs the same as this, then all of a sudden you have a lot more air under there, and there are a lot more little forces that add up.

Karen: Oh I understand that. I like that picture, that's true. So if you fill the balloon up it gets bigger, so there is more puny air pushing up - holding it up.

Ted: So each little piece of air pushes up with a tiny bit of force, and so the reason that two things like this fall at the same speed is that the amount of air pushing or resisting that falling down is so little it just doesn't matter, and the force of gravity pulling down is so large it overcomes it.

Claire: OK, so therefore you are saying that different shapes of objects makes little change, but if you go from one extreme to the other it can...

This section of dialogue shows the teachers actively proposing explanations, and applying their current understanding to explain what was happening in the investigation. I injected a little information about the effect of air in the room, and they were able to make sense of what they were seeing. Having the teachers conduct the investigations as students allowed them to experience working through a problem as a group, and experience the pedagogical value of the activity for themselves, before applying it in their classrooms. It also gave them a chance to explore, and deepen their own understanding.

The teachers are working out, through their discussion, how the invisible forces of gravity and air resistance work together to cause the various falling objects to behave as they do. This type of discourse is central to learning in the social constructivist model (Jennings, 2009; Lemke, 1990; McNeill \& Pimentel, 2009). Teachers working together on investigations, and discussing their thinking also provides opportunities for formative assessment which is difficult to achieve in a didactic presentation of material (Araceli Ruiz-Primo \& Furtak, 2006; Bell \& Cowie, 2006).

\section{Assessment}

During the first topic-focused session I began by creating a concept map to gauge the teachers' understanding of Newton's laws. I asked the teachers what terms and concepts they associated with Newton's laws. As in the first iteration, I recorded the responses using a whiteboard computer application (Scapple, 
2014 Version 1.2, Literature and Latte). The map, shown in Figure 29 shows the teachers had some familiarity with vocabulary associated with Newton's laws. I asked the teachers to suggest which terms might be related to one another, and the two dotted lines connected were added by the teachers. I suggested that we would require some additional terms to describe Newton's laws, and added the terms inertia, momentum, and energy. Although the teachers had heard of the terms, they did not suggest connections between them and other terms on the map. Connections between concepts in a concept map normally indicates understanding, and my tentative conclusion was that the teachers' understanding may not go beyond a basic knowledge of the terms involved (Novak \& Gowin, 1984). I told the teachers that we would be working over the next several weeks to make connections between the various concepts represented on the map.

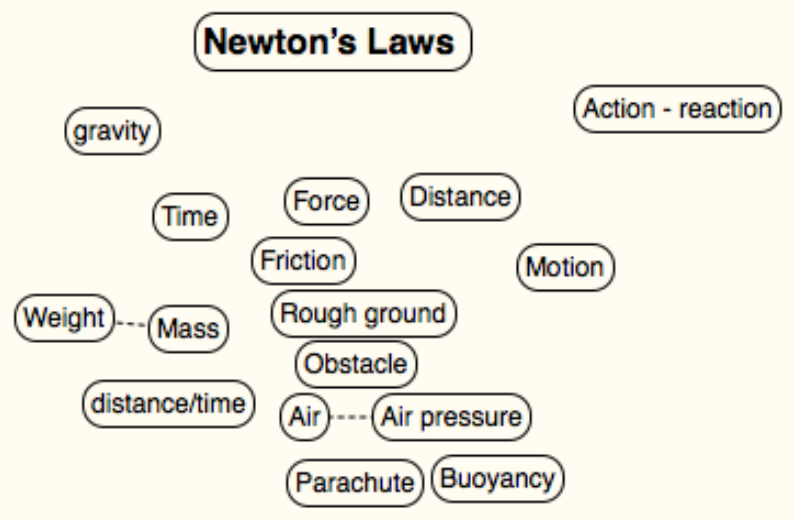

Figure 29: Initial concept map of Newton's laws

In addition to the concept map, the introductory PLD session investigation of gravity described in section 5.1.2 revealed a misconception that air is required for gravity to act. This is a common misconception in younger students, which becomes less prevalent among students in secondary school (Bar, Sneider, \& Martimbeau, 1997; Bar, Zinn, Goldmuntz, \& Sneider, 1994; Lelliott \& Rollnick, 2009). The presence of this misconception in the teachers at School-two was not surprising given their level of science education; however, their misconception about gravity would hinder their ability to teach concepts that 
build on a correct understanding of gravity, such as planetary motion or flight. The informal formative assessment which came about through discussion during the investigation revealed the teachers' level of understanding, as well as exposing a misconception that should be addressed by the PLD. Additionally, the concept map and discussions provided an idea of the teachers' level of initial knowledge, which was useful in selecting the level of content to include in planning the PLD; therefore, the inclusion of some type of topic knowledge assessment is supported.

\section{Foundational concepts}

Newton's laws of motion involve the relationships between mass, force, velocity, and acceleration. In order to discuss the relationships between these concepts, I had to ensure that the teachers had an adequate understanding of each. It would be easy to learn the words of Newton's first law, i.e., an object at rest remains at rest, and an object in motion remains in motion until a force causes a change in that motion, but without understanding the difference between uniform motion and acceleration it would be difficult to see the laws at work in everyday situations. We conducted an investigation to look at the difference between a ball rolling along a flat surface, and one rolling down a ramp. We used a metronome app on a cellphone as the timer and marked the position of a bowling ball each half-second as it rolled along a flat surface, then did the same experiment as it rolled down a ramp. The calculation of velocity (speed) allowed the teachers to use the fundamental concepts of distance and time to calculate speed, as well as observing how the speed constantly increased when the force of gravity was pulling the ball down the ramp. Another investigation involved the concepts of weight and mass. I made two identical boxes, one filled with marbles and the other filled with styrofoam beads. I asked the teachers to examine the boxes without lifting them from the table, and tell me which one was heavier. They were able to tell quickly by moving the boxes back and forth, which provided an opportunity to define mass as differentiated from weight, as well as inertia and momentum. 
At our next session we were reviewing the concepts of velocity and inertia:

Karen: So its velocity is zero, you push it and it has a velocity, then the floor provides friction to slow it down and get it back to no velocity.

Ted: However if ... I gave it a push and there weren't friction forces on it, it would just keep going.

Claire: In that direction. The ball has inertia. Massive things have inertia. Karen: The larger the inertia, the more you need to change it.

Here Karen is describing what is happening when a real-world object slides across the floor and comes to a stop, and the subsequent dialogue indicated to me that Claire and Karen had an understanding of Newton's first law and the underlying concepts.

During another session we were discussing possible investigations, and I told the teachers about an investigation I used with my physics students in which students would position themselves along a road and calculate the speed of cars. The teachers picked up on the idea, noting all they would have to do is have two students a certain distance apart, and have one make a signal when a car passed, and the second signal when the car reached them. They could use cell phones to measure the time, and knowing time and distance they could calculate the speed.

The teaching support materials provided by the MOE which provide teachers with background material and suggested activities for physical science include Making Better Sense of the Physical World (MOE, 1999) and applicable booklets in the Building Science Concepts series e.g., Parachutes (MOE, 2003). These resources provide high level background information for teachers; however, the information provided assumes a degree of prior knowledge which was not present in the teachers at iteration-two. For example, in "Parachutes" (MOE, 2003) the applicable "Big Idea" concept hierarchy presented in Table 7 below. 
Table 7: Big ideas about parachutes

\begin{tabular}{|c|c|c|c|}
\hline $\begin{array}{l}1 \\
\text { When objects drop } \\
\text { through the air, the } \\
\text { process is called } \\
\text { "falling". }\end{array}$ & $\begin{array}{l}2 \\
\text { Earth's gravity is the } \\
\text { force that pulls objects } \\
\text { down through the air. }\end{array}$ & $\begin{array}{l}\text { 3 } \\
\text { The force of gravity } \\
\text { remains constant - all } \\
\text { objects would fall at } \\
\text { the same rate if no } \\
\text { other forces were } \\
\text { acting on them. }\end{array}$ & $\begin{array}{l}\text { 4 } \\
\text { An object reaches its } \\
\text { maximum rate of fall } \\
\text { ("terminal velocity") } \\
\text { when the forces of air } \\
\text { resistance and gravity } \\
\text { are balanced. }\end{array}$ \\
\hline
\end{tabular}

In the 'Teacher's Notes', the terms gravity, mass and weight are used in the description of falling objects:

An object falls through air because of its weight (the effect of gravity on its mass). Air also has mass and like other fluids, has to be "pushed out of the way" for an object to move through it. (p. 4.)

Although the terms gravity and mass are defined in the glossary at the end of the booklet, ${ }^{4}$ the meaning and implications of a phrase such as "the effect of gravity on mass" will be challenging to understand without further elaboration.

The time spent establishing the foundation concepts of gravity, speed and mass allowed us to build up the more complex concepts of inertia and momentum which were important in Karen and Claire's eventual understanding of Newton's laws. Including the discussion of foundational concepts as implementation advice is therefore supported by the experience in iteration-two.

\section{Data handling}

When considering the investigations I planned to conduct with the teachers at School-two, I anticipated the need to record accurate experimental data. As the PLD developed however, teaching the basic concepts of motion, such as velocity and acceleration, did not require systematic and accurate measurements. I concluded that concentrating on the tabling of exacting data,

\footnotetext{
${ }^{4}$ Gravity: The force that attracts a body towards the centre of the Earth or towards any other body having mass

Mass: The quantity of matter that a body contains
} 
and making decisions about data manipulation and outlying data would overly complicate things. I decided to forgo the opportunity to concentrate on laboratory technique (e.g., exact measurement, data averaging and outlier elimination), and instead focus on the science concepts on display (e.g., distances stay about the same, or are getting bigger and bigger) (Abrahams \& Millar, 2008; Millar, 1989, 2010). However, in a PLD situation in which the teachers were seeking to integrate a science investigation with mathematics, and use the data in a more quantitative way, a focus on data gathering and manipulation would be appropriate and therefore I am choosing to leave it in the framework.

\section{Everyday examples}

Although School-two did not integrate their curriculum around a school theme, it was a priority for the teachers to find ways to make the science relevant in the everyday lives of their students:

Claire: A big thing with the New Zealand curriculum is authentic context. Ted: What does that mean in physical science I wonder? Claire: It means relating physical science, or like the understanding of inertia to everyday situations, so it means an authentic context where the kids would naturally experience it, so in all sorts of things, speed, or whatever it is, it is that - I clicked in one of the sessions. We were talking about spreading out weight, and I remember thinking, a lot of things like magicians' tricks are like that, and once I started thinking like that I started seeing it more and more and becoming more interested in how it was relating to other aspects of my life or experiences in my life too. And they do say in the New Zealand curriculum our learning should be including authentic context, it isn't just learning a strategy, but it's about taking it out to the real world when you go across the road to the cafe there, you know. ... It is a real conscious effort for me, personally. That's why last week you said something about spreading the weight, and I was thinking about the bed of nails, so I have to keep trying to think of that - to keep the science alive rather than science separate, to keep the science in every - in life. Does that make sense?

Karen: And like the advert with the car, that was perfect, particularly yesterday when we were talking about it. You know, what travels in the car? Oh yeah, the brain is still going, the apple comes from the back seat even though the car is still moving. Like they [her students] said today about the water balloon. I don't 
know if it is right, but does the water still keep traveling even though the balloon bit has stopped, [is that] what is happening? They said that to me! Like the skin of the balloon doesn't weigh anything. That's what they said, and if you try to catch it like (clap) the balloon stops, but the water is still moving. That's very good.

This dialogue between Claire and Karen illustrates how they are beginning to find everyday examples of the physical laws we had been examining in the PLD. For these teachers, understanding the science allows them to see examples of the science all around them, giving them the potential to bring examples into their classrooms that were not covered in the PLD.

The decision to include friction in the PLD arose because although Newton's first law states that an object in motion stays in motion, we are unable to observe this in our everyday lives. Everyday experience shows that objects in motion here on earth eventually come to a stop because of friction. Friction came up in almost all of our discussions, so rather than ignoring friction, we decided to investigate how frictional forces work, and included the topic in the PLD.

\section{Focus on understanding - depth rather than breadth}

The additional implementation advice to assist teachers with narrowing the topic selection from the NZC discussed in section 5.2.1.2 has an implication in the SMK-PCK area also. Teachers in iteration-two expressed a desire to have more investigations on a narrow topic, such as Newton's law of inertia, so that they would gain a better understanding. This desire to understand a narrow range of science concepts deeply, rather than achieving a shallower understanding of a broader range of science concepts would lend support to an emphasis on foundational concepts discussed earlier. An emphasis on understanding was also suggested by the experience in iteration-one. During that iteration we covered a variety of topics related to sound, but did not develop an understanding based on underlying principles. Therefore, an additional piece of 
implementation advice "Focus on understanding - depth rather than breadth" was added to the framework.

\subsubsection{Subject matter knowledge reinforcement}

\section{Information fade}

The teachers in iteration-two began using the material during and immediately following the PLD (see section 5.1.4), and did not mention any fading of information described by the teachers in iteration-one. Avoidance of a lengthy delay between the PLD and the teaching of the concepts covered in the PLD appears to be supported.

\section{Documentation of the science investigations}

I had provided documentation for the iteration-two teachers in the form of summaries of the lessons covered thus far, and review sheets for the concepts covered. I observed that Claire added extensive notes to the summaries, and her comments and questions indicated a high level of motivation. It may have been for Claire that note taking was an established habit, but given that she demonstrated a greater level of engagement than the other teachers I thought there may be a connection between personal active documentation and engagement.

The teachers mentioned during the final session that they wished they had taken pictures of the equipment we used during the investigations. I noticed the other teachers took some notes, but did not seem to have a system in place to document the PLD. The teachers in iteration-one experienced information fade, and described their desire to review pertinent material prior to teaching a topic. The teachers in iteration-two also expressed a need for reinforcement or review prior to teaching a topic. Primary school is structured in a way that allows teachers very limited opportunity to gain experience repeatedly teaching a topic. In a high school situation, a teacher may teach the same lesson to several classes in one day. A primary school teacher will likely not teach the same 
lesson until the next year, and in a combined classroom it may be two years, if at all. It is therefore important that a system of documentation should be provided as part of the PLD to record information that would be reviewed prior to teaching the material. I will describe the decision to use the "Content Representation Framework" (Loughran, Berry, \& Mulhall, 2012b), a system designed to capture SMK specifically as it relates to teaching, as the documentation system in section 5.2.7. The additional implementation advice: Documentation - make active documentation an integral part of PLD using PCK tools: CoRe (Content Representation framework)-was added to the framework.

The Subject matter understanding area with the newly added features in bold print is shown in Figure 30.

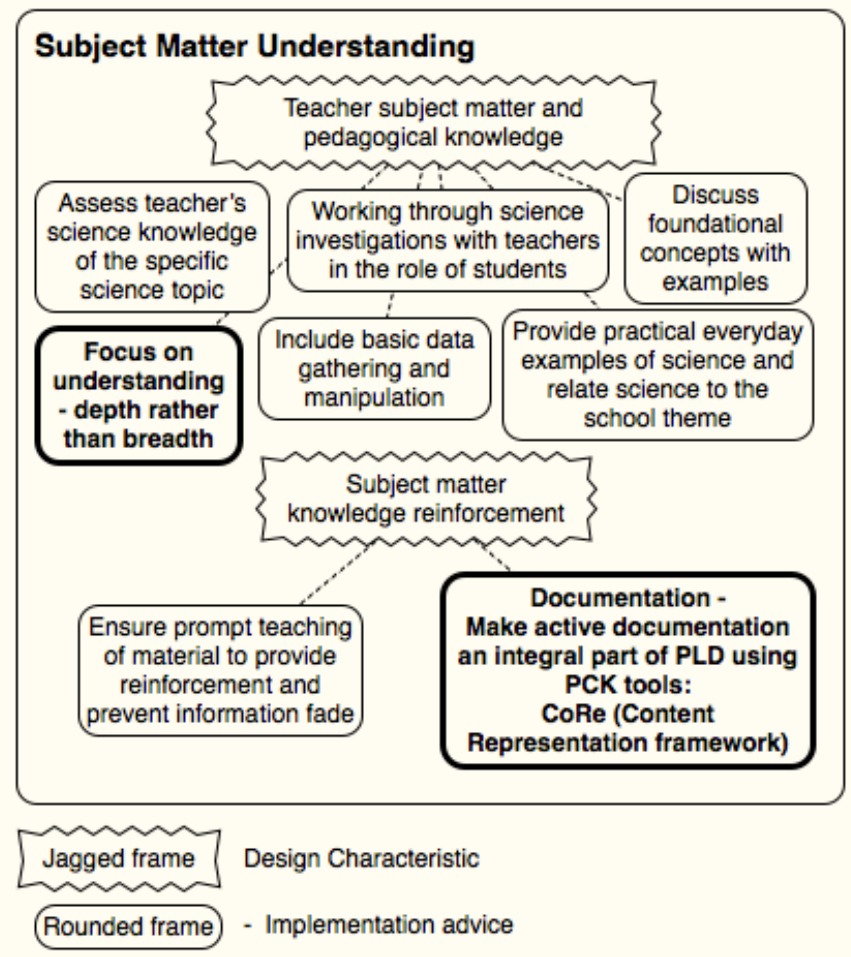

Figure 30: Subject matter understanding - iteration-two

\subsubsection{Teaching practice}

The teaching practice area of the framework was changed during the first iteration by adding the implementation advice, acknowledging that teachers in 
New Zealand understood the advantages of teaching science through investigation, and special emphasis was not needed in this area (see Figure 31). This was confirmed during iteration-two. The other design characteristics and implementation advice were also supported, and no additional characteristics or implementation advice were indicated during iteration-two as evidenced below.

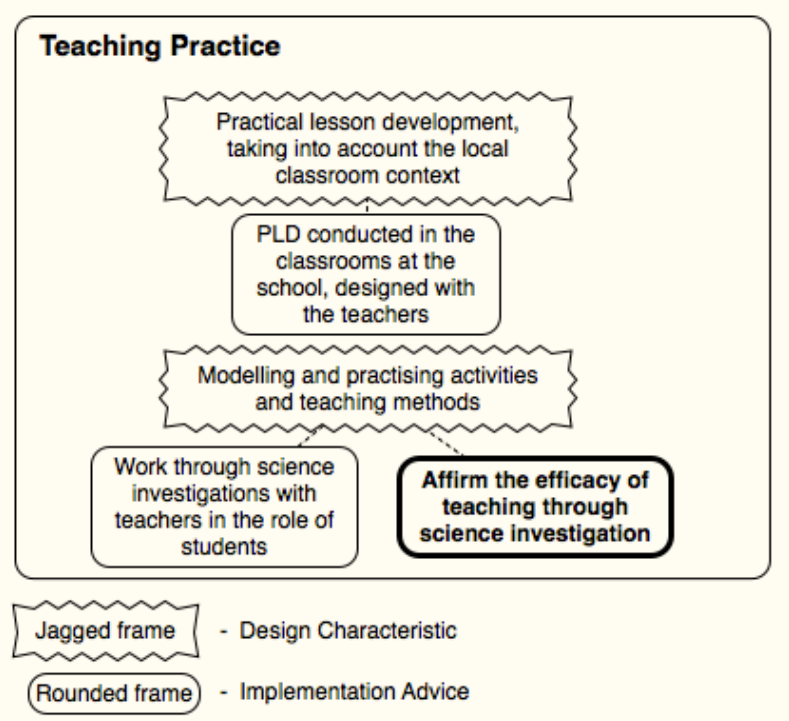

Figure 31: Teaching practice as established in iteration-one

5.2.3.1 Practical lesson development, taking into account the local classroom context

The development of the Newton's laws PLD began with the construction of the concept map described in section 5.2.2.1. The concept mapping exercise identified what the teachers understood about concepts related to Newton's laws, and my experience in teaching high school physics students provided an idea of the common misconceptions, and challenging concepts. For example, the concept of inertia tends to be difficult for students, as does the distinction between mass and weight. I designed the first two topic-focused PLD sessions around investigations involving mass, inertia, velocity, and momentum. 
The topic of the PLD was chosen by the teachers, and the content of the PLD was chosen by me based on an assessment of the teachers' subject knowledge. The selection of science investigations took into account the resources available in the school, a factor which was important to Ann, and the physical layout of the classrooms:

I wouldn't say it's a barrier, probably more time management, but it is the equipment side of things. Where the school hasn't ... and then you have to resource it yourself, ... it makes me stop and think what I'm going to do. Lots of your activities are really cool [but] I would avoid the time-consuming ones, because I have other time commitments. In saying that, with the resources, when they are there, I don't mind doing science, but that's probably my thing, just what's available, and if it's not available, I'm not someone who will spend my holidays making stuff.

Ann is honestly stating a limitation which was also voiced by the teachers in iteration-one, that it is important that equipment be simple, easy to obtain, and quick to set up. Designing the PLD with these factors in mind was supported in iteration-two.

\subsubsection{Modelling and practising activities and teaching methods}

One teacher in iteration-two voiced a concern that during science investigations the classroom can be quite noisy, and look chaotic. During the first PLD meeting Ann and Karen discussed the issue:

Ann - ... I have in the back of my mind all of the noise, and this is a bad thought, but I think who's going to walk into my room and seeing the kids, it looks kind of chaotic when you are doing science actually, it doesn't look like you have control. And I just worry about that stuff.

Karen - See, that's a personal thing, because I wouldn't care. My kids are doing stuff. Doing practical stuff like that, and someone walks in, well, isn't this great? Ann - There will be kids that really engage, but there will be kids that take the opportunity of the fact you are all around the room, and will disengage and do something silly. I find that side of the science quite hard to monitor. I'll be talking to one group and behind my back another group is playing up, and that's not just in science but any activity where there is interaction going on. I find that side of the teaching can stress me out a little bit. I would enjoy doing it, but that 
always makes me think, OK, how am I going to manage this, to be sure they are on task?

At the follow-up meeting at the conclusion of the PLD, Ann returned to this point. In the following, she is describing the investigation in which her students made a simple force measuring device, and investigated friction:

... although today was very good, other times there is quite a big noise level when they are creating things, and I struggle working with a group and seeing other people mucking around, but that wasn't happening today, and that was great, but, yeah, I don't like it when kids have an opportunity to not do what they are meant to be doing during an activity, not just science, but other areas as well.

Although Ann appeared to still be concerned with classroom management, she had a positive experience in running this particular investigation. I suggest this is at least partially because she had done the investigation herself, and therefore had confidence that it would work, and could give her students helpful advice which made the investigation go smoothly, providing her with a greater sense of control and purpose. Ann's experience supports the importance of the teachers working through the investigations; knowing what is involved in an investigation allows teachers to enact their knowledge of students to identify when and where individuals will need support, and builds teacher confidence and belief in their ability to effectively guide behaviour and learning during the investigation.

The teachers in iteration-two were similar to the teachers in iteration-one in their strong support for the use of science investigations as their preferred method of teaching. During the first meeting with the teachers in iteration-two we were discussing their experience with science when they were in school:

Claire: Even as we sit now I can remember walking over with my hard covered book into this cold room sitting down in forms and having the apparatus in front, and opening up a book, and it was like a cloze form of activity, like having a sentence and having to put in the right words. I can't actually remember using the apparatus, but it was there. 
Karen: I remember quite a bit, because we didn't do book work, we did things with the apparatus on the table. We were all sitting in rows and facing the front, but we actually did things. We lit the Bunsen burner, we mixed the crystals, we did all of those things.

Ann: I remember walking in, and on the board he would have - he had drawn the plant, and all the parts to it, and he would talk about it, and we'd have to draw it and write it down. And I think once we got to light the Bunsen burner, and do glass things, but a kid got silly and it was all over, that was it, back to the books, and we were like [sigh] and that was our experience.

Karen: It is quite different isn't it? I must have had a teacher who was maybe a little forward thinking, I don't know, or a little more original in that area, it was all hands-on.

Claire: Different school.

Karen: Different school, different way of teaching I guess.

Ann: We were always promised that more would come if we took it the following year. Like that was what the promise was, that it gets more experimental as you went up in the high school, but it didn't interest me by then. It was all words, and I was like - yuck.

They stated their preference for teaching through hands-on science investigations at our first meeting, and at several points throughout the PLD. The implementation advice that teachers understand the advantages of teaching through investigation is supported. The resulting Teaching practice area is shown in Figure 32. 


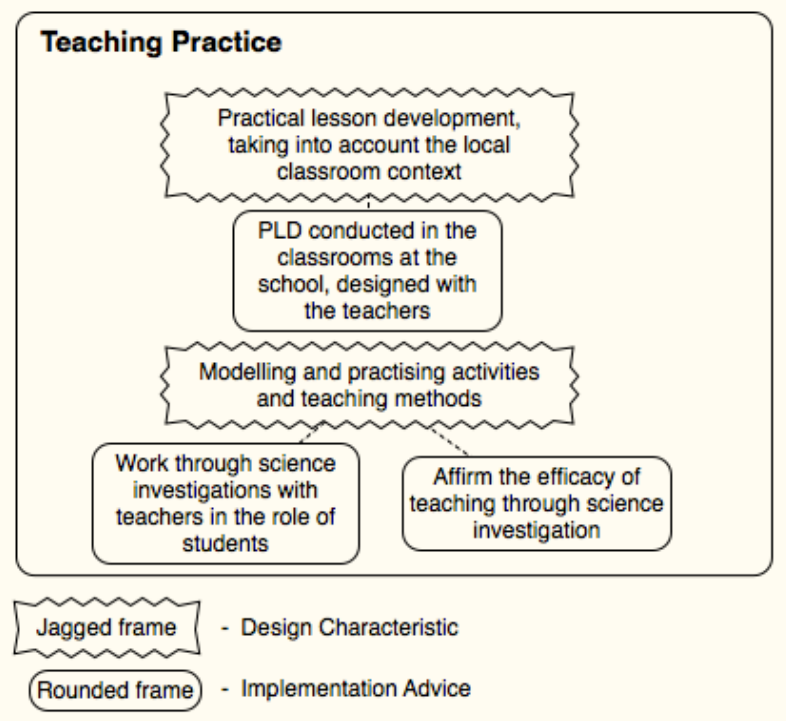

Figure 32: Teaching practice - iteration-two

\subsubsection{Support}

The support area of the PLD framework was modified after iteration-one to include advice to provide sources of cogent review material (see Figure 33). In light of the changes made in the Subject matter understanding area, this implementation advice was removed from the framework, as described below. 


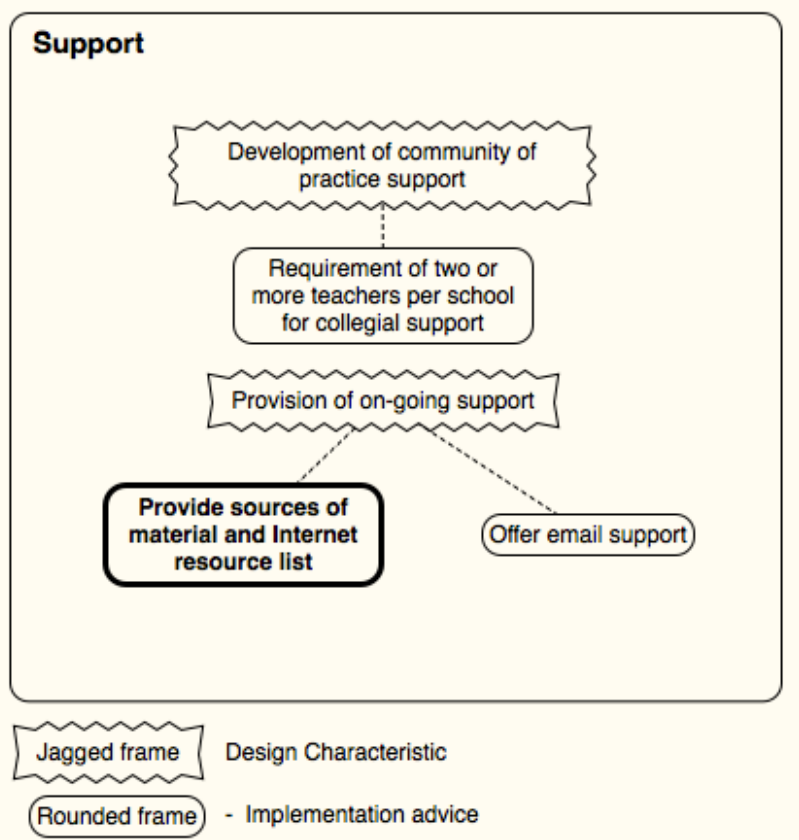

Figure 33: Support as established in iteration-one

\subsubsection{Community of practice}

Similar to the situation in iteration-one, the teachers in iteration-two were all from the same school, and had worked together, planned together, and shared ideas and equipment prior to the PLD. Ann described how the planning process worked:

We sit down when we do our syndicate thing, and we plan out, like we said, before you came, we planned out that we were going to do science things. None of us were really comfortable. We decided we needed to do it.

The group had decided together to teach NZC Physical World topics involving forces and motion. When the PLD research project came to their attention they decided to participate in order to further their knowledge in the area.

It was important to Claire to continue working on science as a group:

Claire: We were wondering about carrying our science on, and it would be good, not for the sake of the kids but for the sake of us, not to lose any of this PLD and to put it into action. ... Even if we had a theme each week, like we look 
at inertia for a week... we don't have to go away and find everything, because a lot of the experiments we have done with you, but we could draw on that now.

The teachers' group planning as well as their collaborative work on the science road show (the student-led half-day science show their classes conducted for the junior students) demonstrated how they worked together as a community of practice.

Finally, for the first-year teacher, Jane, her involvement in the PLD provided an opportunity to observe how the other more experienced teachers incorporated science investigations into their documentation, planning, and teaching. The subject of how to document a science investigation came up during one of the sessions. The current practice of sharing the learning intentions with students in advance of the lessons, and how that practice can spoil the surprise of a science investigation was discussed:

Ann: As teachers we're told ... to give them the learning intentions before we've even taught anything, and their success criteria, so we're spoon feeding them that, and not letting them inquire, "why are we making these?" "what will happen?" What I saw today was pure inquiry, they came up with it all ... and I thought "what if I told them at the beginning we were going to learn about forces and how to pull, and gravity and friction, if I told them all of that there would be no -

Karen: That's maybe where you just need to flip it over sometimes, to do the thing, and then go "what did you learn?"

Ann: What if [observers] are coming in at that point and saying what is it that you are learning and [the students] can't answer it, or having been asked where the learning intentions are here in your book, and they'd say "we don't have it." Claire: I think you have to keep in mind the point of it, what the picture is, often I'll do that, teach and then ask what have you learnt? I think that's also where the co-construction comes in that it's not been spoon fed, it's a constructivist theory that the kids are constructing the learning themselves, so they're directing it, and we're nudging or guiding if we want it to go in a particular direction.

Ann: We're told to put it in underneath the date, the learning intentions.

Karen: I leave a big gap.

Claire: For the kids, so I always have a challenge with having something so prescribed like that, to me that is your autonomy as a teacher reflecting the needs of your kids as we knew kids construct or do or shake up - change up. 
Claire: The planning you have to submit ... But not... like Jane in her planning, she has [learning intentions] and success criteria, but when she comes to work with the kids she doesn't tell them what her success criteria is, they construct the success criteria together, and it won't be exactly the same, it will be whatever they've come up with.

The dialogue provides Jane with a view of how different teachers handle planning requirements and lessons that have the potential to change based on student questions and/or interest. Here Ann is quite concerned about filling in the documentation, but Karen and Claire voice the opinion that the documentation serves the teaching rather than the other way around. This example provides evidence of the benefit of PLD delivered to a group that functions as a community of practice.

\subsubsection{Provision of on-going support}

\section{Offer email support}

The teachers in iteration-two, like teachers in iteration-one, did not contact me with any questions that were not related to scheduling. Although the teachers did not take advantage of the offer, no evidence exists to remove it from the framework.

\section{Provide sources of material and internet resource list}

In addition to highlighting relevant sources of information produced by the New Zealand MOE (e.g., Parachutes MOE, 2003), and web resources as in iterationone, at the beginning of each PLD session I provided the teachers with a summary of what we had covered thus far (see example in Appendix E). I used the summary to review material covered previously and preview the next topics to be covered. Teachers in iteration-two expressed appreciation for the resources, and there is no evidence to alter the implementation advice. The resulting Support area is therefore unchanged as a result of iteration-two, and is shown in Figure 34. 


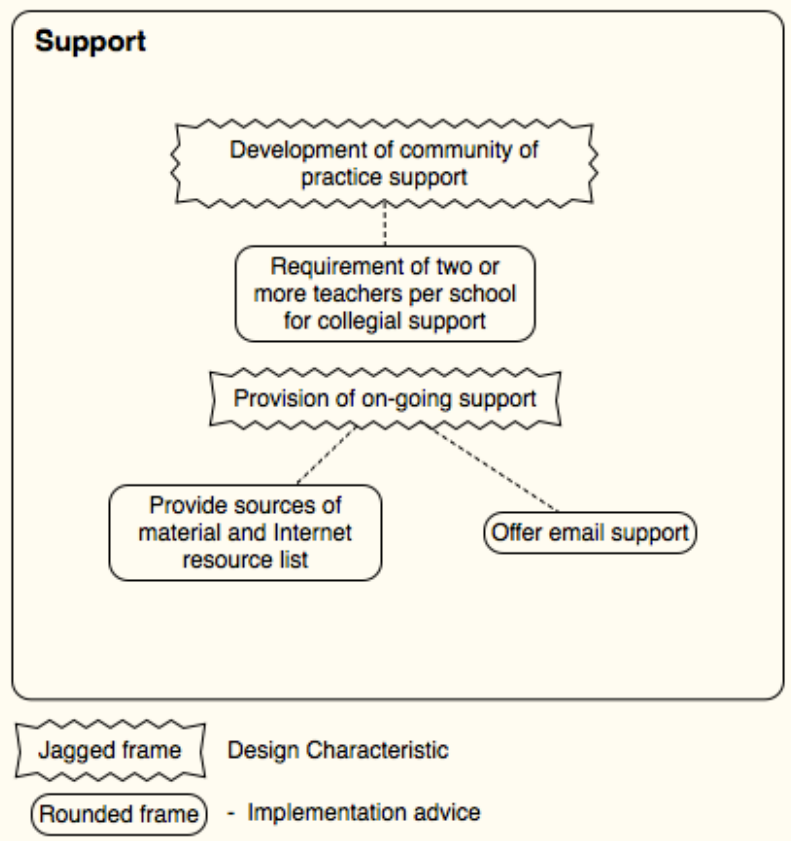

Figure 34: Support - iteration-two 


\subsubsection{Logistical considerations}

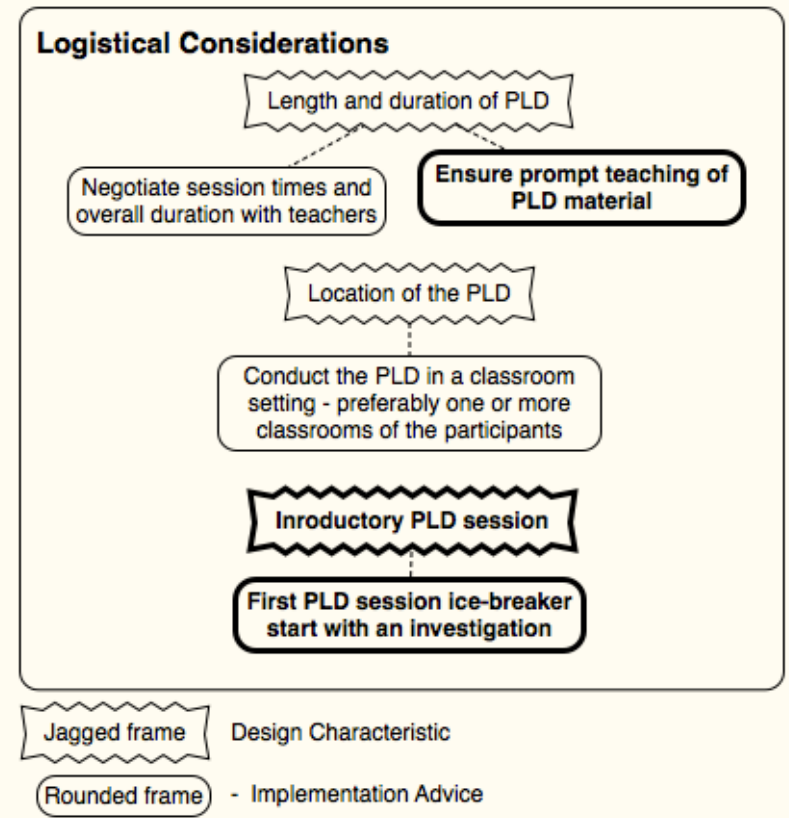

Figure 35: Logistical considerations as established in iteration-one

\subsubsection{Length and duration}

During our first meeting the teachers and I agreed that we would meet for five topic-focused sessions lasting approximately 90 minutes, and come together for one additional meeting following the classroom observations. This was the same duration and number of meetings as agreed with the teachers in iterationone. The actual durations varied between approximately 60 and 120 minutes because of occasional after-school commitments.

Agreeing the length and duration with the teachers in advance meant that the teachers had input into the PLD. The result was that they chose a commitment level that was appropriate for them, and as a result were committed to the process, and all teachers attended each PLD session.

\subsubsection{Location of PLD}

The PLD in iteration-two was conducted primarily in Karen's classroom due to size and central location. We rearranged the tables as needed and made use of 
various objects around the classroom in the investigations. For example, when we were examining friction, we used books as the objects to drag and investigated the difference between friction between the book and table, and book and carpet. The teachers used the books to transform the tables into ramps in other investigations. As already reported, Ann made a comment about the importance of investigations that work, utilising equipment that requires relatively little time to prepare in advance:

I wouldn't say it's a barrier, probably more time management. When the school hasn't ... and you have to resource it yourself it makes me think about what I'm going to do. Lots of activities are really cool looking, ... but I would avoid the time-consuming ones. ... When the resources are there I don't mind doing science. ... You've done that before and you know it works.

The ability to model investigations using improvised equipment made from items that are readily available in the classrooms allowed the teachers in iteration-two to see how hands-on science could be done with relatively little advanced preparation. These experiences support the importance of locating the PLD in the teachers' classrooms.

\subsubsection{Introductory session}

We began the PLD with the investigation of the speed of falling balls of different size and weight as described in Section 5.1.2. Beginning with an investigation set an active tone for the PLD, and since it was chosen to align with the previously agreed topic of Newton's laws, it proved to provide valuable formative assessment data described in Section 5.2.2.1, which lends support to the addition of this design characteristic added in iteration-one. The resultant Logistical considerations area is shown in Figure 36, unchanged as the result of experience gained in iteration-two. 


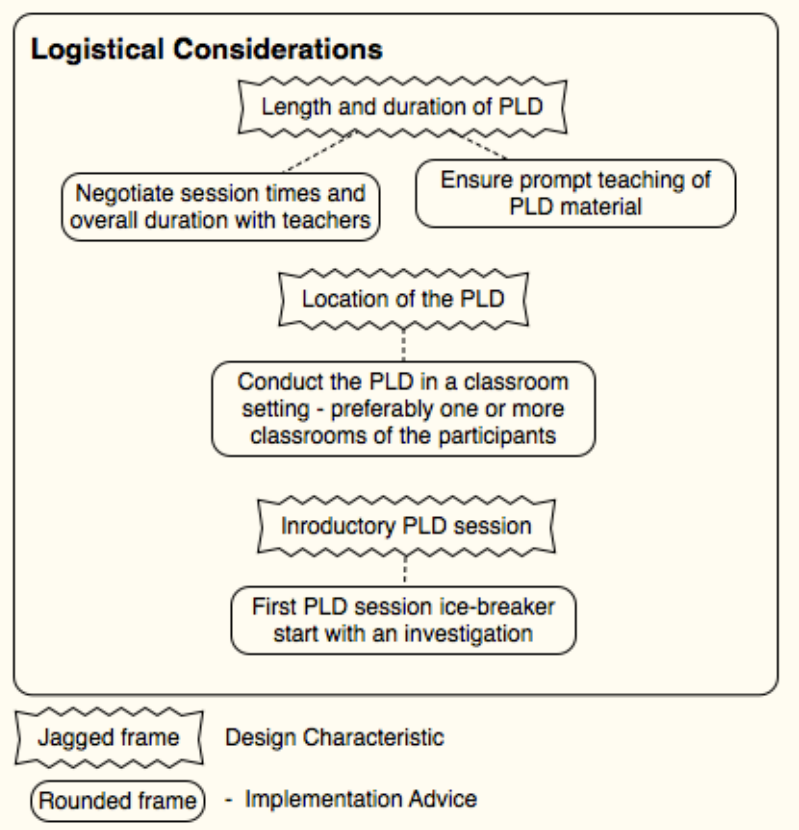

Figure 36: Logistical considerations - iteration-two

\subsubsection{Classroom observation}

The teachers selected a day for me to conduct the classroom observations at School-two shortly following the final topic-focused PLD session. I was able to arrange the schedule so that I could observe one class period (lasting approximately 45 minutes) for each teacher on the same day, and we held the final wrap-up session after school that day.

Jane's class began with an investigation involving motion, force and friction. The class started with the students outside, grouped as partners with a kickball. She asked the students to kick the ball to their partner, and posed the questions: "What is happening when you stop the ball?", and "What happens when you miss the ball?" One student commented that it was good they were on grass rather than concrete. Jane asked her students to write down what they observed and why grass slowed the ball down faster than concrete. She gathered the class back together inside and discussed how the ball behaved under the various conditions, ending with the students concluding that when the ball was caught the person provided the force, but when the ball was missed 
friction provided the force, and that was the difference in the grass versus the concrete.

She then told the class they were to investigate friction, looking at how friction worked on different surfaces. She showed the class a simple force measuring device made from a rubber-band, cardboard, and paperclips, and had them divide into small groups to make and calibrate the force measurer using the weight of various numbers of marbles to set a scale.

Jane is a first-year teacher. The teacher selection criteria required teachers to have a minimum of three years teaching experience to minimise issues such as classroom control and other complications associated with being a new teacher. Jane's experience in the PLD indicated that including her in the PLD was a good decision from a research perspective for developing a community of practice. Jane was very quiet during the PLD, deferring to the other teachers, and asking very few questions. Observing her at work in her classroom revealed a mixed result. I was very impressed by her decision to introduce the topic of friction by asking the students to observe the motion of kickballs. However, the class became quite playful, which was frustrating for her. When she brought them back inside, she gave the students step-by-step instructions on how to make the force measurer. The pace of progress was quite slow and the class grew restless during the construction. Jane appeared to be frustrated by the students' attitudes during this portion of the class. Once the construction was finished, she outlined what she wanted them to accomplish, leaving the exact procedure for them to determine, and they responded by behaving well and completing the calibration.

Ann had introduced the concept of friction previously, and began with a demonstration. Her students gathered around as she showed them her force measurer, and how it worked. She began by hooking it to a book and had the students watch the scale as she pulled the book across the floor. The students noticed that the force was highest just before the book started to move, then 
was constant while the book was moving at a steady pace. She then increased the pace and asked what they observed. They noticed that the force went up while she was speeding up, then went back to the same level. The students were very engaged during the demonstration.

She then asked the students to find a partner and help themselves to the materials (card board, rubber-band, and paperclips) and to make a force measurer of their own, explaining that they needed it to measure between 50 and 200 marbles worth of force. She gave no step by step instructions, but rather allowed the students to figure out how to make it themselves. The class ended just as the students were beginning to investigate pulling books across various surfaces.

During the PLD Ann was particularly concerned about the potential of her class being noisy, and appearing to be out of control during science investigations. This did not occur during my observation of her class. She, in contrast to Jane, gave minimal instructions on how to make the force measurers, allowing the students to use their ingenuity.

Karen began her lesson by pointing out a list of words on the board that the students were to use when they described their investigations. She divided the class into groups of four, and asked each group to work through a number of investigations during the class period. The investigations were at various stations around the room and outside, and included: a water balloon toss, pulling a table cloth from under light and heavy objects, a soft ball connected to a string which was swung around and released to try to hit a target, a push-off involving rolling office chairs with different sized people on them, and blowing heavy and light balls through an obstacle course. The students were very well organised and behaved. The group with the ball and string had problems initially, but Karen helped them understand what they were expected to do and they were able to accomplish the task. The students made notes of each investigation, which they were to use in the discussion the next day. 
The students were attentive, and the class was well organised. Karen gave clear instructions, and picked up on groups that were having trouble with their investigation, and was able to make suggestions that helped them see the point in the investigation, without simply telling them the answers.

Claire had taught several lessons on motion and forces prior to this class. She began her class by asking the students to write down what they thought of when they heard the word inertia. She quickly divided the class into groups of four or five and had them discuss it for one minute. She then gathered the group into a circle and asked them what they had written. The responses included: Force is applied to something at rest; objects like to stay still; a quality of matter; combination of three forces, gravity, velocity, and friction - friction slows it down and stops it, gravity pulls it down, velocity speeds it up; in a car - when you stop, things keep going forward; objects keep doing what they are doing until a force acts on it. Claire asked: "if gravity stopped, what would happen?"; she then swung the ball on a string in a circle and let it go. She asked them to watch again, and then turn to the student next to them and discuss what they saw, and repeated swinging the ball and letting it go several times. She asked them what the ball "wants to do" when you are spinning it, and what force is acting on it. The students were very engaged, and actively discussed what they saw in small groups. Claire brought them back together and held a full class discussion on what the groups had concluded.

The students in Claire's class were attentive and engaged. The first time Claire went through the ball on a string demonstration, the students reported the ball went straight out from the centre of the circle. As she repeated the demonstration, the students observed more carefully and gradually came to the conclusion that the ball travelled tangentially from the circular path.

After the fourth week of the PLD, the teachers decided to have their classes put on a "science road show" for the junior classes. Students worked in small groups to choose a science topic and create a demonstration illustrating some 
aspect of physical science. They set up tables in the hall, and from 9:30 until lunch the students gave science demonstrations to the junior students. As Claire described it:

I think you'd be quite taken by today - it was a bit manic [laughing] and by the end it was quite messy, but the kids had selected their own experiments. They were encouraged to do 'forces', but if it went into other things we didn't worry about it. And we were encouraging the kids to use the scientific language, especially the explanations, and some of them were just awesome. A really good understanding, and the way they explained them...

The science road show was not part of the PLD, and I did not find out about it until after it had happened. The teachers spent several class hours helping their students do research on a science topic that they could demonstrate and explain:

Ted - Is that something you have done every year?

Claire - We do science every year.

Karen - No, not to let the kids do something.

Ted - It sounds like a spectacular idea. It was like a micro science fair.

Karen - Only it was way better than a science fair. We've done science fairs in the past we've had to pose the question and they've done the research ... just walk around and just look at it - this was way more entertaining.

Ann - Better ... The hands-on thing made it so much easier to understand, because ... in my class, they had to show them to our class, and if we understood it, then we knew they were ready for them, but if we didn't then I asked questions on how they could explain it. Karen - I made my class do that with everybody as well, to practise. I got the kids to go - yes that was OK...

Ann - It taught them a lot too, if they couldn't explain it, they were like - oh, I know what to do but I just can't explain it. [I said] go back and read your notes and find out how to explain it. It was good.

During my observations, the teachers all used investigations similar to those conducted in PLD, but they all adapted the investigations to suit their classroom. Jane's use of the kickball was particularly innovative in that she was able to illustrate Newton's second law (kicking and stopping the ball), the first law (ball kept rolling on the concrete), and the force of friction (concrete versus grass) in 
one simple investigation. Karen's choice to conduct several investigations simultaneously, asking the students to record their results using scientific vocabulary, to be discussed the following day, was in sharp contrast to Claire's approach of illustrating one particular concept, emphasising careful unbiased observation to see something that is counter to expectations. I was impressed by the variety of approaches, as well as the adaptation of the investigations. They all had the science concept they wanted to teach clearly enough in their minds to be able to adapt the procedures to suit their teaching style, and their classes.

The science road show occurred because the teachers saw an opportunity to put some of the concepts we were covering in the PLD to use in their classrooms and simultaneously promote science to the younger students. Early in the PLD I introduced the teachers to a number of simple science "tricks" that illustrate concepts involving mass, inertia, and friction, such as pulling a tablecloth from a set of very light Styrofoam dishes versus heavy dishes, flicking a card out from under a coin which falls into a glass, and others. The teachers decided to show the demonstrations to their class, and encouraged their students to choose a demonstration relating to the Newton's law topic, but allowed them to research and select any physical science demonstration they wanted to perform, providing it was safe, and they could explain it. The teachers reported the road show was a very positive experience for themselves and the students.

When the teachers told me about the road show I had mixed feelings about the educational effectiveness. On one hand the students were able to have a positive experience in science, but on the other hand the demonstrations were isolated, and not part of a coherent unit plan. Claire described her motivation for the road show approach:

I really think that we need to take these things we've done with you, and take them into our classroom, we've done a couple of things, but now just grab that and come back and to plan that unit, we wouldn't be teaching it this year, the 
unit would be there for next time. Just ground what we've learned as well. And then also if we've done more with our class then we can come back and say this didn't work and this did work and when somebody asked me why about whatever it is I didn't know how to explain it, so it will be our professional knowledge growing.

Claire makes it clear she understands the value in teaching a coherent unit, but also instinctively knew that unless the newly learned material from the PLD is put to use promptly, understanding may fade or be lost. Claire's plan was to teach the various concepts from the PLD this year, and afterwards evaluate the material and plan a coherent unit. The PLD provided Claire with confidence and motivation to teach lessons on the various Newton law topics; however, she did not feel that she could develop a unit plan until she had the experience of teaching the material, and observing the response from her students.

I was impressed by the courage and ingenuity exhibited by the teachers in iteration-two in organising the science road show for the junior classes. In one week the teachers were able to guide their students in choosing an appropriate science topic to illustrate with a demonstration that could be done using materials they could find for themselves, and practise the demonstrations with their classmates asking questions. As already noted, the teachers felt the road show provided an experience for their students that was richer than the science fair experience. The scope of the road show was much less, and students did not conduct an independent investigation; however, they learned about, and were able to explain a scientific phenomenon; and had the opportunity to share their understanding and enthusiasm with their younger schoolmates.

The need for teachers to evaluate the effectiveness of PLD inspired changes is a common factor of several of the models of teacher development described in Section 2.3.2. In Clark and Hollingsworth's (2002) model, for example, the process of using the new material, and subsequent evaluation of effectiveness is called "professional experimentation". The extension of the PLD to include classroom observation was primarily to provide data for evaluation of the framework; however, the theoretical models and Claire's comments suggest that 
the PLD process is not complete until the teachers put the material into use, evaluate the effectiveness, and adapt it for their own use. The process involves growing the subject matter understanding of the teachers to the stage where they are confident enough to teach the material, at which point they become the participant observers in their own professional experimentation. Observing how their students endeavour to learn the material builds their PCK.

\subsubsection{Discussion}

The experience in iteration-two highlighted three areas that bear further examination - the importance of documentation, the NZC, and focusing the PLD on a specific area within the physical sciences - which are discussed below. The major findings from all three iterations will be discussed in the final summary discussion chapter.

\subsubsection{Documentation}

As mentioned previously, Claire took extensive notes during the PLD; however, the other teachers did not. Given her stated plan for the teachers at School-one to teach the PLD material to their students this year, and not design a coherent unit sometime afterward, some documentation system that would record the information that is the most relevant for teaching would have been very useful. The teachers in iteration-two, like most teachers in NZ, are generalists, and have little time to review specific science content that they may not have thought about since the last time they taught it, frequently two years (in the case of teachers who teach combined Year 7 and 8 students). Those considerations are what led me to select the Content Representation ( $\mathrm{CoRe}$ ) framework, described by Loughran, Berry, and Mulhall (2012b) to provide documentation for the PLD for iteration-three. The framework was developed as a method of making the abstract concept of PCK more explicit, to quote the authors: "The CoRe framework created a coherent way of conceptualizing science content that reflected (for us) the inherent knowledge of practice that we saw in expert teachers but which they themselves so often struggled to articulate" (p. 10). 
Although not developed for documentation of PLD, the structure of the CoRe incorporates both pertinent subject matter information as well as relevant teaching decision information, which is precisely the type of information, PCK, that teachers would find useful when teaching a topic, as Claire is indicating at the end of Section 5.2.6.

The horizontal axis of the CoRe framework consists of the "Big Ideas", identified by the teachers as vital for the students to grasp in order to understand the science topic. These are similar to the "Big Ideas" contained in the curriculum support materials provided by the New Zealand MOE (e.g., MOE, 2003). The vertical axis of the CoRe consists of a set of prompts: What you intend the students to learn about this idea; Why it is important for students to know this; What else you might know about this idea (that you don't intend students to know yet); Difficulties/limitations connected with teaching this idea; Knowledge about students' thinking which influences your teaching of this idea; Other factors that influence your teaching of this idea; and Teaching procedures (and particular reasons for using these to engage with this idea).

The framework was developed over several years of working with successful science teachers with the aim of capturing the concrete and specific questions they consider regarding the content they choose to teach on a given topic (Loughran, Berry, \& Mulhall, 2012c). ${ }^{5}$ Although developed through working with experienced science teachers, the CoRe has been found to be beneficial working with novice teachers as well. For example, working with student teachers, Hume (2010) found that her students benefitted from using the CoRe, although they found it challenging to complete because of their lack of classroom experience. Teachers in PLD situations, however, frequently have classroom experience, and in the course of the PLD they gain a deeper

\footnotetext{
${ }^{5}$ A second element of the framework (Pedagogical and Professional-experience Repertoires) captures the accounts of experience gained while teaching the topic. While this may well be a valuable tool in documenting the entirety of PCK, I did not deem it appropriate in documenting the content portion of the PLD.
} 
understanding of the subject matter as well as PCK; therefore, the CoRe framework appears to be a good fit for science PLD documentation.

\subsubsection{Curriculum}

The teachers in iteration-two, unlike the teachers in iteration-one, used some of the curriculum materials provided by the MOE, specifically Making Better Sense of the Physical World (MOE, 1999). They did not, however, use the resources to learn about the underlying science, but rather for a source of science activities for their classroom. I was intrigued about how the teachers would tackle a topic they had not taught before, so I asked the teachers what they would do if they were asked to teach a specific topic such as heat:

Karen - So you tend to stick with what you are comfortable with. Now and then you might think, now it's time to learn something,

Ann - We sit down when we do our syndicate thing, ${ }^{6}$ and we plan out, like we said before you came, we planned out that we were going to do science things. None of us were really comfortable. We decided we needed to do it.

Claire - We need resources to trigger ideas and get you thinking and soak up a little information to get us started, eh?

Ann - yes, and I think as teachers we know that we have a responsibility to give them a variety during their time at school, so, I'm aware that you can't do the same thing every time.

Karen - Yes, and I think what would help would be if there was a list of people, for want of a better word, if we had to do heat in three weeks time, if there was someone like yourself that could just sit down and go, chug, chug, chug.

Karen - Because what I did here was basically what you did with us. So if there was somebody, or somewhere you could go, where there are suggestions, and you'd think, yea, I could actually do that because it's not hard, or I can do that because

Claire - I get it

Karen - yes, because I get it, dead right. That would help. Like they used to have the science advisors.

Ann: We have YouTube ... It [YouTube] doesn't just throw ideas at you, you have to find an idea and then you can YouTube it, but for ideas themselves...

${ }^{6}$ A syndicate is a group of teachers who work and plan together. 
This dialogue shows that the teachers in iteration-two are similar to the teachers in iteration-one in that they feel the NZC does not restrict what they are to teach, but they are unsure where to start, and are in need of "resources to trigger ideas". They also highlight a problem with the quantity of resources that are available via the internet. Ann's assessment of the trove of YouTube videos is that you have to know something about what you are looking for before you can construct a search likely to produce meaningful results.

Similar to the challenge faced by the teachers in iteration-one (see Section 4.2.7), the teachers in iteration-two spoke of not knowing enough physical science to be able to choose topics that are appropriate for their students. However, when they gained a basic understanding of the fundamentals of a topic, resources available via the MOE materials mentioned previously (e.g., MOE, 1999) could be used by the teachers as review material. Once a foundation is laid in a topic, teachers are able to search the internet in a more targeted manner.

Another challenge presented by the NZC is to ensure the chosen topics are relevant to the students. Put another way, teachers are tasked with unveiling the science present in the everyday lives of the students. In Section 5.2.2.1 Claire described her experience of suddenly beginning to see examples of the laws of motion all around her that she was unaware of until she developed an understanding of the concepts.

The teachers in iteration-two had taught a short unit on electricity, and a unit on sound waves, and were keen to teach at least one additional physical science topic. When the opportunity for science PLD was offered, they chose the topic of Newton's laws as something they felt their students would find interesting. A barrier for them was similar to the teachers in iteration-one, which is how to pick an area of science to teach, when they lack the basic knowledge of what areas of science exist, or might be appropriate. In the absence of a specific curriculum that requires teaching a particular topic, they literally don't know 
where to start. Science is just one of many subjects, and the time pressure of their teaching made it difficult to develop sufficient background to investigate the potential areas of science they could cover. A PLD is a jump start, which identifies an area of science and gives them the motivation and enough background to engage with support material.

\subsubsection{Physical science at primary level}

In a discussion during the second PLD session, we were talking about why large and small steel balls fall at the same speed, but a balloon falls slower than a marble. Karen felt her students would grasp that concept easily:

Karen - I think they will work that out actually, way quicker than we will because their perceptions are way less entrenched than ours.

Claire - entrenched? LAUGHTER

Karen - Well they are, especially in my case.

Ann - That's what you think will happen?

Claire - We have certain assumptions, and this doesn't match those assumptions and it's not necessarily an educated assumption -

Karen - Whereas they haven't been around as long to have the same perceptions that we have. I think that they will come to some sort of understanding way quicker.

Karen's suggestion that young people can often come to an understanding of the counter-intuitive aspects of physical science easier than adults is supported in the longitudinal research of Novak (2005) (see section 1.2.5), which documents not only the ability of younger students to master fundamental science concepts, but also the benefits which come from early exposure. This discussion, along with the previous quote from Claire, highlights the importance of fostering an understanding of the physical sciences in primary school children. Building deep understanding, however, involves spending time and laying a solid foundation for a narrow selection of material. Given the breadth of the Physical World section of the NZC (MOE, 2007a), and the relatively small amount of classroom time devoted to science, building understanding in one area at the expense of other areas may be a difficult choice for schools. Nevertheless, Claire expressed the desire to focus quite narrowly to achieve a 
deeper understanding of Newton's first law of inertia (see section 5.2.1.2) rather than attempting to cover all three laws.

\subsubsection{Design changes}

This chapter described the second iteration of the PLD design framework, beginning with the framework as it existed after iteration-one. Changes in the framework that occurred as the result of iteration-two are shown in bold in Figure 37. The third and final iteration of the framework will be described in the following chapter. 


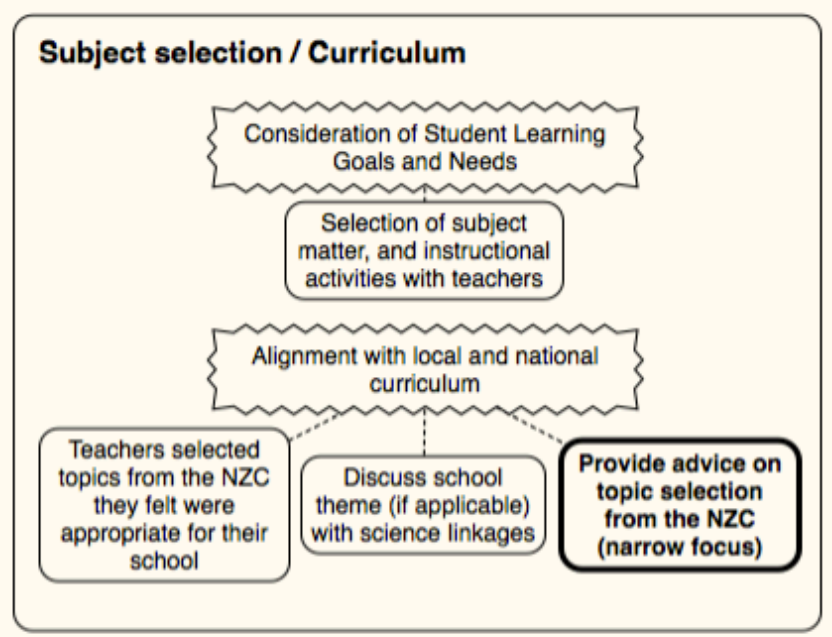

\section{Teaching Practice}

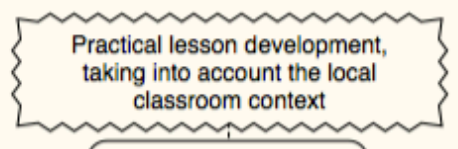

PLD conducted in the
classrooms at the classrooms at the
school, designed with the teachers
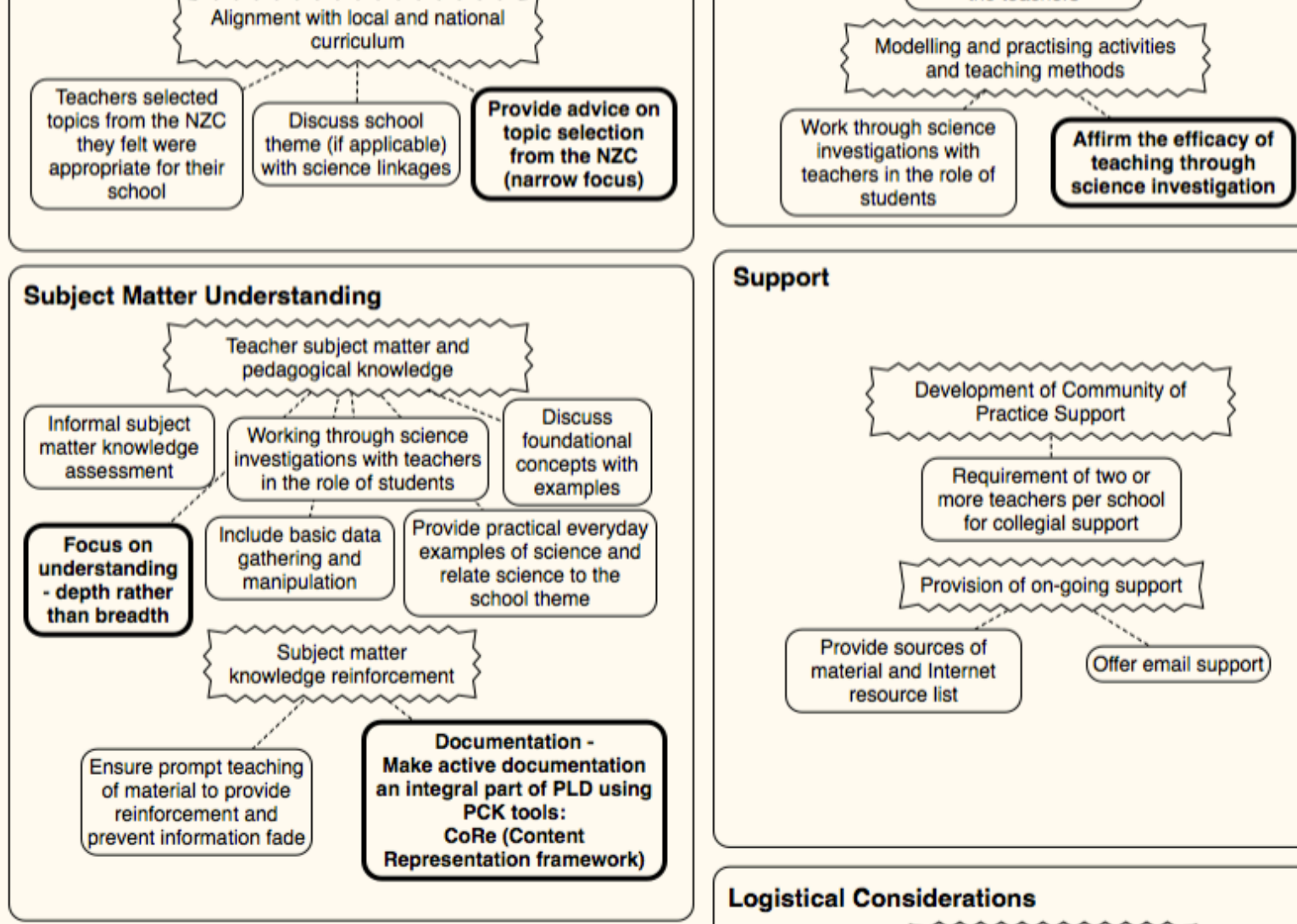

Support

Logistical Considerations
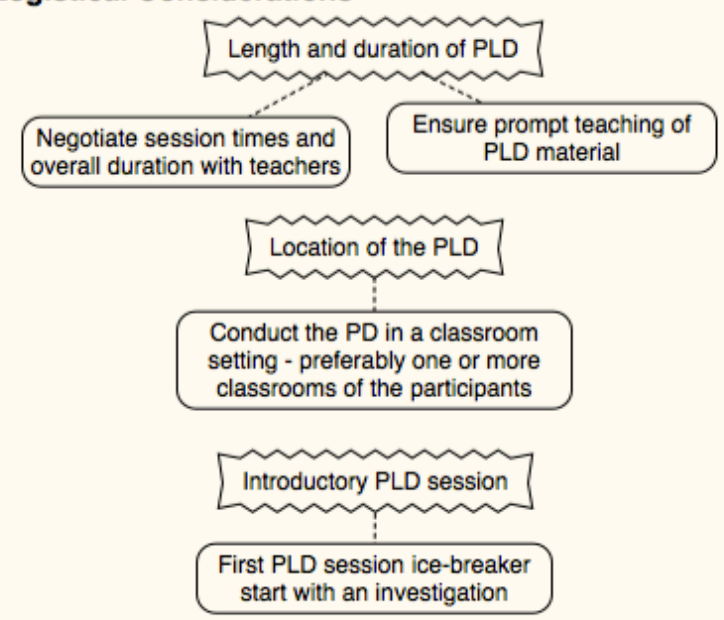

Figure 37: Design framework - iteration-two 


\section{Chapter 6 Third Iteration}

\section{Introduction and overview}

This chapter is the third and final iteration of the science PLD for a group of Year 7 and 8 teachers. Decisions made during the planning, design, and execution of the PLD were made using the PLD framework developed from analysis of the literature and refined through the previous two iterations (see Figure 37).

This chapter follows the pattern of the previous two iteration chapters, presenting a description of the school and teachers, an overview of the PLD, and a review of the PLD framework, examining each area in light of the experience gained during this iteration.

\section{The school and teachers}

The canvas of decile 5-7 schools in the local area did not result in any additional candidates for the PLD. A decision was made to widen the inclusion criteria to include schools in deciles 4 and 8 , which produced 18 more potential schools. The reason for limiting the decile range of schools was to avoid variability which could be introduced by the affluence of the community. While increasing the decile range increases the variability slightly, the extremes of the range are still avoided (see Section 3.6). A subsequent canvas yielded two potential schools. A group of three teachers from School-three, and a single teacher from Schoolfour initially expressed interest in forming a group for iteration-three. The research design called for at least two teachers from each school in order to provide for sufficient collegial support; however, the design also called for a group of four to six teachers in iteration-three. I decided to proceed with the mixed school group, with the intention of exploring other avenues of support for the single teacher. After the initial meeting with teachers from School-three, two additional School-three teachers expressed interest in joining, and became part of the group following the initial meeting. The single teacher from School-four attended three of the PLD sessions, but eventually withdrew due to schedule 
conflicts and transportation issues. Transcriptions from that teacher are not used for analysis.

School-three is a decile 8 intermediate school with an enrolment of approximately 600 Year 7 and 8 students. The group of five teachers in iteration-three are Jenny, Tammy, Paul, Anna, and Betty. The teachers at School-three are from two different syndicates. Jenny was the lead teacher in her syndicate, and Anna was the lead teacher in hers.

None of the teachers had taken any science papers at university. Tammy, Jenny, and Anna had the most teaching experience with 29, 20, and 10 years respectively, and Paul and Betty had the least experience, each being in their third year of teaching. Tammy had completed a four-day PLD science academy course in 2014.

\subsection{PLD overview}

This section provides an overview of the structure and content of the PLD. The PLD structure is the same as in the previous iterations, consisting of a brief initial meeting, followed by an introductory PLD session to set the tone of the PLD, a series of topic-focused PLD sessions, a classroom observation, and a final wrap-up session.

\subsubsection{Initial meeting}

For scheduling reasons, I met initially with Jenny, and followed that up with a brief meeting with the other teachers a few days later. The purpose of the meeting was to discuss the research project and answer any questions they may have had after reading the description of the research they had been provided with previously. We also discussed potential science topic areas so that the introductory PLD session would be an investigation that would be germane to the PLD. During the initial meeting with Jenny, we discussed a number of potential areas, including magnetism, gravity, sound, and light. I 
suggested she discuss potential topics with the other teachers involved. When I met with the other teachers they had decided on light as a topic.

We decided to meet weekly after school in a classroom for six meetings lasting 60 to 90 minutes.

\subsubsection{Introductory PLD session}

As in the previous iterations, iteration-three began with an investigation. I prepared a "mystery box" which was lined with dark paper and contained a good quality colour spectrum ranging from violet to red. The box was sealed except for a viewing slit, and was equipped with light emitting diodes (LED) for illumination. Three different coloured LEDs - red, green, and blue - could be turned on, one at a time so that the light illuminating the spectrum was monochromatic. The teachers were not told in advance what the object in the box was, and they were asked to simply make observations of the object illuminated by the three different coloured lights.

After all of the teachers had had a chance to make observations, I asked them to describe what they saw, after which we opened the box to the room lights and briefly discussed what they observed. We concluded the meeting with the semistructured interview described in section 3.9.

\subsubsection{Topic-focused sessions}

As in the previous iterations, the topic-focused sessions were a mixture of investigations and discussions. School-three did not have a school theme, but since the school had recently conducted some activities commemorating the "year of light", the teachers felt light would be a popular topic for their students.

A change in the PLD framework introduced following iteration-two was to use the CoRe tool as a way for the teachers to organise the information from the PLD. As discussed in section 5.2.2.2, the CoRe is implemented by selecting a 
key "big ideas" (sub-topics) about the topic in question, and then answering various questions about those big ideas.

The experience in iteration-one, when I asked the teachers what sub-topics of sound they wanted to include, resulted in their being frustrated that they did not know enough about sound to choose appropriate topics. I was therefore hesitant to ask the question directly to the teachers in iteration-three, and took a different approach.

I began by asking the teachers what they knew about light and developing a concept map, as in the previous iterations. I extended the process in this iteration by asking the teachers what questions they had about light, and what questions they thought their students might have about light. I proceeded to link concepts that were related. The linked questions fell into three groupings with a few that did not connect to any others. From the three groups of linked questions we formed questions concerning the "big ideas" that would be the focus for the PLD. The questions were: "What is light?", "What happens to light when it hits stuff?", and "How does colour work?"

When preparing for the meeting I had made a list of potential topics, which I showed the teachers, and we added a few of the topics from my list to theirs. I also added potential investigations and demonstrations that we could do during the PLD. I planned the topic-focused sessions; however, the exact order of topics was driven by the questions that arose from the investigations. The resulting content of the topic-focused sessions is summarised in Table 8. 
Table 8: Topics and investigations in iteration-three

\begin{tabular}{|c|c|c|}
\hline Session & Subject matter content & Investigations \\
\hline PLD 1 & $\begin{array}{l}\text { Develop Big ideas } \\
\text { Light as waves }\end{array}$ & $\begin{array}{l}\text { Squeezing a beam of light between } \\
\text { pencils, looking at the edges of } \\
\text { shadows, putting light through a small } \\
\text { hole. }\end{array}$ \\
\hline PLD 2 & $\begin{array}{l}\text { Finalised } 3 \text { big ideas } \\
\text { Frequency, wavelength, amplitude } \\
\text { Waves and energy } \\
\text { Electromagnetic spectrum } \\
\text { Diffraction }\end{array}$ & $\begin{array}{l}\text { Made waves on a slinky } \\
\text { Looked at clear lamp with diffraction } \\
\text { gratings }\end{array}$ \\
\hline PLD 3 & $\begin{array}{l}\text { Where light comes from } \\
\text { Plane reflection } \\
\text { Diffusion }\end{array}$ & $\begin{array}{l}\text { Image in plane mirror, Full length mirror } \\
\text { Made diffraction gratings from CDs }\end{array}$ \\
\hline PLD 4 & $\begin{array}{l}\text { Refraction } \\
\text { Prism } \\
\text { Colour }\end{array}$ & $\begin{array}{l}\text { Spear fishing } \\
\text { Lasers through glass blocks } \\
\text { Colour optical illusions }\end{array}$ \\
\hline PLD 5 & $\begin{array}{l}\text { Colour continued } \\
\text { Rainbows } \\
\text { Polarisation }\end{array}$ & $\begin{array}{l}\text { Working with prisms } \\
\text { Polarising filters }\end{array}$ \\
\hline PLD 6 & $\begin{array}{l}\text { Lenses and the eye } \\
\text { Ray tracing } \\
\text { Polarisation continued }\end{array}$ & $\begin{array}{l}\text { Lenses and images } \\
\text { Polarising filters }\end{array}$ \\
\hline
\end{tabular}




\subsubsection{Unit planning, observation, and wrap-up}

The teachers in iteration-three, like the teachers in iteration-two, began to teach the material of the PLD prior to finishing the PLD. Although this was not in line with the way I envisioned the research project, I did not feel I could, or should, dictate what they would do in their classrooms. They began teaching light topics after the fourth PLD topic-focused session. I decided to discuss unit planning during the final topic-focused session, at which time we would have covered all of the subject matter of the PLD, and they would have an idea how their classes responded to the material they had presented thus far. I encouraged the teachers to think about the topics we had covered, and consider what big ideas they would want to include in a unit on light. Jenny pointed out that a big idea such as "what is light?" was really made up of a lot of big ideas, and suggested "how do we see colours?", and "how does light behave?" The teachers discussed the options for big ideas, and considered how best to approach the topic.

At one point in the discussion Jenny asked: "Do you think we'll be able to plan this on our own next year?", and the answer from the other teachers was an enthusiastic yes. Anna mentioned that she would likely have many of the same students next year, and that she would be fine doing more next year, because light was such a broad topic and she felt she had plenty of material to choose from.

I arranged to observe one lesson for each teacher, which I will describe in section 6.2.6.

The final wrap-up session was held after school the day I observed all of the teachers. I asked the teachers to reflect on the PLD, and share their observations and suggestions for improvement. The teachers had several comments, which I will incorporate into the analysis and discussion that follows. 


\subsection{Framework review - iteration-three}

The structure of the framework review will follow the pattern of the previous iteration chapters, using the design framework as it exists following iteration-two (see Figure 37). The existing framework will be evaluated in light of data from the PLD, and additional content design characteristics and/or implementation advice will be added if data from the PLD support a change.

\subsubsection{Subject selection / curriculum}

The design characteristics and associated implementation advice from iterationtwo (see

Figure 38) were supported by the experience gained in iteration-three, with no new implementation advice added. The teachers in iteration-three did not have a science topic in mind prior to starting the PLD. On my initial meeting with Jenny, we talked about a number of potential topics. She indicated the school did not use a thematic approach, although the school had just done some activities to commemorate the "year of light". She discussed the matter with the other teachers involved and decided that we would focus on the topic of light.

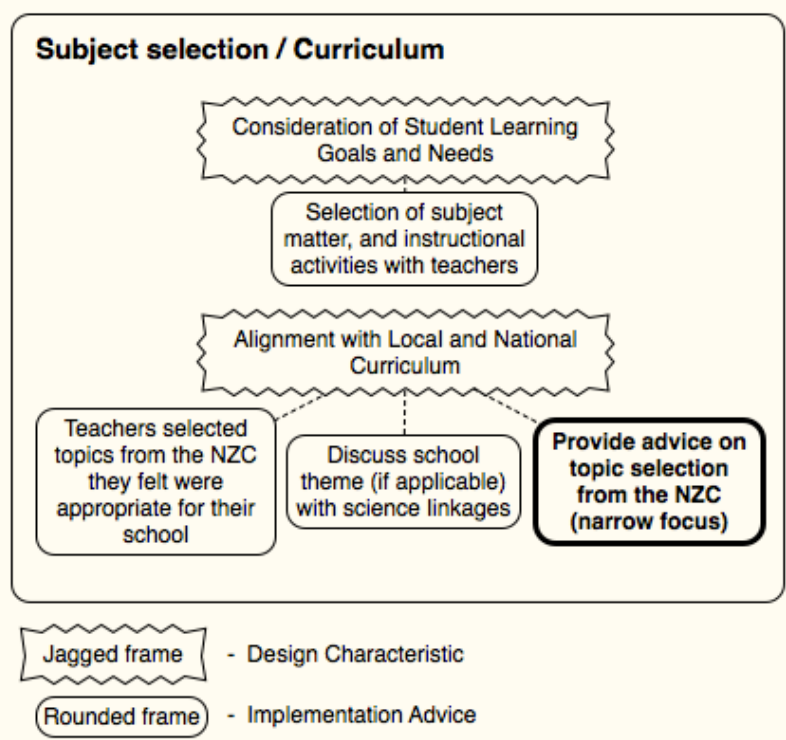


Figure 38: Subject selection / curriculum as established in iteration-two

\subsubsection{Consideration of student learning goals and needs}

\section{Subject matter selection}

During my first meeting with Jenny, she mentioned that she was keen to teach a topic in the physical science area. She felt that the PLD would be a good way learn material to "spark their [students] interest" in a topic. Tammy described working with the NZC this way:

The way the curriculum has been written in New Zealand is to give complete flexibility, you know it's not skills based, you know? ...the flexibility makes it a little bit grey, and what can end up happening is, ... I had been teaching full time at that school for about five years, and in that time we had never done planet earth and beyond throughout the school. So feasibly a student could have gone all the way through school just about without having looked at that at all, and there were big gaps. What tends to happen is literacy and numeracy is a bit discrete, integrated into topics, but it exists on its own doesn't it? ... I think that is a problem with the curriculum in New Zealand, it varies extremely from school to school, and who the staff is at the time, and the expertise and interest from the staff as to what kinds of things you might end up doing.

Tammy expressed concern that breadth of the science portion of the NZC, combined with the limited teaching time allocated to science, meant broad areas were being missed, and that the specific science topics covered varied substantially from school to school.

The teachers in iteration-three indicated that, because of the limited amount of time they could spend on their own subject matter learning, their topic choices were influenced not only by consideration of what the students would need, but also by what topics teachers were familiar with:

Betty: What is holding me back at the moment is that I have to think through what I need to do quite a bit, and I have to get fresh with it. So like today, I just went to the DVD, and that was science today. That's what is holding me back, not so much time, but the time out of class to get my head around what I want to do. 
Jenny: The other thing I was thinking, like what Betty was saying, is what actually guides you, as much as the students is what do I feel knowledgeable about? That's why I haven't done [physical science].

Here Betty and Jenny describe the challenge posed by limited science knowledge and time pressure influencing them to select topics from among things that they are familiar with, rather than considering all potential topics from the NZC, and choosing ones that were most interesting to their students, or best suited to their school environment.

Although my working with the teachers to select the topic for the PLD allowed them to select a topic area in which to build knowledge and confidence to teach, the problem of not being able to assess the merits of various topic options in the NZC with regard to student learning goals and needs remains. In some ways light was an arbitrary choice, as the connections between aspects of the science of light, and their students were not revealed until the teachers learned more about the topic. I will return to the challenge posed by topic selection in the final discussion chapter.

\subsubsection{Alignment with local and national curriculum}

\section{Teachers selected topics from the NZC appropriate for their school}

As mentioned in the introduction, the teachers in iteration-three were from two different syndicates, and the choice of specific science topic had to be agreed by both groups. This additional coordination requirement reaffirms the importance of selecting the PLD topics with the teachers.

\section{Alignment with school theme}

School-three did not have a school theme, and therefore no consideration had to be given to making connections between the topic and the theme. However, when a school uses a thematic approach to the curriculum the consideration is relevant, therefore the implementation advice remains valid. 


\section{Provide advice on topic selection from NZC (narrow focus)}

The implementation advice to assist with topic selection from the NZC, added in iteration-two, was employed in this iteration during the co-operative planning session described in detail in section 6.2.3.1. In the process of selecting the content to be included in the PLD, I was able to highlight questions and topics that were related by their common foundational concepts, and that could be successfully covered in the time allotted. For example, topics covered in the "What is light?" area laid a foundation for topics in the other sections. Other topics of interest to the teachers, such as how light affects emotional states, and how light affects plants, would have required additional background material, and were not included in the PLD. This advice was supported by the experience in iteration-three.

All of the implementation advice from the literature review and subsequent iterations was supported by the experience in iteration-three; the resulting Subject selection / curriculum area is shown in Figure 39.

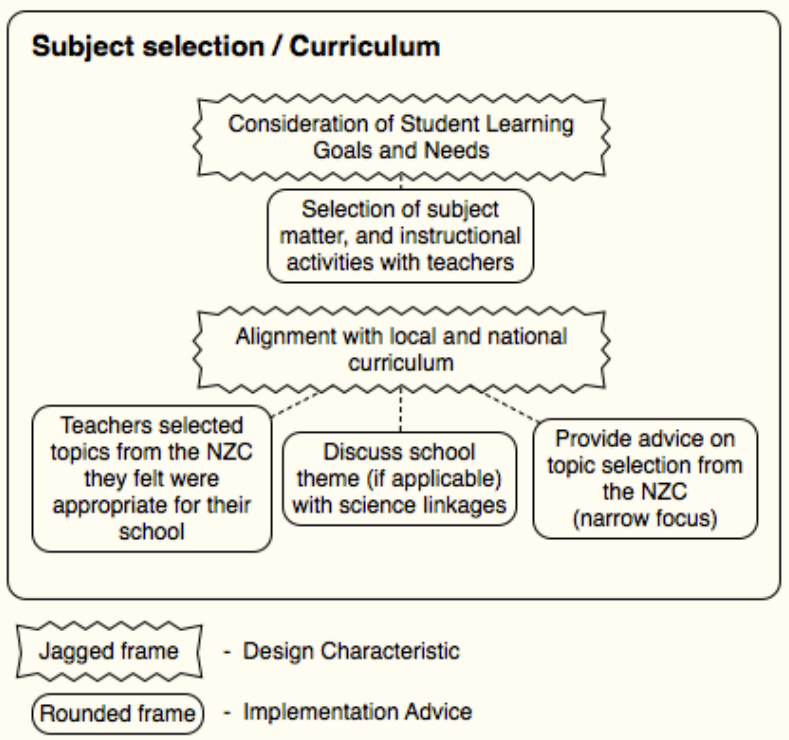

Figure 39: Subject selection / curriculum - iteration-three 


\subsubsection{Subject matter understanding}

The area of Subject matter understanding was expanded following iteration-two (see Figure 40) to include the additional implementation advice to ensure a focus on in-depth understanding (see section 5.2.2.1), and two additional areas involving documentation, providing summary documentation of the investigations, and to make documenting the PLD an integral part of the PLD. The introduction of the CoRe framework as the documentation system seemed to have a positive effect on this iteration as evidenced below.

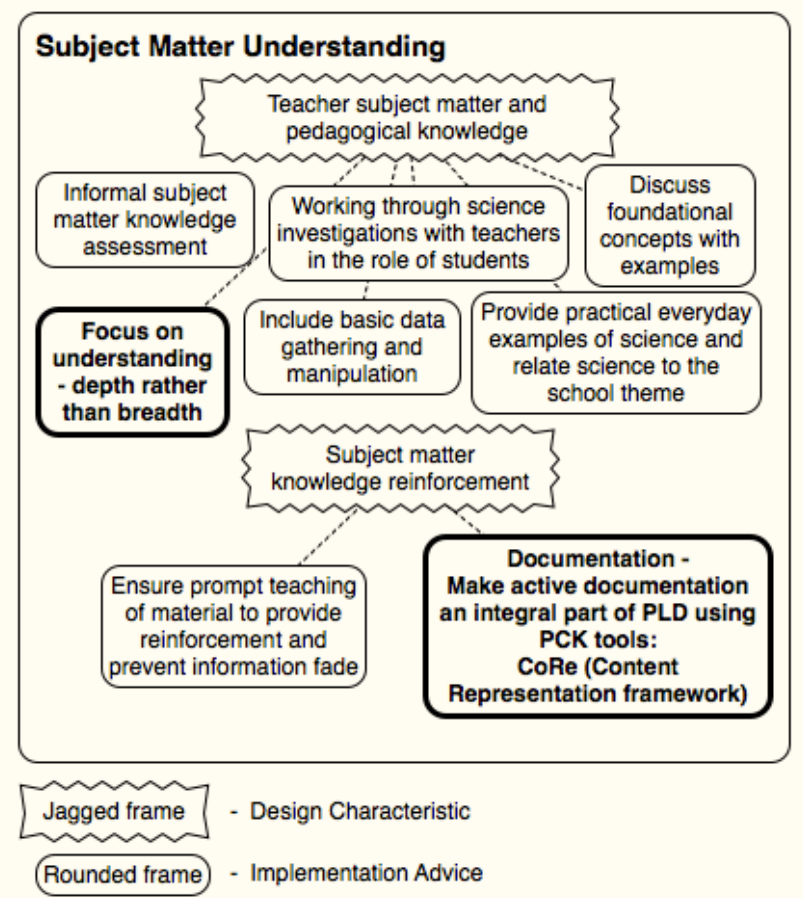

Figure 40: Subject matter understanding as established in iteration-two

\subsubsection{Teacher subject matter and pedagogical knowledge}

\section{Assessing teachers' science knowledge}

As in the other iterations, I assessed the teachers' knowledge through the informal means of discussions and by creating a map of concepts related to light. The concept map for this iteration was similar to previous iterations, revealing some knowledge of light terms, and relatively few connections 
between the terms. In all three iterations this initial concept mapping process revealed the teachers did not have a great deal of knowledge about the PLD topic, and therefore one may be tempted to abandon it. In all three iterations, however, it was a useful early step in focusing the groups, and on the off-chance that a group, or individual teacher, had deeper knowledge it would be important to understand that at the beginning in order to recognise the expertise and incorporate it into the PLD.

As mentioned in section 6.1.3, I extended the concept mapping process in this iteration and I will discuss that further in section 6.2.3.2.

\section{Teachers in the role of students}

In this iteration we conducted one complex investigation, which involved locating an image in a mirror by ray tracing using a cardboard base, paper, a small mirror and sewing pins. The investigation illustrated the concept of an optical image, and provided experience in tracing light rays from an object to an observer, a necessary skill when working with lenses, which would come later in the PLD. I provided the teachers with the materials and gave them brief instructions on how to conduct the investigation. I explained that investigation involves looking at the reflection of an object in a mirror, and then placing two pins so that they are in the direct line of site to the reflected object, then moving your eye so that you are looking from a different vantage point, and placing two additional pins in the new line of site. You can then draw the reflected rays of light from the surface of the mirror to your eye from the two vantage points. When you extend the lines through the surface of the mirror, where the lines meet is where the reflection of the object appears to be. Jenny got the idea quickly, and simplified my instructions by explaining that: "you just line all three pins up".

This investigation is an example of a concept that is difficult to comprehend until an investigation is undertaken. The phenomenon of an investigation triggering deeper understanding is described by Goldberg and McDermott (1986), who 
found the students in their study were not able to interpret common ray diagrams correctly until after they had experienced the investigation, despite having a verbal understanding of the laws involved. While the time involved in working through the investigations with the teachers in the student role is substantial, their trust in the workability of the investigations, as well as their own knowledge development, argue for the practice.

During the follow-up meeting with teachers we talked about why relatively little classroom time is devoted to science:

Anna: ...we as children in the primary school system also didn't get a lot of science. We don't feel confident too I expect.

Ted: Confident in?

Anna: Explaining or teaching the concepts. ... We've been able to do an inquiry, because we know more, and we can guide their work.

In this dialogue, Anna talks about the importance of having confidence in the investigations, and adequate understanding to guide students when engaging in hands-on science.

\section{Discussing foundational concepts with examples}

The foundational concepts for light include waves, wave behaviour, and energy, among others. To illustrate the parts of waves, and the relationship between energy and waves, the teachers used a large spring (slinky). Teachers made waves on the spring, and investigated the relationship between the length of a wave and frequency, defined the basic parts of a wave, and by attaching a marker to a point on the spring we looked at the difference between what was travelling along the spring, versus how the spring was actually moving. Visualising the material of the spring moving back and forth while the wave moved along the spring allowed us to visualise energy moving along the spring, and separate from the motion of the medium. We also looked at two different ways to add more energy to a wave by increasing the frequency and increasing the amplitude. 
When we were reviewing how energy and waves were related, Paul recalled: "...more energy the higher the frequency. I remember watching Anna, she was going crazy, using her own energy and increasing the frequency." He doesn't have to simply memorise the relationship, he can understand it through his own (or Anna's) experience. The components of a wave, and the use of a spring as the medium for visualising waves, were also used in the study of sound in iteration-one, and would also be applicable to a number of other types of physical phenomena. Paul's statement that his understanding of wave energy came from the investigation also supports teachers working through the investigations as students.

\section{Focus on understanding}

The implementation advice to focus on understanding was added during iteration-two as a result of the teachers expressing their desire to understand the concepts we were studying more deeply, even at the expense of covering more topics. The experience of iteration-three reinforced this advice. Although the teachers did not explicitly express it in the way the teachers of iteration-two did, their desire to really understand was apparent in several interactions.

The following dialogue occurred when we were discussing the relationship between light shining on an object and its colour:

Ted: Does somebody want to ... explain the surface colours to Paul? You haven't had any of that yet...

Betty: ... that was the one that Anna explained, eh?

Betty: It was actually why, the actual science behind, the molecular reasons why light hits stuff and you see a colour, like why is that green and why is that black.

Jenny: So when we look at blue, blue is reflected into our eyes, why? Jenny: I don't think they need to know that, they just need to know, well, with my kids I just simplified it a little bit, so I went when you see blue, blue is reflected into your eye, when you see black, all of the colours are absorbed. Paul: I did not know that. I thought it was the absence of colour.

Anna: It is, because there is an absence of reflection, because it is absorbing like, all of the colours. 
I had the impression that Anna was on the brink of understanding the relationship between an object's colour and the light colour, so I asked a probing question:

Ted: So wait a minute, if I want to make black, and I have a whole bunch of colours, what would I do?

Anna: All of the colours of light get together and make white. So why is the opposite, I had this...

Tammy: So the light comes in, and some colours can't get out again.

Anna: We talked about this afterwards, and we really got it,

Ted: You do get it, you've got it, but you need to explain it to someone before you really understand it, and that's what I want you to do to me now.

Anna: Can you explain it again, and then we can explain it to each other?

Jenny: Because light comes in, and hits blue, it absorbs all of the other colours but blue, and blue is reflected off.

Paul: That's a good explanation.

Anna: It actually absorbs all of the other colours, and what's left of the white light is blue, all the rest is still in there. And that's why things that are black absorb all of the light. That's why they get hot, because they are absorbing all of the energy.

Here I asked Anna a question to probe her understanding, and her response indicated some uncertainty between colours of light and colours of surfaces. She seemed unhappy with her understanding and asked for me to explain it again, but before I had the chance, Jenny offered the explanation in her words. Anna then went on to solidify the explanation by extending it to include an explanation of why black coloured things get hot in the sun. This exchange showed an eagerness to understand colour beyond a casual understanding, as well as the desire to solidify the understanding through constructing explanations for others.

The desire to explain phenomena in their own words happened frequently beginning after the second topic-focused lesson when Paul had to leave early and missed an investigation, and I asked one of the other teachers to fill him in. They realised that explaining a concept to the group led to their own deeper 
understanding. We talked about this effect at the conclusion of the fifth PLD session:

Ted: I think today was a really good day. I'm really pleased with the explaining of it to each other.

Anna: It's a miracle, it's quite hard, explaining it. Jenny: Quite a powerful tool.

Betty: It's a good reminder about being a good teacher eh?

Ted: It's all about asking questions.

Anna: It makes me put lots of thought into it.

Jenny: I suppose what I would want is for the kids to be as engaged as I feel about it.

Active participation by the teachers in leading reviews of material and explaining concepts to the group will be discussed further in section 6.2.3.2.

Another example of teachers in iteration-three wanting to understand the material deeply involved what I consider an error I made when we were working on an investigation of polarising filters. I introduced the concept of polarisation using a standard analogy of how a transverse wave interacts with a physical object such as a picket fence or a cooling rack (see Chandrasekhar, Rainwater, Litherland, Swope, \& VanNest, 1995, for example). The first filter selects for a particular plane of polarisation, and the second filter either lets the light through (when the filters are aligned in parallel) or blocks the light (when aligned perpendicular). I was impressed how easily the teachers picked up on how polarisation works, and how the demonstration showed the wave nature of light. In the penultimate PLD session during a review of polarisation I made the error of showing them that the introduction of a third filter, between the two filters, would unblock the light, and allow it to pass. I was aware of the effect, and thought it would be good to show them that the model of the picket fence was limited. What I had not counted on was their dissatisfaction of having their model destroyed by the demonstration, and not going into the underlying science. They spent the next 15 minutes asking questions and attempting to make sense of this new information. The reasons for the effect involve a mathematical representation of the electric field vectors, which is a topic well 
beyond what I had intended to cover with the teachers. I was able to explain the effect to some degree, but I fear the result was not very satisfactory for the teachers. They had become used to understanding the phenomena we observed in our investigations and were not satisfied until they had a new model that explained their observations. I was able to use the experience as an example of when I should have considered an item on the CoRe framework that asks "What else you know about this idea (that you do not intend students to know yet)" (Loughran, Berry, \& Mulhall, 2012c, p. 22). Another positive aspect of this discussion was a reminder to the teachers that the models we create to envision phenomena always have limitations, and that they are only models, and therefore do not completely describe a phenomenon. Subsequent to the polarisation discussion we talked about analogies and models:

Ted: Do your students get the concept of an analogy? Is that... Jenny: Yes, it's not actually that, but just like that. Yes.

Ted: What the purpose of those [analogy] are? Because that is a critical part of science.

Jenny: We talk quite a lot at the start that these things, this is just a model of it. They quite like the idea that you can't really see these things, so we have models of them.

Ted: Some of them are completely unobservable.

Jenny: We can never truly know, but we keep getting closer to different ideas.

Ted: And the purpose of the model?

Anna: Is to prove or disprove theories.

Betty: Go probe aspects of it and be able to understand it.

Ted: when you say explore aspects of it, what do you mean by that exactly?

Anna: It's behaviour.

Jenny: ...yes, predictions, and to get your head around parts of it.

Here Jenny, Betty, and Anna indicate they are not only aware of the use and limitation of models, but they make sure their students understand also. Jenny's comment that "we can never truly know, but we keep getting closer..." indicates a sophisticated understanding of the nature of scientific explanations. 
Include basic data gathering and manipulation

The PLD developed for this iteration did not involve any numerical data gathering; therefore, there is no evidence to support or refute this advice. From previous iterations, however, one should not assume teachers have skill or practice in collecting or manipulating experimental data, and therefore I will retain this implementation advice. 


\section{Provide practical everyday examples}

The teachers in iteration-two (Newton's Laws) were quite focused on finding linkages between the material and everyday occurrences. Perhaps the topic of light naturally led to these observations, but the linkages occurred frequently in iteration-three. For example, they made the link between our discussion of colour, reflection, absorption and energy and the effect of wearing white or black clothing (see the discussion in section 6.2.3.2). The direction of travel of the PLD was frequently guided by questions about everyday phenomena that are connected to the concept we were discussing. For example, Paul asked about whether radio waves and light behave the same as you get further and further away, which led to our discussion of the inverse square law. The teachers' questions about how rainbows work led to a great discussion about colour, refraction and reflection. Consideration of practical everyday examples was supported in iteration-three.

\subsubsection{Subject matter knowledge reinforcement}

\section{Ensure prompt teaching of material}

Iteration-three began prior to the conclusion of the third term at School-three. The teachers elected to continue meeting during the two-week break between terms, and began teaching the material when the next term started, which was prior to finishing the PLD. Having the PLD going while teachers were teaching material had the advantage of being able to discuss how the teaching was going. The teachers spoke positively about talking to their students about being involved in the PLD, as mentioned by Anna: "I've represented myself as a learner with this, we're working with a scientist, and have been learning heaps, and were exploring this stuff, not all of it makes sense to me yet, but let's try this out..." The benefits of teaching the PLD material promptly are supported by the experience of iteration-three. 


\section{Provide summary documentation of investigations}

The introduction of the CoRe framework gave the teachers in iteration-three an appropriate way to record and summarise the investigations. In addition to their own documentation, the teachers set up a shared folder and provided me access to it so that I could post useful documents and investigations. The provision of some documentation is probably useful, although somewhat redundant. The implementation advice will be retained.

\section{Active documentation an integral part of PLD (CoRe)}

The introduction of the CoRe framework was enthusiastically taken up by the teachers of iteration-three. The organisation around "big ideas" was positive, and the teachers felt the questions posed were useful and relevant. When we were discussing how the teachers would approach preparing to teach a new science topic, Anna responded:

Probably try to recreate this process - as in like in a group. I really like the key big ideas, key questions, like "what happens when light hits stuff?" I found that really focusing. How does light travel? The umbrella of big ideas [support from others].

Anna's statement was strongly supported by the other teachers.

The teachers found the questions on the CoRe helpful in thinking about the teaching process as a whole. Jenny, in describing how she would ascertain students' understanding or confusion, felt it was important "for students to use their knowledge to describe a phenomenon in their own words", and would look for evidence of their "seeing the big ideas in action" in everyday life.

Evidence from iteration-three does not provide any comparisons of different documentation systems, so there is no basis to suggest the CoRe framework is superior to other systems. It is, however, developed to capture the specific type of information that teachers use in teaching. The organisation around big ideas is not unique; however, the questions in the framework tease out specific 
aspects of the big ideas that are relevant and useful for teaching. The positive reaction of the teachers in iteration-three support the use of the CoRe framework as a documentation system for the PLD.

\section{Ask teachers to lead the review of material and review of instructions for investigations}

The value of asking teachers to conduct the review of material became apparent when I asked for a volunteer to explain surface colours to Paul, which I described earlier in this section. After that initial review, the teachers sought out opportunities to test, and deepen their understanding by explaining the scientific concepts to a group. Asking for a volunteer to lead the review provided a natural opening for a peer to assume the role of a teacher in the group. The explanations provided the dual benefit of reinforcing the subject matter, as well as a chance to develop PCK by translating their understanding into the language used to explain it to someone else (Shulman, 1986b). The same implementation advice is also found in Section 6.2.3.2, operationalising the Modelling and practising activities and teaching methods design characteristic.

The resultant Subject matter understanding area is shown in Figure 41. 


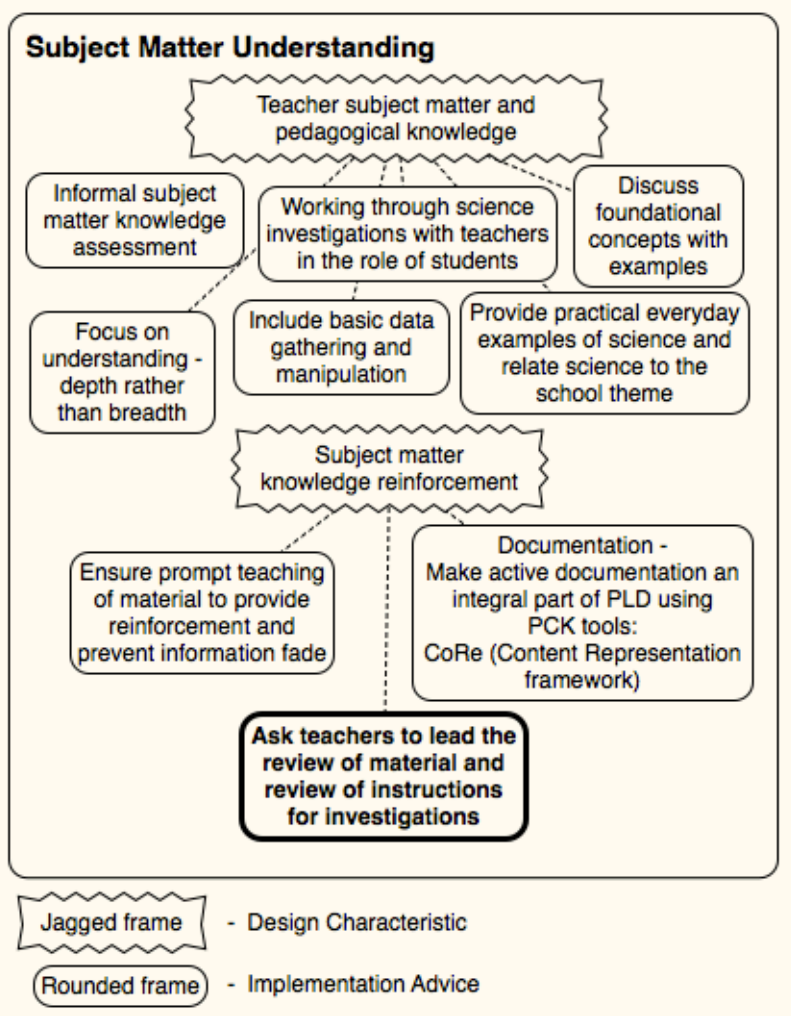

Figure 41: Subject matter understanding - iteration-three

\subsubsection{Teaching practice}

The Teaching practice area of the PLD framework was modified in iteration-one, and confirmed in iteration-two (see Figure 42). The existing areas were supported in iteration-three. The experience of iteration-three, however, suggested modification and addition of new implementation advice in the Practical lesson development design characteristic, and additional advice in the Modelling and practising activities and teaching methods design characteristic, explained below. 


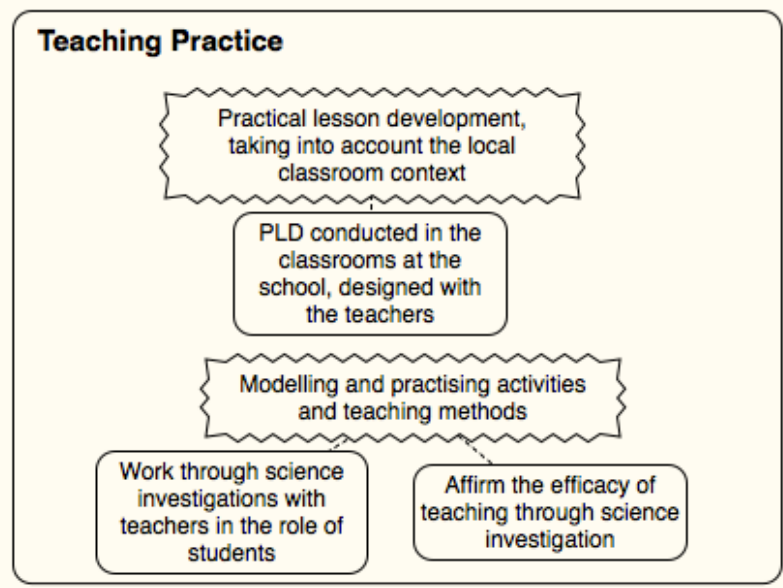

mane

Jagged frame - Design Characteristic

Rounded frame - Implementation Advice

Figure 42: Teaching practice as established in iteration-two

6.2.3.1 Practical lesson development, taking into account the local classroom context

PLD conducted in the classrooms at the school, designed with the teachers

Locating the PLD in the school environment was very helpful in iteration-three.

The investigations involving light frequently required the ability to darken the room, and understanding the school environment allowed the teachers to consider ways to optimise their classrooms or find alternative spaces for the investigations. The location of the PLD in familiar classroom environments was beneficial in all three iterations, particularly with regard to selecting investigations that took advantage of the layout or resources in the classroom.

Work with teachers to define the key questions and/or big ideas of the subject matter of the PLD

Iteration-three began in much the same way that the previous iterations began, by choosing a topic, and producing a concept map to establish the level of preexisting knowledge of the topic. The results were much the same in all three iterations in that the teachers named a number of terms related to the topic, but 
did not demonstrate much knowledge of how the terms were meaningfully connected to related concepts.

The next step in the process was new to this iteration (described in section 6.1.3) and involved asking the teachers to consider questions they had, or thought their students might have about the topic. This addition led to the generation of a large number of questions about light and light related phenomena shown in Figure 43. The process up to this point was driven by the teachers. I then proceeded to use expert knowledge to link the questions that were related. The questions divided naturally into three groups, which were used to generate the three big ideas as a group. Beginning the PLD in this way put the teachers in charge of the content of the PLD at a higher degree than in the other iterations.

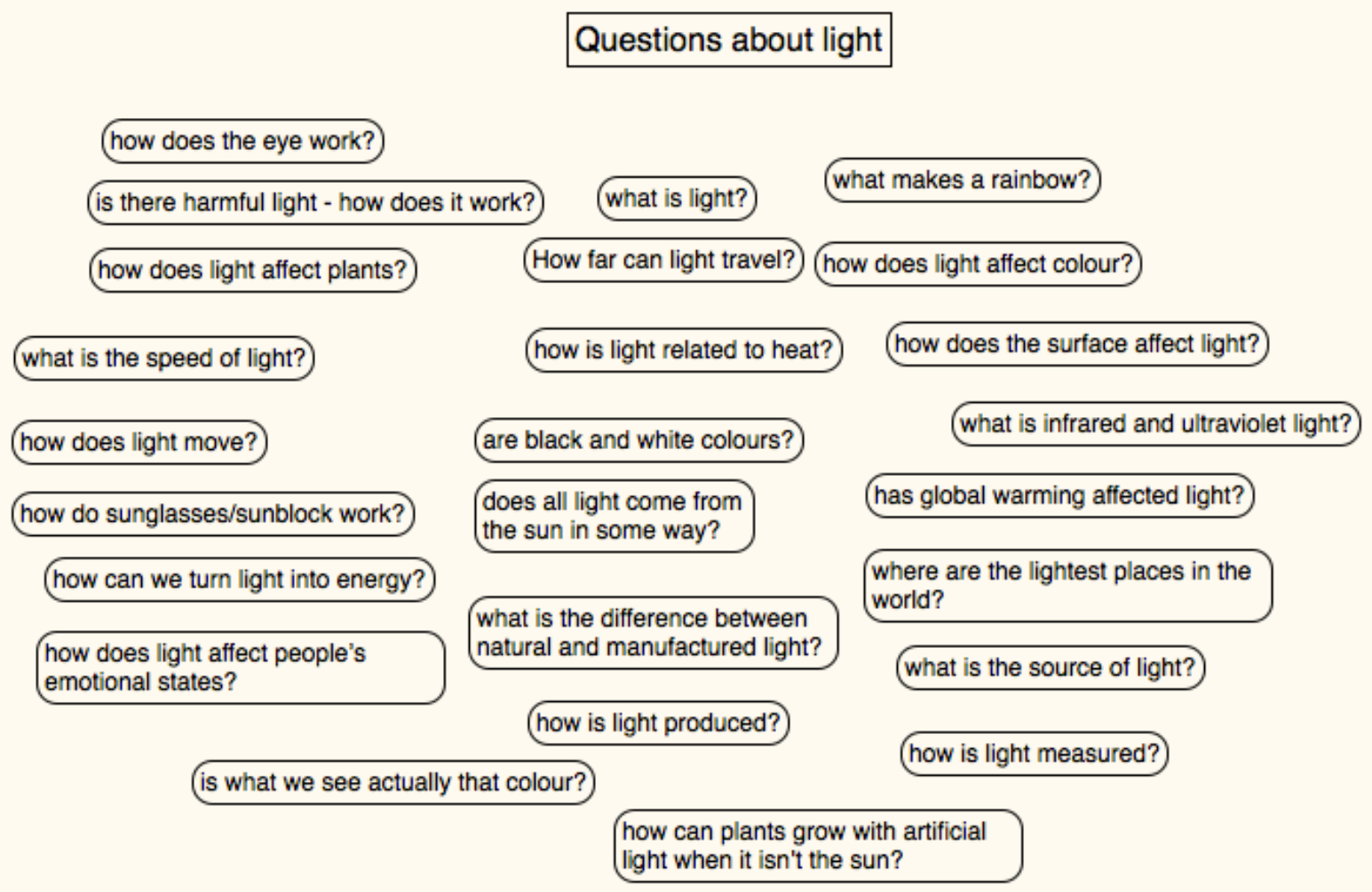

Figure 43: Teacher questions about light 
I took the document home and organised the content into the three big ideas we agreed on earlier: "What is light?", "What happens when light hits stuff?", and "How does colour work?" I edited the questions, and added some questions and statements of my own that I felt were necessary in order to establish the foundation for understanding the big idea questions, and added some potential investigations that we would conduct. At the next PLD session I showed the diagram to the teachers so they could see and question my planning and thinking process (see Figure 44). 


\section{니GHT - Big Ideas}

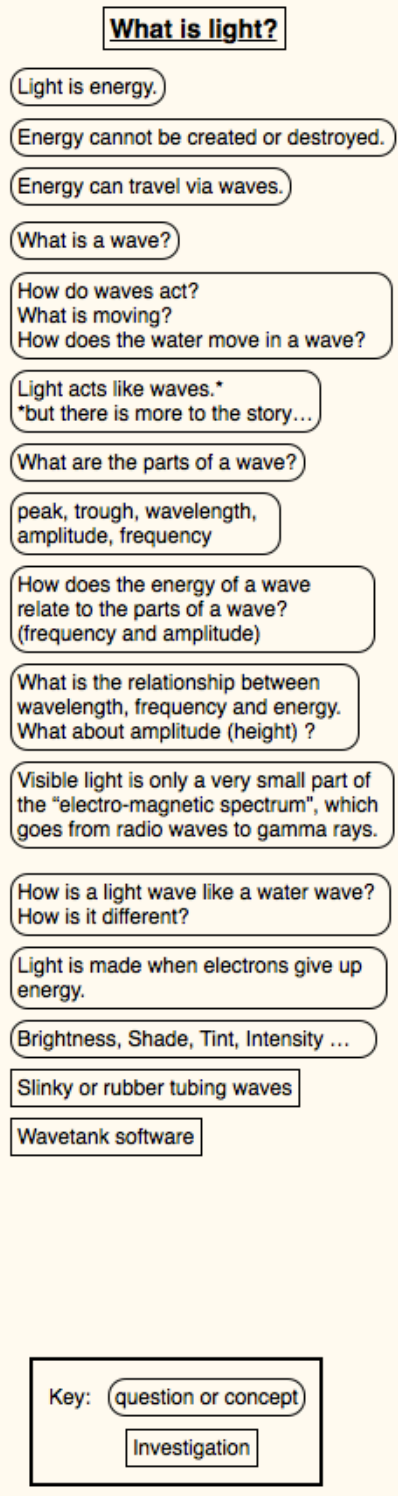

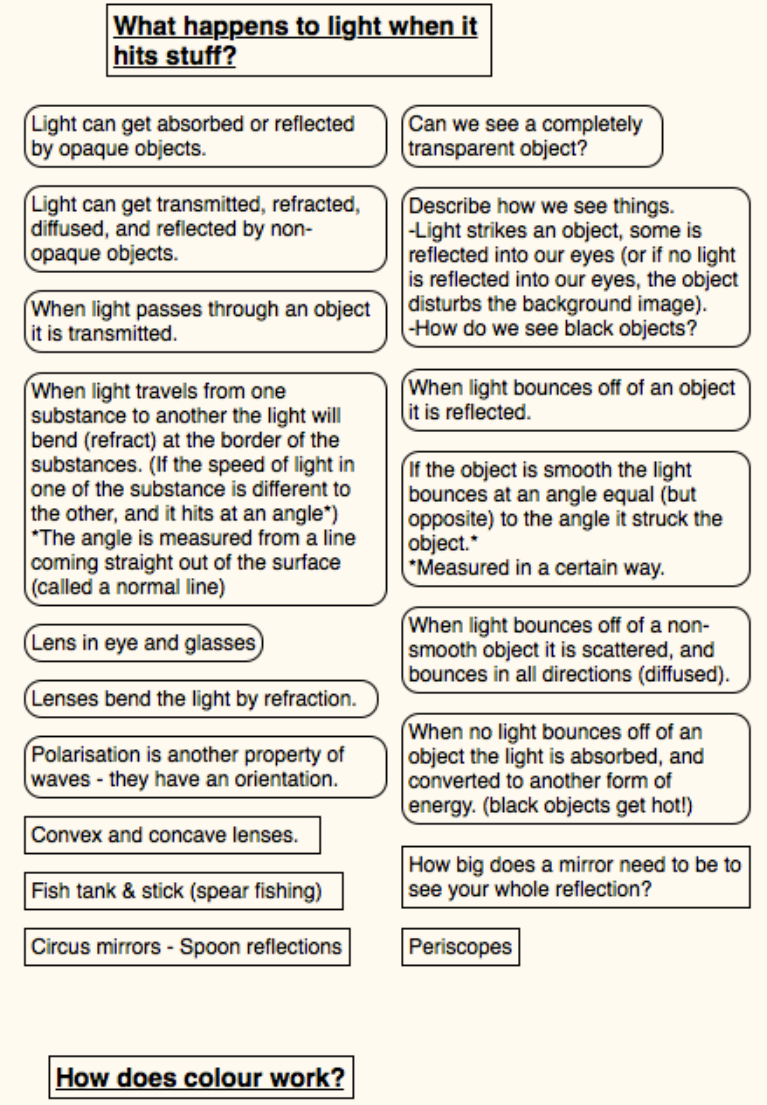

White light is made up of all colours.

Proof: if we send white light through a prism, the different coloured

components travel at different speeds

(or bend different amounts) and get

spread out. A single colour sent

through a prism bends as it goes

through, but does not split into colours.

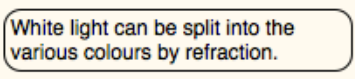

Different colours travel at different speeds in substances.

When going from air to glass (or diamond) the lower frequency (longer slower steps) red light is (longer slower steps) red light is
slowed less, and therefore bends less than the higher frequency (faster shorter steps) violet light.

A coloured object absorbs some
colours of light, and reflects others.
The colour of the light reflected is
what we call the colour of the
object.

How do rainbows work?

What makes the sky and ocean blue when water is clear?

Our eyes can sense the colour of light.

Why would ultra-violet light be more dangerous than infra-red?

Fluorescent chemicals have the ability to absorb light of various colours, and give off light of a specific colour. They work in white light, but the effect is most noticeable under ultra-violet light.

CD diffraction gratings

Prisms

Coloured light box

Fluorescent markers

\section{Figure 44: Light PLD topics and investigations}


The teachers were enthusiastic during the development of the big ideas, and referred back to them frequently when discussing the content. The concept of organising a topic around the "big ideas" is also consistent with the structure of the Making Better Sense of the Physical World curriculum support materials provided by the MOE (1999). The exact process worked through in iterationthree may not be appropriate for all groups or all facilitators; however, working through the design of the PLD with the teachers was effective, and served as a model for approaching unfamiliar material (see section 6.2.7). The implementation advice is therefore modified to reflect the importance of involving the teachers more intimately in the planning process. The original implementation advice is shortened to "PLD is to be conducted in the classrooms at the school", and an additional piece of implementation advice to "Work with teachers to define the key questions and/or big ideas of the subject matter of the PLD" was added.

\subsubsection{Modelling and practising activities and teaching methods}

In previous iterations I had considered this design characteristic to be limited to asking teachers to participate in the science investigations as students. During the course of this iteration I asked teachers to review material from previous sessions, or to take a previously absent teacher through an investigation. The teachers enjoyed the review process, and it became apparent during iterationthree that the teachers regarded as beneficial the chance to reinforce their understanding of the material by formulating explanations:

Ted: Frankly, I taught physics for 8 years and didn't really understand how diffracting gratings work, until I came here to teach you guys.

Tammy: It's that thing isn't it, when you go to teach it you dumb it down and it helps you understand it yourself.

Ted: It's not really dumbing it down, it's understanding it well enough to explain it simply.

Jenny: Which is why the research says peer tutoring is so effective.

During the second PLD session Tammy and Jenny were reacting to my admission that I had not understood a concept that I was teaching them. 
This is an exchange that occurred during the fourth PLD session on colour:

Ted: So, explain it to me.

Anna: Because there is something in there that absorbs all the other colours.

Ted: So what happens when I shine red light on it?

Ted: What do you think happens to the energy when you do that?

Anna: I was just thinking

Jenny: That's why it absorbs, and that's why it heats up.

Tammy: Yes, exactly

Anna: Absorbed by being transferred into heat

Tammy: So we should all wear black so it's much warmer in the winter.

Tammy: We did talk about how cricket players and tennis players wear white, and summer sports in New Zealand.

Ted: And so why is white the perfect choice? Why not blue?

Betty: Because blue is on the spectrum.

Tammy: It would absorb the least amount, it would heat up the least.

Ted: Why does it absorb the least?

Tammy: It reflects all the others.

Betty: It reflects everything. Good job Tammy!

Here the teachers make the link between light absorption, energy and temperature. We had not talked about energy in relation to reflection or colour, yet the teachers were able to apply what they understood about light and energy.

As mentioned in Section 6.2.2.1, in this iteration I asked the teachers to conduct the review of previous material, and when a teacher missed a session, asked one of the teachers to explain what we covered during their absence. Asking the teachers to teach the topics to their peers put the teachers in a position to clarify their understanding, to model and practise the process of knowledge construction, and to build up their PCK:

Ted: ...explain it to me.

Betty: Prompt me.

Anna: So give her a green piece of paper.

Betty: Sorry guys, I'm like the slow kids today... repetition, repetition... can you just start me off?

Anna: Green paper, white light. The light is coming into the green paper and what happens to the light when it gets to the green paper? The light is white, 
the light goes onto the green paper, and because it absorbs the other colours you only see green, it sort of cancels the other colours out.

Betty: So every different colour around this room has a different molecular structure. wow. So a blue one of these and a red one of these has a different molecular structure?

Ted: Well, a different chemical is added to whatever the basic plastic is that gives it that colour.

Betty: That chemical is different, not necessarily everything about this, just that chemical changes it because it is there.

Here I am asking Betty to explain why when we look at a green coloured object, it is green. She and Anna work out the explanation together.

The teachers looked for opportunities to talk through the concepts, and appeared to grow in confidence in the process of asking and answering questions with each other:

Betty: I have another question. I can see why questioning is important now. I need to work things out.

Ted: I don't know how to teach without asking questions.

Tammy: It must be frustrating to the kids though too eh? Because ... kids who want to answer, and they're busting to show you they know.

The experience of iteration-three suggested the addition of the implementation advice: "Ask teachers to lead reviews of material and reviews of facilitation of investigations".

Teachers in iteration-thee reacted positively to the experience of defining the content of the PLD based on questions they generated during the concept mapping process. They also seized the opportunity to test their knowledge by explaining the material to each other whenever the chance arose. These additions to the framework have the disadvantage of not being scrutinised in subsequent iterations. Thinking back to previous iterations, the difficulty teachers in iteration-one had in selecting areas of interest may well have been alleviated by the techniques used in iteration-three. Beginning with questions is much more natural than choosing from a list of vaguely known topics. The information fade experienced by the teachers in iteration-one may also have 
been helped by providing knowledge reinforcement by asking them to conduct the reviews. The Teaching practice area at the conclusion of iteration-three is shown in

Figure 45.

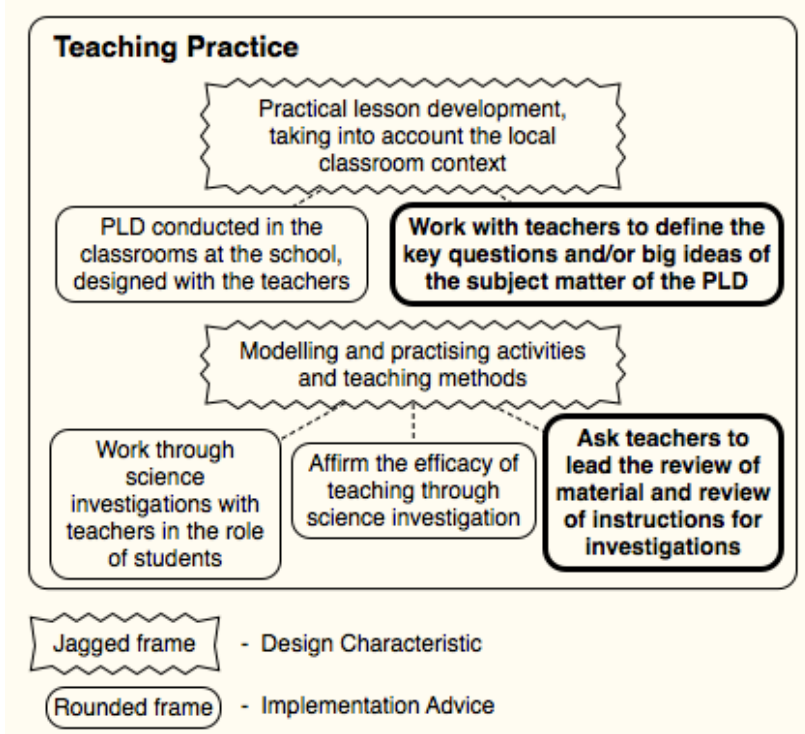

Figure 45: Teaching practice - iteration-three

\subsubsection{Support}

The Support area was unchanged in iteration-two and was used as the starting place for this iteration (see Figure 46). The development of the community of practice among the teachers in iteration-three was more apparent than in the other iterations. The teachers in iterations one and two had been working as teams prior to the PLD. The teachers in iteration-three came from different syndicates (teams) and the PLD was the first time that they had worked together as a group. The groups in previous iterations had established ways of sharing information; however, the iteration-three group found it useful to set up a shared mechanism for information sharing during the PLD and beyond. 


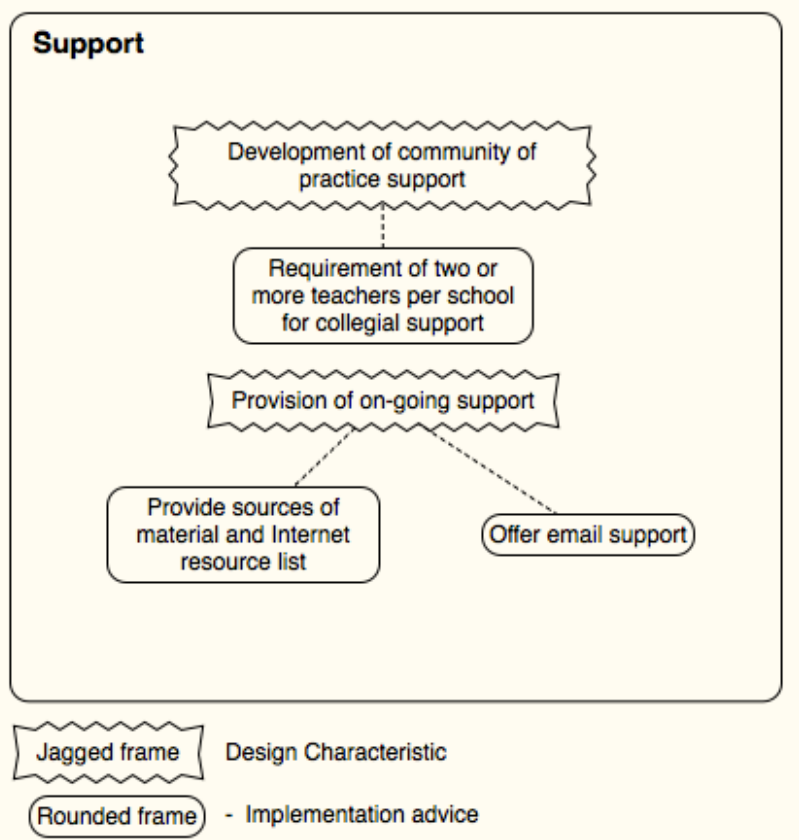

Figure 46: Support as established in iteration-two

\subsubsection{Community of practice}

\section{Requirement of two or more teachers per school}

During the follow-up meeting I asked the teachers what they thought were the significant barriers that kept teachers from teaching more science:

Paul: I did that one year post graduate degree, the focus was really reading, writing, and maths, and I think I had ... three lectures on science. I went to my first year teaching, they wanted kids to read, write, and do maths, and did not care about anything else, just read, write, and maths. In actual fact the focus of that year was reading, some kids at 10 years old were reading at the 5-year-old level, so we didn't really do anything else, just basics. We don't have the training behind it. I'm quite comfortable teaching reading, writing, and maths, because we trained on it, but [not with science].

In other words, Paul did not take any science related papers at university, and obtained his teaching credentials though a one-year postgraduate degree. He described his science training as three lectures, and he had limited opportunity to teach science at his previous school. He was an enthusiastic participant in the PLD, but appeared nervous about teaching science to his students, 
particularly in handling the questions that might arise in a science investigation. In the dialogue that follows, Jenny describes her plans to begin the study of light with her class by providing her students with a couple of counter-intuitive experiences with light and then allowing the questions raised to influence the order of the topics:

Jenny: I'm going to do the light box tomorrow morning, and get the pencils and have them predict what they'll see. We can see how that goes and see where that goes, then we can...

Paul: And where do you go from there, you do the box and the pencils and then what?

Jenny: You see where the questions lead I suppose, is where I would go to next, to go well, then you go to waves, and what's happening with the light when it goes through the gaps... I'd explain it like the waves going through, l'd explain it...

Paul: Ask the questions to you, or write them down?

Paul: I'd like to watch you, because there is some great stuff here, but I'm not really sure where to go as a teacher, you know what I mean... I'd like to watch someone who had more of an idea.

In this dialogue Paul appears to be uncomfortable with an open-ended approach, and is reaching out to his colleague for help or informal mentoring. It would be unlikely that options for this type of support could occur if participants came from different schools, which supports the implementation advice of at least two participants from each school.

Another advantage of working with teachers located at the same school involved shared resources. I supplied the teachers with a wiring diagram for the multi-coloured LED light source used in the box in the introductory PLD session. School-three has a resource person who used the design and built a light box as a shared resource for the teachers.

During the wrap-up meeting I mentioned that I was impressed that the teachers were conducting investigations with their classes that we had not done during the PLD. The teachers explained that they had used the PLD investigations, and: 
Anna: We worked together on that, and you may have seen some of the things repeated around because we have worked together and I think that is one of the key things as well.

Tammy: Collaboration.

Jenny: Because we have been in this group we've collaborated therefore we've done better, I wouldn't have taken pictures [if Tammy had not suggested it].

Jenny is referring to the investigation she conducted during my observation of her class, discussed in section 6.2.6. There is ample evidence that the requirement of two or more teachers from each school is supported. Further, the community of practice that developed during the iteration-three PLD was significant for the teachers, and resulted in collaboration they had not experienced previously. It is difficult to discern what factors led to the sense of community. In all three iterations as a facilitator, I attempted to create a nonjudgemental atmosphere in which the teachers felt safe; however, in this iteration, as discussed above, the teachers had more visibility of the my thinking process in designing the PLD, and they also took an active role in reviewing the content, leading at times to admitting they had not yet quite understood it (see section 6.2.2.1). This experience in iteration-three resulted in the additional implementation advice to "Establish a safe, non-threatening environment for learning".

\subsubsection{Provision of on-going support}

\section{Offer email support}

Jenny contacted me via email while she was preparing a lesson in which her students were making diffraction gratings out of old CDs and wanted a diagram illustrating how a diffraction grating separates white light into colours. She wanted to be prepared when the students asked questions about how it worked. She explained that she had tried to draw the diagram, and looked for one on the internet, but was unable to find one suitable. I located one and sent it to her for use in class the next day. Jenny's was the only such request I received during the three iterations of the research, despite making it clear to all three groups 
that I would be happy to respond to requests. Although the offer of email support was not used extensively, it was appreciated by all the groups.

\section{Sources of material and internet resource list}

This implementation advice was added to the PLD framework as a way to provide a form of on-going support to help teachers filter the huge amount of material available on the internet in the form of a short list of high quality websites. A recent study by Ibieta, Hinostroza, Labbé, \& Claro (2017) found that $91 \%$ of teachers they surveyed indicated they always, or almost always use the internet to find teaching resources. Providing the PLD teachers with a list of pre-screened high-quality websites containing teaching resources and review material seemed be a solution to their expressed need for instructional resources; however, a webpage Uniform Resource Locator (URL) is not stable over time. In an analysis of URL citations in scholarly journals published between 2008 and 2012, the rate of missing URLs ranged from 34\% to 69\%, after just two years (Kumar, Kumar, \& Parameshwarappa, 2015). One is reminded of the old adage of giving someone a fish, versus teaching them to fish. An ideal outcome of a PLD programme is to give teachers the competence and confidence to engage with the plethora of resources available via the internet and select high quality material to use in their classrooms. During this iteration the teachers found and used several investigations that were not covered in the PLD, but were described in websites mentioned on the resource list provided. They also adapted and altered investigations that were part of the PLD (see Section 6.2.6). The relatively short shelf life of URLs limits the usefulness of static resource lists; however, given the widespread use of internet resources, and the limited use of other curricular support materials shown by teachers in all three iterations, providing a list of science content resources is supported.

Another situation involving ongoing support arose during the first PLD topic session, when Tammy suggested that we set up a shared internet folder where we could share resources and materials from the PLD. The teachers and I used 
the folder throughout the PLD as a way to share useful diagrams, investigations, and other teaching materials. The resource folder was still being used by teachers at School-three as a collection point for high quality resources more than a year after the PLD ended. Implementation advice to suggest the establishment of a shared resource, into which teachers working collaboratively could collect and share teaching materials, was added to the framework, shown in Figure 47.

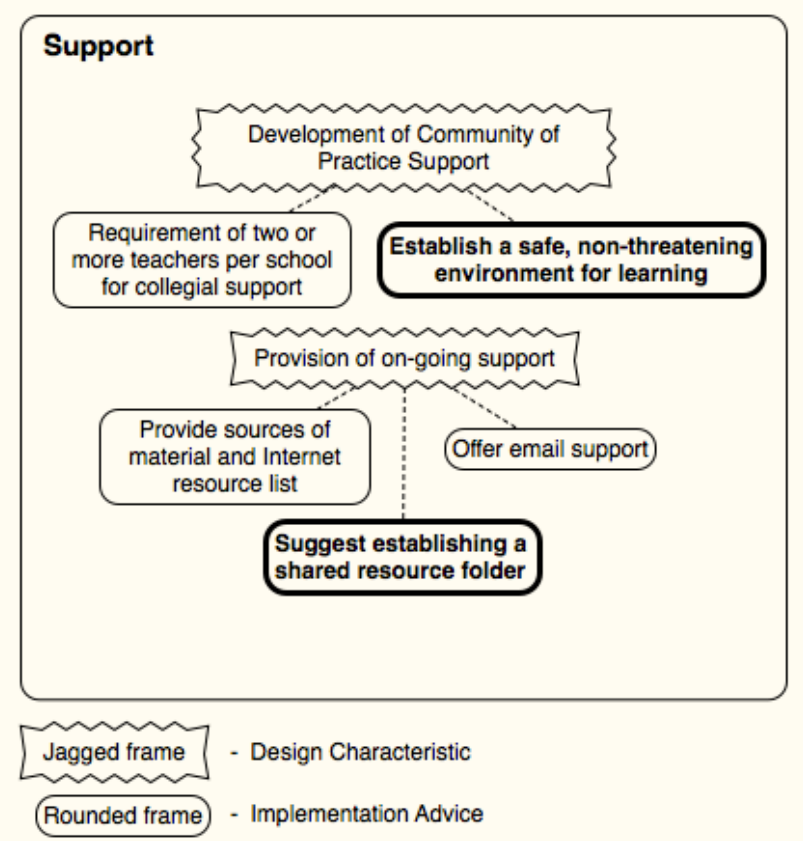

Figure 47: Support - iteration-three

\subsubsection{Logistical considerations}

The logistical considerations regarding the length and duration, location, and introductory PLD session established in iteration-two (see Figure 48) were all supported during iteration-three. No new design characteristics or implementation advice were indicated. 


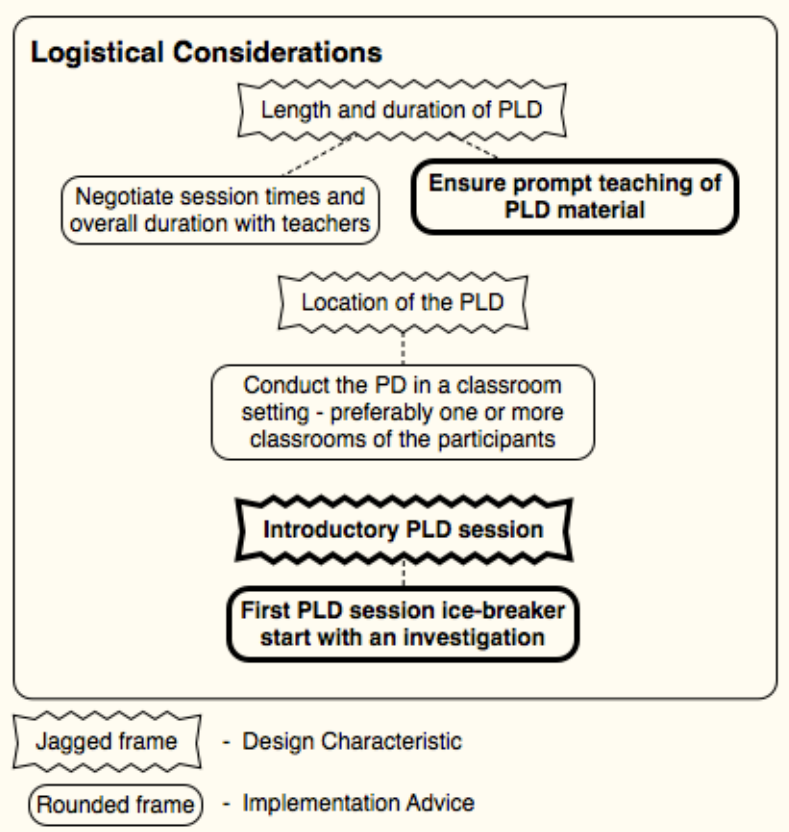

Figure 48: Logistical considerations as established in iteration-two

\subsubsection{Length and duration}

\section{Negotiate session times and overall duration with teachers}

The teachers in iteration-three decided that six weeks of PLD would be the amount that would fit their schedule. This was the one session that was longer than the other two iterations, meeting after school for approximately 90 minutes. The teachers decided to continue meeting through the school holidays, and we met at 10 AM weekly during the two-week break between terms, concluding two weeks into the following term.

\subsubsection{Location of PLD}

\section{Conduct PLD in classroom setting}

The argument for conducting the PLD in classrooms was made in Section 6.2.3.1. In addition to the advantages listed earlier, locating the PLD in the school is convenient for the teachers, and, assuming the PLD is scheduled at the conclusion of the school-day, eliminates transportation time and allows the PLD to start promptly. 


\subsubsection{Introductory session}

\section{Introductory investigation}

Selecting an introductory investigation suited to the chosen topic was useful in iteration-three. The investigation, as described in section 6.1.2, was referenced frequently during the PLD. The teachers in iteration-three made a similar box to use between their classrooms, and developed additional investigations that used the mono-chromatic closed light environment several times in their classrooms.

Beginning the PLD with an attention-grabbing investigation set an active tone in all three iterations. Targeting the investigation to the topic allows the introductory investigation to also contribute to the suite of topic-focused investigations.

\subsubsection{Classroom observation}

The teachers in iteration-three agreed on a day for me to visit the school and observe their classes. The observation was about two weeks following the last topic-focused PLD session. The teachers chose the earliest possible date following the PLD that they could all teach science on the same day.

I began with an observation of Tammy's Year 8 class of 32 students. Tammy began her class with a question and answer review of the previous lesson on refraction. The students defined refraction as what happens when light hits transparent things. So far they had looked at objects in the bottom of bowls of water and prisms. In today's class they would carry on with their study of refraction; working in table groups ( 3 students) they placed coins in plastic cups and put clear plastic wrap on top of the cups. She asked the students to observe and report, and the students said the coin looked normal, "just like in your hand". She then had them fill the area on top of the plastic wrap with water, and observe and report. The students reported that the coin "looks spread out", and "goes from the size of $5 \mathrm{c}$ to $50 \mathrm{c}$ ". She asked the students to 
talk in table groups about what is happening when the light goes through the water.

Tammy then handed out pages from a magazine and petri dishes and asked the students to put a drop of water onto the petri dish and look at the printing through the drop. Students reported the water made the printing look bigger. She asked them to look at the drop from the side and describe the shape of the water. Students noticed that as they picked up the petri dish, the printing got even bigger, and if they held it way up it made the printing look smaller, and some students noticed it made the printing turn upside down. Tammy then passed out magnifying glasses to the class, and asked them what they noticed about their shape. The students noticed the shape of the glass was thicker in the middle and was similar to the shape of the water drop. They also noticed things look bigger when the glass was close to them, but got smaller and flipped over when the glass is farther away. Tammy asked the students to write up their observations in their notebooks, and showed the class a film clip of Bill Nye describing lenses. She stopped the film frequently and talked to the class, asking them to make predictions of what would happen, talking to the person next to them. The bell rang for morning tea and she told the class they would finish the video after morning tea, and I ended my observation.

Tammy had very good classroom control. Even though using water on the student desks was a little messy, the students were very cooperative and enthusiastically followed her instructions, and participated in small group and whole class discussions.

I next visited Betty's class of 29 Year 8 students, where she also began with a review of what they had been doing in the light unit. They had been looking at light going through different mediums, and being bent or refracted. She had the students gather around a table, she placed a bowl on the table and put a coin in the bottom of the bowl and asked the students to back up until they could no longer see the coin over the lip of the bowl. She then poured water into the 
bowl and suddenly the students could see the coin again. When the students were seated again she made the connection between the "appearing coin" trick and the spear fishing investigation they had done previously, drawing a picture of the bowl and coin, with and without water on the whiteboard.

Betty then brought out a prism and shone the flashlight through a slit in a piece of cardboard through the prism making a spectrum. She made a connection between what you see when you look at a rainbow and the spectrum from the prism. She then showed a video clip of white light hitting a transparent object, stopping the clip at points and asking questions of the class. She asked the class to recall the wave activity (linked arms walking as a wavefront and encountering a medium where you have to slow down), and relate it to the video, which showed a simulated light wave striking a medium and slowing down. She ended the class at that point.

Betty's class was a little noisier than Tammy's and at times she struggled for control. The students responded well to the questions, and gave their full attention to the discussions.

The last class of the morning, just before lunch, was Paul's class of 29 Year 8 students. Paul started with a video clip reviewing wave characteristics. He had some technical problems getting the video to work and the class became somewhat restless during the 10 minutes or so it took to get things set up. When the 15-minute video was finished Paul reviewed the previous class investigation of prisms. He asked the class what a prism does, and a student answered that it slows the light down. He then showed a short video of white light going into a prism. He then asked the class to list the three light terms they had studied so far: reflection, refraction, and diffraction, which he defined for them. Just before the class ended Paul went through a series of demonstrations of a laser going through the prism, and a glass of water, illustrating refraction, ending the class with the coin in the bowl demonstration which was done in Betty's class. 
The technical problems with the video made an awkward start to Paul's class. He struggled with classroom control, but had the students' attention when he did the light demonstrations.

After lunch, I visited Jenny's class of 27 Year 7 students. She began the class with a review of refraction, asking her students "what do you know or remember about how light travels through things?" The students responded that light bends when it goes through things, and that the faster the wave is vibrating, the further it bends. She then showed a two-minute video on refraction and colour, stopping the video at points and reviewing the investigations they had done in class. A student asked: "Why can't you see light, like from a laser?", and Jenny asked the class if anyone could think of a reason, and another student suggested that you need dust particles.

Jenny then introduced an investigation, dividing the class into groups of three, and giving each group a chopstick in a glass of water. She asked them to look at the chopstick from different angles and, using the classroom iPads, take a picture of what they saw. She gave the class a few minutes to work and called them together to project their pictures onto the classroom monitor and share their results with the class. One group reported that "the water wasn't letting the light through easily" and that is what causes it to bend.

For the second investigation Jenny divided the class into groups of 2-4, and had them make a video of a coin in the bottom of a bowl when water is added (the same investigation as in the other classes. The students made a quick video of the coin appearing, and shared them with the class while explaining what they saw, and why.

Jenny's students were extremely engaged and enthusiastic. She had their full attention the whole time, and the students were efficient and polite, while still showing humour and creativity. One group, somehow, introduced an animated Star Wars character into their video of the appearing coin, which got laughter and a round of applause from the class while showing the appearing coin. They 
seemed to genuinely enjoy the investigations, and took their role as investigators seriously.

I ended the day of observations with Anna's class of 30 Year 7 students. She began with a recap of refraction, asking the students to provide the explanations. The review included light waves, from infrared to ultraviolet, how light travels, how it acts like waves and particles, and how light cannot be seen directly (e.g. You cannot see a laser beam from the side unless it bounces off of something). The review continued with the students discussing other things that happened besides refraction, when light hits stuff, including reflection, absorption, and diffraction. She then brought out the large spring (slinky) and had the students make waves on the spring showing the difference between infrared and ultraviolet light, noting the difference in frequency and wavelength. She then introduced the concept of amplitude changes without changing the frequency.

After the demonstration, Anna took the students outside and drew some shapes on the playground. She drew a large rectangle, prism and a lens and had a group of students link arms and march toward the shapes. She told the students that they were a beam of light, and asked them to march at a certain speed, and slow down when they hit the shape, and speed up when they came out the other side. The marching students illustrated how the light bean naturally bends because it slowed down.

Anna had the attention of the students, and they were enthusiastic and cooperative throughout.

I was very impressed with what I saw in Tammy's, Jenny's, and Anna's classrooms. The students were engaged and attentive, and the teaching was creative. Although Betty and Paul struggled for classroom control, the students settled down when involved in an investigation, or when engaging in class discussions. It is interesting to note that Betty and Paul had much less teaching experience than the others. The difference between their classes and the other 
teachers was noticeable, and lends credence to the research design requirement of selecting experienced teachers.

All of the teachers engaged in investigations that were not covered in the PLD, and several conducted the same (or similar) investigations. During the follow-up discussion, the teachers talked about working together:

Tammy: Everybody is recreating the wheel in their individual classrooms. Ted: But when I came today, you guys did other stuff than what I did with you. Jenny: Because a lot of us have done the things we did with you already. Anna: We worked together on that, and you may have seen some of the things repeated around because we have worked together and I think that is one of the key things as well...

The teachers in iteration-three became a functional community of practice because of the PLD experience. Although they were in different syndicates, and had not worked together before, they shared ideas and equipment, and planned the light unit as a subject focused community of practice.

The teachers in iteration-three felt it was important that they be able to clearly explain the science, and spent time during the PLD engaging in what appeared to be practice explanations of the phenomena we were observing. It was interesting to note that although the ability to create explanations was important to them, they did not use didactic explanations as a teaching technique.

\subsubsection{Discussion}

The experience in iteration-three was extremely positive. My subjective opinion was that the teachers were more engaged, and enthusiastic than in the previous iterations. I do not propose to know if this is the result of the things done differently or simply personality differences in the participants. However, I would like to explore two factors that were changed in iteration-three.

The first involves the more extensive involvement of the teachers in the development of the content of the PLD described in section 6.2.3.1. The process was transparent, and allowed the teachers to see my thinking process 
as we selected the material to include. Making the process of development of the PLD more teacher driven and more transparent is germane to the Subject selection / curriculum area also; however, it involves consideration of not only student goals and needs, but also teacher goals and needs. The process followed in iteration-three placed the teachers at the centre of the subject selection process, and may have increased their sense of ownership.

During the final PLD session I asked the teachers:

Ted: When you approach a new topic in science, suppose next year you want to do, say, sound, what would you do?

Anna: Probably try to recreate this process - as in like in a group. I really like the key - big ideas, key questions, like "what happens when light hits stuff?", I found that really focusing. How does light travel? [lt created an] umbrella of big ideas [support from others].

Anna's comments highlight an additional benefit of making the planning process more transparent, which is to provide a model of how to approach an unfamiliar topic. Here Anna was voicing confidence in the group's ability to tackle an unfamiliar topic using the methods modelled in the PLD.

The second factor involves the use of teacher led reviews of previously covered material. This process began during PLD session four, and took the form of teachers volunteering to lead a review of a topic we had covered previously.

At the beginning the explanations took a fairly high degree of prompting. For example:

Ted: If we think about light as waves, we can look at how energy works in waves, and we did a little of that on the gym floor. Can someone remind me of what we did there and how that worked?

Anna: We made waves on a spring, and then we put more energy in that increased the frequency, which was the number of wave cycles per, time? Ted: If we thought about the length of a wave, and energy, how does that go? Jenny: The longer the wave the less energy.

Ted: If you keep the wavelength the same, and the frequency the same, how can you put more energy into it?

Betty: Amplitude. 
Ted: So if you make the wave taller, that's another way to get more energy into it. So, red you get longer waves, what do you get to?

Anna: Infrared

Ted: How do we feel that?

Anna: (and all) Heat.

Gradually, the group began to ask the questions and explain to each other, for example here is a discussion relating a simulation we did as a group showing how a wave front bends when it hits a different medium obliquely to the investigation of how a stick appears to bend when going into water at an angle, but does not bend when going straight into the water:

Tammy: So the person on this side, hit the line first and slowed down, while the other people at the other end of the line were still taking big steps, it was a line of us all linked up, we were like, just imagine us people all lined up like this we were like a ray of light going like that, we're all lined up, marching along like that, and it turns your line this way, if the line comes straight into a surface, the beam would go straight, it would go straight in.

Paul: Just like air?

Anna: It's not like air, it's just that it isn't on an angle.

Tammy: It all slows down at the same rate, it all hits at the same time so it's not bending.

Jenny: Like you know how we talked about spear fishing? When you're fishing from up here, and it goes straight down into the water, it goes straight to where you're going.

Anna: You have to imagine us in the beam of light, it's not turning because we're all hitting it at the same time.

The teachers felt increasingly comfortable offering explanations, and began to see taking a turn explaining an experiment or observation as a chance to practise teaching.

Providing an opportunity for the teachers to practise giving explanations or instructions for an investigation is like a hands-on investigation of teaching for teachers. The group had formed developed a degree of trust sufficient to allow each other to attempt explanations and practice without the stigma of looking silly. I am not sure what made that happen for this group. Some of them had worked closely together before, but others were fairly new to the school. They 
all shared a sincere desire to learn, and I tried to set a tone that no questions were silly and they were not expected to know anything about this material ahead of time.

\subsubsection{Design changes}

This chapter described the third and final iteration of the PLD design framework. The changes made in the framework as the result of iteration three are shown in bold in Figure 49. In the following chapter I will present a summary of the development of the framework and discuss aspects of the final design in light of existing literature, discuss barriers and issues that became apparent during the project, limitations, and implications for future work in the New Zealand context. 

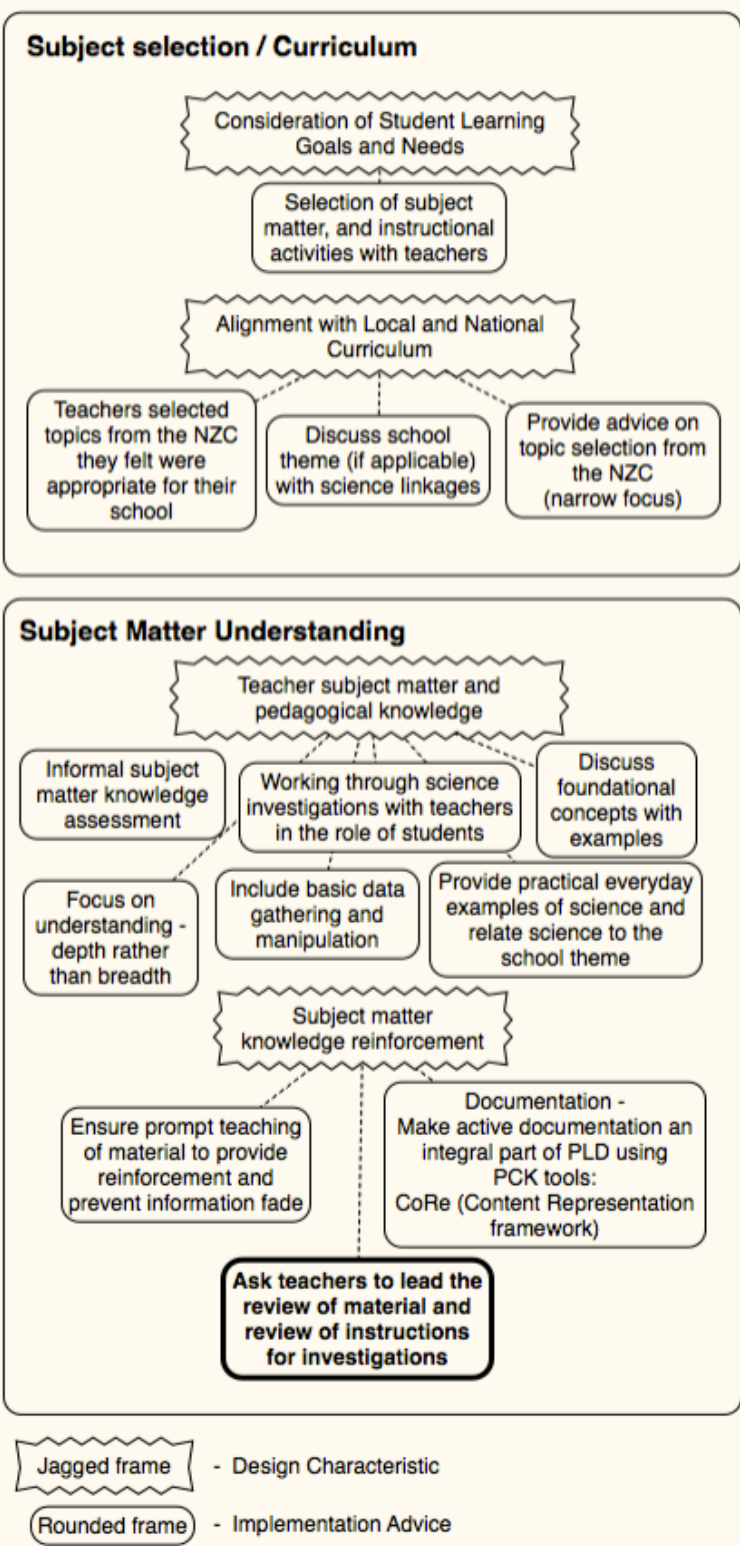

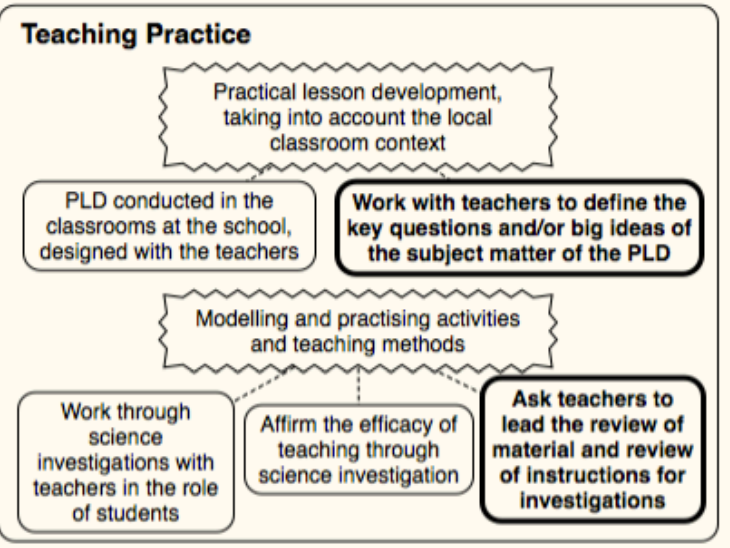

Support
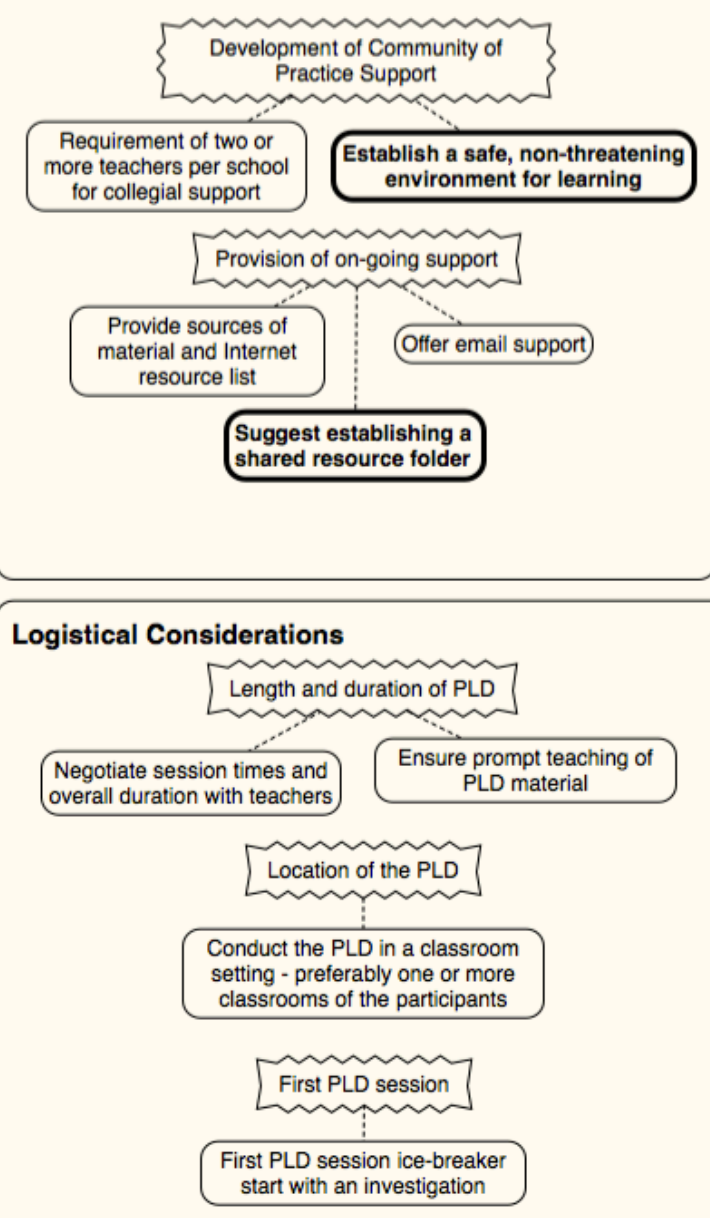

Figure 49: Design framework - iteration-three 


\section{Chapter 7 Discussion and Conclusions}

\subsection{Introduction}

In Section 3.1.1 I introduced the primary research question for this study: What are the components of a PLD programme that will empower New Zealand middle school (Years $7 \& 8$ ) primary school teachers to teach the Physical World contextual strand of the NZC? In the first part of this chapter I will address this question by presenting a review of the development of the PLD framework shown in Figure 50 (Section 7.2.7). In the remainder of the chapter I will discuss the related research questions for this study, limitations, and future directions.

\subsection{Summary of PLD framework development process}

\subsubsection{Teacher empowerment}

The purpose of the PLD designed using the framework developed in this research is to empower middle school teachers with the confidence and competence to teach physical science. Classroom observations provided an opportunity to search for evidence of teacher empowerment, and signs of empowerment were found in all three iterations.

Teachers in iteration-one described being uncertain while talking with their students about some sound concepts (4.2.7.3), but spoke confidently about others (4.2.6). The concepts we defined, but did not cover in depth, such as frequency were uncertain, but the concepts that we covered in depth, such as the propagation of sound waves in solids, liquids, and gasses were spoken of with confidence.

During the classroom observations, two of the teachers in iteration-one conducted an investigation involving sound waves travelling along strings (4.2.6). In both classrooms, the teachers introduced extensions to the 
investigation that we had not included in the PLD sessions, in order to demonstrate aspects of the phenomena the teachers wanted their students to understand. The teachers' confidence in their SMK to extend the investigation empowered them to alter the investigation to make the precise point they wished to make clear to their students.

In iteration-two, without my awareness, teachers began teaching the concepts covered in the PLD in their classrooms before the PLD finished (5.1.4). They felt it was important to put the concepts into practice as soon as possible. They also decided, on their own initiative, to plan and conduct a science "road show" (5.1.4) in which groups of students conducted physical science demonstrations for younger students.

The majority of the investigations I observed in iteration-three classrooms involved investigations we had not done or even discussed during the PLD sessions (6.2.6). Iteration-three teachers worked together to find investigations they felt were appropriate to help their students understand the concepts the teachers wished to include in their unit on light. They went beyond simply using the material covered in the PLD in their classrooms; they had the SMK and PCK to independently search for, evaluate, and select materials to support their students' learning.

The innovation and confident teaching I observed in the classrooms of teachers in all iterations of this research is evidence that they felt empowered to creatively use the SMK they gained in the PLD.

\subsubsection{Subject selection / curriculum}

The two design characteristics in the Subject selection / curriculum area suggested from the literature, Consideration of Student Learning Needs, and Alignment with Local and National Curriculum, were supported by findings from the three iterations of this research, and no additional design characteristics emerged. 
The concept that teachers should be involved in decisions regarding the topics and teaching methods was a strong theme in many studies examined in section 2.3 (e.g., Fishman et al., 2003; Loucks-Horsely et al., 2010). However, the challenge faced by teachers with limited science background in selecting topics of interest and relevant to their students from the broad and non-prescriptive NZC was not highlighted in the literature. This challenge was present in all three iterations, but was particularly evident in iteration-one, in which the teachers faced the additional constraint of aligning physical science topics with the school theme, and is reflected in the additional implementation advice regarding discussion of the theme.

An additional piece of implementation advice was added after iteration-two, in which the teachers had decided to teach a unit on Newton's laws prior to the PLD, because they realised their students had little previous opportunity to experience this aspect of science, and suggested the PLD cover Newton's three laws. When the teachers began to understand the underlying concepts of mass, force, friction, gravity, inertia, and energy, they expressed their desire to narrow the focus, and concentrate on teaching a unit in which their students would understand the concepts involved in Newton's first law, rather than the broad focus initially conceived. The desire of these experienced teachers aligns with the findings of Eylon and Linn (1988), in their review of the science education literature, who concluded that the research "strongly suggests that indepth coverage of several science topics will benefit students far more than fleeting coverage of numerous science topics" (p. 251). This conclusion is further supported by the findings of Schwartz, Sadler, Sonnert \& Tai (2009), who urge teachers to "use their judgment to reduce coverage in high school science courses and aim for mastery by extending at least 1 topic in depth over an extended period of time" (p.798). The experience in iteration-two led to the implementation advice regarding advice on topic selection from the NZC, specifically regarding narrowing the focus. 


\subsubsection{Subject matter understanding}

The Subject matter understanding area changed the most through the three iterations of this research. Although the literature reviewed in section 2.3 clearly indicated that all effective PLD programmes in science involved subject matter content and associated PCK, the nature of the science content however varies greatly between studies, and is therefore not as clear. During the first interview with teachers in iteration-one they were emphatic that their main priority in the PLD was SMK, and the importance of developing an understanding of science concepts was a priority for teachers in the two subsequent iterations which also highlighted the importance of this aspect to the teachers themselves.

The initial design characteristics for the PLD to include SMK and PCK, and the implementation advice to have teachers work through the investigations as students were affirmed in all iterations. Observing the teachers in their classrooms, particularly in iteration-thee confirmed the guidance of LoucksHorsley et al. (2010):

As teachers become familiar with the curriculum and go through the materials as learners, they see the various teaching strategies they will use with their students. Specific attention is paid to helping teachers translate their own learning experiences into those that are appropriate for their students. (p. 247)

Several additions to the implementation advice in the Subject matter understanding area emerged during the three iterations, and are summarised in the following paragraphs.

During iteration-one it became clear that in order to develop a PLD programme to help the teachers expand their SMK, I needed to assess their pre-existing knowledge of the selected topic. A formal examination of SMK was part of the original research design, to provide a quantitative measure of the success of the PLD; however, this was changed during iteration-one (see Section 3.5). The need for assessment from a teaching perspective remained however, which led to the advice to include an "Informal SMK assessment", which was 
accomplished both by constructing a concept map of the selected topic and through informal discussions.

The teachers in iteration-one expressed frustration at not really being sure they understood what they were talking about when teaching parts of the sound unit, finding themselves frequently unsure, and unable to address students' questions. I had designed the PLD to include a number of concepts involved with sound, but had not approached the topic by developing the basic foundational concepts such as the relationship between sound waves and energy, and the teachers had only a superficial understanding of how the various topics were related. The need expressed by the iteration-one teachers echoed the finding by Buczynski and Hansen (2010) in their work with Year 4-6 teachers:

Frequently we think teachers do not care about the theoretical underpinnings concerning what they teach and just want practical ideas. However teacher comments revealed that they were appreciative about receiving foundational knowledge about how students learn and think about science. Whether through a deeper understanding of content, validation of prior content knowledge, or clarification of misconceptions, teachers indicated that content enrichment enhanced the effectiveness of their teaching. (p. 602)

Because of this experience, the advice to "Discuss foundational concepts with examples" was added to the framework.

Several investigations in iteration-one involved collecting and manipulating data. I assumed the teachers had some experience with data, and was surprised that they were not familiar with organising data collection, concepts such as collecting multiple samples, and rejecting outlying data points. This experience led to the addition of advice to "include basic data gathering and manipulation". The PLD sessions in iterations two and three did not involve investigations in which data collection and manipulation were involved; however, the advice still applies when investigations involve numerical data collection. The final advice 
was altered to "include basic data gathering and manipulation when numerical data are collected".

The teachers in iteration-one informed me that the science topic we chose needed to relate to the school theme for the term. The use of a curriculum integration approach is described in Section 4.1.2; the specific theme for School-one was "iBod" (relating to the human body), which meant that science topics taught in the term were required to explicitly relate to the human body. Teachers in iteration-one had difficulty finding examples that related sound to the school theme. Given well-documented physical science SMK challenges faced by generalist teachers (e.g., Kind, 2014), and the abstract nature of many of the topics, it follows that highlighting everyday examples of the topics under observation, and advice on how the topics relate to school themes may need to be provided. The final implementation advice to "provide practical everyday examples of science, and (if applicable) relate science to the school theme" reflects the fact that not all schools employ a school theme as a means of curriculum integration.

The implementation advice added regarding narrowing the focus described in section 7.1.1 has an implication in the SMK area as well. The teachers in iterations one and two expressed their desire to understand the concepts they were teaching well enough to feel competent to scaffold investigations, and handle student questions. Their concern regarding the SMK and PCK necessary to successfully guide students in science investigations is not unusual, with similar findings reported by several researchers (e.g., Crawford, 2000, Kim \& Tan, 2011, Kleickmann, et al., 2015). Their desire to understand the concepts, given the relatively short amount of time involved in the PLD implies a limit to the breadth of material that can be covered, which led to the implementation advice to "focus on understanding, depth rather than breadth."

Iteration-one teachers were not able to teach the material until several weeks after the PLD, creating a substantial gap between learning the material, and 
using the material in their classrooms. At the final meeting with iteration-one teachers they made it clear that the delay was undesirable, and they felt their knowledge faded in the absence of reinforcement. This issue was also found by Summers and Kruger (1994) in their longitudinal study of improving primary teachers' science SMK:

There was evidence of "slipping back", that is, marked short-term gains which were no longer so evident in the longer term.... There is a need to find ways of supporting teachers following training so that their knowledge and understanding can be reinforced and validated. (p. 516).

This led to adding the additional design characteristic for SMK reinforcement, and the associated implementation advice to "ensure prompt use of the material to provide reinforcement and prevent information fade".

Teachers in iteration-one mentioned that it is at least a year, and sometimes two or more between repetitions of a topic, and they expressed their desire for high quality review materials. A teacher in iteration-two (see Section 5.2.2.2) took extensive notes on the handouts and review materials I provided during the PLD so that she could refer to them when teaching the material in the future. The need expressed by teachers in iterations one and two for a way to document the PLD in a way that provided a concise review of science subject matter and teaching ideas led to the implementation advice to introduce the content representation framework (CoRe) (Loughran et al., 2012) as a way to capture SMK and PCK, and the advice to "make active documentation an integral part of PLD using PCK tools: CoRe (Content Representation framework)" was added to the PLD framework. The CoRe was originally developed to capture and represent PCK; however, the use of the system as a way of documenting the PLD was valued by teachers in iteration-three. Another use of the CoRe for documentation purposes (subsequent to the use in this project) was reported by Lehane and Bertram (2016), where they report the use of the CoRe to record PCK aspects of a science curriculum development project. 
In the first two iterations I began each topic-focused PLD session with a brief review of material we had covered previously. During iteration-three it occurred to me that the reviews could be used to reinforce the subject matter by asking teachers to lead them. Shulman (1987) described a transformation of ideas that is necessary when teaching, "To reason one's way through an act of teaching is to think one's way from the subject matter as understood by the teacher into the minds and motivations of learners" (p. 16). Subject matter is altered, and additional connections are made when constructing explanations and teaching (Abd el Khalick, 2006; Lederman et al., 1994). The teachers in iteration-three found that leading the review periods became an important part of how they learned the material. Implementation advice to "ask teachers to conduct reviews of material and investigations" was added to the framework.

\subsubsection{Teaching practice}

The two design characteristics in the Teaching practice area suggested from the literature - Practical lesson development, taking into account the local classroom context; and Modelling and practising activities and teaching methods; were supported through the three iterations.

The original implementation advice that the PLD should be conducted in the classrooms at the school and designed with the teachers was altered with the experience in iteration-three. In the previous iterations I used the concept mapping exercise to gauge the SMK of the teachers, and designed the PLD to increase the SMK of the teachers relying on my expertise, with the input from the teachers limited primarily to topic selection. I felt the process I followed was in line with the literature, suggesting that effective science PLD programmes involve teachers in the planning process along with subject matter experts and university professors who select content and design the PLD programme (e.g., Capps et al., 2012a,b; Loucks-Horsley et al., 2010). In iteration-three I altered the planning process to make it more transparent (see Section 6.2.3.1), and by structuring the process around teachers' questions, made the process more centred on the teachers, and modified the implementation advice accordingly. 
The process followed in iteration-three was a more collaborative approach that extended the teacher input into the design of the PLD content, and created a genuine collaborative environment. The collaborative learning environment created in iteration-three is similar to what is described by Hargreaves and Dawe, (1990), and Borko, Jacobs, and Koellner (2010). The implementation advice to "work with teachers to define the key questions and/or big ideas of the subject matter of the PLD" was added to the framework.

The advice to have teachers work through the activities in the role of students fulfilled the design characteristic of modelling and practising activities and teaching methods, and was supported in all iterations. While a reading of the international literature might lead one to expect teachers would need to be convinced that using science investigations in their teaching was effective (e.g., Appleton, 2005; Capps \& Crawford, 2012a ; Haney \& Lumpe, 1995, Little, 1993; van Aalderen-Smeets \& van der Molen, 2015; Van Driel, Veijaard, \& Verloop, 2001), the teachers in this study needed no convincing. During iteration-one, the teachers expressed a clear preference to teach the science content through science investigations rather than teacher-centred approaches, and the advice to simply "affirm the efficacy of teaching through science investigation" was added to the framework.

The experience of teachers leading the reviews of previous material and investigations in iteration-three provided a natural opportunity for them to create explanations, build and test their own understanding, and to explore different ways to explain and conceptualise the science content. Using the newly learnt material in teaching builds the bridges between subject matter and teaching, and is described in the same literature that was cited previously in the final paragraph of Section 7.2.3. This experience led to the additional implementation advice to "ask teachers to conduct reviews of material and investigations." 


\subsubsection{Support}

The design characteristics in the Support area: Development of Community of Practice Support, and Provision of Ongoing Support, arising from the survey of literature (see, for example Bell et al., 2004, Capps et al., 2012b, and LoucksHorsley et al., 2010) were supported in the three iterations of this research, and no additional characteristics emerged.

The benefits of the formation of a community of practice were somewhat masked during the first two iterations because the teachers involved had been working together as teams prior to the PLD experience. The experience in iteration-three was different in that the teachers involved had not worked together prior to the PLD. During iteration-three a sense of community emerged during the PLD. The group became a safe place to try out explanations, and admit to not really understanding aspects of the science, leading to the implementation advice to "establish a safe, non-threatening environment for learning."

\subsubsection{Logistical considerations}

The Logistical considerations area was originally a catch-all category for operational details of the PLD programme, namely length, duration and location. During the first iteration I decided to begin with an investigation to set an active participatory tone for the PLD, which worked well and was added as a design characteristic. The other change that occurred in the Logistics area was the advice to schedule in prompt teaching of the material (Summers et al., 1994), which is described in detail in Section 7.2.3 above, where it functions to reinforce the SMK.

\subsubsection{Final framework}

The final framework is presented in Figure 50. 

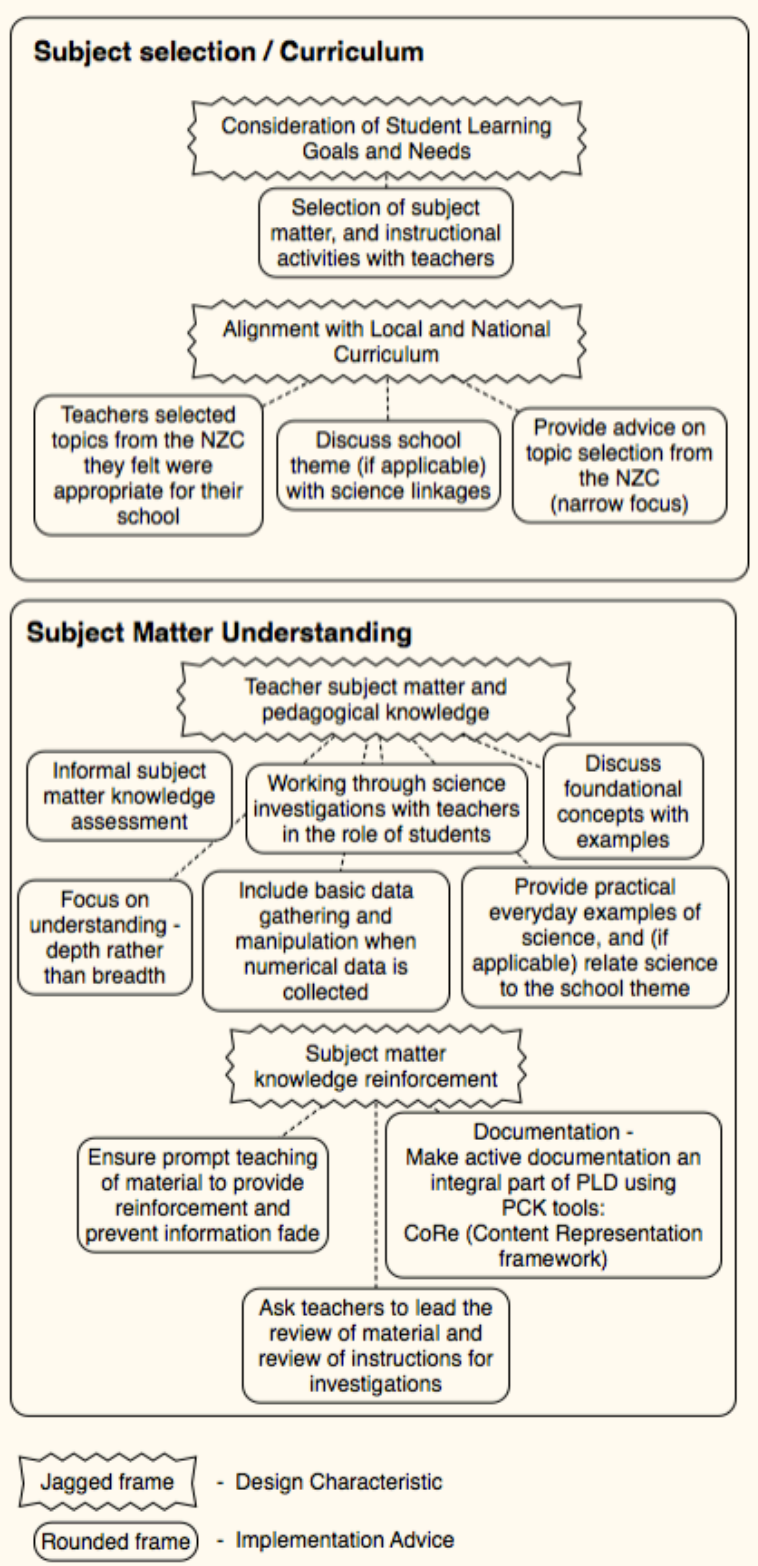

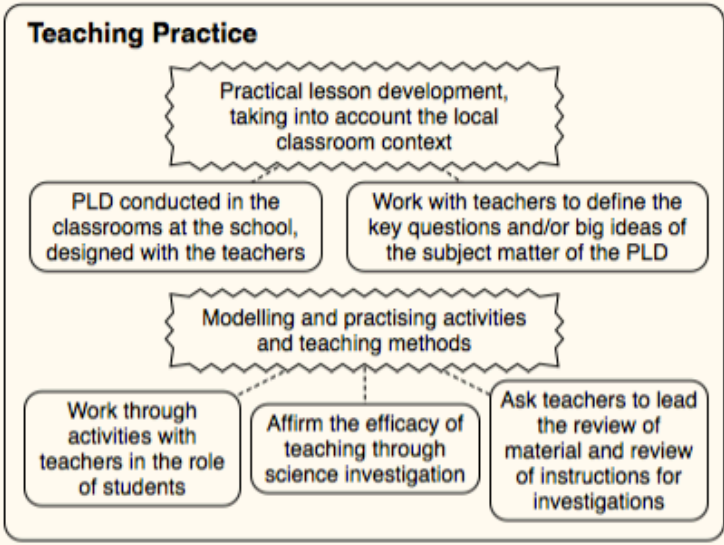

Support
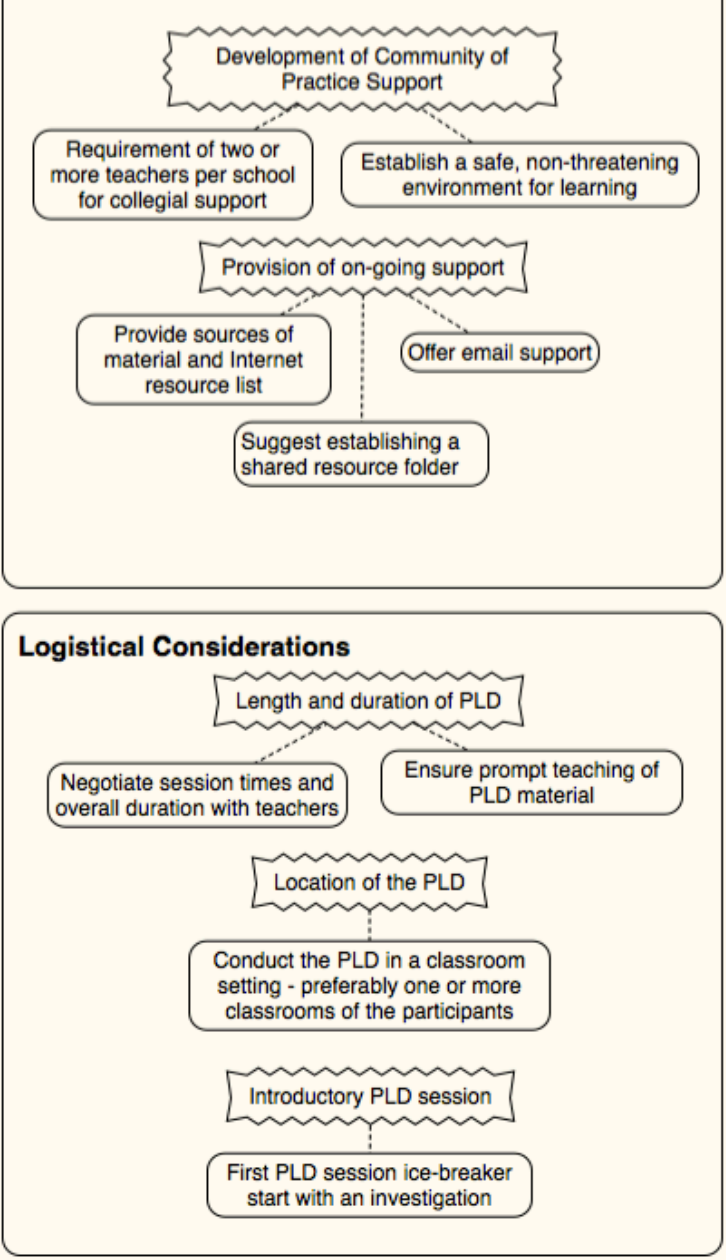

\section{Figure 50: Final Design framework}

This framework began as a distillation of design characteristics gathered from the international literature linked with initial advice regarding how to implement 
the characteristics. The framework was subjected to three iterations of use, analysis, and alteration working with New Zealand generalist middle school teachers who wanted to teach physical science topics in their classrooms. It takes into account the issues encountered by three different groups of teachers in three different New Zealand schools, teaching three different physical science topics. The result is a uniquely optimised operational framework to guide the creation of physical science PLD programmes for New Zealand middle school teachers.

\subsubsection{Facilitator qualities}

As discussed in section 2.3.4, use of this PLD framework requires specific skills and knowledge. In this section I will reflect on the knowledge and experience I drew upon to use the framework to deliver the three PLD iterations.

\section{Interpretation of framework}

The development of the PLD framework consisted of gathering best practice characteristics of PLD programmes from the literature and then refining them through three cycles of use and evaluation. As noted by Van Veen et al. (2012) (see section 2.3.3) generalised characteristics are difficult to interpret, and the authors suggest translating the general characteristics into usable specific advice. The framework, therefore, contains the high-level design characteristics, with one or more pieces of specific implementation advice to enable unambiguous interpretation of the characteristics.

The PLD framework is not designed to guide the production of a generalised PLD programme, but rather to use as a guide in all phases of producing a bespoke PLD for a unique group of teachers. 


\section{Facilitation - content expertise and teaching experience}

The rather limited research literature in this area (see section 2.3.4) indicates that facilitation of PLD requires someone who has: experience in teaching; specialised content knowledge; and the ability to develop a 'workshop culture', defined as an atmosphere of respect, acceptance, and a willingness to share ideas.

The literature does not specify the type of teaching experience required, and in my case the experience was at the senior high school level in chemistry and physics, which was the reason I recruited teacher participants who wanted PLD in the physical sciences. I had taught a unit on sound and light in my high school physics classes for eight years, and I had taught about forces and gravity as part of the physics class; however, I had never taught a specific unit on Newton's laws, which was a Year 9 topic at the schools where I taught.

During the PLD on sound (iteration-one), and light (iteration-three) I was able to draw on my experience to make decisions on the order of topics, and to select investigations that I knew worked well in classroom situations. Having taught those topics many times, I have considerable PCK in those areas, and was able

to anticipate challenging concepts and common misconceptions. I found myself less able to anticipate the challenges and misconceptions about Newton's laws in iteration-two, and have the subjective feeling that I was more effective teaching sound and light than I was teaching Newton's laws. I had studied Newton's laws in physics classes at university, and felt very confident in my knowledge of the topic; however, the lack of specific teaching experience in the area meant that I did not have the experience of students' questions that illuminate the challenging areas of a topic. In short, I had much less PCK in the area of Newton's laws than in sound or light. My experience in this project indicates that PCK specific to the chosen topic is advantageous in a facilitator.

It should be noted that I began this research with no previous experience in facilitating science PLD for middle school teachers. I began with some 
knowledge of the PLD literature, and the SMK and PCK of an experienced high physics school teacher. As the research progressed, I undoubtedly added to my own form of PCK for facilitating PLD, which may explain my decision to expand the concept mapping process in iteration-three to be more inclusive and transparent. It is also probable that a facilitator's topic specific PCK would be enhanced through the experience of working with groups of teachers in lessfamiliar topics. For example, I suspect I have gained PCK in the area of Newton's laws.

\section{Group dynamics}

In planning this research, it seemed obvious that an objective measure of SMK before and after the PLD would be a valuable measure of the efficacy of the PLD. During the first meeting with teachers in iteration-one I made an instinctive decision to forgo those data in order to create a non-threatening environment which made a change to the research plan, deciding to not subject the teachers to a formal test of SMK (see Section 3.5). The establishment of a non-threatening environment and a safe place in which to acknowledge gaps in knowledge and take risks doubtless contributed to the sense of community I described in Section 7.2.5. The group size was not one of the variables I intended to examine in this study. A decision to start with a small group of three and gradually increase the size of each iteration was a pragmatic choice to control the amount of data generated and the scope of the project. Research involving focus groups suggests an optimum group size of five to ten participants (Krueger \& Casey, 2014). Focusing on group communication,

Beebe and Masterson (2014) suggest smaller groups with three to six members are more likely to become cohesive than larger groups and take less time to become productive. As mentioned earlier, iteration-three was the only group that had not previously worked as a team. The five teachers in iteration-three were enthusiastic from the beginning, and established a positive group dynamic in a relatively short time, affirming the advice of Beebe and Masterson. It is worth noting that the community of practice established in iteration-three shares 
many of the characteristics of the recent MOE Communities of Learning | Kāhui Ako (CoL) initiative which seeks to improve education through improving teaching practice, and enabling teachers to share knowledge and experience (ERO, 2017). The Kāhui Ako (CoL) groups are designed to be safe sharing environments, and range in size from five to eight members. In practice, the actual size of a PLD group will need to accommodate the school environment; however, given the need to create a safe and supportive group dynamic large groups should be avoided.

\subsection{Related research questions}

\subsubsection{Barriers that inhibit physical science teaching}

The two major barriers that emerged while working with the three groups of teachers in this research project are: SMK, and curriculum. These barriers are not independent, and each contribute to the challenges teachers face when considering physical science topics.

The SMK knowledge challenges of generalist primary school teachers in New Zealand and internationally have been well established in the literature described in Section 2.2.3. The suggestions in the literature have been borne out in each iteration of PLD in this research project and discussed earlier in Section 7.1.2, as well as the Subject matter understanding sections of each iteration chapter. The teachers in each iteration were motivated to develop their SMK, and identified SMK as one of the main barriers of teaching science (see Section 4.2.2).

The experience in this research, particularly in iteration-one suggests PLD designed around SMK without addressing the related PCK would not be optimal. In iteration-one the PLD consisted of topics related to sound, providing teachers with science investigations and background science theory for them to use in their classrooms. Iteration-one teachers did not have an opportunity to reinforce the material (Summers et al., 1994) or begin to build PCK by translating the newly learnt concepts and developing their own ways of 
describing or explaining the concepts in a teaching context (Shulman, 1987). When they finally used the material in their classrooms they felt uncertain, and described not being as confident as they wished to be (see Section 4.2.2.1). The delay between the PLD and teaching was addressed, and the teachers in iteration-two began teaching while the new concepts were relatively fresh. They still, however, faced the situation of transforming their understanding into the actions of teaching, for the first time publicly in their classrooms in front of their students. The third iteration was altered to provide a degree of PCK building in the form of teachers being asked to construct descriptions and explanations for their peers, prior to classroom teaching.

A PLD that is designed to address SMK, and also be structured to provide knowledge reinforcement as well as initial PCK building addresses the first barrier.

The second barrier observed in this research was the curriculum, specifically the non-prescriptive design of the NZC (MOE, 2007a). The NZC is a framework that provides guidance to schools to use in development of curricula that are locally meaningful and relevant. However, the ERO found that the majority of schools examined did not have useful plans for science teaching, and that much of the planning that existed lacked coherence, and did not provide for coverage across all science strands of the NZC with a heavier concentration on the biological strands (ERO, 2012). An analysis of the overall science planning of the schools was outside the scope of this research; however, other issues relating to the curriculum did become apparent.

The teachers in iterations one and three did not have a specific topic in mind prior to the beginning of the PLD, and expressed a reluctance to select a specific topic from the NZC. Teachers in iteration-one described their reluctance as "you don't know what you don't know", which they explained as not knowing enough about the various topics in the Physical World strand of the NZC to make an informed choice. Teachers in iteration-three spoke of working the 
science they knew and were comfortable with into the various streams of the curriculum. They viewed the breadth in the curriculum as an advantage for teachers, but not necessarily for the students. The avoidance of areas (or the entirety) of the science curriculum (ERO, 2012) does students a disservice. The teachers who volunteered for this research project wanted to participate in PLD so that they could become more comfortable with some physical science topics and thereby be able to include them in their teaching. However, not all teachers may recognise the importance of including physical science in the locally developed curriculum, or take the initiative to find ways to build their knowledge and confidence.

Teachers in iterations two and three made use of the Making Better Sense materials mentioned earlier, and were able to develop individual science units using the suggestions and investigations in those materials; however, teachers in iteration-one did not. This observation is in line with a survey of New Zealand teachers conducted by the MOE in 2012 (Hipkins \& Hodgen, 2012), which indicated that approximately 65 percent of primary teachers had used booklets in the Building Science Concepts series (e.g., MOE, 2003) and 55 percent had used the Making Better Sense series (e.g., MOE, 1999). It is important to note that the BSC and MBS books were developed several years prior to the current NZC, and that no specific science curriculum support materials or PLD accompanied the NZC rollout. This lack of curricular support, combined with the discontinuation of the science advisors (Bull, 2014) makes the development of coherent local science curricula challenging. The situation is summed up by Sexton (2017) as:

The New Zealand Curriculum was developed to facilitate this integration of science with social, cultural, educational and personal experiences (Linn and Eylon, 2006). The problem, unfortunately, has been that the teachers who were expected to implement this new curriculum were expected to do so without any guidance or professional development. (2017, p. 231)

In summary, the science areas of NZC contain broad high-level guidance for the development of local curricula at the school level. However, the primary science 
curriculum support material for physical science: Making Sense of the Physical World (MOE 1999), is now 18 years old, and only available in hard-copy form. Without materials and support specifically aligned to the NZC to help teachers translate the NZC framework into coherent specific local science programmes it is not surprising that many schools are unable to do so (ERO, 2012).

\subsubsection{Key issues}

Two primary issues arose during this research which relate to approaching PLD in the New Zealand context: the selection of curriculum topics, and the question of balancing the breadth and depth of content coverage.

\subsubsection{Selecting curriculum topics}

An early issue that arose in this project involves a combination of conditions that makes the selection of topics from the NZC challenging for teachers. The situation results from the combination of four factors: the nature of physical science, the physical science SMK level of primary school teachers, the nature of the NZC, and the lack of specific curriculum support and guidance. This issue is made even more challenging when schools choose to integrate their curriculum around a specific theme.

I have discussed each of these subjects previously: In Section 1.2.5 I described the hierarchical nature of physical science (see also Venville, Rennie, \& Wallace, 2012; Venville, Wallace, Rennie, \& Malone, 2002); in Sections 2.2.2 and 2.2.3 I discussed the SMK needed for teaching physical science, and the research regarding teacher SMK; and in Section 2.1.2 I discussed the NZC and available curriculum support.

To illustrate how these conditions combine to make curricular choices difficult, I will use the example of the teachers in iteration-one. The teachers were faced with the need to select topics from the NZC which they could relate to the school theme "iBod" (relating to the human body). The NZC Physical World stand states that their students will: "Explore, describe, and represent patterns and 
trends for everyday examples of physical phenomena, such as movement, forces, electricity and magnetism, light, sound, waves, and heat" (MOE, 2007c, p. 18). I would suggest that teachers with a background in science would have no difficulty seeing potential connections of any of the topics in the curriculum to the school theme. However, for the teachers in iteration-one, those concepts were little more than a list of words, which may or may not fit the theme or be interesting to their students.

A teacher with little background in science, as was the case with these teachers, would first have to select a concept from the list, seek out for resources to begin to build their own understanding of the topic and teach themselves enough about the topic so that they can determine if the topic aligns with the theme. Only at that point could they make a decision whether or not the topic is appropriate for the theme and for their students. If it is, they could then begin to search for resources and investigations appropriate for their students, plan the unit, and finally teach it. It is no wonder they are hesitant to blindly choose.

Teachers in iteration-one were among the $35 \%-45 \%$ (Hipkins \& Hodgen, 2012) of teachers not aware of the science resources provided by the MOE such as the Making Better Sense books and the Building Science Concepts series and specially designed websites such as the Science Learning Hub (http://www.sciencelearn.org.nz) or the science areas of the Te Kete Ipurangi website (http://scienceonline.tki.org.nz). These internet resources contain teaching ideas, investigations, and other resources which are helpful for teachers once a topic is chosen. The internet resources do not, however, suggest learning progressions or teaching sequences to address a topic such as sound or light, and do not contain material to help teachers understand the basic foundational concepts that are necessary to select a topic and plan a coherent unit in physical science. 


\subsubsection{Breadth versus Depth}

In iterations one and two my initial plan for the amount of subject matter that could be covered in the PLD was reduced during the course of the PLD. In iteration-one I initially proposed to look at both sound and force, as they related to the human body; however, as the PLD progressed the teachers expressed interest in understanding how sound worked at a deeper level, and elected to look only at the concept of sound. Likewise, the teachers in iteration-two suggested that an understanding of Newton's first law, involving mass, force, and inertia would be enough material for a complete unit, and we concentrated more deeply on those concepts. The debate of curriculum coverage, and whether to emphasise depth or breadth is one of the classic dilemmas in education (Anderson, 1995; Katz \& Raths, 1992). The teachers in the iterations of this study were definitely on the side of depth of understanding, at least as applied to their PLD.

Eylon and Linn (1988) examined the science education literature from four perspectives: concept learning, developmental, differential, and problem solving. They concluded that:

...these perspectives collectively point out that systematic, sustained coverage of a few science topics can simultaneously address students' incomplete or inaccurate notions and can promote development of problem-solving skills. Such coverage also has more to offer students constrained by development or ability than does more superficial instruction. ... The cognitive need for systematic "in-depth" coverage of a few science topics is at odds with the conventional "in-breadth" coverage of many science topics. (p. 290)

Their finding aligns with a conclusion in the US National Research Council's Taking Science to School (2007):

Conclusion 8: Sustained exploration of a focused set of core ideas in a discipline is a promising direction for organizing science instruction and curricula across grades $\mathrm{K}-8$. A research and development program is needed to identify and elaborate the progressions of learning and instruction that can support students' understanding of these core ideas. The difficult issue is deciding what to emphasize and what to eliminate. (p. 358) 
The NZC also encourages teachers to choose depth over breadth, stating: "when curriculum coverage and student understanding are in competition, the teacher may decide to cover less but cover it in greater depth" (MOE, 2007a, p.34).

One challenge for teachers using the NZC is breadth of topics presented in the curriculum (see Figure 3), and particularly the Physical World achievement objectives. The PLD framework developed in this research helped teachers to build their understanding of a narrow portion of a single concept from the list of physical phenomena. This is a limitation; however, the PLD helped the teachers develop sufficient competence and confidence to plan and teach a unit in that area. It also (in the case of iteration-three) provided a pattern to follow when approaching a new curriculum topic.

A second challenge for teachers is found in the last sentence of the National Research Council's (2007) conclusion 8 above, and is related to the issue of topic selection earlier in this section. In order to narrow the focus, a decision on what science topics to include or leave out can only be reasonably made by someone who has sufficient understanding of the topics, to evaluate them, and make judgements regarding their value to the community, interest to students, and relative importance.

\subsection{Limitations}

An obvious limitation of the research is the specificity of focusing a PLD on physical science for experienced middle school teachers. The reasons for doing so are addressed in Chapters 2 and 3, however the danger of over specificity is that implementation advice would be overly specific, and be tuned to the specific parameters of the study. In the case of subject choice, it was a deliberate decision based on the unique challenges presented by physical sciences. In the case of the target year levels the focus was to limit variability in the groups. 
A logical question is whether the framework would be helpful for inexperienced teachers, other year level teachers, other science subject areas, or other subjects entirely. The decision to work with experienced teachers was based on research showing that PLD programmes for beginning teachers should be structured differently than programmes for experienced teachers (Tseng et al., 2012), and the experience of Jane, a first-year teacher, during iteration-two supported that conclusion (see Section 5.2.6). My expectation would be that the framework would work well with other homogeneous grade levels. I would also expect it would work quite well with mixed grade levels; however, I would anticipate the need for additional implementation advice in the Teaching practice area, as the questions and big ideas selected for Year 1 may be quite different to those for Year 8 . The specificity of the framework regarding physical science may extend to other science areas, however, as discussed in Section 2.2.3, the nature of the physical sciences is unique and may have given rise to specific advice, particularly in the Subject matter understanding area.

The design was optimised over only three iterations of PLD groups. The degree of change was highest in the first iteration, and less change was required in the subsequent iterations; however, some change resulted from iteration-three, and therefore the design is probably not fully optimised. Further iterations would be required to ensure a stable design.

Another limitation of this research is the inherent sample bias caused by the non-random selection of subjects. The teachers involved in this research volunteered to take part knowing they would receive PLD in physical science, and may be more willing and eager to learn than teachers from a random sample. A bias of this type might result in teachers who have pre-existing motivation to learn about physical science, and if the framework were applied to a non-motivated teachers more motivational aspects might need to be considered for inclusion. 
It was not within the scope of the research project to test if the PLD created lasting change, and if the content provided in the PLD became a lasting part of the local curriculum. Nor was it within the scope to develop instruments and measure student performance changes as a result of the PLD intervention.

Finally, this research employed a participant observer methodology, and the designer of the PLD framework was also the tester of the same framework, creating a potential bias. I have attempted to address this by explaining my thinking, and the resulting decisions made throughout the development process.

\subsection{Future direction}

The PLD framework developed in this project is optimised for middle school physical science teachers in New Zealand. The variables held constant were the subject matter, grade level, and national context. This research stopped with three iterations; however nothing prevents other researchers from starting with the existing framework and optimising it with teachers of other or mixed grade levels, subject matter, or location, as discussed in section 7.4 , thus extending the usefulness of the framework. An obvious advantage of optimising the framework for mixed grade level groups of teachers would be to use the PLD to help the school coordinate the coverage and presentation of the physical science topics and plan for logical progress.

\subsection{Final thoughts and implications}

In this research project, I have looked at the puzzle of what can be done to inspire the teaching of high quality physical science in New Zealand primary schools. This research concentrated on one proposed solution, that being bespoke PLD to relatively small groups of teachers. The PLD design framework represents an application of principles suggested by the literature, which have been adapted and augmented to work specifically with middle school teachers in the New Zealand environment teaching physical science topics. 
I chose the lens of social constructivism for this study, and on reflection it was a fitting choice on several levels. The DBR methodology iteratively builds up a design based on interpretation of data; the nature of science learning requires making sense of observations, and building on pre-existing knowledge; and the nature of science itself is the process of the building up of understanding via a systematic process of observation, negotiation, and meaning making (Staver, 1998).

I was impressed by several things during this research. The SMK gaps were completely predictable from the literature, however, the teachers' eagerness to learn, and their tenacity, and unwillingness to settle for surface level understanding was a pleasant surprise, and sometimes a challenge as a facilitator. Their fundamental understanding of the value and importance of constructivist teaching in their use of student centred investigations was also surprising, particularly in light of the emphasis in the international literature. And finally, the demonstrated ability of the teachers to combine the newly acquired SMK with their existing pedagogical knowledge to modify investigations from the PLD, and in some cases, develop new ones showed a level of mastery that was impressive and inspiring.

The teachers in this research taught me the necessity of having both the pedagogical and content components of PCK. I came with a sound knowledge of physics and experience in teaching at the secondary level, which served me well in facilitation of the PLD. However, in working with the primary teachers I began to appreciate the way their pedagogical knowledge of their students shaped and stimulated their desire to learn science SMK. I found that they recognised their limited SMK, and they knew they needed to learn, but they didn't know what they needed to learn or where to start.

The teachers in iteration-three indicated they would follow a similar format that we used to define the topic and choose the "big idea" concepts that help narrow the broad topics down into smaller, and more researchable sub-topics. One 
challenge they would face would be finding appropriate support materials for themselves and their students. The four Making Better Sense books provide some science background information for teachers; however, they are structured as a cogent review rather than a resource for approaching the material for the first time. A potential resource exists in specifically designed educative curriculum materials that support teacher learning (Davis \& Krajcik, 2005). Materials produced using science domain-specific design heuristics, combined with other professional learning opportunities support teacher professional learning (Davis, Palincsar, Smith, Arias, \& Kademian, 2017). Recent analysis of the effectiveness of these materials shows that when they are used in conjunction with PLD, they are effective in facilitating teacher learning and instrumental in changing teaching practice (Donna \& Hick, 2017; Pringle, Mesa, \& Hayes, 2017).

The risk in relying on curriculum materials alone is summed up by a comment from Bree, a teacher in iteration-one:

...make it simple too, even for us teachers, it needs to be not complex at all, very simple, so if we read it and we saw that and read it and didn't understand it, you would just go "yeah-no" and put it to the side and do something else, you wouldn't go through it at all, whereas if it was something simple that you could read and go - "oh yeah, that's right, I understand what that means" then you're more likely to keep going.

A challenge with specifically designed curriculum support resources is pitching them at the right level. In the quote above, Bree is looking for a resource that is understandable for her specific knowledge level; however, a resource well suited to Bree would unlikely be well suited to teachers with different levels of content knowledge. The starting place for each individual is unique, and in many ways similar to the situation faced by classroom teachers every day. If materials alone could do the job of education, there would be no need for teachers.

The status quo with regard to the teaching of science in primary school in New Zealand is not working, and changes must be made if the situation is going to 
change. I was impressed with the enthusiasm and dedication shown by the teachers in this study; and there is scant reason to believe that they are not representative of the majority of teachers in New Zealand. They were eager to learn the physical science concepts so that they could teach with confidence and competence.

The fundamental question is what Bree and other teachers like her need in order to teach physical science topics confidently and creatively. This research suggests that targeted small group PLD that is facilitated not by expert scientists, but rather by facilitators with expertise in science and teaching, could make a substantial difference.

The findings in this study have highlighted the central role that SMK plays in empowering teachers to teach physical science. The PLD design framework produced in this research guides the construction of a PLD programme that allows teachers to acquire SMK in a way that also builds the corresponding PCK, enabling the teachers to create dynamic learning environments.

The challenge of teacher self-efficacy, and the difficulty shown in the selection of topics from the NZC in this study all flow from teachers' SMK and associated PCK. When those are in place, teachers can make the types of decisions around inclusion of topics and the depth to which they wish to cover those topics. When those enlightened decisions can be made schools can fulfil the vision of the NZC and create a school curriculum which is in harmony with its community. 


\section{Appendices}

Appendix A: Principal Letter

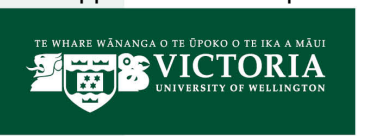

SCHOOL OF EDUCATION Te Puna Akopa

PO Box 17-310, Donald St, Karori, Wellington 6147, New Zealand Phone + 64-4-463 9500 Fax +64-4-463

9521 Email sepp@vuw.ac.nz Web www.victoria.ac.nz/education

28 May 2014

«Recipient»

«Title»

«School_Name»

«Address_1»

"Address 2"

"Address_3"

Dear «Title» «Recipient_Sirname»:

Re: Year $7 \& 8$ professional development in science

I am a science education PhD candidate at the Faculty of Education, Victoria University of Wellington. My research involves the design of science professional development (PD) programmes for teachers of Year 7 and 8 students. The research project involves current classroom teachers who have at least three years teaching experience and would like to teach more science in their classrooms.

I would like your support in contacting year 7 and 8 teachers at «School_Name» who have been teaching for 3 or more years, to invite them to participate in a PD programme as part of my research. I will be working with the teachers on physical science topics, with a strong emphasis on science investigation. There will be no financial cost to the school or the teachers other than some time. The length of the PD will be worked out with the teachers, but I envisage 2-4 afterschool sessions over 2 or 3 weeks.

I was a physics and chemistry teacher for 8 years in the United States in the mid 1980s, and then spent several years doing research at the University of lowa before our family moved to New Zealand in 2003. I was employed at the New Zealand Ministry of Health in various capacities prior to my decision to re-enter the field of education. Watching my sons make the transition from primary school to college, and taking note of their view of science influenced the direction of my research interest.

I have enclosed an information sheet about my project. My goal is to work with two teachers from each participating school, and to conduct the PD in the participating schools at a time mutually agreed with the teachers involved.

If you have any teachers that may be interested and you are happy for them to participate, or if you need more information please don't hesitate to contact me (details below).

Sincerely,

Ted Cizadlo

PhD Candidate

School of Education

Victoria University of Wellington

ted.cizadlo@vuw.ac.nz

Ph: 0275964889 


\section{Appendix B - Principal consent form}

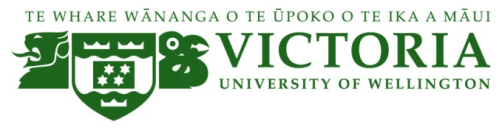

Professional Development Design for Middle-School Science Teachers

Principal Consent Form (Research)

I consent to participate in this research and that:

- I have had the Professional Development Design for Middle-School Science Teachers research project explained to me

- I understand what would be required of the teachers and students from this school who participate in the research.

- I understand that teachers' and students' participation in the research is voluntary and that they may withdraw from it during the data gathering.

- I understand that the teachers', students' and school's identity would be protected.

- I understand that all data would be stored in password protected files and in locked offices at Victoria University and will be destroyed 5 years after the completion of the research.

- I understand that students' responses may be used in papers or presentations that are concerned with learning and self-assessment and researching with children.

I consent to teachers and students being invited to be part of the research. I consent to provide the researchers with any relevant school documents about teaching learning and assessment.

Signed:

Date: 


\section{Appendix B - Teacher consent form}

\section{TE WHARE WĀNANGA O TE ÜPOKO O TE IKA A MĀUI}

$\underline{\text { Professional Development Design for Middle-School Science Teachers }}$

\section{Teacher Consent Form (Research)}

\section{I consent to participate in this research and that:}

- I have had the Professional Development Design for Middle-School Science Teachers research project explained to me.

- I understand what would be required of me and my students.

- I understand that my participation in the research is voluntary and that I may withdraw from this research before the data analysis begins [March, 2015].

- I understand that my identity would be protected and recordings will not be used in presentations or publications.

- I understand that all data would be stored in password protected files and in locked offices at Victoria University and will be destroyed 5 years after the completion of the research.

- I understand that data collected may be used in papers or presentations and that students should not be identified.

- I understand that I will need to provide the researchers with any relevant planning and assessment documents.

- I agree to maintain the confidentiality of others involved in this research, including students, fellow teachers and schools.

Signed:

Date: 


\section{Appendix B - Principal information sheet}

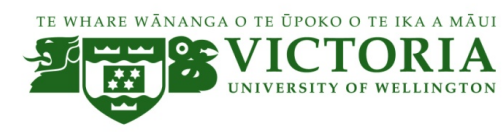

Professional Development Design for Middle-School Science Teachers

Principal Information Sheet

Researchers' introduction

I am a PhD candidate in the school of Educational Policy and Implementation at Victoria University of Wellington. My PhD research entails designing professional development to help middle school teachers who would like to teach more science in their classes. The title of my research proposal is: "Professional Development Programme Design for MiddleSchool Science Teachers."

Project description and invitation

I am proposing to work with groups of teachers to develop and refine a professional development (PD) programme designed to empower primary teachers to teach science lessons through science investigation. It is my view that having a positive experience teaching in this way will support teachers to teach more science. The research will focus on year $7 \& 8$ teachers with a minimum of 3 years teaching experience.

Participation in this research will involve working with the participating teacher and their class. Teachers involved in this research will:

- Participate in individual and group interviews;

- Teach science lessons with a research observer in the classroom;

- Participate in professional development sessions in school classrooms;

- Participate in interviews reflecting on the observed lessons; and

- Provide feedback and suggestions on improvement of the professional development.

Student involvement will involve observation by a researcher during up to three science lessons. Additionally, the researcher will work with the teacher to select a student focus group. Student focus group participants will participate in focus group interviews.

Interviews with teachers and students will be scheduled at times that are convenient for the school and least disruptive for the teachers and students.

\section{Participant identification}

Identities of the schools, teachers and students involved in the research will be confidential to the researcher, and will not be used in any publications or presentations arising from this research. Pseudonyms will be used in reporting individual responses, or when referencing individual participants or schools.

\section{Dissemination of results}

Findings from this research will be shared with the participating teachers. Results may be shared at science education conferences and developed for publication in academic journals. 


\section{Appendix B - Principal information sheet (continued)}

All data will be stored in password protected files and locked offices at Victoria University and will be destroyed 5 years after the completion of the research. My proposal has been reviewed by the Faculty of Education, and has been approved by the Victoria University Human Ethics Committee (number 0000020480). If you have questions about the way the research is being conducted you may conduct Dr Allison Kirkman (Allison.kirkman@vuw.ac.nz), Chair of the Victoria University of Wellington Ethics Committee.

I am inviting your school to participate in this research and asking for your support to work with teachers in your school. The project will be led by Ted Cizadlo, under the supervision of Dayle Anderson and Craig Rofe. Should you require any further information please get in touch with us.

Yours sincerely

Kind regards

Ted Cizadlo

PhD Candidate

School of Education

Victoria University of Wellington

ted.cizadlo@vuw.ac.nz

Ph: 04 476-7733

Dr Dayle Anderson

Senior Lecturer

School of Education

Victoria University of Wellington

dayle.anderson@vuw.ac.nz

Phone: 044639630

Dr Craig Rofe

Senior Lecturer

Te Kura Maori

Faculty of Education

Victoria University of Wellington

craig.rofe@vuw.ac.nz

Phone: 044639539 


\title{
Appendix B - Teacher information sheet
}

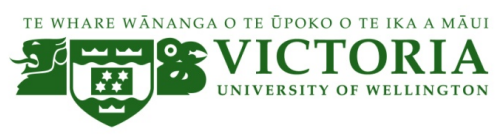

\section{Professional Development Design for Middle-School Science Teachers}

\author{
Teachers Information Sheet
}

\section{Researchers' introduction}

I am a PhD candidate in the school of Educational Policy and Implementation at Victoria University of Wellington. My PhD research entails designing professional development to help middle school teachers who would like to teach more science in their classes. The title of my proposed research is: "Professional Development Programme Design for MiddleSchool Science Teachers."

\section{Project description and invitation}

I am proposing to work with groups of teachers to develop and refine a professional development (PD) programme designed to empower primary teachers to teach science lessons through science investigation. As a former teacher I know the challenges of teaching science through investigation, but I also understand the benefits. It is my view that a PD programme designed in collaboration with the participating teachers will be effective and will support teachers to teach more science.

I am inviting year 7 and 8 teachers who have had at least 3 years teaching experience and are interested in teaching science through science investigation. Participation in this research will involve working with you and your class.

Teachers involved in this research will:

- Participate in individual and group interviews;

- Teach science lessons with a research observer in the classroom;

- Participate in professional development sessions in school classrooms;

- Participate in interviews reflecting on the observed lessons; and

- Provide feedback and suggestions on improvement of the professional development.

Student involvement will involve observation by a researcher during up to three science lessons. Additionally, the researcher will work with the teacher to select a student focus group. Student focus group participants will participate in group interviews. Interviews with teachers and students will be scheduled at times that are convenient for the school and least disruptive for the teachers and students.

The participation of your class in this research can also provide an opportunity to let the students see the process of science at work. You will be asked to tell your class about the research project, and to let them know how their participation has shaped the research. 


\section{Appendix B - Teacher information sheet (continued)}

\section{Participant identification}

Identities of the schools, teachers and students involved in the research will be confidential to the researcher, and will not be used in any publications or presentations arising from this research. Pseudonyms will be used in reporting individual responses, or when referencing individual participants or schools.

\section{Dissemination of results}

Findings from this research will be shared with the participating teachers. Results may be shared at science education conferences and developed for publication in academic journals.

All data will be stored in password protected files and locked offices at Victoria University and will be destroyed 5 years after the completion of the research. My proposal has been reviewed by the Faculty of Education, and has been approved by the Victoria University Human Ethics Committee (number 0000020480). If you have questions about the way the research is being conducted you may contact $\mathrm{Dr}$ Allison Kirkman (Allison.kirkman@vuw.ac.nz), Chair of the Victoria University of Wellington Ethics Committee.

I am inviting your school to participate in this research and asking for your support to work with teachers in your school. If you are interested in participating or have any questions please contact Ted Cizadlo (ted.cizadlo@vuw.ac.nz). I will be accepting a maximum of two teachers per school, and the number of participants will be limited.

The project will be led by Ted Cizadlo, under the supervision of Dayle Anderson and Craig Rofe. Should you require any further information please get in touch with us.

Yours sincerely

Kind regards

Ted Cizadlo

PhD Candidate

School of Education

Victoria University of Wellington

ted.cizadlo@vuw.ac.nz

Ph: 04 476-7733

Dr Dayle Anderson

Senior Lecturer

School of Education

Victoria University of Wellington

dayle.anderson@vuw.ac.nz

Phone: 044639630

Dr Craig Rofe

Senior Lecturer

Te Kura Maori

Faculty of Education

Victoria University of Wellington

craig.rofe@,vuw.ac.nz

Phone: 044639539 


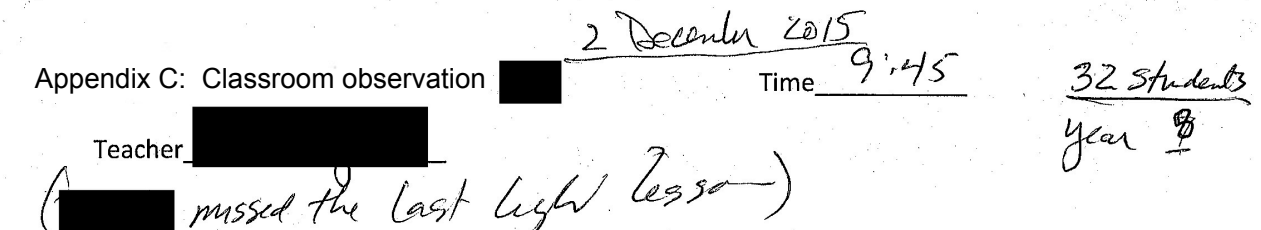

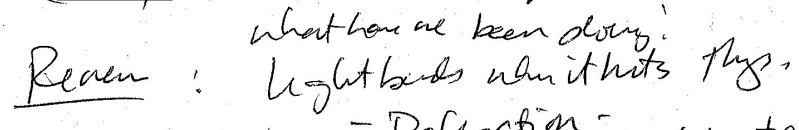

$$
\begin{aligned}
& \text { - Refraction - inget hts transpant thys } \\
& \text { - Water in bowe. } \\
& \text { - Prisms. } \\
& \begin{array}{l}
\text { Caryingan: } \\
\text { worky in tuble grmps. (3peoser) }
\end{array} \\
& \begin{array}{l}
\text { Looby at plastic cup icouns, } \\
\text { glad may on top foup. }
\end{array} \\
& \text { Obserne coin theng the plastic. }
\end{aligned}
$$

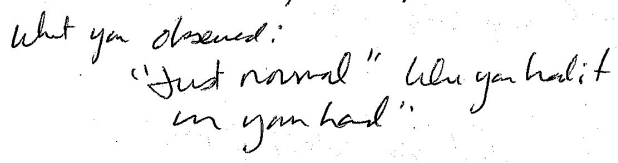

$$
\begin{aligned}
& \begin{array}{l}
\text { how fill up area on top of plastic SHeO } \\
\text { with watu. }
\end{array} \\
& \text { What hem jan Noticed? } \\
& \text { "The coin looks speead ant a leth" } \\
& \text { goses fim sign of } 5 \text { to } 50 \mathrm{C} \text {. } \\
& \text { What is hagzenion when lyght gos thinh thavat - } \\
& \text { (es tables tulky abut it) } \\
& \text { now-a page frma anagagen. I studuti2 } \\
& \text { Punta sugh drop of vater- "ciha sicentist" } \\
& \text { onto the pruation. }
\end{aligned}
$$

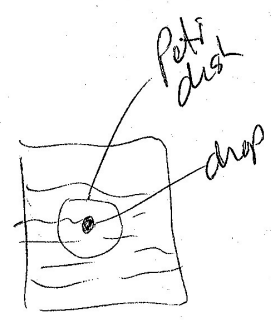

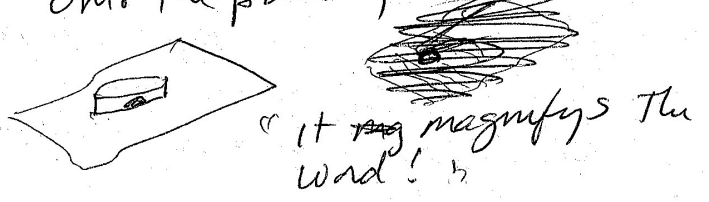


Appendix C Classroom observation (continued)

(2)

what do yo notice ales the shape of the dep? (from the side?) teat

Some students holding the dot up? many the magurfrativ moe.

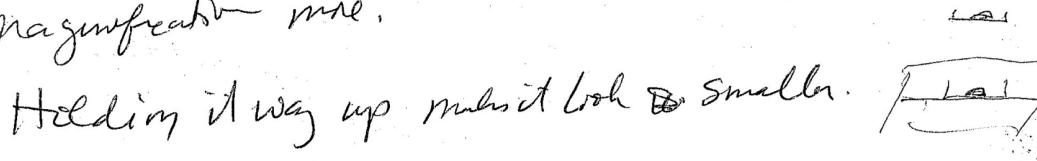

- The activity is challying pecans of the water $m$ the destetogs, - but students an cooperative.

- Cess discussion.

How is this useful?

How dos Viffect is?

"now I want th What han seen? to then ale it, to do The scarce part "s

Went did yon notice. magnifud. Il tarns il upsededom abe yen hold 1 high. dip stage is a exp-(studet comus.?

holds up a magnify in glass $t$ passes Them ant.

wo ut all can you notice abut the magnify ing glass.

What hem gan noticed?

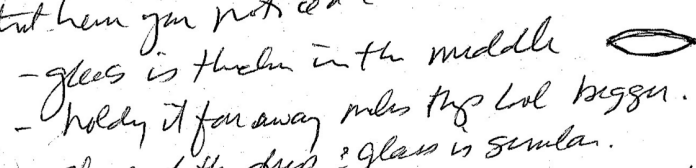

- slug ft th drip : glam in simla.

- Thy s flop roots upside den war you hold i for any.

254 
Appendix C Classroom observation (continued)

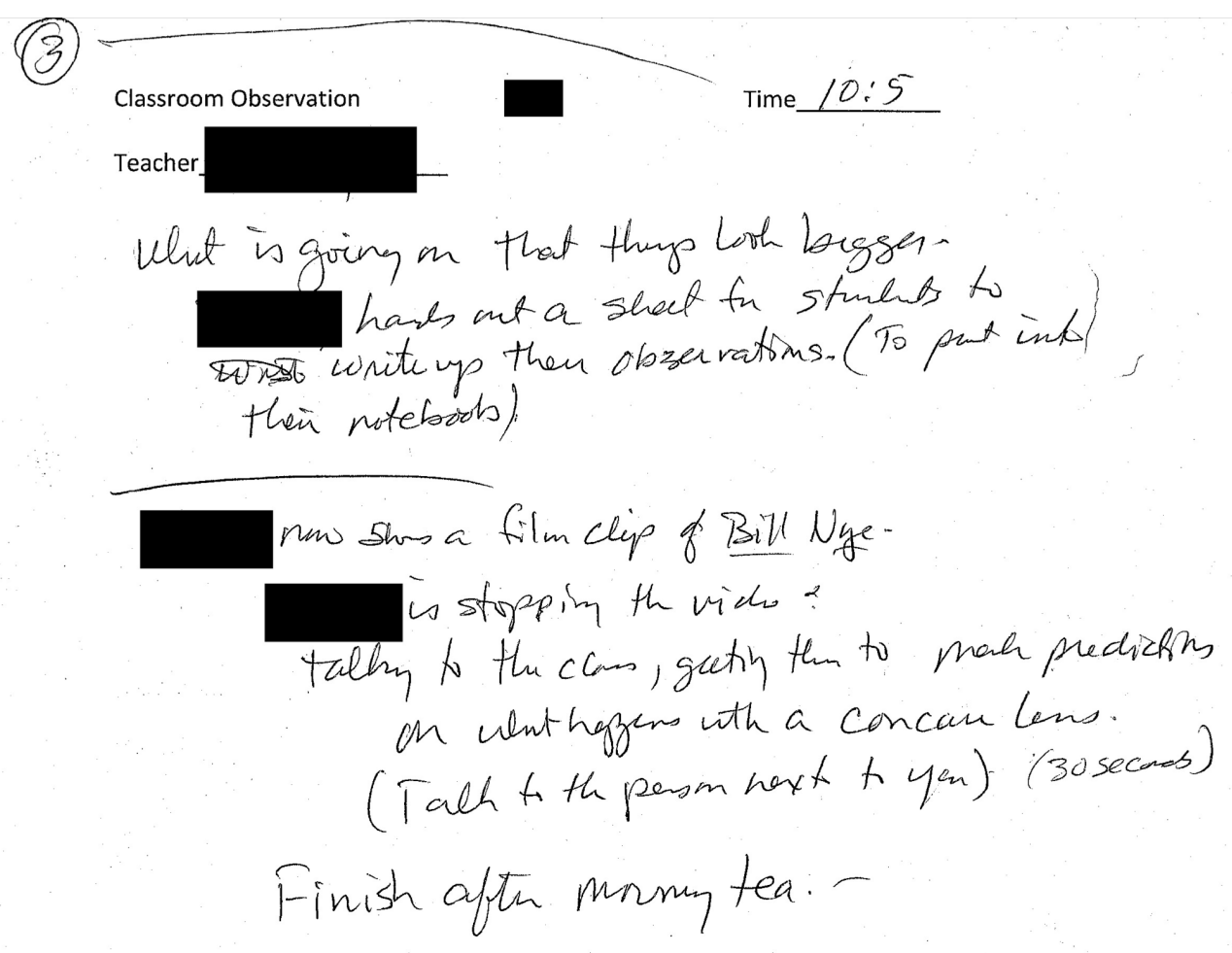




\begin{tabular}{|c|c|c|c|c|c|}
\hline$\stackrel{-1}{3}$ & $\stackrel{-1}{3}$ & $\stackrel{-1}{3}$ & $\begin{array}{l}\text { 㞧 } \\
\mathbb{\infty}\end{array}$ & $\vec{\Phi}$ & $\begin{array}{l}0 \\
\frac{0}{\lambda} \\
\text { d }\end{array}$ \\
\hline $\begin{array}{l}\text { O } \\
\text { ij } \\
\text { ஸi }\end{array}$ & 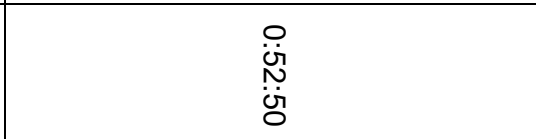 & $\begin{array}{l}\text { o } \\
\text { ì } \\
\text { ஸr } \\
\text { oi }\end{array}$ & 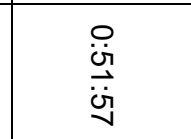 & 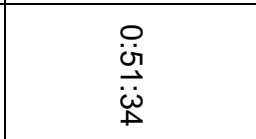 & \\
\hline 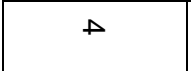 & $A$ & $A$ & $\triangle$ & 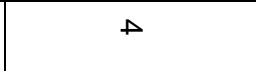 & 果 \\
\hline 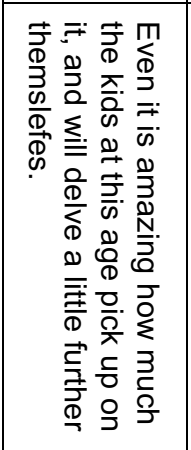 & 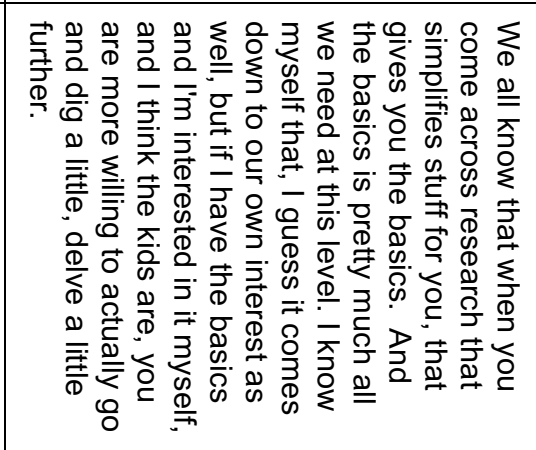 & 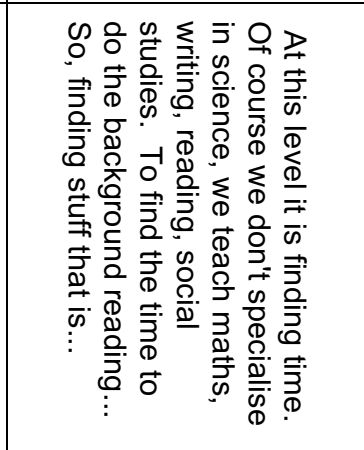 & 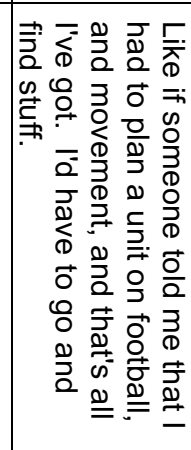 & 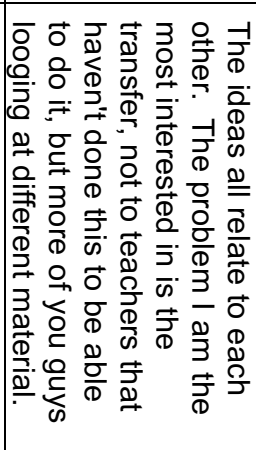 & : \\
\hline$\vec{v}$ & $\stackrel{\infty}{3}$ & $\begin{array}{l}\infty \\
\mathscr{N} \\
\end{array}$ & $\stackrel{\infty}{3}$ & $\underset{⿱ 亠 乂}{\text { 芳 }}$ & $\begin{array}{l}8 \\
\frac{8}{0}\end{array}$ \\
\hline$\dot{t}$ & $\dot{A}$ & 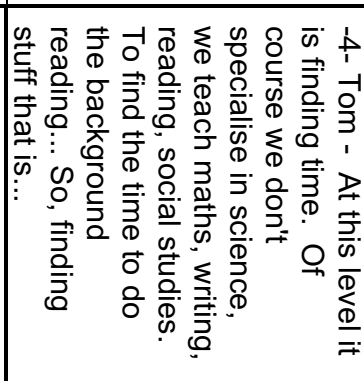 & 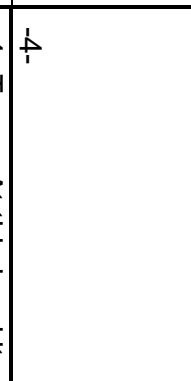 & $\dot{A}$ & 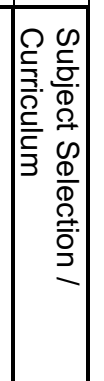 \\
\hline i & 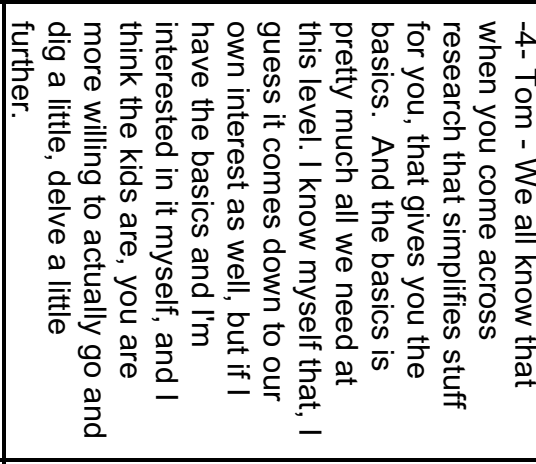 & 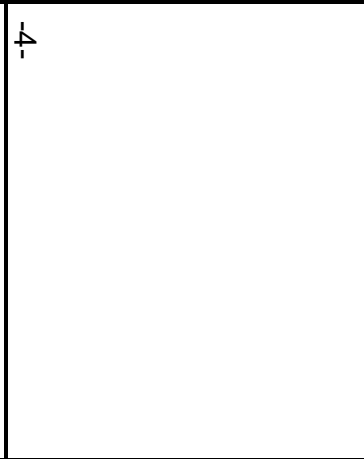 & 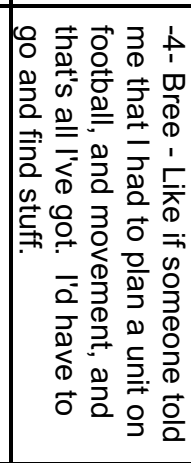 & 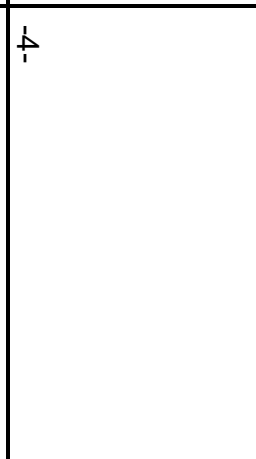 & 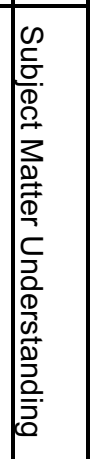 \\
\hline 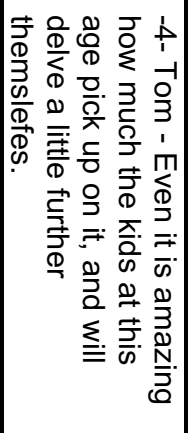 & A & $\dot{A}$ & $\stackrel{f}{i}$ & $A$ & 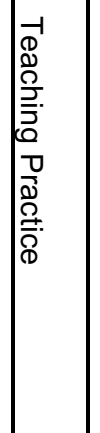 \\
\hline$A$ & $A$ & $A$ & $A$ & A & 告 \\
\hline
\end{tabular}




\begin{tabular}{|c|c|c|c|c|c|c|c|c|}
\hline 岕 & $\vec{\Phi}$ & $\begin{array}{l}\underset{\mathbb{D}}{\mathbb{D}} \\
\mathbb{D}\end{array}$ & 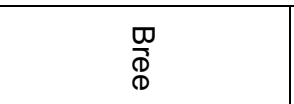 & 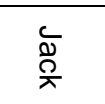 & 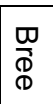 & $\frac{\stackrel{-1}{3}}{3}$ & $\stackrel{-1}{3}$ & \\
\hline 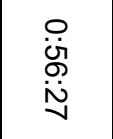 & 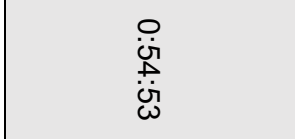 & 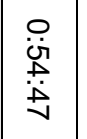 & 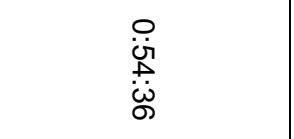 & 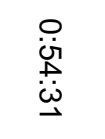 & 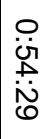 & 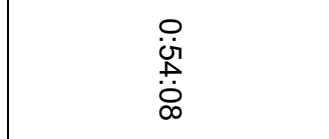 & 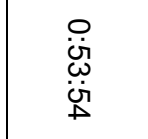 & $\begin{array}{l}\stackrel{\rho}{\mathcal{j}} \\
\stackrel{\omega}{\dot{\phi}} \\
\dot{\infty}\end{array}$ \\
\hline 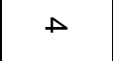 & A & $A$ & A & A & $A$ & $\Delta$ & $\Delta$ & $A$ \\
\hline 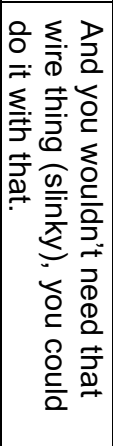 & 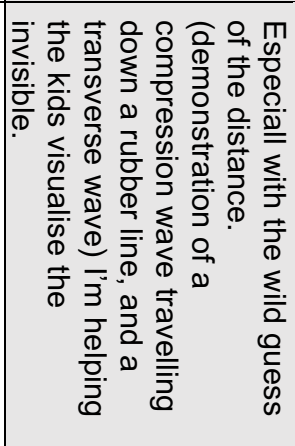 & 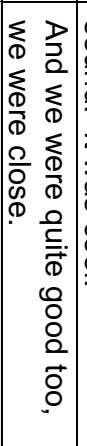 & 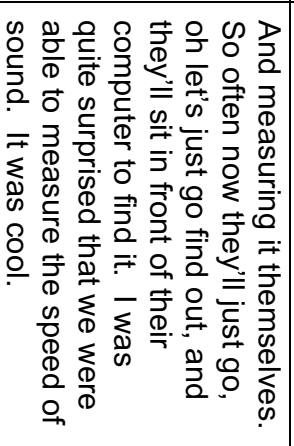 & 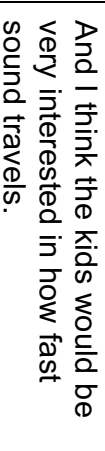 & & 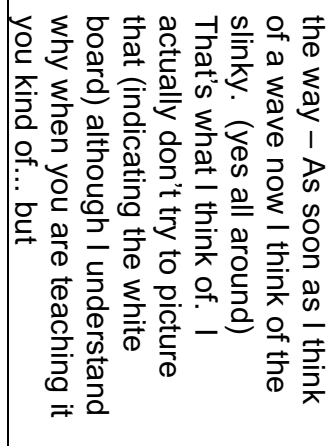 & 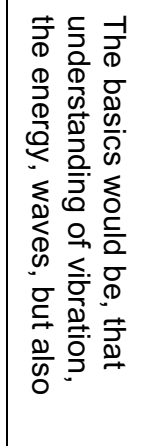 & 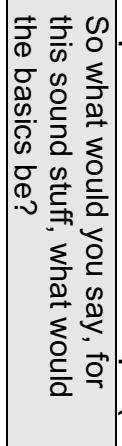 \\
\hline$\underset{⿱}{\text { 荠 }}$ & $\underset{⿱ 亠 䒑}{\text { 芳 }}$ & $\underset{⿱ 亠 䒑}{\text { 芳 }}$ & $\frac{1}{0}$ & $\stackrel{\infty}{3}$ & 芠 & $\stackrel{\infty}{3}$ & $\stackrel{\infty}{3}$ & $\underset{⿱}{\stackrel{*}{J}}$ \\
\hline$\dot{t}$ & $\dot{t}$ & $\dot{t}$ & $\dot{t}$ & $\dot{p}$ & $\stackrel{f}{p}$ & P & $\stackrel{f}{\prime}$ & $\stackrel{t}{ }$ \\
\hline t & t & $\stackrel{p}{\prime}$ & $\vec{t}$ & 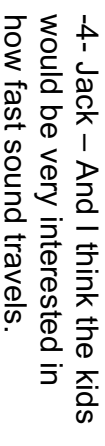 & ti & 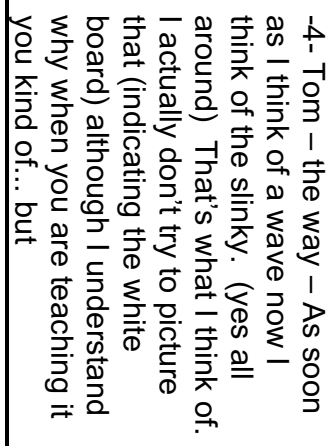 & 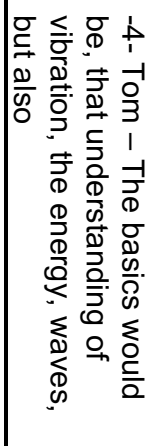 & $\mid$ \\
\hline$\stackrel{+}{i}$ & $\stackrel{t}{t}$ & $\vec{t}$ & 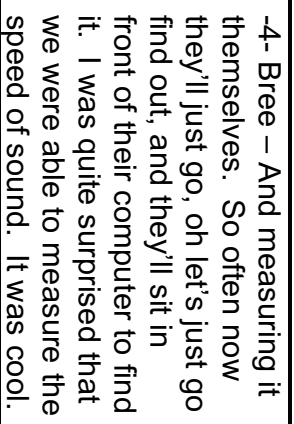 & s & $\vec{t}$ & $\stackrel{A}{A}$ & it & i \\
\hline t & $A$ & t & t & t & t & $\stackrel{f}{A}$ & $\stackrel{A}{A}$ & 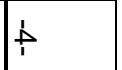 \\
\hline
\end{tabular}




\begin{tabular}{|c|c|c|c|c|}
\hline$\frac{\mathbb{D}^{-1}}{2}$ & $\stackrel{\text {-1 }}{3}$ & 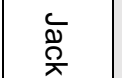 & $\stackrel{\vec{\Phi}}{\Omega}$ & $\frac{0}{3}$ \\
\hline $\begin{array}{l}\text { ơ } \\
\text { ij } \\
\text { oj }\end{array}$ & 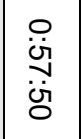 & 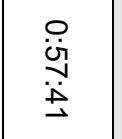 & 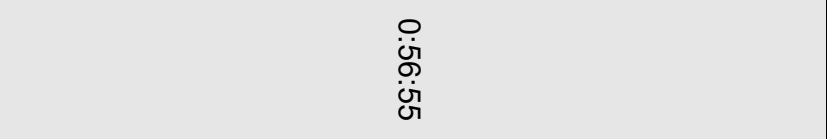 & 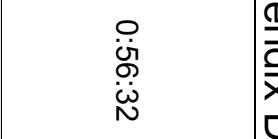 \\
\hline$A$ & 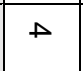 & 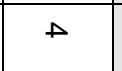 & 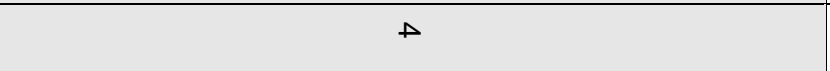 & 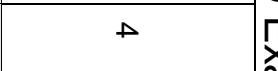 \\
\hline 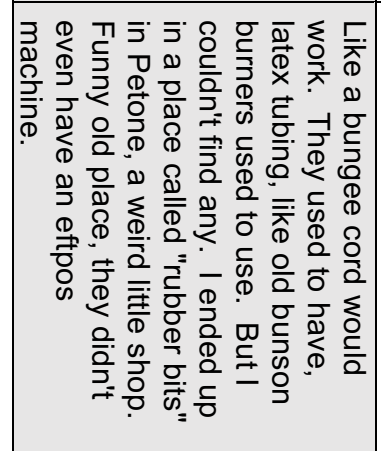 & 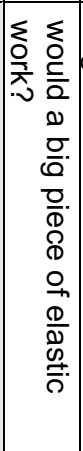 & 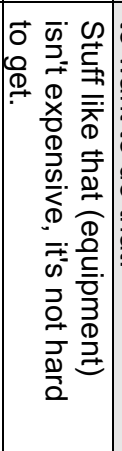 & 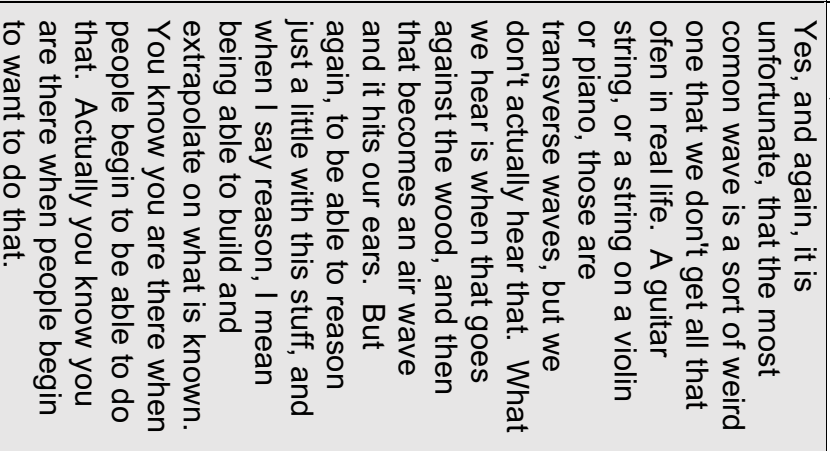 & 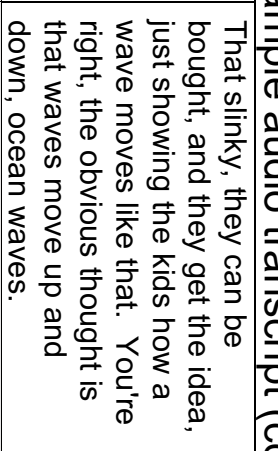 \\
\hline 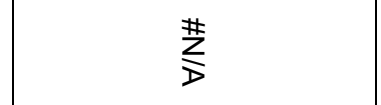 & $\underset{⿱}{\text { 芳 }}$ & $\stackrel{0}{3}$ & $\underset{⿱ 亠 䒑}{\text { 芳 }}$ & $\stackrel{\infty}{3}$ \\
\hline$\dot{f}$ & $\dot{t}$ & + & f & t \\
\hline+ & $\vec{t}$ & 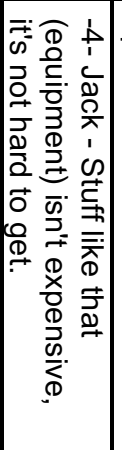 & t & 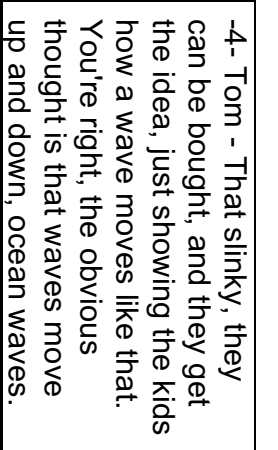 \\
\hline 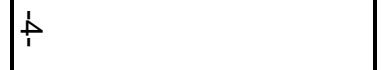 & $\vec{t}$ & $\vec{t}$ & $p$ & $t$ \\
\hline$\stackrel{A}{A}$ & 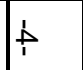 & $\rightarrow$ & t & $\stackrel{A}{A}$ \\
\hline
\end{tabular}




\section{Appendix E: Review sheet}

PD Session 4

Connections. Seeing Newton's laws everywhere - Continued

1) Newton's first law (law of inertia) things at rest stay at rest, things in motion stay in motion unless a force acts on them.

a. What is a force? (construct a force measurer)

b. What is inertia? (Mass, or how much stuff there is - combined with it's state of motion)

c. Explain - every day things in terms of Newton's $1^{\text {st }}$ law. (begin to see inertia everywhere) i. Things in cars when they stop and start

d. Additional poker chip \& comb activity *

e. Why do things come to a stop? (Friction) *

f. Measuring friction (sliding something at a constant speed - using the force measurer) * i. Anti-lock brakes (extension)

g. Circular motion requires a force inward (which way do things go when the force stops?)

2) Newtons's $2^{\text {nd }}$ Law - Forces affect Masses in certain ways

a. $\quad$ Force $\mathrm{x}$ Time $=$ Mass $\mathrm{x}$ Velocity --OR-- Force $=$ Mass $\mathrm{x}$ Acceleration

i. Momentum is Mass $\mathrm{x}$ Velocity (Newton: quantity of motion)

ii. Momentum is conserved - easy to see in elastic collisions (less friction)

a) The total momentum you start with = the total momentum after collision

iii. How FT $=$ MV works in the world. (examples)

Activities include: $\quad$ Keep a constant FORCE on something as it moves

Catching water balloons (eggs) ( 2 person game or sheet/towel)

Collisions - balls, poker chips, cars (hot wheels would be best)

Large \& small ball bouncing

Car crash video (?)

3) Action always gets a reaction (forces are either balanced or things are accelerating)

a. When something pushes in one directions, something has to push back in the other

b. If is still, or going a constant speed, it must not have any (net) force on it.

Activities include:

rolling chairs -

Pushing away from each other

Throwing light and heavy ball

Pushing off of a wall (whole world)

Balloon rockets

Try to make them go a certain distance (stop at a target)

Less air or more mass

What if we used a helium balloon? (extension)

4) Energy can take many forms

a. Some examples of energy:

i. Motion (kinetic energy)

ii. Position (potential energy)

iii. Heat (molecules are moving)

iv. Elastic (stretched or compressed)

v. Chemical (stored in molecules - like gasoline or wood)

vi. Electrical (electrons and protons)

vii. Light (electro-magnetic)

viii. Sound (vibration)

ix. Nuclear

b. Energy is conserved - transformed, but conserved. 


\section{References}

Abd el Khalick, F. (2006). Preservice and Experienced Biology Teachers' Global and Specific Subject Matter Structures: Implications for Conceptions of Pedagogical Content Knowledge. Eurasia Journal of Mathematics, Science \& Technology Education, 2(1), 1-29. http://doi.org/10.12973/ejmste/75435 Abell, S. K. (2007). Research on Science Teacher Knowledge. In S. K. Abell \& N. G. Lederman (Eds.), Handbook of research on science education (pp. 1105-1149). Abingdon: Routledge.

Abell, S. K. (2008). Twenty years later: Does pedagogical content knowledge remain a useful idea? International Journal of Science Education, 30(10), 1405-1416. http://doi.org/10.1080/09500690802187041

Abrahams, I., \& Millar, R. (2008). Does Practical Work Really Work? A study of the effectiveness of practical work as a teaching and learning method in school science. International Journal of Science Education, 30(14), 19451969. http://doi.org/10.1080/09500690701749305

Adler, P. A., \& Adler, P. (1987). Membership Roles in Field Research. Thousand Oaks: SAGE.

Aikenhead, G. S. (1996). Science education: Border crossing into the subculture of science. Studies in Science Education, 27, 1-52.

Ainley, M., \& Ainley, J. (2011). Student engagement with science in early adolescence: The contribution of enjoyment to students' continuing interest in learning about science. Contemporary Educational Psychology, 36(1), 412.

Anderson, C. W. (1980). An observational study of classroom management and information structuring in elementary school science lessons (Doctoral dissertation, University of Texas at Austin).

Anderson, D., \& Clark, M. (2012). Development of syntactic subject matter knowledge and pedagogical content knowledge for science by a generalist elementary teacher. Teachers and Teaching, 18(3), 315-330. https://doi.org/10.1080/13540602.2012.629838

Anderson, R. D. (1995). Curriculum Reform: Dilemmas and Promise. Phi Delta Kappan, 77(1), 33-36.

Anderson, T., \& Shattuck, J. (2012). Design-Based Research A Decade of Progress in Education Research? Educational Researcher, 41(1), 16-25.

Appleton, K. (1993). Using Theory to Guide Practice: Teaching Science From a Constructivist Perspective. School Science and Mathematics, 93(5), 269274. http://doi.org/10.1111/j.1949-8594.1993.tb12242.x

Appleton, K. (1995). Student teachers' confidence to teach science: is more science knowledge necessary to improve self-confidence? International Journal of Science Education, 17(3), 357-369.

http://doi.org/10.1080/0950069950170307

Appleton, K. (2002). Science activities that work: Perceptions of primary school teachers. Research in Science Education, 32(3), 393-410. 
Appleton, K. (2003). How do beginning primary school teachers cope with science? Toward an understanding of science teaching practice. Research in Science Education, 33(1), 1-25.

Appleton, K. (2008). Developing science pedagogical content knowledge through mentoring elementary teachers. Journal of Science Teacher Education, 19(6), 523-545. http://doi.org/10.1007/s10972-008-9109-4

Appleton, K. (Ed.). (2005). Elementary Science Teacher Education. Mahwah, New Jersey: Laurence Erlbaum Associates.

Araceli Ruiz-Primo, M., \& Furtak, E. M. (2006). Informal Formative Assessment and Scientific Inquiry: Exploring Teachers' Practices and Student Learning. Educational Assessment, 11(3-4), 237-263. http://doi.org/10.1080/10627197.2006.9652991

Arzi, H. J., \& White, R. T. (2008). Change in teachers' knowledge of subject matter: A 17-year longitudinal study. Science Education, 92(2), 221-251. http://doi.org/10.1002/sce.20239

Baker, G. L., \& Blackburn, J. A. (2005). The Pendulum : A Case Study in Physics Oxford: Oxford University Press.

Baker, R., \& Jones, A. (2005). How can international studies such as the international mathematics and science study and the programme for international student assessment be used to inform practice, policy and future research in science education in New Zealand? International Journal of Science Education, 27(2), 145-157. http://doi.org/10.1080/0950069042000276695

Ball, D. L., Thames, M. H., \& Phelps, G. (2008). Content Knowledge for Teaching What Makes It Special? Journal of Teacher Education, 59(5), 389-407. https://doi.org/10.1177/0022487108324554

Bar, V., Sneider, C., \& Martimbeau, N. (1997). Is there gravity in space? Science and Children, Vol. , No. , P. 38-43, -1, 38-43.

Bar, V., Zinn, B., Goldmuntz, R., \& Sneider, C. (1994). Children's concepts about weight and free fall. Science Education, 78(2), 149-169. http://doi.org/10.1002/sce.3730780204

Baumgartner, E., Bell, P., Hoadley, C., Hsi, S., Joseph, D., Orrill, C., \& Tabak, I. (2003). Design-based research: an emerging paradigm for educational inquiry. Educational Researcher, 32(1), 5-8.

Baviskar, S., Hartle, R. T., \& Whitney, T. (2009). Essential Criteria to Characterize Constructivist Teaching: Derived from a review of the literature and applied to five constructivist-teaching method articles. International Journal of Science Education, 31(4), 541-550. http://doi.org/10.1080/09500690701731121

Beebe, S.A., Masterson, J.T. (2014). Communicating in small groups: Principles and practices. 11th edition. New York: Pearson.

Bell, B. (2005). Learning in Science: The Waikato Research. New York, NY: Routledge. 
Bell, B., \& Cowie, B. (2006). Doing formative assessment. In B. Bell, \& B. Cowie Formative assessment and science education (pp. 130-136). Dordrecht: Kluwer.

Bell, B., \& Gilbert, J. (2004). A model for achieving teacher development. In J. Gilbert (Ed.), The RoutledgeFalmer reader in science education (pp. 258278). New York: RoutledgeFalmer.

Bell, R. L., Smetana, L., \& Binns, I. (2005). Simplifying inquiry instruction. The Science Teacher, 72(7), 30-33.

Berger, R. (2015). Now I see it, now I don't: Researcher's position and reflexivity in qualitative research. Qualitative research, 15(2), 219-234.

Beyerbach, B. A., \& Smith, J. M. (1990). Using a computerized concept mapping program to assess preservice teachers' thinking about effective teaching. Journal of research in science teaching, 27(10), 961-971. http://doi.org/10.1002/tea.3660271005

Bickman, L., \& Rog, M. D. J. (2009). The SAGE Handbook of Applied Social Research Methods. Thousand Oaks: SAGE.

Bolstad, R., \& Hipkins, R. (2008). Seeing yourself in science. Wellington: New Zealand Council for Educational Research.

Borko, H. (2004). Professional Development and Teacher Learning: Mapping the Terrain. Educational Researcher, 33(8), 3-15. http://doi.org/10.3102/0013189X033008003

Borko, H., Jacobs, J., \& Koellner, K. (2010). Contemporary Approaches to Teacher Professional Development. In P. Peterson, E. Baker, \& B. McGaw (Eds.), International Encyclopedia of Education (3rd ed., Vol. 7, pp. 548557). Elsevier Science.

Borko, H., Koellner, K., \& Jacobs, J. (2014). Examining novice teacher leaders' facilitation of mathematics professional development. The Journal of Mathematical Behavior, 33, 149-167. http://doi.org/10.1016/j.jmathb.2013.11.003

Boyd, S. E., \& Hipkins, R. (2012). Student inquiry and curriculum integration: Shared origins and points of difference (Part A). Set: Research Information for Teachers, 3, 15.

Brown, A. L. (1992). Design experiments: Theoretical and methodological challenges in creating complex interventions in classroom settings. The Journal of the Learning Sciences, 2(2), 141-178.

Buczynski, S., \& Hansen, C. B. (2010). Impact of professional development on teacher practice: Uncovering connections. Teaching and Teacher Education, 26(3), 599-607. http://doi.org/https://doi.org/10.1016/j.tate.2009.09.006

Bull, A. (2014). Rethinking professional learning and development in primary science. Retrieved from http://www.nzcer.org.nz/system/files/Rethinking\%20professional\%20learnin g\%20and\%20development\%20in\%20primary\%20science.pdf

Bull, A., Gilbert, J., Barwick, H., \& Baker, R. (2010). Inspired by Science (A Paper Commissioned by the Royal Society and the Prime Minister's Chief 
Science Advisor). Wellington: New Zealand Council for Educational Research.

Bybee, R. W., \& McCrae, B. (2009). PISA Science 2006: Implications for science teachers and teaching. Arlington, VA: NSTA press.

Cain, T., \& Allan, D. (2017). The invisible impact of educational research. Oxford Review of Education, 43(6), 718-732. http://doi.org/10.1080/03054985.2017.1316252

Cañas, A. J., Coffey, J. W., Carnot, M. J., Feltovich, P., Hoffman, R. R., Feltovich, J., \& Novak, J. D. (2003). A summary of literature pertaining to the use of concept mapping techniques and technologies for education and performance support. Report to the Chief of Naval Education and Training. Pensacola, FL: Institute for Human and Machine Cognition.

Capps, D. K., \& Crawford, B. A. (2012a). Inquiry-Based Instruction and Teaching About Nature of Science: Are They Happening? Journal of Science Teacher Education, 24(3), 497-526. http://doi.org/10.1007/s10972012-9314-z

Capps, D. K., Crawford, B. A., \& Constas, M. A. (2012b). A Review of Empirical Literature on Inquiry Professional Development: Alignment with Best Practices and a Critique of the Findings. Journal of Science Teacher Education, 23(3), 291-318. http://doi.org/10.1007/s10972-012-9275-2 Caygill, R., Hanlar, V., \& Singh, S. (2016). TIMSS 2014/15 Key Findings (pp. 18). Wellington: New Zealand Ministry of Education.

Caygill, R., Kirkham, S., \& Marshall, N. (2013). TIMSS-2010-11-Year-5Students-Science-Achievement-Full-Report (pp. 1-124). New Zealand Ministry of Education.

Caygill, R., Singh, S., \& Hanlar, V. (2016). TIMSS 2014/15 Key Findings Science Year 9 (pp. 1-170). Wellington: New Zealand Ministry of Education.

Chamberlain, M., \& Caygill, R. (2013). Key Findings from New Zealand's Participation in the Progress in International Reading Literacy Study (PIRLS) and Trends in International Mathematics and Science Study (TIMSS) in 2010/11. Comparative Education Research Unit, Research Division, New Zealand Ministry of Education.

Chandrasekhar, M., Rainwater, D. L., Litherland, R. Q., Swope, R. A., \& VanNest, A. (1995, October). Polarization puzzles for the upper elementary grades. In 1995 International Conference on Education in Optics (Vol. 2525, pp. 182-193). International Society for Optics and Photonics. Bellingham, WA, USA. DOI: 10.1117/12.224011

Clarke, D., \& Hollingsworth, H. (2002). Elaborating a model of teacher professional growth. Teaching and Teacher Education, 18, 947-967.

Cochran, K. F., DeRuiter, J. A., \& King, R. A. (1993). Pedagogical Content Knowing: An Integrative Model for Teacher Preparation. Journal of Teacher Education, 44(4), 263-272. http://doi.org/10.1177/0022487193044004004

Coenders, F., \& Terlouw, C. (2015). A Model for In-service Teacher Learning in the Context of an Innovation. Journal of Science Teacher Education, 26(5), 451-470. http://doi.org/10.1007/s10972-015-9432-5 
Collins, A. (1992). Toward a design science of education. In E. Scanlon \& T. O'Shea (Eds.), New Directions in Educational Technology (pp. 15-22). Berlin: Springer.

Collins, A., Joseph, D., \& Bielaczyc, K. (2004). Design research: Theoretical and methodological issues. The Journal of the Learning Sciences, 13(1), 15-42.

Cowley, V., Hamlin, M. J., \& Grimley, M. (2011). Where has all the physical education gone? Results of a generalist primary schools teachers' survey on teaching physical education. World Academy of Science, Engineering and Technology, 77, 672-677.

Crawford, B. A. (1999). Is It Realistic to Expect a Preservice Teacher to Create an Inquiry-based Classroom? Journal of Science Teacher Education, 10(3), 175-194. http://doi.org/10.1023/A:1009422728845

Crawford, B. A. (2000). Embracing the essence of inquiry: New roles for science teachers. Journal of Research in Science Teaching, 37(9), 916-937. http://doi.org/10.1002/1098-2736(200011)37:9<916::AID-TEA4>3.0.CO;2-2

Creswell, J. W. (2013a). Qualitative inquiry and research design: Choosing among five approaches. Los Angeles, CA: SAGE.

Creswell, J. W. (2013b). Research design: Qualitative, quantitative, and mixed methods approaches. Thousand Oaks: SAGE.

Creswell, J. W., \& Clark, V. L. P. (2011). Designing and Conducting Mixed Methods Research. Thousand Oaks: SAGE.

Crooks, T., Smith, J., \& Flockton, L. (2008). National assessment monitoring project: Science assessment results 2007. Wellington, NZ: Ministry of Education.

Cunningham, D., \& Duffy, T. (1996). Constructivism: Implications for the design and delivery of instruction. In D. H. Jonassen (Ed.), Handbook of research for educational communications and technology (pp. 170-198). New York: Macmillan.

Davis, E. A. (2003). Knowledge Integration in Science Teaching: Analysing Teachers' Knowledge Development. Research in Science Education, 34(1), 21-53. http://doi.org/10.1023/B:RISE.0000021034.01508.b8

Davis, E. A., Palincsar, A. S., Smith, P. S., Arias, A. M., \& Kademian, S. M. (2017). Educative Curriculum Materials: Uptake, Impact, and Implications for Research and Design:. Educational Researcher, 46(6), 293-304. http://doi.org/10.3102/0013189X17727502

Davis, E. A., \& Krajcik, J. S. (2005). Designing Educative Curriculum Materials to Promote Teacher Learning. Educational Researcher, 34(3), 3-14. http://doi.org/10.3102/0013189X034003003

Denscombe, M. (2014). The Good Research Guide: For Small-Scale Social Research Projects. Berkshire: McGraw-Hill Education (UK).

Denzin, N. K., \& Lincoln, Y. S. (2005). INTRODUCTION. In N. K. Denzin \& Y. S. Lincoln (Eds.), The SAGE Handbook of Qualitative Research (3rd ed., pp. 1-41). Thousand Oaks, CA.

The Design-Based Research Collective. (2003). Design-Based Research: An Emerging Paradigm for Educational Inquiry. Educational Researcher, 32(1), 5-8. Retrieved from http://www.jstor.org/stable/3699927 
Desimone, L. M. (2009). Improving Impact Studies of Teachers' Professional Development: Toward Better Conceptualizations and Measures. Educational Researcher, 38(3), 181-199. http://doi.org/10.3102/0013189X08331140

Dewey, J. (1902). The Child and the Curriculum. University of Chicago.

Dewey, J. (1933). How We Think: A Restatement of the Relation of Reflective Thinking to the Education Process. Boston: DC Heath.

Diaconu, D. V., Radigan, J., Suskavcevic, M., \& Nichol, C. (2012). A multi-year study of the impact of the Rice Model Teacher Professional Development on elementary science teachers. International Journal of Science Education, 34(6), 855-877.

Donna, J. D., \& Hick, S. R. (2017). Developing Elementary Preservice Teacher Subject Matter Knowledge Through the Use of Educative Science Curriculum Materials. Journal of Science Teacher Education, 28(1), 92-110. http://doi.org/10.1080/1046560X.2017.1279510

Driver, R., \& Oldham, V. (1986). A constructivist approach to curriculum development in science. Studies in Science Education, 13(1), 105-122. http://doi.org/10.1080/03057268608559933

Driver, R., Asoko, H., Leach, J., Scott, P., \& Mortimer, E. (1994). Constructing scientific knowledge in the classroom. Educational Researcher, 23(7), 5-12. http://doi.org/DOI: 10.3102/0013189X023007005

Driver, R., Leach, J., Miller, A., \& Scott, P. (1996) Young people's images of science. Buckingham: Open University Press.

Education Review Office. (2010). Science in Years 5 to 8: Capable and Competent Teaching (pp. 1-45). Retrieved From http://www.ero.govt.nz/review-reports/

Education Review Office. (2012). Science in The New Zealand Curriculum: Years 5 to 8 (pp. 1-30). Retrieved from http://ero.govt.nz/NationalReports/Science-in-The-New-Zealand-Curriculum-Years-5-to-8-May-2012

Education Review Office. (2017). Communities of Learning | Kāhui Ako in action (pp. 1-30). Education Review Office. Retrieved from http://www.ero.govt.nz/assets/Uploads/Communities-of-Learning-Kahui-AkoAction.pdf

Educational Assessment Research Unit \& New Zealand Council for Educational Research. (2013). National Monitoring Study of Student Achievement, Science 2012, Report 1 (pp. 1-122). Wellington: Ministry of Education. Retrieved from http://nmssa.otago.ac.nz/reports/2012_Science_ONLINE.pdf Eylon, B. S., \& Linn, M. C. (1988). Learning and Instruction: An Examination of Four Research Perspectives in Science Education. Review of Educational Research, 58(3), 251-301. http://doi.org/10.3102/00346543058003251

Feynman, R. P. (1969). What is science. The Physics Teacher, 7(6), 313-320. Feynman, R. P. (1998). The Meaning of it All. New York: Basic Books.

Feynman, R. P. (2005). The Pleasure of Finding Things Out. New York: Basic Books.

Fisher, A., \& Ussher, B. (2015). A Cautionary Tale: What are the signs telling us? Curriculum versus standards reflected in schools planning. New Zealand Journal of Teachers' Work, 11(2), 221-231. 
Fishman, B. J., Marx, R. W., Best, S., \& Tal, R. T. (2003). Linking teacher and student learning to improve professional development in systemic reform. Teaching and teacher education, 19(6), 643-658. https://doi.org/10.1016/S0742-051X(03)00059-3

Flick, U. (2008). Managing Quality in Qualitative Research. Thousand Oaks, CA: SAGE.

Fraenkel, J., Wallen, N. E., \& Hyun, H. (2012). Observation and Interviewing. In J. Fraenkel, \& N. Wallen (Eds.), How to Design and Evaluate Research in Education (pp. 444-477). New York: McGraw-Hill.

Garet, M. S., Porter, A. C., Desimone, L. M., Birman, B. F., \& Yoon, K. S. (2001). What Makes Professional Development Effective? Results From a National Sample of Teachers. American Educational Research Journal, 38(4), 915-945. http://doi.org/10.3102/00028312038004915

Gess-Newsome, J. (1999). Pedagogical content knowledge: An introduction and orientation. In J. Gess- Newsome (Ed.), Examining pedagogical content knowledge: The construct and its implications for science education. Dordrecht: Kluwer Academic.

Gess-Newsome, J., \& Lederman N.G. (Eds) (1999). Examining pedagogical content knowledge. Dordrecht: Kluwer.

Glaser, BG, Strauss, A.L. (1968). The Discovery of Grounded Theory. London: Weidenfeld \& Nicolson.

Gluckman, P. (2011). Looking ahead: Science education for the twenty-first century. A report to the Prime Minister from the Prime Minister's Chief Science Advisor. Office of the Prime Minister's Science Advisory Committee. Auckland.

Goldberg, F. M., \& McDermott, L. C. (1986). Student difficulties in understanding image formation by a plane mirror. The Physics Teacher, 24(8), 472-481. http://doi.org/10.1119/1.2342096

Good, T. L., \& Brophy, J. E. (2008). Looking in classrooms (10th ed.) Boston: Pearson/Allyn and Bacon.

Gowin, D. B. (1981). Teaching. In D. B. Gowin Educating. (pp. 62-83). Cornell University Press.

Guba, E. G. (1981). Criteria for assessing the trustworthiness of naturalistic inquiries. ECTJ, 29(2), 75. http://doi.org/10.1007/BF02766777

Guskey, T. R. (2002). Professional development and teacher change. Teachers and teaching, 8(3), 381-391. https://doi.org/10.1080/135406002100000512

Haney, J. J., \& Lumpe, A. T. (1995). A teacher professional development framework guided by reform policies, teachers' needs, and research. Journal of Science Teacher Education, 6(4), 187-196. http://doi.org/10.1007/BF02614642

Hardy, I., Jonen, A., Möller, K., \& Stern, E. (2006). Effects of instructional support within constructivist learning environments for elementary school students' understanding of 'floating and sinking.'. Journal of Educational Psychology, 98(2), 307-326. http://doi.org/10.1037/0022-0663.98.2.307

Hargreaves, A., \& Dawe, R. (1990). Paths of professional development: Contrived collegiality, collaborative culture, and the case of peer coaching. 
Teaching and Teacher Education, 6(3), 227-241.

http://doi.org/10.1016/0742-051X(90)90015-W

Hashweh, M. (2005). Teacher pedagogical constructions: a reconfiguration of pedagogical content knowledge. Teachers and Teaching, 11(3), 273-292. http://doi.org/10.1080/13450600500105502

Herrington, J., McKenney, S., Reeves, T. C., Oliver, R. (2007). Design-based research and doctoral students: Guidelines for preparing a dissertation proposal. Retrieved from www.editlib.org/d/25967/proceeding 25967.pdf

Hewson, P. W. (2007). Teacher professional development in science. In S. K. Abell \& N. G. Lederman (Eds.), Handbook of Research on Science Education (pp. 1179-1203). New York: Routledge.

Hipkins, R., \& Bolstad, R. (2005). Staying in science. Student Participation in Secondary Education and on Transition to Tertiary Studies. Wellington: New Zealand Council for Educational Research.

Hipkins, R., Bolstad, R., Baker, R., Jones, A., Barker, M., Bell, B., et al. (2002). Curriculum, learning and effective pedagogy: A literature review in science education. Wellington, New Zealand: Ministry of Education. Retrieved from http://www.nzcer.org.nz/research/publications/curriculum-learning-andeffective-pedagogy-literature-review-science-education

Hipkins, R., \& Hodgen, E. (2012). Curriculum support in science: Patterns in teachers' use of resources. Wellington, New Zealand: New Zealand Council for Educational Research.

Hodson, D., \& Hodson, J. (1998). From constructivism to social constructivism: A Vygotskian perspective on teaching and learning science. School Science Review, 79(289), 33-41.

Hulleman, C. S., \& Harackiewicz, J. M. (2009). Promoting Interest and Performance in High School Science Classes. Science, 326(5958), 14101412. http://doi.org/10.1126/science. 1177067

Hume, A. C. (2010). A pedagogical tool for science teacher education: Content Representation (CoRe) design. Science Teacher Education, 59, 29-38.

Ibieta, A., Hinostroza, J. E., Labbé, C., \& Claro, M. (2017). The role of the Internet in teachers' professional practice: activities and factors associated with teacher use of ICT inside and outside the classroom. Technology, Pedagogy and Education, 26(4), 425-438. http://doi.org/10.1080/1475939X.2017.1296489

Ingvarson, L., Meiers, M., \& Beavis, A. (2005). Factors affecting the impact of professional development programs on teachers' knowledge, practice, student outcomes \& efficacy. Education Policy Analysis Archives, 13(10), 126.

Jennings, L. B. (2009). Constructing a Discourse of Inquiry: Findings From a Five-Year Ethnography at One Elementary School. The Teachers College Record, 111(7), 1583-1618.

Johnston, J., \& Ahtee, M. (2006). Comparing primary student teachers' attitudes, subject knowledge and pedagogical content knowledge needs in a physics activity. Teaching and Teacher Education, 22(4), 503-512. http://doi.org/10.1016/j.tate.2005.11.015 
Katz, L. G., \& Raths, J. (1992). Six Dilemmas in Teacher Education. Journal of Teacher Education, 43(5), 376-385.

http://doi.org/10.1177/0022487192043005007

Kennedy, M. (1998). Form and Substance in Inservice Teacher Education. Research Monograph. Madison: National Institute for Science Education.

Kim, M., \& Tan, A. L. (2011). Rethinking Difficulties of Teaching Inquiry-Based Practical Work: Stories from elementary pre-service teachers. International Journal of Science Education, 33(4), 465-486. http://doi.org/https://doi.org/10.1080/09500691003639913

Kinchin, I. M. (2000). Using concept maps to reveal understanding: A two-tier analysis. School Science Review, 81(296), 41-46.

Kind, V. (2009). Pedagogical content knowledge in science education: perspectives and potential for progress. Studies in Science Education, 45(2), 169-204.

Kind, V. (2014). Science Teachers' Content Knowledge. In H. Venkat, M. Rollnick, J. Loughran, \& M. Askew (Eds.), Exploring Mathematics and Science Teachers' Knowledge (pp. 15-29). Abingdon: Routledge.

Kirkham, S., \& May, S. (2016). PISA 2015: The science context for PISA. Retrieved December 7, 2016, from https://www.educationcounts.govt.nz/_data/assets/pdf_file/0017/180611/PI SA-2015-Science-Context_v2.pdf

Kirkham, S., \& May, S. (2016, December 5). PISA 2015: The science context for PISA. New Zealand Ministry of Education.

Kleickmann, T., Tröbst, S., Jonen, A., Vehmeyer, J., \& Möller, K. (2016). The effects of expert scaffolding in elementary science professional development on teachers' beliefs and motivations, instructional practices, and student achievement. Journal of Educational Psychology, 108(1), 21. http://dx.doi.org/10.1037/edu0000041

Krueger, R. A., \& Casey, M. A. (2014). Focus groups: A practical guide for applied research. Thousand Oaks: SAGE.

Lederman, N. G., Gess-Newsome, J., \& Latz, M. S. (1994). The nature and development of preservice science teachers\&apos; conceptions of subject matter and pedagogy. Journal of Research in Science Teaching, 31(2), 129-146. http://doi.org/10.1002/tea.3660310205

Lederman, N. G., Schwartz, R. S., Abd-El-Khalick, F., \& Bell, R. L. (2001). Preservice teachers' understanding and teaching of nature of science: An intervention study. Canadian Journal of Science, Mathematics and Technology Education, 1(2), 135-160. http://doi.org/10.1080/14926150109556458

Lehane, L., \& Bertram, A. (2016). Getting to the CoRe of it: A review of a specific PCK conceptual lens in science educational research. Educación Química, 27(1), 52-58. http://doi.org/10.1016/j.eq.2015.09.004

Lelliott, A., \& Rollnick, M. (2009). Big Ideas: A review of astronomy education research 1974-2008. International Journal of Science Education, 32(13), 1771-1799. http://doi.org/10.1080/09500690903214546 
Lemke J. L., (1990), Talking science: language, learning, and values, Norwood, $\mathrm{NJ}$ : Ablex

Linn, M. C., \& Eylon, B.-S. (2006). Science education: Integrating views of learning and instruction. In P. A. Alexander \& P. H. Winne (Eds.), Handbook of educational psychology (2nd ed., pp. 511-544). Mahwah: Lawrence Erlbaum Associates.

Lipowsky, F., \& Rzejak, D. (2015). Key features of effective professional development programmes for teachers. Ricercazione, 7(2), 27-51.

Literature and Latte. (2014). Scapple. Literature and Latte. Retrieved from [Available at https://www.literatureandlatte.com/scapple.php]

Little, J. W. (1993). Teachers' Professional Development in a Climate of Educational Reform. Educational Evaluation and Policy Analysis, 15(2), 129-151. http://doi.org/10.3102/01623737015002129

Lotter, C., Smiley, W., Thompson, S., \& Dickenson, T. (2016). The impact of a professional development model on middle school science teachers' efficacy and implementation of inquiry. International Journal of Science Education, 38(18), 2712-2741. http://doi.org/10.1080/09500693.2016.1259535

Lotter, C., Yow, J. \& Peters, T. (2014). Building a community of practice around inquiry instruction through a professional development program. International Journal of Science and Mathematics Education, 12, 1-23. doi:10.1007/s10763-012-9391-7

Loucks-Horsley, S., Stiles, K., Mundry, S. E., Love, N. B., \& Hewson, P. W. (2010). Designing professional development for teachers of science and mathematics (3rd ed.). Thousand Oaks: Corwin.

Loughran, J., Berry, A., \& Mulhall, P. (2012a). Examining The Use and Value of Core(S) and Pap-Ers. In J. Loughran, A. Berry, \& P. Mulhall (Eds.), Understanding and Developing Science Teachers' Pedagogical Content Knowledge (pp. 211-221). Rotterdam: Sense. http://doi.org/10.1007/978-946091-821-6_10

Loughran, J., Berry, A., \& Mulhall, P. (2012b). Portraying PCK. In J. Loughran, A. Berry, \& P. Mulhall (Eds.), Understanding and developing science teachers' pedagogical content knowledge (pp. 15-23). Rotterdam: Sense.

Loughran, J., Berry, A., \& Mulhall, P. (2012c). Understanding and developing science teachers' pedagogical content knowledge (2nd ed.). Rotterdam: Sense.

Lourie, M. (2016). Bicultural education policy in New Zealand. Journal of Education Policy, 31(5), 637-650.

http://doi.org/10.1080/02680939.2016.1159339

Luft, J. A. (2001). Changing inquiry practices and beliefs: The impact of an inquiry-based professional development programme on beginning and experienced secondary science teachers. International Journal of Science Education, 23(5), 517-534. http://doi.org/10.1080/09500690121307

Maclntyre, W. (2013). Are we preparing primary science educators for a science leadership role in the primary classroom? In D. Panizzon (Ed.), (pp. 1-27). Presented at the ASERA Conference, Wellington. 
Martin, M. O., Mullis, I. V. S., Foy, P., \& Hooper, M. (2016). TIMSS 2015. International Results in Science. International Association for the Evaluation of Educational Achievement. Herengracht 487, Amsterdam, 1017 BT, The Netherlands.

Martin, M. O., Mullis, I. V., Foy, P., \& Stanco, G. M. (2012). TIMSS 2011 International Results in Science. International Association for the Evaluation of Educational Achievement. Herengracht 487, Amsterdam, 1017 BT, The Netherlands.

May, S., \& Hill, R. (2005, April). Bilingual education in Aotearoa/New Zealand: At the crossroad. In ISB4: Proceedings of the 4th international symposium on Bilingualism (Vol. 30, pp. 1567-1573).

May, S., Cowles, S., \& Lamy, M. (2013). PISA 2012 New Zealand Summary Report. Retrieved from https://www.educationcounts.govt.nz/_data/assets/pdf_file/0008/144872/10 15_PISA-Summary_2012.pdf

May, S., Flockton, J., \& Kirkham, S. (2016). PISA 2015 New Zealand Summary Report (pp. 1-56). Wellington: Ministry of Education.

McConnell, T. J., Parker, J. M., \& Eberhardt, J. (2013). Assessing Teachers' Science Content Knowledge: A Strategy for Assessing Depth of Understanding. Journal of Science Teacher Education, 24(4), 717-743. http://doi.org/10.1007/s10972-013-9342-3

McGee, C., Jones, A., Cowie, B., Hill, M., Miller, T., Harlow, A., \& Mackenzie, K. (2003). Curriculum stocktake: National school sampling study. Hamilton: The University of Waikato.

McKenney, S., Reeves, T. C. (2012). Conducting educational design research. London: Routledge.

McKnight, K., OMalley, K., Ruzic, R., Horsley, M. K., Franey, J. J., \& Bassett, K. (2016). Teaching in a Digital Age: How Educators Use Technology to Improve Student Learning. Journal of Research on Technology in Education, 48(3), 194-211. http://doi.org/10.1080/15391523.2016.1175856

McNeill, K. L., \& Pimentel, D. S. (2009). Scientific discourse in three urban classrooms: The role of the teacher in engaging high school students in argumentation. Science Education, 94(2), 203-229. http://doi.org/10.1002/sce.20364

Merriam, S. B. (2009). Qualitative research: A guide to design and implementation. San Francisco, United States: Jossey-Bass.

Mertens, D. (2005). Research and evaluation in education and psychology. Integrating diversity with quantitative, qualitative and mixed methods (2nd ed.). Thousand Oaks, CA: SAGE.

Millar, R. (1989). Bending the evidence: The relationship between theory and experiment in science education. In R. Millar (Ed.) Doing Science: Images of Science in Science education (pp. 38-61). Philadelphia: Falmer Press.

Millar, R. (2009). Analysing Practical Science Activities to Assess and Improve Their Effectiveness. York: Centre for Innovation and Research in Science Education, University of York. 
Millar, R. (2010). Practical work. In O. Jonathan \& J. Dillon (Eds.), Good Practice in Science Teaching (pp. 108-134). McGraw-Hill International.

Ministry of Education. (1993). Science in the New Zealand Curriculum. Wellington: Learning Media.

Ministry of Education. (1999). Making Better Sense of the Physical World. Wellington: Learning Media.

Ministry of Education. (2002). Properties of Sound: How Sound-makers and Musical Instruments Work. Building Science Concepts Book 19. Wellington: Learning Media.

Ministry of Education. (2003). Parachutes: Floating and Falling in Air. Wellington: Learning Media.

Ministry of Education. (2007a). The New Zealand Curriculum. Wellington: Learning Media.

Ministry of Education. (2007b). The New Zealand curriculum: Achievement Objectives by Learning Area (pp. 1-31). Wellington: Learning Media.

Ministry of Education. (2007c). The New Zealand curriculum: Achievement Objectives by Level. Wellington: Learning Media. Retrieved from http://nzcurriculum.tki.org.nz/content/download/1109/11992/file/Charts1.pdf

Ministry of Education. (2010). Education Statistics of New Zealand. Wellington: Ministry of Education. Retrieved from https://www.educationcounts.govt.nz/_data/assets/pdf_file/0017/80225/200 9-Education-Statistics-of-NZ-Booklet.pdf

Ministry of Education. (2013). Roll by FYL \& Student Type 1996-2016. Retrieved from http://www.educationcounts.govt.nz/statistics/schooling/studentnumbers $/ 6028$

Ministry of Education. (2106, September 13). School deciles. Retrieved from http://www.education.govt.nz/school/running-aschool/resourcing/operational-funding/school-decile-ratings/

Minner, D. D., Levy, A. J., \& Century, J. (2010). Inquiry-based science instruction-what is it and does it matter? Results from a research synthesis years 1984 to 2002. Journal of Research in Science Teaching, 47(4), 474496. doi:10.1002/tea.2034710.1002/tea.20347

Moshman, D. (1982). Exogenous, endogenous, and dialectical constructivism. Developmental Review, 2(4), 371-384. http://doi.org/10.1016/02732297(82)90019-3

Mulholland, J., \& Wallace, J. (2005). Growing the tree of teacher knowledge: Ten years of learning to teach elementary science. Journal of Research in Science Teaching, 42(7), 767-790. http://doi.org/10.1002/tea.20073

Murphy, C., Neil, P., \& Beggs, J. (2007). Primary science teacher confidence revisited: ten years on. Educational Research, 49(4), 415-430. http://doi.org/10.1080/00131880701717289

National Research Council. (2007). Taking Science to School: Learning and Teaching Science in Grades K-8. National Academies Press.

Naylor, S., \& Keogh, B. (1999). Constructivism in classroom: Theory into practice. Journal of Science Teacher Education, 10(2), 93-106. 
Nickerson, R. S. (1985). Understanding understanding. American Journal of Education, 93(2), 201-239. http://doi.org/10.1086/443791

Novak, J. D. (2002). Meaningful learning: The essential factor for conceptual change in limited or inappropriate propositional hierarchies leading to empowerment of learners. Science Education, 86(4), 548-571. http://doi.org/10.1002/sce.10032

Novak, J. D. (2005). Results and Implications of a 12-Year Longitudinal Study of Science Concept Learning. Research in Science Education, 35(1), 23-40. http://doi.org/10.1007/s11165-004-3431-4

Novak J. D., Gowin D. B. (1984) New strategies for evaluation: concept mapping. In: Novak J. D., Gowin D. B. (eds) Learning how to learn. Cambridge University Press, Cambridge, pp 93-108

Novak, J. D., \& Cañas, A. J. (2008). The theory underlying concept maps and how to construct and use them (Tech. Rep. IHMC CmapTools 2006-01 Rev 01-2008). Pensacola: Florida Institute for Human and Machine Cognition.

Novak, J., Gowin, D. B., \& Kahle, J. (1984). Learning How to Learn. Cambridge: Cambridge University Press. doi:10.1017/CBO9781139173469

Novak, J. D., Gowin, D. B., \& Johansen, G. T. (1983). The use of concept mapping and knowledge vee mapping with junior high school science students. Science Education, 67(5), 625-645. http://doi.org/10.1002/sce.3730670511

O'Brien, J. and Jones, K., 2014. Professional learning or professional development? Or continuing professional learning and development? Changing terminology, policy and practice. Professional development in education, 40 (5), 683-687.10.1080/19415257.2014.960688

Ornek, F., Robinson, W. R., \& Haugan, M. P. (2008). What Makes Physics Difficult?. International Journal of Environmental \& Science Education, 3(1), 30-34.

Osborne, J. F. (2014). Teaching Scientific Practices: Meeting the Challenge of Change. Journal of Science Teacher Education, 25(2), 177-196. http://doi.org/10.1007/s10972-014-9384-1

Owen, H., \& Dunmill, M. (2014). The Long Journey: Developing a Model of PLD for the Future. Australian Journal of Teacher Education, 39(1), 117-136. http://doi.org/10.14221/ajte.2014v39n1.9

Pedaste, M., Mäeots, M., Siiman, L. A., de Jong, T., van Riesen, S. A. N., Kamp, E. T., et al. (2015). Phases of inquiry-based learning: Definitions and the inquiry cycle. Educational Research Review, 14, 47-61. http://doi.org/10.1016/j.edurev.2015.02.003

Penuel, W. R., Fishman, B. J., Yamaguchi, R., \& Gallagher, L. P. (2007). What Makes Professional Development Effective? Strategies That Foster Curriculum Implementation. American Educational Research Journal, 44(4), 921-958. http://doi.org/10.3102/0002831207308221

Perry, E., \& Boylan, M. (2017). Developing the developers: supporting and researching the learning of professional development facilitators.

Professional Development in Education, 13(2), 1-18.

http://doi.org/10.1080/19415257.2017.1287767 
Piaget, J. (1952). The origins of intelligence in children. (M. Cook, Trans.). New York, NY: W W Norton \& Co. http://doi.org/10.1037/11494-000

Posner, G. J., Strike, K. A., Hewson, P. W., \& Gertzog, W. A. (1982). Accommodation of a scientific conception: Toward a theory of conceptual change. Science Education, 66(2), 211-227.

Priestley, M., \& Sinnema, C. (2014). Downgraded curriculum? An analysis of knowledge in new curricula in Scotland and New Zealand. The Curriculum Journal, 25(1), 50-75. http://doi.org/10.1080/09585176.2013.872047

Pringle, R. M., Mesa, J., \& Hayes, L. (2017). Professional Development for Middle School Science Teachers: Does an Educative Curriculum Make a Difference? Journal of Science Teacher Education. http://doi.org/10.1080/1046560X.2016.1277599

Redish, E. F. (1994). Implications of cognitive studies for teaching physics. American Journal of Physics, 62(9), 796-803.

Reeves, T. C. (2000). Enhancing the worth of instructional technology research through 'design experiments' and other development research strategies. Paper presented at the American Educational Research Association (AERA) Annual Meeting, New Orleans, LA. Retrieved from: http://it.coe.uga.edu/ treeves/ AERA2000Reeves.pdf

Richter, D., Kunter, M., Klusmann, U., Lüdtke, O., \& Baumert, J. (2011). Professional development across the teaching career: Teachers' uptake of formal and informal learning opportunities. Teaching and teacher education, 27(1), 116-126. http://doi.org/10.1016/j.tate.2010.07.008

Roth, W. M., \& Roychoudhury, A. (1993). The concept map as a tool for the collaborative construction of knowledge: A microanalysis of high school physics students. Journal of Research in Science Teaching, 30(5), 503-534. http://doi.org/10.1002/tea.3660300508

Rubin, H. J. \& Rubin, I. S. (2005). Qualitative interviewing (2nd ed.): The art of hearing data Thousand Oaks, CA: SAGE. doi: 10.4135/9781452226651

Sadler, P. M., Sonnert, G., Coyle, H. P., Cook-Smith, N., \& Miller, J. L. (2013). The Influence of Teachers' Knowledge on Student Learning in Middle School Physical Science Classrooms. American Educational Research Journal, 50(5), 1020-1049. http://doi.org/10.3102/0002831213477680

Sagan, C. (1979). Broca's Brain: Reflections on the romance of science. New York: Presidio Press.

Salomon, G., \& Perkins, D. N. (1998). Individual and social aspects of learning. Review of Research in Education, 23, 1-24.

Sanders, L. R., Borko, H., \& Lockard, J. D. (1993). Secondary science teachers' knowledge base when teaching science courses in and out of their area of certification. Journal of Research in Science Teaching, 30(7), 723-736. http://doi.org/10.1002/tea.3660300710

Sandoval, W. A., \& Bell, P. (2004). Design-Based Research Methods for Studying Learning in Context: Introduction. Educational Psychologist, 39(4), 199-201. http://doi.org/10.1207/s15326985ep3904_1

Schulte, P. L. (1996). A definition of constructivism. Science Scope, 20(3), 2527. 
Schwab, J. J. (1962). The teaching of science as enquiry. In J. J. Schwab \& P. F. Brandwein (Eds.), The teaching of science (pp. 3-103). Cambridge, MA: Harvard University Press.

Schwab, J. J. (1964). The structure of disciplines: Meanings and Significance. In G. W. Ford \& L. Pugno (Eds.), The Structure of Knowledge and the Curriculum. Chicago: Rand McNally.

Schwartz, M. S., Sadler, P. M., Sonnert, G., \& Tai, R. H. (2009). Depth versus breadth: How content coverage in high school science courses relates to later success in college science coursework. Science Education, 93(5), 798-826. http://doi.org/10.1002/sce.20328

Schwartz, M. S., Shapiro, I. I., \& Gregory, B. (2013). Confronting the Need for Conceptual Change in Pre-Service Science Education. Higher Education Studies, 3(5), 1-19. http://doi.org/10.5539/hes.v3n5p11

Seago, N. (2004). Using videos as an object of inquiry for mathematics teaching and learning. In J. Brophy (Ed.), Using video in teacher education (pp. 259e286). Oxford, UK: Elsevier.

Sewell, M. (2002). Constructivism and Student Misconceptions: Why every teacher needs to know about them. Australian Science Teachers Journal, 48(4), 24-28.

Sexton, S. S. (2017). In The New Zealand Curriculum: Is It Science Education or Education Through Science? One Educator's Argument. In Science Education: A Global Perspective (1st ed., Vol. 120, pp. 219-233). Springer International Publishing. http://doi.org/10.1007/978-3-319-32351-0_11

Shulman, L. S. (1986a). Paradigms and research programs in the study of teaching: A contemporary perspective. In Wittrock, M. C. (Ed.), Handbook of research on teaching (3rd ed., pp. 3-36). New York: Macmillan

Shulman, L. S. (1986b). Those who understand: Knowledge growth in teaching. Educational Researcher, 15(2), 4-14.

Shulman, L. S. (1987). Knowledge and teaching: Foundations of the new reform. Harvard Educational Review, 57(1), 1-23.

Shymansky, J. A. (1992). Using constructivist ideas to teach science teachers about constructivist ideas, or teachers are students too! Journal of Science Teacher Education, 3(2), 53-57. http://doi.org/10.1007/BF02614740

Shymansky, J. A., Kyle, W. C., \& Alport, J. M. (1983). The effects of new science curricula on student performance. Journal of research in Science Teaching, 20(5), 387-404. http://doi.org/10.1002/tea.3660200504/full

Shymansky, J. A., Hedges, L. V., \& Woodworth, G. (1990). A reassessment of the effects of inquiry-based science curricula of the 60's on student performance. Journal of Research in Science Teaching, 27(2), 127-144. http://doi.org/10.1002/tea.3660270205

Skamp, K. R. (1989). General science knowledge and attitudes towards science and science teaching of preservice primary teachers: Implications for preservice science units. Research in Science Education, 19(1), 257-267. http://doi.org/10.1007/BF02356865 
Solomon, J. (1986). When should we start teaching physics? Physics Education. http://doi.org/10.1086/651086?ref=searchgateway:9534f670e7413f1540bca4709ef6bff0

Solomon, J. (1987). Social influences on the construction of pupils' understanding of science. Studies in Science Education, 14, 63-82.

Staver, J. R. (1998). Constructivism: Sound theory for explicating the practice of science and science teaching. Journal of Research in Science Teaching, 35(5), 501-520. http://doi.org/10.1002/(SICl)10982736(199805)35:5<501::AID-TEA3>3.0.CO;2-T

Stepans, J., \& McCormack, A. (1985). A Study of Scientific Conceptions and Attitudes Toward Science of Prospective Elementary Teachers. Presented at the Northern Rocky Mountain Educational Research Association, Jackson Hole, WY.

Stokes, D. E. (1997). Pasteur's quadrant: Basic science and technological innovation. Washington: Brookings Institution Press.

Stolk, M. J., Bulte, A. M., de Jong, O., \& Pilot, A. (2009). Towards a framework for a professional development programme: empowering teachers for context-based chemistry education. Chemistry Education Research and Practice, 10(2), 164-175. http://doi.org/10.1039/B908255G

Stutchbury, K., \& Fox, A. (2009). Ethics in educational research: introducing a methodological tool for effective ethical analysis. Cambridge Journal of Education, 39(4), 489-504. http://doi.org/10.1080/03057640903354396

Summers, M. \& Kruger, C. (1994). A longitudinal study of a constructivist approach to improving primary school teachers. Subject matter knowledge of science. Teaching and Teacher Education, 10, 499-519. https://doi.org/10.1016/0742-051X(94)90003-5

Thrupp, M. (2013). National Standards for student achievement: Is New Zealand's idiosyncratic approach any better? Australian Journal of Language and Literacy. 36 (2) (2013), pp. 99-110

Thrupp, M. \& White, M. (2013). Research, analysis and insight into National Standards (RAINS) Project. Final report: National Standards and the Damage Done. Wellington, New Zealand: NZEl. Retrieved from http://www.education2014.org.nz/?page_id=16

Timperley, H. (2011). Realizing the power of professional learning. London: Open University Press.

Timperley, H., Wilson, A., Barrar, H., Fung, I. (2007). Teacher professional learning and development: Best evidence synthesis iteration (BES). Auckland, New Zealand: University of Auckland. Retrieved from http://educationcounts.edcentre.govt.nz/goto/BES

Tseng, C.-H., Tuan, H.-L., \& Chin, C.-C. (2012). How to Help Teachers Develop Inquiry Teaching: Perspectives from Experienced Science Teachers. Research in Science Education, 43(2), 809-825. http://doi.org/10.1007/s11165-012-9292-3

Tytler, R. (2012). Constructivist and socio-cultural views of teaching and learning. In G. Venville \& V. Dawson (Eds.), The Art of Teaching Science (pp. 23-40). Sydney: Allen \& Unwin. 
Tytler, R., \& Osborne, J. F. (2012). Student attitudes and aspirations towards science. In B. J. Fraser, K. Tobin, \& C. J. McRobbie (Eds.), Second International Handbook of Science Education (pp. 597-625). Dordrecht: Springer.

Tytler, R., Osborne, J. F., Williams, G., Tytler, K., \& Clark, J. C. (2008). Opening up pathways: engagement in STEM across the primary-secondary school transition. Canberra: Australian department of Education, Employment and Workplace Relations. Retrieved from https://pdfs.semanticscholar.org/26d3/9dde4d8dcb50de6855a3a4f229649dc ce104.pdf

van Aalderen-Smeets, S. I., \& van der Molen, J. H. W. (2015). Improving primary teachers' attitudes toward science by attitude-focused professional development. Journal of Research in Science Teaching, 52(5), 710-734. http://doi.org/10.1002/tea.21218

Van Der Veer, R., \& Valsiner, J. (1994). The Vygotsky reader. Cambridge: Blackwell.

van Driel, J. H., Beijaard, D., \& Verloop, N. (2001). Professional development and reform in science education: The role of teachers' practical knowledge. Journal of Research in Science Teaching, 38(2), 137-158. http://doi.org/10.1002/1098-2736(200102)38:2<137::AIDTEA1001>3.0.CO;2-U

van Driel, J. H., Meirink, J. A., van Veen, K., \& Zwart, R. C. (2012). Current trends and missing links in studies on teacher professional development in science education: a review of design features and quality of research. Studies in Science Education, 48(2), 129-160. http://doi.org/10.1080/03057267.2012.738020

van Strien, P. J. (1997). Towards a Methodology of Psychological Practice: The Regulative Cycle. Theory \& Psychology, 7(5), 683-700. http://doi.org/10.1177/0959354397075006

van Veen, K., Zwart, R. C., \& Meirink, J. A. (2012). What Makes Teacher Professional Development Effective? In M. Kooy \& K. van Veen (Eds.), Teacher Learning that Matters (pp. 3-21) Abingdon: Routledge.

Vanderlinde, R., \& van Braak, J. (2010). The gap between educational research and practice: views of teachers, school leaders, intermediaries and researchers. British Educational Research Journal, 36(2), 299-316. doi:10.1080/01411920902919257

Vannier, D. M. (2012). Primary and Secondary School Science Education in New Zealand (Aotearoa): Policies and Practices for a Better Future. Wellington: Fulbright New Zealand.

Venville, G., Rennie, L. J., \& Wallace, J. (2012). Curriculum Integration: Challenging the Assumption of School Science as Powerful Knowledge. In Second International Handbook of Science Education (pp. 737-749). Dordrecht: Springer, Dordrecht. http://doi.org/10.1007/978-1-4020-9041749

Venville, G., Wallace, J., Rennie, L., \& Malone, J. (2002). Curriculum Integration: Eroding the High Ground of Science as a School Subject? 
Studies in Science Education, 37(1), 43-83.

http://doi.org/10.1080/03057260208560177

Vermette, P., Foote, C., Bird, C., Mesibov, D., Harris-Ewing, S., \& Battaglia, C. (2001). Understanding constructivism(s): a primer for parents and school board members. Education, 122(1), 87-94.

Vinay Kumar, D., Sampath Kumar, B. T., \& Parameshwarappa, D. R. (2015). URLs Link Rot: Implications for Electronic Publishing. World Digital Libraries-An international journal, 8(1), 59-66. http://doi.org/10.18329/09757597/2015/8105

Warren, J. W. (1986). At what stage should energy be taught? Physics Education, 21(3), 154-156. http://doi.org/10.1088/0031-9120/21/3/307

WHTR Television. (2012). Big Ben - behind the scenes. Retrieved from https://www.youtube.com/watch?v=inD5GnTjs_E

Wilson, S. M., Shulman, L. S., \& Richert, A. E. (1987). '150 different ways' of knowing: Representations of knowledge in teaching. In Calderhead, J. (Ed.) Exploring Teachers' Thinking. New York: Taylor and Francis, 104-124.

Wittenburg, P., Brugman, H., Russel, A., Klassmann, A., \& Sloetjes, H. (2006, May). ELAN: a professional framework for multimodality research. In Proceedings of LREC (Vol. 2006, p. 5th).

Wood, D., Bruner, J. S., \& Ross, G. (1976). The Role of Tutoring in Problem Solving. Journal of Child Psychology and Psychiatry, 17(2), 89-100. http://doi.org/10.1111/j.1469-7610.1976.tb00381.x

Yager, R. E. (1991). The constructivist learning model. The science teacher, 58(6), 52-57.

Yager, R. E., Engen, H. B., \& Snider, B. C. (1969). Effects of the laboratory and demonstration methods upon the outcomes of instruction in secondary biology. Journal of Research in Science Teaching, 6(1), 76-86. http://doi.org/10.1002/tea.3660060115/full 